\title{
Social assistance and activation in the pursuit of happiness: shedding new light on old policy solutions to social exclusion
}

Citation for published version (APA):

Petrovic, M. (2013). Social assistance and activation in the pursuit of happiness: shedding new light on old policy solutions to social exclusion. [Doctoral Thesis, Maastricht University]. Maastricht University. https://doi.org/10.26481/dis.20131205mp

Document status and date:

Published: 01/01/2013

DOI:

10.26481/dis.20131205mp

Document Version:

Publisher's PDF, also known as Version of record

Please check the document version of this publication:

- A submitted manuscript is the version of the article upon submission and before peer-review. There can be important differences between the submitted version and the official published version of record.

People interested in the research are advised to contact the author for the final version of the publication, or visit the DOI to the publisher's website.

- The final author version and the galley proof are versions of the publication after peer review.

- The final published version features the final layout of the paper including the volume, issue and page numbers.

Link to publication

\footnotetext{
General rights rights.

- You may freely distribute the URL identifying the publication in the public portal. please follow below link for the End User Agreement:

www.umlib.nl/taverne-license

Take down policy

If you believe that this document breaches copyright please contact us at:

repository@maastrichtuniversity.nl

providing details and we will investigate your claim.
}

Copyright and moral rights for the publications made accessible in the public portal are retained by the authors and/or other copyright owners and it is a condition of accessing publications that users recognise and abide by the legal requirements associated with these

- Users may download and print one copy of any publication from the public portal for the purpose of private study or research.

- You may not further distribute the material or use it for any profit-making activity or commercial gain

If the publication is distributed under the terms of Article $25 \mathrm{fa}$ of the Dutch Copyright Act, indicated by the "Taverne" license above, 


\title{
SOCIAL ASSISTANCE AND ACTIVATION IN THE PURSUIT OF HAPPINESS:
}

Shedding new light on old policy solutions to social exclusion

\author{
DISSERTATION \\ to obtain the degree of Doctor at \\ Maastricht University, \\ on the authority of the Rector Magnificus, Prof.dr. L.L.G. Soete \\ in accordance with the decision of the Board of Deans, \\ to be defended in public \\ on Thursday 5 December 2013, at 14.00 hours \\ by
}

Marina Petrovic 


\section{Supervisor:}

Prof.dr. Chris de Neubourg

\section{Co-supervisors:}

Prof.dr. Mihail Arandarenko, School of Economics, University of Belgrade, Serbia Dr. Franziska Gassmann

\section{Assessment Committee:}

Prof.dr. L. de la Rive Box, chairman

Prof.dr. G. Matkovic, University Singidunum, Serbia

Prof.dr. M. Spoor, Erasmus University Rotterdam

Dr. M.P. Vink, Maastricht University, and Robert Schuman Centre for Advanced Studies, European University Institute 


\section{Acknowledgments}

I've never been good at this but I certainly know that my thesis wouldn't have got off the ground without the help of others. First, I'd like to gratefully acknowledge my supervisors. I thank Chris and Mihail whose continuous support was instrumental in wrapping my mind around the topic. Second, but no less important, I extend my gratitude to Franziska whose input was invaluable - I would have never reached this point without your comments and your motivating me to complete this! I would also like to thank members of the reading committee for enduring through this bulky work of mine and providing useful suggestions for improvements.

Next, I want to thank the people at MGSoG/UNU-MERIT, particularly the student affairs office, Mindel, and Eveline for being so receptive. I would also like to mention the people of my cohort (Victor, Patrick, Henry, Jinjing, Manuel, Matthieu, Lala, Nicola, Treena, Metka, Robert, Judit, and Maha) and the cohorts I overlapped with during my three-year stay in Maastricht. Such a diverse group of people made my PhD life an unforgettable experience. Of course, my special thanks go to Maha and Judit, my great office mates, whose loudness and lucidness I find exceptional and so dear. Renée, thank you for providing home where I never thought home would be. I would also like to pick out two PhD related events: Metka, Renée, Victor - guys, I'd always go with you to Slovenia-like summer schools; Maha, Henry, Matthieu, Jelena - I'll definitely join you for another Mimi vice reunion.

I owe thanks to many people who have supported and challenged me in the writing of this thesis. First among these are Raphaela Schlicht and two referees of COMPASSS who provided important comments on early versions of my fuzzy-set analysis. Henry, Vladane, and Victor big thanks for crunching the numbers with me on several occasions and walking through all that fuzziness together. I thank the Poverty Reduction and Social Inclusion Unit of the Government of Serbia for commissioning the study on the overall experience of social assistance beneficiaries who participated in public works and Ministry of Economy and Regional Development for facilitating my fieldwork. I also acknowledge the support of my colleagues at the CLDS, UNDP (Irma), and ILO (Dragana and Valli) for letting me test some of my ideas on activation on the ground. Mirtha Muñiz Castillo and Caterina Ruggeri Laderchi spent a lot of time reading my qualitative analysis and providing recommendations for improvements. I'm thankful to them for that. Jelena and Matt, thank you for reading and proofreading parts of my draft thesis at the moments when I already wasn't able to see the forest because of the trees. 
Jasna, without your final touch, the printable version of my manuscript would have never seen the light of the day (without pay) - thanks a million!

The story of acknowledgements doesn't go without naming few persons whose professional guidance and overall support I've enjoyed largely in my life. They were of great importance in particular parts of my career, which often involved life-changing moments. Professor Drenka Vukovic was my first champion in the social policy arena and a passionate advocate of my involvement in a PhD program. I believe I never thanked her enough. Gogo, I probably owe you a whole list of thanks, but this time I'll thank you for each and every single encounter from which I came out a better and wiser person. I would also like to acknowledge the colleagues from the World Bank whose great advice I always appreciated. Carolyn, Loraine, Dena and others - a big thank you!

The most substantive work on revisions and compiling the pieces of this thesis was carried out in the summer of 2011 in Istria, Croatia. I would like to offer my gratitude to the Hrelja family for their extraordinary hospitality and Renée for joining me on this journey. The work was concluded a year later on the Montenegrin coast. My dear and numerous members of Knezevic-Prnjak family, thank you for having me there and treating me so well. This brings me to my closest ones. Verkic, deepest thank you for being my ears in both good and bad times. Finally, big hugs of appreciations, I extend to all my Petrovics who are always there for me... and for holding the fort.

I dedicate this book to Olga and Buki. 


\section{Table of content}

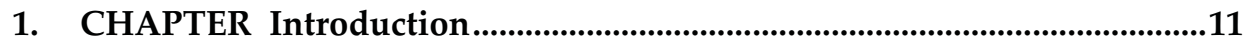

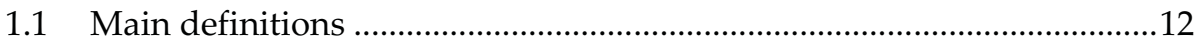

1.2 Social exclusion: Theoretical underpinnings .........................................14

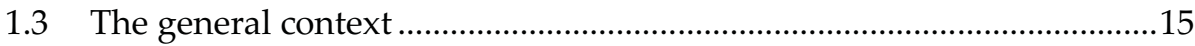

1.4 Research question, main hypotheses, and sub-questions ........................18

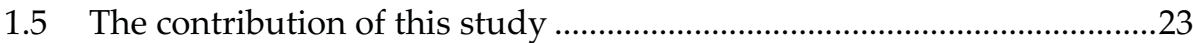

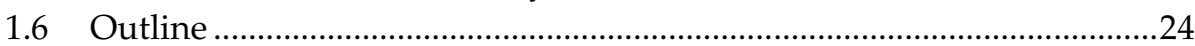

2. CHAPTER Qualitative Comparative Analysis of Active Social Assistance Polices and Their Impact on Poverty: The Case of Twelve European Union (EU)

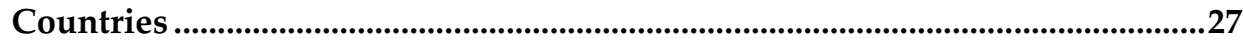

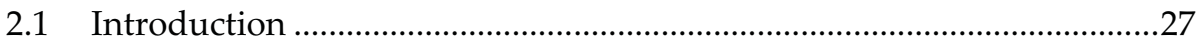

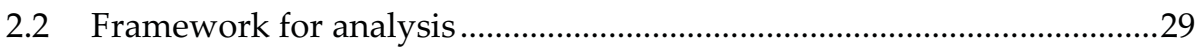

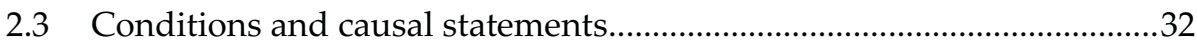

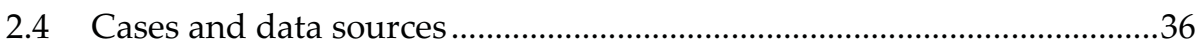

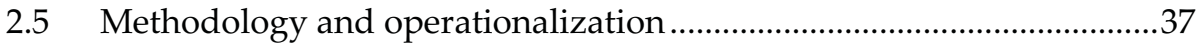

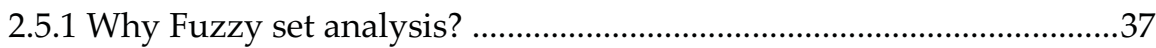

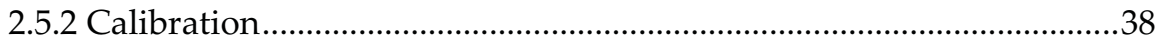

2.5.3 The fuzzy-set procedure ..................................................................... 42

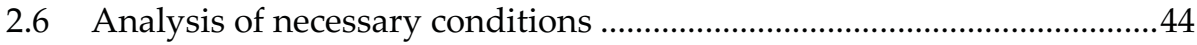

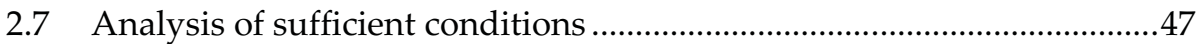

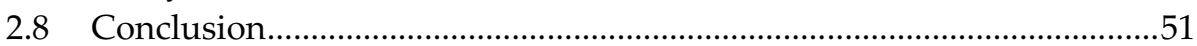

3. CHAPTER A Closer Look At Structural and Social Assistance Specific Conditions: The Cases of Estonia and Slovenia ..................................................54

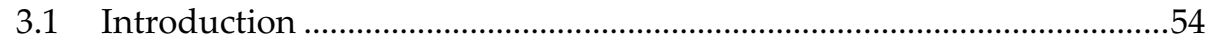

3.2 Structural conditions framing different reform paths.............................56

3.3 Inequality and poverty outcomes in Estonia and Slovenia .....................59

3.4 Resulting social assistance designs .....................................................61

3.4.1 Definition, coverage, and spending ..................................................6

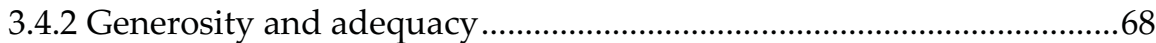

3.4.3 Social Assistance and Activation............................................................72

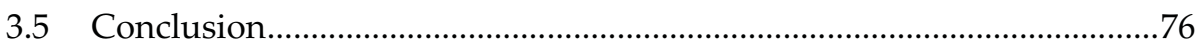

4. CHAPTER Defining and Measuring the Multi-Dimensional Nature of Social Exclusion: The Case of Serbia ..................................................................78

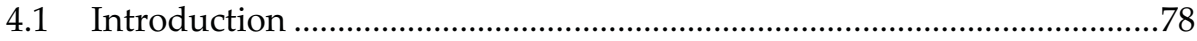

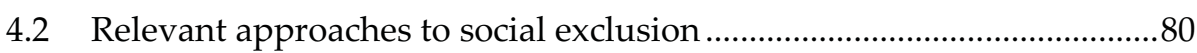

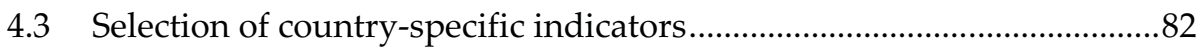




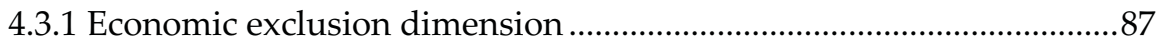

4.3.2 Exclusion from health, education and other services..........................89

4.3.3 Exclusion from civic and social life and networks..............................91

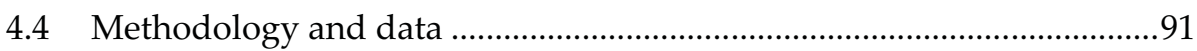

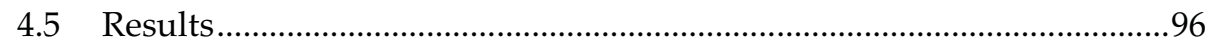

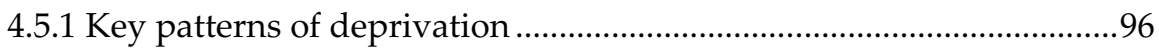

4.5.2 Multidimensional index of social exclusion .......................................102

4.5.3 Monetary and non-monetary deprivation .........................................104

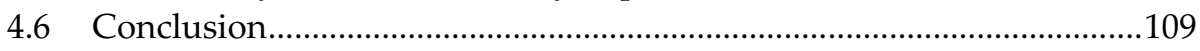

5. CHAPTER Addressing Social Exclusion through Work Activation: Taking into Account Subjective Well-Being of Social Assistance Recipients ............111

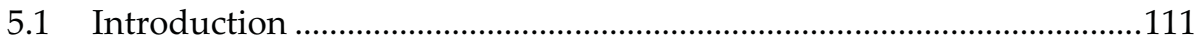

5.2 Conceptualizing subjective well-being.................................................112

5.3 Context: Linking social assistance with public works.............................116

5.4 Measuring subjective well-being of deprived groups............................118

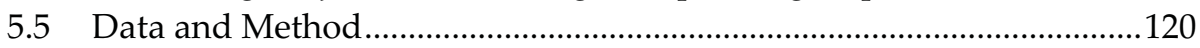

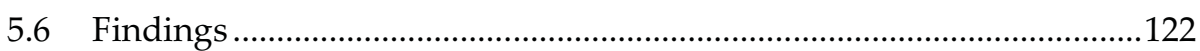

5.6.1 The livelihoods of social assistance respondents and public work

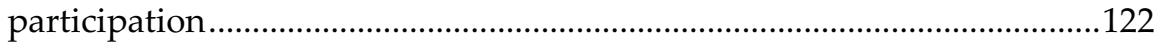

5.6.2 Subjective well-being and employability ...........................................125

5.6.3 Subjective well-being and social inclusion .......................................127

5.6.4 Participation in pubic work and overall subjective well-being .........128

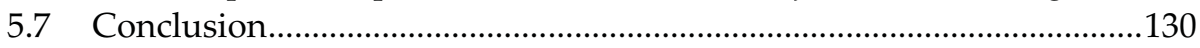

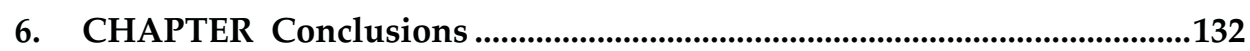

6.1 Summary of findings ........................................................................ 132

6.1.1 Activation as a necessary or sufficient condition for better poverty

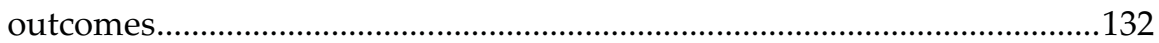

6.1.2. Multidimensional nature of social exclusion.......................................133

6.1.3 The link between activation, subjective well-being, and social inclusion

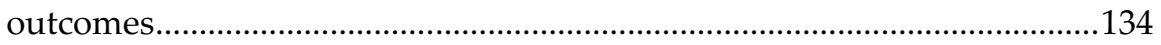

6.1.4 Two important pathways for reaching the social inclusion goal......134

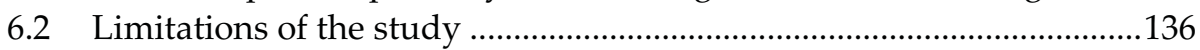

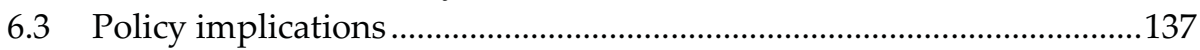

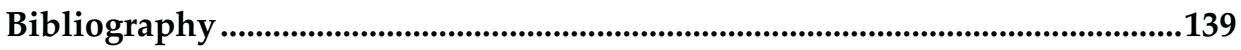

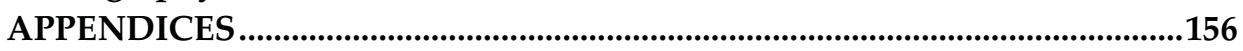

Appendix 1: Short overview of GMI schemes .............................................156

Appendix 2: fsQCA with alternative consistency and cut-off values.............161

Appendix 3: Initial Factor Method and correlation matrix ............................162

Appendix 4: Logistic regression outputs for dependent variables referring to different areas of deprivation 
Appendix 5: Financial Social Assistance (FSA) program in Serbia and key characteristics of its beneficiaries...................................................................169 Appendix 6: In-depth interview guide (Public Works Program in Serbia) ..185 Appendix 7: Questionnaire (Survey on FSA) ......................................................189

Samenvatting in het Nederlands 219

Biography. .223

MGSoG Dissertation Series. 224 


\section{List of Tables}

Table 2.1: Social assistance: Model of welfare production and conditions for fsQCA 31

Table 2.2: The raw values and the fuzzy-set membership scores (fz) of the outcome and conditions

Table 2.3: Analysis of necessary conditions and their negation - both for the presence and the absence of the outcome $(r p)$

Table 2.4: Distribution of cases across causal combinations and set-theoretic consistency of causal combination as subsets of low at-risk-of-poverty rate

Table 2.5: Measures of fit for sufficient fsQCA solution for the outcome low relative poverty (five conditions; frequency cut-off $=1$; consistency cut-off $=0.8$ )

Table 3.1: At-risk-of-poverty rate at $60 \%$ of the median income and absolute poverty rate at 10 euro/day, by country, 2004

Table 3.2: Social assistance as a "pull" side response to the "push" side developments 62

Table 3.3: Coverage, benefit levels, and spending on GMI (\% of GDP) in Slovenia and Estonia, 1995-2005 66

Table 4.1: Lists of dimensions and indicators of multidimensional social exclusion

Table 4.2: Demographic profile for all individuals 84

Table 4.3: Social exclusion indicators and distribution (individuals), percent 95

Table 4.4: Monetary and non-monetary deprivation (all individuals), percent. Table 4.5: The predictors of reporting deprivation across five areas and recorded odds ratios 107

Table 5.1: Dimensions of subjective well-being (SWB) 115

Table 6.1: Two pathways for reaching the social inclusion goal through activation 


\section{List of Figures}

Figure 1.1: Map of Central and Eastern Europe ..................................................... 17

Figure 1.2: Possible pathways to social inclusion...................................................... 19

Figure 2.1: High activation and socio-professional integration as a necessary

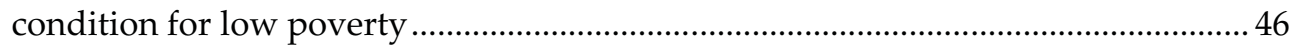

Figure 2.2: Sufficient conditions for low relative poverty ......................................... 49

Figure 3.1: Estonia and Slovenia: Growth rates (\%) and GNI per capita (US\$ PPP),

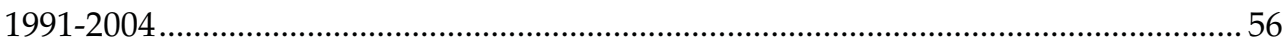

Figure 3.2: Share of GDP spending on social assistance programs (GMI), percent. 67 Figure 3.3: Social assistance (yearly amount for a single person) indexed for wages and prices in Estonia and Slovenia, 1995-2005 (index 1995=100)

Figure 3.4: Adequacy of minimum income protection for single persons, lone parents, and families

Figure 4.1: Social exclusion index for Serbia based on different cut-off thresholds (8, 9, or 10 deprivations), total and by different groups, percent 102

Figure 4.2: The contribution of each dimension to the total score of deprivations (outer ring) and the social exclusion index (inner ring) 103 


\section{List of Boxes}

Box 3.1: Work intensity of Estonian and Slovenian households, 2004 ...................... 74

Box 5.1: Examples of questions related to life satisfaction or happiness................. 118

Box 5.2: Social assistance recipients' impressions about work engagement........... 124

Box 5.3: Perceptions about the impact of work activity on mental health .............. 124

Box 5.4: Perceived changes with regard to chances for employment..................... 126

Box 5.5: Perceived changes with regard to the level of social contacts .................... 128 
"We have come to a clear realization of the fact that true individual freedom cannot exist without economic security and independence.

Necessitous men are not free men. People who are hungry and out of a job are the stuff of which dictatorships are made."

Franklin D. Roosevelt in his "Second Bill of Rights" (1944)

\title{
1. CHAPTER \\ Introduction
}

\begin{abstract}
Alienated and excluded population groups have a long history and still persist in every modern society. Their members often feel ruthlessly marginalized with little hope for the future. The problems associated with social exclusion can often be traced to circumstances such as medical disabilities, broken families, prevalence of drugs and crime, on the one hand, and deep poverty, unemployment, or racial discrimination on the other. Despite professed social inclusion goals, many European countries have not been effective in responding to the root problems linked to impoverishment and joblessness. The response would need to be predominantly active and geared at facilitating people's greater integration into the society. The relationship between financial wellbeing, jobs, and social inclusion is however neither straightforward nor direct. The aim of this thesis is to disentangle these relationships and show how government support in providing opportunities to succeed in life can help reduce social exclusion and increase social inclusion. More specifically, the study explores to what extent activation polices, such as training and employment, implemented within the scope of government-run social assistance programs yield better social inclusion outcomes.
\end{abstract}

Fighting social exclusion and increasing social inclusion has reached the top of policy agendas in the European Union (EU) towards the end of the nineties and beyond its borders in the post-2000 period. This development overlapped with the move from treating poverty solely as income insufficiency to include other economic, social, cultural and political dimensions in the discussion. In terms of government policy responses, the majority of newly designed social inclusion measures were developed in relation to poverty and work. One important type of policy, the traditional social assistance program providing passive support in the form of cash transfers, had to be reshaped and complemented with stronger work 
activation requirements to underpin the growing social inclusion agenda. This "new generation" social assistance was not principally different from workoriented forms of social assistance that have been practiced in the past. The objectives have certainly changed.

The idea of work-oriented social assistance originates in the Poor Law created in nineteenth century England. The poor were required to labor in workhouses in order to receive poverty relief benefits (Lodemel \& Trickey, 2000). While work orientation was, more or less, retained in many schemes over time, modern social assistance systems have generally changed by increasing the work requirements along with providing opportunities for the able-bodied adults to become involved in education and training. This shift could be partially explained as a consequence of significant budget constraints and pressures to increase benefit levels, and pressure to confront the issue of welfare dependency. From the political and economic perspective, welfare-to-work types of policies appeared to be more acceptable than traditional benefit reductions. These policies were more inclusionary and at the same time they were not expected to increase welfare caseloads, benefit levels, or to encourage dependency. In many countries the introduction of different kinds of activation measures occurred in concert with the changing composition of social assistance recipients in favor of migrants and younger populations. It is still assumed that providing these groups with more opportunities in the labor market increases their chances for greater integration in the society. ${ }^{1}$ The aim of this research is to look into these integration goals and overall social inclusion outcomes.

\subsection{Main definitions}

In a sea of buzzwords, social exclusion, activation, and social inclusion stand out as concepts carefully researched though not clearly and comprehensively articulated for a wide audience. In order to shed light on the intertwined processes and relations between social assistance, activation, and social exclusion/inclusion in a simple and understandable manner, we first provide short definitions of the main terms used in this study. A thorough description of each of the underlying concepts is offered in the subsequent chapters.

\footnotetext{
1 Another popular approach that goes beyond sole provision of money to the poor and which makes it conditional upon school enrollment and attendance or health care service utilization involves the so called conditional cash transfers (CCTs). While focusing on different areas both activation and CCTs extend beyond mitigating risks of poverty and vulnerability and include increasing productivity and earning capacity in the long run.
} 
There is no one straightforward definition of social exclusion. In line with the general UNDP (2011) understanding, we approach social exclusion as a process that prevents certain individuals from participating fully in relevant social, economic, cultural, and political aspects of life. Other definitions of social exclusion are presented later in the text. The literature recognizes many indicators of social exclusion, which relate to one or more of its dimensions. The presented research applies both single and multi-dimensional approaches to studying social exclusion.

Social assistance refers to government income support programs targeted to poor households, families, and individuals with income and assets below the determined minimum level. This is the most conventional definition of social assistance (see Adema, 2006; DFID, 2005; European Union, 2000; European Commission, 2006; International Labor Organization, 2000; World Bank, 2001). The types of social assistance transfers and services may vary significantly across different countries. The social assistance programs discussed in this study cover only cash payments that guarantee minimum income to poor individuals and households or GMI schemes.

Activation has a broad definition in the literature. It involves different forms of activities such as social activation targeted to welfare recipients who face problems of specific nature such as alcoholism, drug abuse and structural unemployment. These are the main facets of activation encompassed by most of the academic definitions (Dropping, Hvinden, \&Vik, 1999; Lodemel \& Trickey, 2000). In this thesis, activation refers to programs and policies that connect people who are formally at risk of poverty and exclusion, namely the welfare recipients, to jobs through training and work activation. We embrace the "activation" over similar concepts related to work requirements and opportunities for people receiving social assistance since this concept is widely accepted in Europe. It is used to describe the participation in active measures that typically include training and subsidized work programs targeted to all of those who are capable to work but who find themselves out of work. We opt for the activation approach because we wish to stress the incentive side by offering additional resources, viable opportunities in the labor market, and alternatives to benefits rather than coercion and threats of sanctions for non-compliance. Viewed in this light, the pro-active social assistance policy is not only about curtailing the spending or fighting welfare dependency, as described earlier, but it is also related to facilitating the transition from the world of benefits to the world of work. It is aimed at helping benefit recipients to change their circumstances through participation in the ways that counteract social exclusion and promote their social inclusion.

Social inclusion is defined as the process that prevents people from becoming excluded and provides them with the opportunities for greater participation in the 
society. Some authors view social inclusion as a policy response which "inserts" or "re-inserts" excluded people (Lodemel \& Trickey, 2000). Others, such as Morel (1998), discuss social inclusion in the context of the role of the state in facilitating social cohesion and mending social bonds. Applied to our study, the question of interest becomes whether the activation of work-capable social assistance recipients through training and work could increase their chances for greater inclusion in the society. In order to promote social inclusion, we first need to understand the concept of social exclusion.

\subsection{Social exclusion: Theoretical underpinnings}

Social exclusion is used as an overarching concept in this thesis. Social exclusion depicts a process that prevents certain individuals from participating fully in relevant social, economic, cultural, and political aspects of life. There are many interpretations of the notion of social exclusion but there is no one simple or agreed upon definition. The related discussions of this topic have been wide in scope and continue to grow. Social exclusion as a concept is broader than poverty alone and it is multidimensional (Atkinson, 1998; Atkinson \& Davoudi, 2000; Burchardt, Le Grand \& Piachaud, 2000; Coates, Farnsworth, \& Zulauf, 2001; European Commission, 2004; Levitas et al., 2007; Sen, 2000; Silver \& Miller, 2003, UNDP, 2011). There are several important definitions of social exclusion that are frequently used in academic work and we present them in detail in Chapter 4.

Common ground for all recent approaches in defining social exclusion is the nonparticipation of different levels, both in society as inadequate cohesion and integration, and with the individual inability to participate in the institutions and activities. Over the last few decades, social exclusion has been tied to the idea of citizenship or, more precisely, social rights. Generally, social and citizenship rights are viewed through the realization or denial of economic and social benefits and services, education, legal processes, and participation in decision making processes. The approach has expanded to other areas as well such as transportation and infrastructure. With increasing controversy, the concepts of social exclusion and citizenship have become more ambiguous and contentious. This revived the debate about theoretical underpinnings for the concept of social exclusion.

Building on the citizenship and social rights tradition, an attempt has been made to refine the concept of social exclusion. Schulte (2002) places the overall discussion within a rights framework. He treats social exclusion as a denial of a number of rights derived from the concept of social citizenship. These include: the right to security and economic wellbeing, full share in the social heritage, as well as the 
right to a life of a person based on the norms and standards that prevail in a given society. However, as Fisher (2008) properly notes, his approach hardly differs from the capability or relative deprivation approaches. In his view, the only difference is in the emphasis of Schulte's discussion on capabilities defined by the relative norms (as in the relative deprivation approaches) rather than on freedom (as it is the case in the capability approach). It is evidently the capability framework that remained dominant and made the most significant theoretical contribution in the overall discussion on social exclusion.

Amartya Sen was the first to place social exclusion in the context of poverty and capability deprivation. He viewed social exclusion as a method to understand poverty, by defining it as capability failure. When a person lacks the capability to live a minimal level, poverty is viewed as capability deprivation (Sen 2000). The importance of understanding social exclusion by this framework is in relation to the interconnections of deprivation of capability (Sen 2000). Social exclusion may have constitutive relevance when being excluded can be in itself a form of deprivation. For example, not participating in social life of the community may impoverish a person's life. According to Sen, social exclusion or deprivation of one kind may also have instrumental importance in leading to further deprivations. For example, lack of access to financial services may not be an aggravating deprivation per se but may lead to further deprivations such as income poverty or the inability to pursue certain economic opportunities.

In addition, Sen (2000) views social exclusion as a result of negative factors affecting the freedom to undertake activities that a person should choose. It occurs because of a deliberate policy or practice and in that case it should be treated as active exclusion. When it is the result of complex societal processes without deliberate actions to exclude, social exclusion should be treated as passive exclusion. In either form, exclusion may result in reduced human capabilities in one or more areas of life. This is described as capability failure by Sen, with exclusion playing a critical role. Sen (2000) further stipulates that the concept of social exclusion needs to be analyzed in relation to its utility in providing new understanding of the nature and causes of poverty, and its contributions to developing policy action to alleviate poverty. Therefore, the remedy is to adopt polices targeted for the disadvantaged groups that are affected the most.

\subsection{The general context}

As the social exclusion discourse started shifting from solely determining the extent and main factors leading to social exclusion towards defining possible 
policy responses, the debate spread beyond the territory of the European Union (EU) to all those countries aspiring towards the EU membership. In Central and Eastern Europe (CEE) a major transition from communism to a market economy occurred in the 1990s. An important focus was on fighting poverty and unemployment caused by this massive political change. For the policy makers and researchers interested in poverty relief programs, it soon became clear that social assistance recipients faced greater risk of social exclusion, but almost nothing was known about the types of policies that fought exclusion and promoted social inclusion. For these countries, going through the highs and lows of transition, this led to a careful deliberation about the kinds of assistance to be provided to the poorest segments of the population.

The CEE region is often defined to cover the Baltic states (Estonia, Latvia, and Lithuania), successor states of former Yugoslavia (Bosnia and Herzegovina, Croatia, Former Yugoslav Republic of Macedonia, Serbia, and Slovenia), postcommunist countries geographically located in central Europe (Czech Republic, Hungary, Poland, and Slovakia), as well as Albania, Bulgaria and Romania (Figure 1.1). The analysis presented in the subsequent chapters involves the following six CEE countries: Czech Republic, Estonia, Latvia, Poland, Slovenia and Serbia.

The choice of six countries for this study was primarily guided by the shared characteristics of their respective social assistance schemes and availability of data on activation and socio-professional integration of social assistance recipients. Three country cases (Estonia, Slovenia, and Serbia) are investigated in depth (Chapters 3 to 5). Despite these countries' vast historical, cultural, social, and economic differences, they also shared two major goals in the recent past - the development of a well-established market economy and the EU accession. In Chapter 2, we extend the analysis to seven more countries - the old EU member states (Germany, France, Sweden, the United Kingdom, Cyprus, Luxemburg, Portugal). This is done for exploratory purposes and in order to understand how different countries fare when it comes to exploring the link between activation and social exclusion outcomes.

For the early reformers, such as the Baltic and Central European states, the prospect of EU accession in 2004 provided a strong push for reforms of social assistance and labor market programs. The end of wars and conflicts in the former Yugoslavia and the EU promises for the successor states were important factors in shaping their sets of policies. In this context, Serbia provided a good and yet unexplored case for the analysis of country-specific social exclusion outcomes, related policy responses, and their impacts. To ensure a valid comparison among the countries involved in this study, the policy responses and related outcomes are examined in the period up to the countries' integration in the EU - for Czech 
Republic, Estonia, Latvia, Poland, Slovenia until the year 2004 and for Serbia up until 2012.

Figure 1.1: Map of Central and Eastern Europe

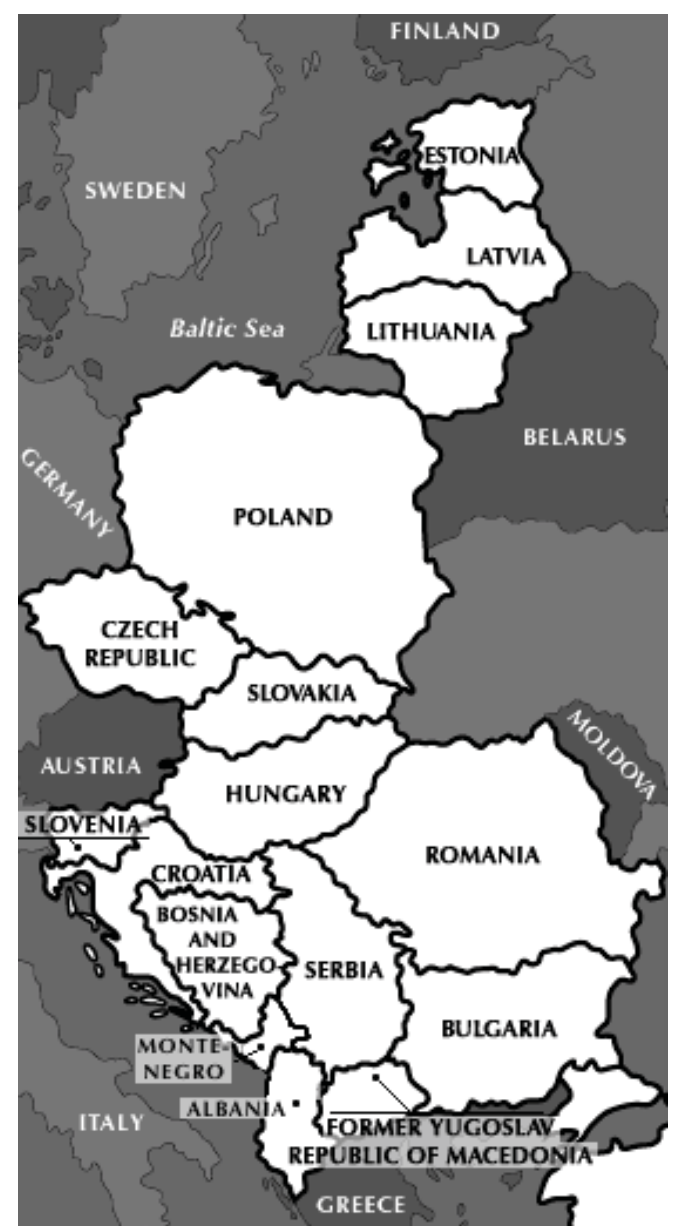

Source: http://archive.rec.org/REC/Maps/eur_map.html

The transition and pre-accession years in this study were characterized by at least two types of social policy measures that are closely related. On the one side, social and labor market policies that emerged in the early transition years were designed to address the challenges of rising poverty and unemployment. Therefore, the countries first developed targeted and streamlined social assistance and unemployment benefit schemes. On the other, with the increased EU aspirations, the discourse moved towards activation and social inclusion agendas. However, this shift towards inclusive social assistance policy did not appear suddenly and it 
was prompted by many interrelated developments, which are explored in Chapters 2 and 3.

High levels of poverty and unemployment experienced by all countries in the 1990s impacted on fiscal policy and increased levels of public expenditures on social security. At the same time, a growing number of unemployed individuals who reached the end of their social insurance benefits' entitlements started seeking social assistance. Moreover, new entrants in the labor market who did not have time to build social insurance history also relied on social assistance. Consequently, the number of people receiving social assistance increased over years, as well as the costs of the programs and further requests to lift the benefits to an adequate level. This has prompted the governments to develop measures to reduce spending and prevent cost increases. On the incentive side a range of measures was developed in order to ease the transition from benefits to employment. Disincentives included tighter conditionality and eligibility criteria.

Attention slowly shifted from the level of welfare expenditures to issues of desirability and usefulness of welfare payments for work-capable recipients who were judged to be available for work. The discourse changed from limiting the spending to improving the outcomes for those in question. Towards the end of the 1990s the countries moved away from traditional social assistance, which was identified as a rather passive form of support, to more active use of funds with a view to provide training and employment and improve the skills and capabilities of the recipients, as well as to assist them in becoming self-sufficient.

Activation came into effect as a new measure promoting labor market integration and self-sufficiency. Compared with the circumstances in which the protection of the poor was unconditional, the main change assumed moving beyond this rather unrestricted provision and making social assistance more conditional and inclusive. Therefore, activation was expected to ensure a better position in society for the groups with lowest income. In this thesis, it is argued that the provision of social assistance was to be done so that the individuals and households are not just able to meet their basic needs but are also able to participate actively in economic, social, and civic life.

\subsection{Research question, main hypotheses, and sub-questions}

As suggested in the previous section, there are at least two different types of justifications for activation and they can be divided into societal-based ones and individual-based justifications. Societal-based justifications focus on improving the 
supply of labor, integration of those out of work in the labor market and society, and reduction of fiscal pressures (Hvinden, 1999). The individual-based ones include improving skills and overall employability together with livelihoods of beneficiaries, reducing the negative personal impacts associated with joblessness, and providing them with a sense of meaning and worth within their societies (Lodemel \& Trickey, 2000). By analogy, the link between activation and social inclusion is also explored as two-fold (Figure 1.2). We argue that social inclusion can be achieved through formal employment but also by improving subjective wellbeing outcomes following the participation in training and temporary work activities.

Figure 1.2: Possible pathways to social inclusion

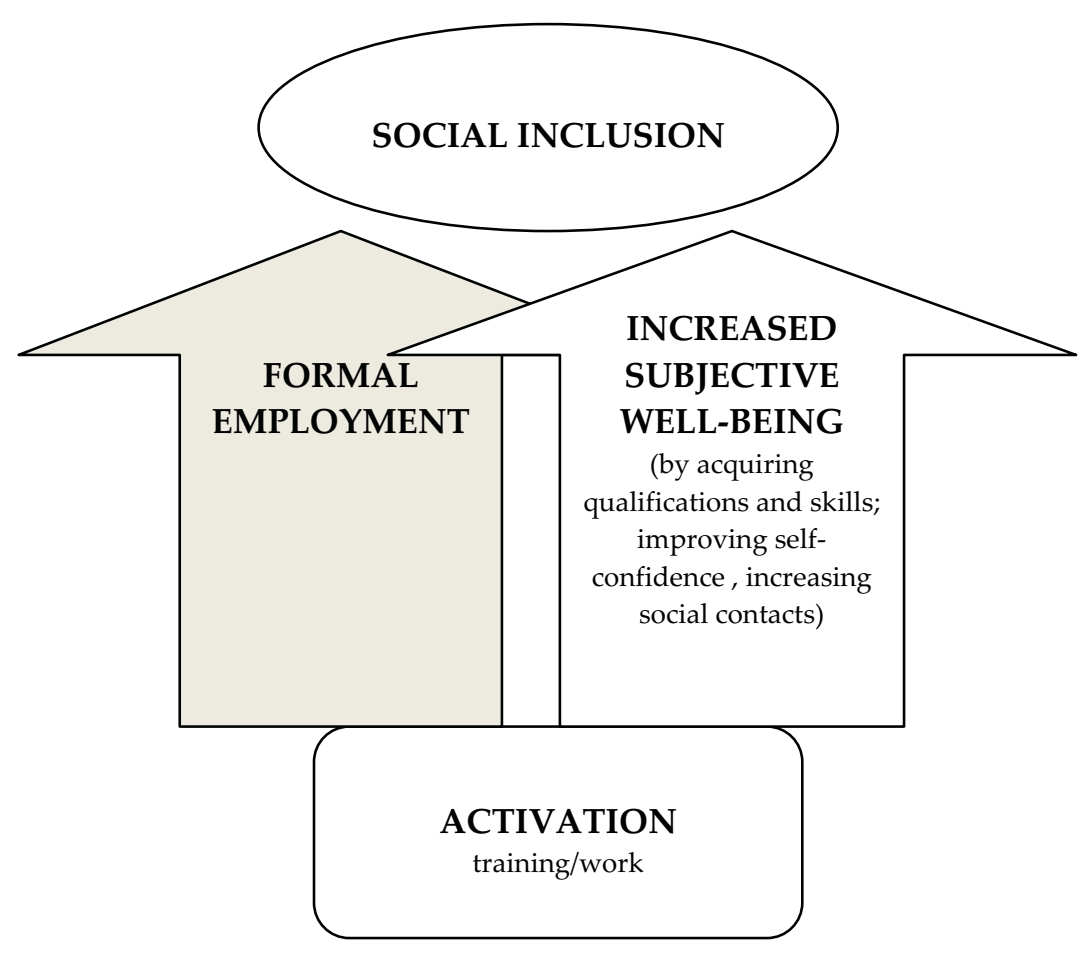

By integrating the findings of various qualitative and quantitative analyses involving the assessment of both objective labor market and subjective well-being outcomes, this dissertation addresses the following main research question:

"To what extent do social assistance programs complemented with activation policy create better social inclusion outcomes for the able-bodied beneficiaries of working age?" 
The overall objective of our study is to analyze the impact of social assistance and activation as a policy instrument to reduce social exclusion and increase social inclusion of social assistance recipients. In this process, we posit three main hypotheses: first, activation and socio-professional integration of social assistance recipients is a necessary condition for reducing their poverty; second, social exclusion of social assistance recipients is multidimensional and significantly higher in certain domains and relative to other population groups; and, third, work activation of social assistance recipients has an important and positive impact on their social inclusion measured in terms of objective (labor market) and subjective (well-being) outcomes.

The above propositions are not exclusive and the corresponding sub-questions cover much larger body of material, all for the benefit of addressing the main research question. In our analysis, we rely on a combination of qualitative and quantitative research methods and various administrative, survey, and interview data. A thorough explanation of each method and data follows in separate chapters. Another distinctive feature of our approach is the use of different units of analysis including countries, households, and individuals.

The following are the key sub-questions addressed in this thesis:

1. Under what conditions does activation become a necessary or sufficient condition for better poverty outcomes?

To provide a more systematic understanding of the link between government supported social assistance policy and social exclusion in terms of relative poverty outcomes $^{2}$, the discussion in this study starts out with the explanation of underlying causal processes and combinations of relevant conditions leading to the defined outcome. Within this scope, the study explores if and how activation and socio-professional integration policies relate to relative poverty rate among social assistance recipients in twelve European countries. We use relative or at-risk-ofpoverty rate among social assistance recipients as the dependent variable. At-riskof-poverty rate reflects the share of individuals living in households with the total equivalent household income that is below the at-risk-of-poverty threshold of 60 percent of the median income.

\footnotetext{
${ }^{2}$ Relative poverty (at-risk-of-poverty rate) is the primary social exclusion/inclusion indicator that is predominantly used in the literature. More details are provided in Chapter 2.
} 
The presented analysis provides insights in the possible combinations of conditions leading to the defined outcome. It uses countries as units of analysis and offers a list of explanatory factors such as their wealth and living standards measurements, the levels of development and financing of social protection systems, as well as the levels of spending on social assistance only and development of activation and socio-professional integration policies within these programs.

In addressing this sub-question, the study puts forward fuzzy-set Qualitative Comparative Analysis (fsQCA), the novel methodology introduced to social science by Charles Ragin (1987, 2000). We apply the fsQCA as an innovative approach to determining inter-linkages between the contexts, social assistance, and social exclusion. Relying on the set-theoretic relations and using the EU administrative and survey data (SILC - Statistics on Income and Living Conditions), the analysis deals with complex causal hypotheses in terms of necessary and sufficient conditions under which low relative poverty occurs.

\section{To what extent and in what areas are social assistance recipients excluded?}

The first step in addressing this sub-question is to provide a workable definition of social exclusion and its multidimensionality. A straightforward definition of social exclusion does not exist but many agree that it is a process that prevents certain individuals from participating fully in relevant social, economic, cultural, and political aspects of life (Atkinson \& Davoudi, 2000; Coates, Farnsworth, \& Zulauf, 2001; Marlier, Atkinson, Cantillon, \& Nolan, 2007; Silver \& Miller, 2003). In line with the UNDP definition, in this study social exclusion is defined as "inability to participate" (UNDP, 2011). The dimensions of exclusion selected for the analysis include economic exclusion, exclusion from health, education and other services, and exclusion from social and civic participation. The measure proposed in this paper applies the Alkire \& Foster's (2007, 2011) dual cut-off approach in constructing a multidimensional social exclusion index.

This analysis involves the development of a context-specific social exclusion index using the case of Serbia. Previous attempts to define and measure social exclusion in Serbia have been limited and based on the Living Standard Measurement Survey (LSMS) and Household Budget Survey (HBS) data which are not specifically designed for social exclusion analyses. We apply our analysis to the rather new 2010 UNDP/UNICEF social exclusion data, which provide an excellent opportunity for a comprehensive study of social exclusion. We use individuals as the main unit of analysis in this chapter. By doing this, we make a significant shift 
from macro-level analysis of different countries and their policies to the exploration of micro-level data specific to a single country context.

In the process of selection of 24 indicators of deprivation we opt for the use of the national social exclusion indicators that have already been defined by the Government of Serbia (Government of Serbia, 2010). In the final step, we offer an index of multi-dimensional social exclusion. The individual is 'multidimensionally' excluded if it is deprived in at least 9 indicators which is equal to 3 deprivations per dimension or deprivation across at least 2 dimensions. As the country-wide single index hides the situation of specific groups, we also analyze how social exclusion outcomes differ by population groups. We are especially interested in the areas of exclusion for households living in rural areas and welfare recipients that appear to be more at risk of poverty and exclusion.

3. How effective is activation through public works in improving social inclusion outcomes?

One way to answer this question is to look at the objective indicator of being employed or unemployed after the completion of a public work activity. Despite the wide adoption of public works programs and their goals being adjusted to different country settings - from mitigation of shocks, consumption smoothing, and poverty relief to ensuring transition to formal employment - little has been done to capture all possible evidence of their effectiveness. The program under analysis is the Public Works Program in Serbia which entails both training and work component and aims at providing temporary employment and poverty relief to selected vulnerable groups. First, we examine the results by using employment status as the dependent variable. Second, from an alternative and subjective wellbeing (SWB) perspective, our study further assesses whether and how the activation through public works affects individuals' moods, abilities, and overall life satisfaction and inclusion in the society. Therefore, we again put the individual in the center of our analytical attention.

Subjective well-being refers to people's assessments of their lives and as such has been investigated both in psychology and economic science (see Diener, 1984; Diener, Suh \& Oishi, 1997; Frey \& Stutzer, 1999, 2002; Layard, 2006; Van Praag \& Ferrer, 2004; Veenhoven, 1991, 2000, 2004). In our study, we apply a set of dimensions for the assessment of subjective well-being outcomes that was developed by Bonin and Rinne (2006). These dimensions include family income situation, health status, personal qualifications and skills, desire to find a job, chances to find a regular job, social contacts, and self-confidence. They are at the same time treated as an additional set of dependent variables under the analysis. 
Our qualitative analysis of the data obtained from semi-structured in-depth interviews focuses on the changes in above mentioned dimensions of subjective well-being from the period before the public work engagement and following the completion of the public work activities. Within this context the analysis of subjective well-being outcomes allowed us to explore levels of social contacts and confidence for social exchange under the notion of social inclusion.

The proposed sub-questions and resulting analyses cut across both conceptual and empirical areas of research and rely on different quantitative and qualitative research methods. Each of these questions is addressed within a separate chapter of this dissertation. A detailed description of the data and methodology is also provided in each of these chapters.

\subsection{The contribution of this study}

This study makes several main contributions, first to the enlarging body of research on causal complexity. It unravels the relationships between the country contexts, social assistance, activation and relative poverty and offers a framework for the analysis of causal complexity. The study is carried out under the broad social policy analysis approach known in the literature as "the model of the production of welfare", which was developed by Hill and Bramley (1986), and uses a novel - fuzzy set - approach to analysis. In most cases, the existing literature deals with one set of policies (macro- or micro-level ones), independent variables, and their isolated impacts on poverty. The proposed novel approach to analysis focuses on the interlinkages among different macro and micro-level factors within given country contexts and their combined effects.

Second, this study contributes towards the existing literature on conceptualizing and measuring social exclusion and social inclusion. To highlight broad areas of exclusion the analysis first breaks down social exclusion to different dimensions and indicators of deprivation. The defined dimensions and carefully selected indicators per dimension create space for the investigation of multiple deprivations and their possible overlaps. Such a breakdown makes the concept of social exclusion more concrete and measurable. The study offers a context-specific index of social exclusion with the emphasis on the specificities of a particular country. The relevance also lies in the development of an index of social exclusion for Serbia in a way that has not been offered before. Additionally, the rather vague concept of social inclusion is operationalized by measuring subjective well-being outcomes such as the perceived level of social contacts and self-confidence before and after 
the participation in a work activity. This is closely linked to the next contribution that this study makes.

The third contribution of the presented study involves a rather unique qualitative assessment of subjective well-being dimensions in the discussion of the effects of a specific public policy measure (public works). The qualitative approach has been adopted in the absence of survey data on transition from unemployment to employment and in addition to the objective indicators on the labor market status. Our aim was not to undermine the role of conventional economic indicators and their analyses but to stress the importance of using subjective well-being measures in addition to them and in the overall explanation of social inclusion. To our knowledge, this is the first study that answers how work activation of social assistance recipients impacts on their subjective well-being outcomes over time. Despite its limitations for wide generalizations, the assessment provides meaningful and detailed insights in the perceptions about work engagement in relation to social inclusion outcomes.

Perhaps the most significant contribution of the presented study lies in its political and social relevance. For instance, the findings on subjective well-being outcomes have important implications for both individuals' lives and decision makers' responses to certain situations. The study shows that the work activation of social assistance recipients is possible and that it yields positive results. This is of particular policy importance for countries in which there is no strong belief that this outcome is possible. Our study shows that despite the unfavorable labor market outcomes, i.e. the very low employment rate following the completion of temporary work activity, the results are positive with regard to the recipients' subjective well-being outcomes. The evidence is strongest in relation to their positive perceptions about the level of acquired qualifications, skills, increased selfconfidence and social contacts. This type of assessment of the effects of a specific public policy measure does not always garner sufficient support as it presents a clear derail from traditional economic analysis. Nevertheless, it gains importance on its political feasibility and equity fronts. The presented study confirms that providing equal opportunities in the labor market to those marginalized and often neglected increases their social inclusion in the society.

\subsection{Outline}

The study consists of six chapters including this introductory chapter. Each of the Chapters 2 through 4 addresses a distinct question and can be treated as a self- 
contained study with its own literature review, conceptual framework, data and methodology descriptions, and the discussion of the main results. Together, the analyses presented across different chapters address the main research question. This section provides a brief overview of each chapter.

Chapter 2 proposes the use of the fuzzy-set variant of the Qualitative Comparative Analysis (fsQCA) as a novel approach for treating social assistance, activation, and social exclusion. In this analysis, explanatory variables, including the features of socio-economic contexts, inputs and social assistance policy outputs, come in configurations that could be systematically compared and counterfactually tested. Instead of the predominant focus on isolated causes of exclusion, the analysis involves a combination of various socio-economic and social assistance related factors, observed across countries. The findings of the fuzzy-set analysis argue in favor of activation policies in addressing poverty. Nevertheless, the results also suggest that activation is neither necessary nor sufficient condition for the occurrence of low poverty. Instead, it reveals possible paths leading to the outcome i.e. various combinations of conditions impacting on the outcome.

In Chapter 3 we elaborate on the dynamics aspect of social exclusion, the discussion of which has been by-passed in the preceding analysis. We take a closer look at the cases of Estonia and Slovenia. The analysis is rather descriptive and questions the similarity in poverty outcomes of Estonia and Slovenia. The results presented in this chapter can be treated as an extension to the fuzzy-set analysis, with its own discussion on social assistance and activation policies in relation to poverty outcomes over time.

Since the analyses so far focus primarily on relative poverty as the only dimension of social exclusion, they are rather constrained in explaining the multidimensional nature of social exclusion. The remainder of the study relies on the classic quantitative and qualitative research methods to address this shortcoming.

In Chapter 4 the study focuses on the case of Serbia and applies quantitative analysis of the UNDP (2010) social exclusion data to develop a country-specific social exclusion index. The approach proposed in this chapter builds on the existing approaches to measuring multidimensional poverty. The analysis employs 24 deprivation indicators within three dimensions of social exclusion. Alkire \& Foster's (2007) dual cut-off approach is applied in a two-step procedure for the identification of the multidimensional poor. Firstly, it is identified whether a person is deprived with respect to a given indicator ('within indicator cut-off'). The second step ('across indicators cut-off') identifies those who are socially excluded by counting the number of indicators across the given dimensions in which a person is deprived. The ultimate focus is on the sub-sample of social assistance 
recipients and the areas of most significant deprivations among them. The concluding findings on patterns of exclusion serve as a starting point for the subsequent discussion on possible policy responses presented in Chapters 5 and 6 .

Chapter 5 of the study offers a thorough insight in a single policy option that could help reduce social exclusion and increase social inclusion among social assistance recipients. It explores the effects of activation through temporary employment on recipients' labor market and subjective well-being outcomes. The program under the study is the Public Works Program in Serbia. The applied qualitative analysis relies on the data obtained from semi-structured in-depth interviews with social assistance recipients participating in the public works. The analysis focuses on their perceptions about the changes in different dimensions of subjective wellbeing before and after the public work activity. More precisely, the data entail a self-assessment of changes concerning family income situation, health status, personal qualifications and skills, desire to find a job, chances to find a regular job, social contacts, and self-confidence.

The findings of our qualitative analysis show that despite the low employment prospects for public work program participants, there are significant positive impacts of work engagement on their subjective well-being. The evidence is strongest in relation to their positive perceptions about the level of acquired qualifications, skills, and social contacts. The findings also confirm that activation is not only about labor market integration but involves social exchange at a qualitatively new level, which leads to further participation in different aspects of social and civic life.

In order to enrich the discussion and in support of the arguments favoring activation, in the same chapter we provide additional data on social assistance recipients in Serbia. They stem from the most recent ad hoc survey (2011) conducted among the recipients of financial social assistance in Serbia. The dataset is geared to identify their labor market and education outcomes, past employment records, job search activities, overall attitudes towards the world of work, and access to multi-agency service delivery.

Chapter 6 presents the main conclusions of the study. It summarizes the main findings, highlights the limitations of the presented research, and offers possible policy recommendations for greater social inclusion of social assistance recipients. 


\section{CHAPTER}

\section{Qualitative Comparative Analysis of Active Social Assistance Polices and Their Impact on Poverty: The Case of Twelve European Union (EU) Countries}

\subsection{Introduction}

In the previous chapter, it has been noted that the concepts of social inclusion and social exclusion are very interrelated. Any discussion on social inclusion outcomes, and particularly the one focusing on the most deprived population, requires a deep understanding of the context and underlying processes leading to social exclusion. It is by now known that different forms of exclusion are often addressed by government interventions. Government social assistance and activation policies for the poor and vulnerable are put at the forefront of the discussion of underlying polices and processes. They constitute the focus of the analysis presented in this study.

The subsequent analysis aims at systematically exploring the link between government supported social assistance programs, activation in particular, and social exclusion defined in terms of poverty outcomes. In this chapter, the focus is on at-risk-of-poverty rate among social assistance recipients specifically. This relative poverty measure (the at-risk-of-poverty rate) is the single most prevailing measure of social exclusion/social inclusion in the EU (Marx \& Bosch, 2007; Organization of Economic Cooperation and Development, 2012). ${ }^{3}$ Another reason for using income measure in our analysis stems from the fact that social assistance, as anti-poverty measure, provides income support to its beneficiaries. The at-riskof-poverty uses a definition according to which all persons living in households with equivalent income that is below 60 percent of median household equivalent

\footnotetext{
3 The at-risk-of-poverty rate was adopted as prime EU social inclusion measure at the Laeken summit in 2001. It is widely used in the absence of a conventionally defined social inclusion indicator. In 2010, the European Council adopted a headline target on social inclusion. The new indicator of at-risk-of poverty or social exclusion combines three subindicators: the at-risk-of-poverty rate, severe material deprivation rate, and people living in households with very low work intensity. We discuss these and additional forms of deprivation in Chapters 3-5.
} 
income in the member state of residence are regarded as being at risk of poverty. Anchoring measure to median the welfare makes it dependent on distributional parameters. This allows for poverty lines and poverty rates to differ across countries with the same level of income per capita.

Our study acknowledges that social exclusion is multidimensional and cannot be expressed only in monetary terms. Chapter 4 elaborates further on this. The primary focus of the analysis presented in this chapter, however, is on different combinations of factors that impact on a single most important dimension of social exclusion - the relative poverty rate - among social assistance recipients of working age.

The main question that is being addressed in this chapter is: Under what conditions does activation as part of social assistance programs become a necessary or sufficient condition for better relative poverty outcomes? By exploring the link between the activation, various contexts, policies, and monetary poverty, we reveal if the activation has any tangible role to play in the social exclusion/inclusion discourse. While the primary focus is on activation, the presented analysis provides insights into different combinations of factors leading to poverty among social assistance recipients. This was done by means of fuzzy-set analysis, in an exploratory manner, and in support of more detailed discussions on the link between social assistance, activation, and social exclusion that is presented in the subsequent chapters.

The literature recognizes the impact of different forms of government interventions, such as social assistance, on social exclusion outcomes. But, it rarely addresses the inter-linkages among different macro and micro level policies. The presented study makes contribution in this regard. Moreover, important structural or context factors appear to be often neglected in the existing analyses. In most cases, the studies apply various statistical analyses and deal with independent variables and their impact on poverty. Contrary to these approaches, the analysis presented in this chapter focuses on the combined effect of different (and differentlevel) variables. Important noting, however, is that the presented analysis is rather exploratory because of limited theoretical underpinnings. Some of its initial findings are further reflected on in Chapters 3 to 5.

In addressing the causal complexity at stake, the study puts forward fuzzy-set Qualitative Comparative Analysis (fsQCA) as a novel methodological approach introduced to social science by Charles Ragin $(1987,2000)$. Relying on the fsQCA and set-theoretic relations, this chapter deals with complex causal hypotheses in terms of necessary and sufficient conditions under which the defined social exclusion outcome occurs. 
As fsQCA is not inference i.e. it does not involve sampling and inferring, the selection of each individual country case for the analysis has been done purposefully and carefully. It involves twelve EU member states with developed national social assistance and activation schemes for which the data on the outcome indicator were available. In terms of general findings, the presented qualitative comparative analysis shows the combinations of conditions leading to low poverty while favoring the affirmative role of activation policies.

The chapter is organized as follows. The next section explains the model of welfare production as framework for our analysis. The third section introduces conditions employed in the analysis and elaborates on their links to the outcome. It is followed by the presentation of country cases and data sources. Next is the explanation of calibration and overall fuzzy-set procedure. Sections six and seven are dedicated to the presentation of the model specifications and main results of the analysis of necessary and sufficient conditions. The final section provides conclusions and offers suggestions for further work.

\subsection{Framework for analysis}

The literature recognizes different approaches to social exclusion: sociologists tend to stress the importance of behavior among different groups within a given society; economists emphasize the role of the labor markets in reducing poverty and social exclusion, while social policy analysis focuses on government designed policies and their impact. Since social exclusion is a complex phenomenon, these isolated approaches provide an explanation of social exclusion that is rather incomplete (Burschardt et al., 2002).

The prevailing focus on individuals by the economic science provides only a partial explanation of social exclusion (Atkinson, 1998). For the dynamic dimension of exclusion, contemporary economic analysis has developed a number of econometric models explaining moves in and out of employment for social assistance beneficiaries (Barret, 2000; Gustafsson et al., 2002; Dahl \& Lorentzen, 2003). However the analyses of underlying causes and causal processes have rarely been reflected in the research. In addition, one may argue that Atkinson's (1998) relativity element, indicating that social exclusion is a product of different events in society, has largely been neglected. At least, it has not been sufficiently addressed in the analysis of the impact of welfare policies and institutions on reducing social exclusion. 
Social policy analysis approach draws from different theoretical traditions, such as social administration (primarily rooted in the U.K.), welfare economics, and political economy (Hill \& Bramley, 1986). In the welfare state literature, the role of social policy and its interventions have been traditionally analyzed in the context of modernization and industrialization processes (Wilensky, 1975; Kapstein \& Milanovic, 2003) or as the consequence of dramatic political and economic shocks (Pierson, 1996). The argument is that as these processes unfold the state functions as a replacement to traditional family, church, and other informal safety nets, providing social protection support within its government run system. This has been an important factor in shaping the traditional European welfare state. With respect to the developing countries, Lindert (1996) argued that even these countries follow the route of the more advanced economies in designing their social policies. Commonly, the economists view social policy as the government response to the failure of markets to provide assistance and insurance that people may require to mitigate various risks (Holzmann \& Jorgensen, 2001; Kapstein \& Milanovic, 2003).

Government social policy is largely interlinked with different macro and micro level policies. In the discussion of various aspects of social policy Musgrave and Musgrave (1975), Hill and Bramley (1986), and later Hall and Soskice (2001) refer to macroeconomic policies viewed as necessary parts of social policy analysis. These policies, for example, influence investments, production outputs, and levels of employment, but also levels of social protection and the distribution of income. The discussion in this study shows that the goals of poverty reduction and greater integration in the society require a broader understanding of both macroeconomic and microeconomic factors impacting on these outcomes. For these reasons and in support of Hill and Bramley's (1986) arguments, macroeconomic policy should always be analyzed within the scope of social policy and is to be treated as part of the overall environment of social welfare policy.

A social policy analysis approach that offers a broad framework to analyze social assistance policy processes and policy impact within given contexts is known in the literature as "the model of welfare production". The model of welfare production was developed by Hill and Bramley (1986) as an effort to identify inputs which determine policy outputs, and possibly, outcomes of a given welfare policy. According to its authors, the model builds on the earlier work by Knap and the Easton and Jenkin's "systems model of the policy process" but refers in particular to the "production of social services and their impact on welfare" ( $p$. 179). The model consists of inputs, production of inputs into outputs, which together with other factors affect the welfare of individuals, households, and society in general. 
In the welfare production model presented in Table 2.1 below, a number of potential factors intervene at different levels and stages of welfare production. In our particular case, inputs are the resources employed to finance social assistance benefits and services as well as physical resources such as staff, buildings and equipment. The financing usually come from budget revenues. Outputs are viewed as definable, intermediate outputs, such as the share of government spending on social assistance, social assistance coverage and benefit levels. Production refers to the process within which inputs are being transferred into outputs. In the case of social assistance provision, these processes include means-testing and work related-testing of benefit claimants. Outcomes, or the final outputs, are regarded as welfare i.e. the state of well-being of individuals and groups that are being analyzed. Welfare implies "the extent to which need is met" (Hill \& Bramley, 1986, p. 181) such as, in our case, beneficiaries' financial need.

Table 2.1: Social assistance: Model of welfare production and conditions for fsQCA

\begin{tabular}{|c|c|c|c|c|}
\hline \multicolumn{5}{|c|}{ Social Assistance: Model of Welfare Production } \\
\hline ENVIRONMENT & $\underset{\Rightarrow}{\text { INPUTS }}$ & $\underset{\Rightarrow}{\text { PRODUCTION }}$ & $\begin{array}{l}\text { OUTPUTS } \\
\Rightarrow\end{array}$ & OUTCOMES \\
\hline $\begin{array}{l}\text { Socio-economic } \\
\text { factors }\end{array}$ & $\begin{array}{l}\text { Staff } \\
\text { Buildings } \\
\text { Equipment } \\
\text { Other } \\
\text { resources }\end{array}$ & $\begin{array}{l}\text { Means-testing } \\
\text { Work-related } \\
\text { requirements }\end{array}$ & $\begin{array}{l}\text { Spending on } \\
\text { social } \\
\text { assistance } \\
\text { Benefit } \\
\text { coverage } \\
\text { Benefit levels }\end{array}$ & $\begin{array}{l}\text { Reduced } \\
\text { poverty } \\
\text { Increased well- } \\
\text { being }\end{array}$ \\
\hline \multicolumn{5}{|c|}{ Conditions used in the fuzzy set analysis } \\
\hline GDP per capita & $\begin{array}{l}\text { Level of } \\
\text { development } \\
\text { of social } \\
\text { safety net } \\
\text { Spending on } \\
\text { social } \\
\text { protection }\end{array}$ & $\begin{array}{l}\text { Activation and } \\
\text { socio- } \\
\text { professional } \\
\text { integration score }\end{array}$ & $\begin{array}{l}\text { Spending on } \\
\text { social } \\
\text { exclusion } \\
\text { n.e.c. }\end{array}$ & $\begin{array}{l}\text { At-risk of } \\
\text { poverty rate } \\
\text { among social } \\
\text { assistance } \\
\text { recipients }\end{array}$ \\
\hline
\end{tabular}

While aimed at explaining policy processes, the model of welfare production might not be fully developed to address the interplay of all causal factors involved in the 
production of welfare or social exclusion. However, this is still the dominant framework of analysis applied in much of the social policy analysis literature. ${ }^{4}$ With existing theoretical underpinnings and by laying the groundwork for an integrative approach that recognizes the causal effect of combined factors, this model may serve as the framework for causal analyses. This certainly requires the application of methodology for the assessment of causal complexity. Recent literature refers to fuzzy set Qualitative Comparative Analysis (fsQCA) to enrich the knowledge about causal complexity (Ragin, 2000; Rihoux \& Ragin, 2009; Rihoux \& Grimm, 2006; Schneider\& Wagemann, 2010; Schneider\& Wagemann, 2012).

\subsection{Conditions and causal statements}

The specification of a set of variables (in the fuzzy-set terminology: conditions) impacting on the social exclusion outcome is a real challenge since poverty is usually affected by a number of economic, social, and political factors. It is rarely the case that one theory explains all the factors influencing complex social policy events (Rihoux \& Grimm, 2006), which makes the selection of relevant conditions even more difficult. Poverty among social assistance recipients is observed as a complex social event which requires the analysis of different socio-economic variables, namely, their combined effect as the subsequent analysis will show. Table 2.1 shows only five factors that have been selected for the fuzzy-set analysis under the framework of welfare production. The number of conditions had to be limited in order for the fsQCA to be feasible. ${ }^{5}$ The conditions employed in the analysis include the following: GDP per capita, the level of development of social safety net, spending on social protection, spending on social exclusion as share of social protection spending, and commitment to activation and socio-professional integration of social assistance beneficiaries.

In the explanation of social policy outcomes, different approaches have to be consolidated and applied. Country comparisons of national wealth and living standards are conventionally made on the basis of nominal gross domestic product (GDP) or by their GDP at PPP (purchasing power parity) per capita. GDP per capita expressed in PPPs is selected as one of the macro-level conditions for the analysis. The expectation here would be that richer countries score better on social exclusion

\footnotetext{
${ }^{4}$ See for example Hagfors and Kajanoja (2007) or Kuivalainen (2004).

${ }^{5}$ The number of logical possible cases (including the non-observed ones) increases exponentially with the number of conditions.
} 
outcomes and that all citizens benefit from their country's economic production. Nevertheless, for the developed welfare states and market economies, authors such as Hyman (1999) and Stiglitz (2000) stress that they do not always produce a distribution of income that is socially acceptable. This requires the inclusion of an inequality of income distribution in the analysis. However, inequality and relative poverty have much in common and, in a way, measure the same. The application of a relative poverty line already incorporates issues of inequality into the analysis. It is done by focusing on inequality at the bottom end of the income distribution. Therefore, we decide to drop the inequality of income distribution indicator from the fuzzy-set analysis.

As a policy response to the existing poverty and inequality, almost all European states have over time reached a certain, rather high, level of development of their social safety nets. The general assumption here is that the well designed and functioning social safety net helps mitigate poverty in the society, which is in line with the existing theory (Holzmann \& Jorgensen, 2001). Based on its relationship to poverty, the level of development of social safety net is included in the analysis as the third condition.

Concerned with the positive and negative effects of efficiency, government financed programs often raise the issue of the kinds and the levels of redistribution (Hayman, 1999). Principles of justice and equity usually contrast the reasoning based on efficiency. A number of theories of justice provide a philosophical basis for the discussion on redistributive policies. Within this scope, positions on social justice are wide ranging and hardly possible to cover in this kind of review without getting insights into political and social philosophy. The diversity of opinions might perhaps be the reason why welfare economics literature does not make confident prescriptions about the distribution function of the state, as properly noted earlier by Hill and Bramley (1986). Redistribution through social protection programs, expressed as a share of GDP, is commonly used in the discussions on poverty and poverty reduction effects (European Commission, 2007; Herrmann, 2008) and as such is included in our analysis. The principal assumption here is that higher redistribution and relatively larger spending on social protection is expected to yield lower poverty levels expressed in relative terms. However, we are primarily interested in poverty outcomes for those who are most deprived and necessitate state financial assistance. Hence, we apply an additional indicator focusing on the share of the overall social protection budget that is being channeled to the poor.

In the model of welfare production, the level of spending on social assistance stands at the point of output. In the EU member states, those are actually social exclusion benefits n.e.c. (not elsewhere classified) that are defined as cash transfers 
aimed at mitigating financial burden of those referred to as "socially excluded" or "those at risk of social exclusion" (Eurostat, 2007, 2008). The terms "social exclusion benefits" and "social assistance benefits" refer to the same type of policy and will be used interchangeably throughout this text. Social assistance benefit transfers are provided by central and local governments and they are received by eligible individuals or households with insufficient resources. Eligibility criteria may involve income and asset tests but also certain requirements related to nationality, residence, age, availability for work and family status. Social assistance as income support is aimed at destitute and vulnerable persons to alleviate their poverty or mitigate difficult financial circumstances. Hence, it is assumed that the more social protection spending is directed to the protection of those who are in need of cash assistance the bigger the impact in terms of poverty alleviation. ${ }^{6}$ The analysis, therefore, employs the share of social protection spending on social exclusion benefits as additional condition.

Social assistance programs, defined as cash transfers targeted at the poor individuals and households, constitute an important part of modern European social safety nets. Besides its poverty reduction goals, another important role of social assistance is its contribution to more equal income distribution and inequality reduction (Förster \& Mira d'Ercole, 2005; Adema, 2006). Over recent decades, the design and provision of social assistance has altered to include a requirement for the able-bodied beneficiaries of working age to work in order to receive benefits (Lodemel \& Trickey, 2000; Adema, 2006). The programs such as social activation, education, training and work requirements have been included in social assistance legislation, signaling that poverty reduction might not be the only social assistance policy objective and that the goals such as self-sufficiency and greater activation and integration of social assistance beneficiaries in the labor market should be observed. Therefore, the final condition employed in the fuzzy set analysis refers to governments' commitment to activation and socio-professional integration policies.

Activation and socio-professional integration of social assistance beneficiaries are to be viewed as part of social assistance programs aimed at reducing exclusion, facilitating and promoting beneficiaries' integration in the society. It refers to a range of policy designs such as mandatory registration with public employment services, individualized approaches to beneficiaries' activation and integration, increased employment and income incentives such as topping up of their benefits, etc. To what extent each of the country programs involves these policy designs is

\footnotetext{
${ }^{6}$ The estimate of effect might be biased in this particular case because the larger poverty rate assumes the greater need for social assistance. At the same time, the result also depends on poverty impacts of other social protection programs, which are not discussed here.
} 
defined in the presented analysis as the government's commitment to activation and socio-professional integration. In line with the argument described above, it follows that the stronger the commitment to activation policy, the better should be poverty outcome among its beneficiaries.

As already noted, at-risk-of-poverty rate among social assistance/social exclusion benefit recipients is viewed as a social exclusion outcome indicator. Previous research has confirmed that for this specific group under investigation insufficiency of recourses and their detachment from the labor market present the main social exclusion challenge (Clark \& Oswald, 1994; Förster \& Mira d'Ercole, 2005). As a measure of relative poverty, the at-risk-of-poverty threshold is defined as 60 percent of the median income. Consequently, for each country case in the analysis, the at-risk-ofpoverty rate indicator reflects the share of individuals living in households receiving social assistance benefits where the total equivalent household income (including social transfers) is below the set at-risk-of-poverty threshold. ${ }^{7}$ As previously noted, this particular outcome indicator is selected because of its wide acceptance as the primary social inclusion indicator and based on the fact that social assistance policy, which is comprehensively investigated in this thesis, actually provides income support.

Despite the fact that we are using a single social exclusion outcome indicator throughout our fuzzy-set analysis, we acknowledge that the nature of social exclusion is multidimensional. The EU Statistical Office (Eurostat) and the research community have over time developed a number of indicators to monitor and compare national performance in fighting social exclusion. Very often, the literature refers to them as "social inclusion indicators" or simply "social indicators" (Marlier et al., 2007). The agreed set of social indicators focusing specifically on

\footnotetext{
7 This is a relative definition of poverty since the poverty rate depends on the average or median income in the country. In addition, another poverty threshold has been introduced at the level of 10 euro a day (in purchasing power standards) to compare the absolute poverty rates. A 10 euro/day threshold was set earlier in the research of the European Center for Social Welfare Policy and Research (Lekles \& Zolyomi, 2008). The intention was to carry out an additional fuzzy set analysis with the absolute poverty rate as the outcome indicator. However, it turned out that the divergence of absolute poverty is very high and much greater than the one of relative poverty. The absolute poverty rates are below 2 percent in half of the analyzed cases, namely the Western European countries. At the same time, absolute poverty is very high in Central and Eastern Europe excluding Slovenia. For example, more than two thirds of the social assistance recipients in Latvia and Poland lived in absolute poverty in 2004. Finally, this polarization of countries on low-level and highlevel poverty ones does not resonate well with the calibration principles in fsQCA. The outcome indicator cannot be dichotomized, which in this case would be a natural procedural step, making it impossible to undertake a proper calibration and fuzzy set analysis.
} 
poverty and social exclusion the, so called, Laeken indicators, focus on different outcomes and include: at-risk-of-poverty rate; persistent at-risk-of-poverty rate; intensity of poverty risk; long-term unemployment rate; population living in jobless households; early school leavers not in education or training; material deprivation; housing; self-reported unmet need for health care; material deprivation; and, child well-being. Some of these indicators and, more broadly, dimensions of social exclusion will be discussed in the subsequent chapters of this study.

\subsection{Cases and data sources}

Cases included in the analysis involve the following twelve EU countries: Czech Republic, Estonia, Latvia, Poland, Slovenia, Germany, France, Sweden, the United Kingdom, Cyprus, Luxemburg, Portugal. The selection of countries is done purposefully. The set of cases consists of a number of old (Germany, France, Sweden, United Kingdom, Cyprus, Luxemburg, and Portugal) and new EU member states which are at the same time the countries of Central and Eastern Europe (Czech Republic, Estonia, Latvia, Poland, Slovenia). While the selection of countries ensures a certain level of diversity the possible universe of cases would involve all EU member states and, of course, Serbia given the predominant focus of the thesis on this country. However, this was not possible due to objective limitations listed below.

The most important requirement for the selection of countries involved having a developed a general social assistance program (the guaranteed minimum income scheme, GMI) run by the government because this was the main focus of the analysis. The countries with decentralized social assistance schemes governed by sub-national levels and multiple legislative acts (Austria, Spain, Greece, Hungary, and Italy) were excluded from the analysis at the outset. Another limitation concerned non-availability of data on the outcome indicator (relative poverty rate among social assistance recipients), summing the number of country cases for the analysis to twelve. Obviously, Serbia is neither the EU member state nor it had the EU-SILC $^{8}$ in 2004 from which the data on the outcome indicator were derived. Therefore, it was not possible to include the case of Serbia in the fuzzy-set analysis. Nevertheless, the type of exploratory analysis presented in this chapter served

\footnotetext{
8 The EU-SILC (Survey on Income and Living Conditions) database contains comparable multidimensional micro-data on income, poverty, social exclusion, housing, labor, education, and health.
} 
multiple purposes feeding into later discussions (Chapters 3-5) on the role of activation policies in the countries undergoing major economic transformations.

In such a limited number of cases, the number of possible conditions had to be decreased to a meaningful level to ensure a proper fuzzy-set analysis. As noted, a potential list of macro and micro level indicators impacting on poverty outcome was long and had to be reduced to reflect only those factors that could be described as strongly related to the outcome. In the final model specifications, the number of conditions is limited to five.

Since all the cases are member states of the EU, the main source of information for social protection related conditions (social protection spending as share of GDP; social assistance spending as share of social protection expenditure) was found in the publicly available Eurostat databases. The GDP per capita (\$PPPs) is taken from the World Bank International Comparison Program (2008). For the level of development of social safety nets, the analysis makes use of the welfare regime variable of the BTI (Bertelsmann Transformation Index). This index is often used for the ranking of the development and transformation of countries in terms of their level of democracy and market economy. The BTI welfare regime variable included in this analysis measures to what extent social safety nets exist to compensate for poverty and other risks such as unemployment and to what extent equality of opportunity exists in a given country. These data have been cross-checked with the secondary data posted in the MISSOC (Mutual Information System on Social Protection in the European Union, 2004) database. MISSOC is an information system created to provide comparative information on social protection systems in EU member states. It includes detailed information on minimum income guaranteed schemes, activation and socio-professional integration policies employed in the analysis, the selection of which is presented in Table A1.1 of the Appendix 1. Finally, at-risk-ofpoverty rates among social assistance recipients were calculated by the author using the EU Survey on Income and Living Conditions (EU-SILC) 2005.

\subsection{Methodology and operationalization}

\subsubsection{Why Fuzzy set analysis?}

The analysis in this chapter involves a fuzzy set Qualitative Comparative Analysis (fsQCA) introduced to research community by Charles Ragin $(1987,2000)$ and taken forward by many authors over the last two decades. The fuzzy set technique has been selected for this research because it captures both quantitative and 
qualitative differences among the analyzed countries. Also, fsQCA appears to be most appropriate for the analysis of small number of cases such as the presented selection of EU countries. In addition, fsQCA addresses the issues associated with the measurement of causal complexity in policy analysis in which explanatory variables come in combinations that are rarely compared. This makes fsQCA suitable in the explanation of a social outcome such as relative poverty among social assistance recipients.

QCA was developed originally for the analysis of crisp sets (Boolean algebra). In crisp sets, variables take either the value of 0 or the value of 1 . Fuzzy sets are an extension of crisp sets that permit membership scores in the interval between 0 and 1 (Ragin, 2000; Ragin, 2008; Rihoux \& Ragin, 2009; Wagemann \& Schneider, 2010; Schneider \& Wagemann, 2012). These fuzzy-set scores do not imply just simple presence (1) or absence (0) of the membership but underline qualitative states between 0 and 1, as shown in Table 2.2. They could also be effectively applied in the assessments of qualitative variables, such as activation and socio-professional integration indicator used in this study. The procedure of assigning the membership scores is known as calibration. The next section explains the calibration procedure pertaining to our analysis.

\subsubsection{Calibration}

The fuzzy sets presented in this section reflect degree of membership in the outcome, i.e. in the set of low at-risk-of-poverty rate among social assistance recipients, as well as degree of membership in the sets of various contextual and social assistance program related factors. The raw data are continuous (except for the qualitative indicator). We apply the direct method of calibration, as suggested in the literature by Ragin (2008) and Schneider \& Wagemann (2012). Central to this method of calibration is the specification of full membership (a fuzzy set score of 1.0), full non-membership (0.0), and the cross-over point of 0.5 for each of the indicators. These are three numerical anchors set by the researcher (based on theoretical knowledge or empirical data at hand) for the assessment of the outcome and related conditions.

Table 2.2 shows the raw data and the fuzzy set membership scores of the outcome and conditions employed in the analysis. The discussion of each of these follows below. 
For the calibration of at-risk-of-poverty rate among social assistance recipients, triple the average poverty rate in the EU or 45 percent is taken as the cross over point (0.5). ${ }^{9}$ This is explained by the fact that the probability of being poor for individuals living in households that receive social assistance is on average 2-3 times higher compared to the corresponding probability for all other households. Hence, the upper boundary is taken as the cross over while the lower boundary, or the poverty rate of 30 percent, is set as the threshold for full membership (1). The threshold for full exclusion (0) has been moved beyond 60 percent to reflect nonmembership and extreme poverty rates, yet present in our raw data.

GDP adjusted for difference in purchasing power is used as indicator of development across countries. Despite existing discussions, the knowledge base for the definition of full membership in the set of developed countries has not yet been provided in social sciences (Ragin, 2008). The calibration of the set of countries is influenced by the choice of cases, namely the within group differences. As in the previous example, the method of calibration of the set of this group of developed countries involves three important qualitative anchors. The cross-over point (0.5) is the value of the interval-scale variable that raises maximum ambiguity with regard to whether the case is more in or more out of the set. For the purpose of this analysis, a GDP per capita income of $\$ 24,000$ is used as the cross over point. The threshold of full membership in the target set is $\$ 32,000$, while the cases with GDP per capita of $\$ 18,000$ or lower are consider fully out of the set of countries at the very high level of development.

\footnotetext{
${ }_{9}$ On average, 15 percent of the EU population lived below the at-risk-of-poverty threshold in 2004, while the rate for social assistance recipients was on average two to three times higher (based on own calculation using EU-SILC 2005).
} 


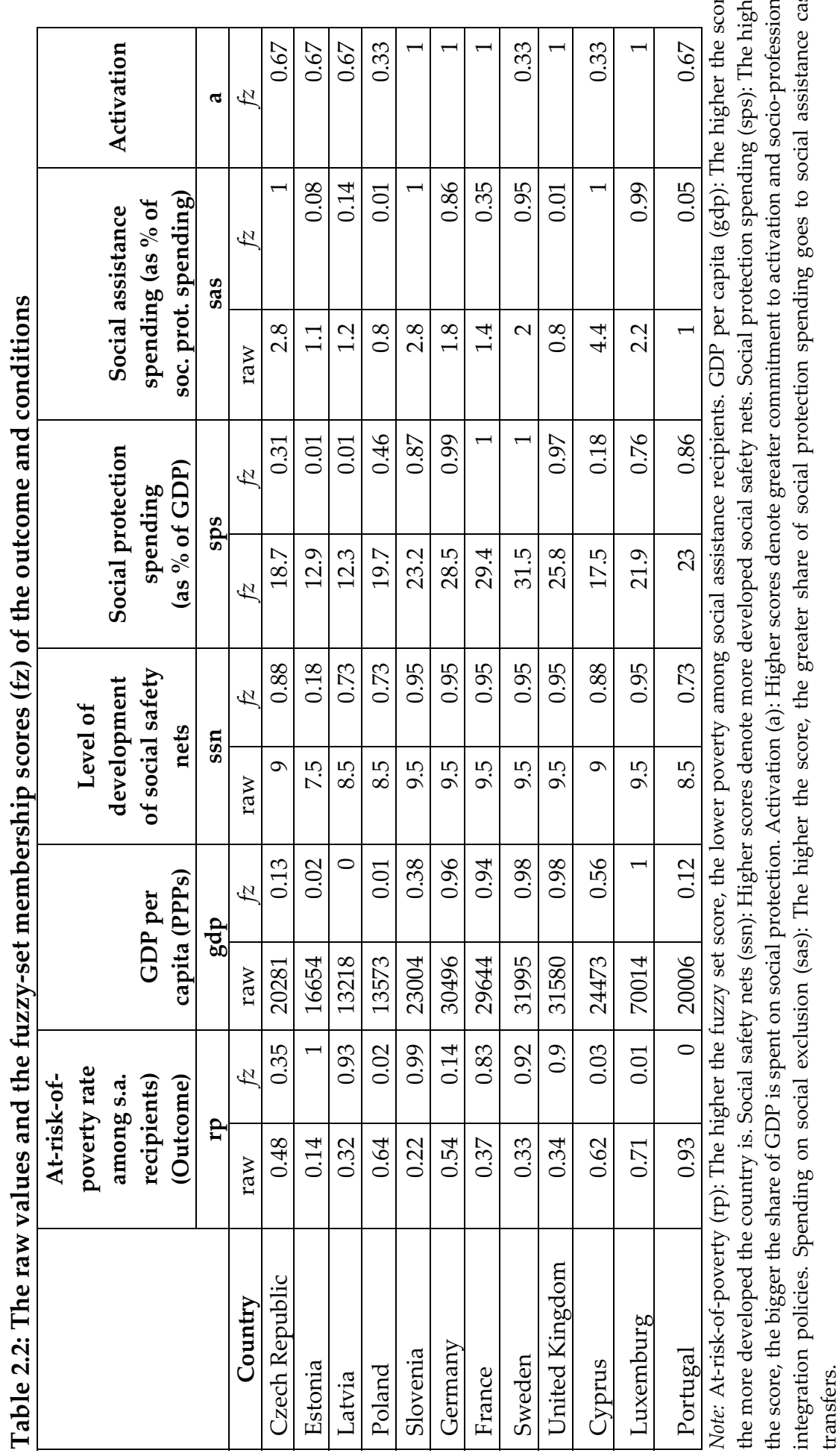


To measure to what extent social safety nets exist to compensate for poverty and other risks such as unemployment and to what extent equality of opportunity exists in a given country, the study utilizes the welfare regime variable from the BTI (The Bertelsmann Transformation Index 2006) combined with the qualitative information available in the MISSOC (2004) database. To qualify for full membership in the set of developed country a case needs to score 9.5 or higher on the welfare regime. The score of 8 is determined as a cross-over point while the threshold for full non-membership is set at 7. Clearly, we were limited in the choice of qualitative anchors in this particular case because of the small diversity among country cases.

In the case of social protection spending, the direct method of calibration follows the logic presented by Veugelers and Magnan (2005) in which the decision on qualitative anchors is based on the knowledge about specific representatives of groups of country cases. In our analysis, full membership in the set of countries with a high social protection spending is set at 25 percent or greater. This level approximates the level of public expenditure of Slovenia, one of the leading examples of successful economic transition, but also of the old EU member state such as the United Kingdom. Full non-membership is assigned to cases that fell on or below 15 percent of public expenditure on social protection to allow for deliberation about low-level spending cases for which only provisional values approximating this percentage have been provided in the EU statistics. The qualitative crossover point is set at 20 percent of expenditure on social protection, the spending level of transitional economies, but, also of the low spenders in the old EU. Veugelers and Magnan (2005) use qualitative anchors for social protection expenditure calibration that differ in few percentage points. This mainly reflects the differences among the country cases included in the analyses.

Social benefits involve transfers by social protection schemes to households and individuals "to relieve them of the burden of a defined set of risks or needs" (Eurostat, 2007, p.115). According to the Eurostat 2004 data, spending on social exclusion as share of total social protection spending averaged to 1.5 percent. This point has been used as a cut-off point for the calibration. Full membership is set at 2 percent and non-membership at 1 percent.

A careful calibration effort was made with respect to the qualitative variable on activation and socio-professional integration. The calibration was done based on the literature review and expert insights. Activation and socio-professional integration refers to the range of policy designs such as mandatory registration with public employment services (PES), individualized approaches to beneficiaries activation and integration, increased income incentives (including topping up of their benefits), and availability of employment opportunities and other activation 
programs. Degree of membership in the set of countries with more or less developed activation and socio-professional integration is assessed in the range of 0.0 (full non-membership in the set) to 1.0 (full membership). To qualify for the membership of 1.0, a country is expected to have a fully developed system of activation policy which includes general scheme, various incentives, and care mechanisms. In some cases activation policy is limited to beneficiaries' obligation to be registered with PES and be available for work and training activity which is treated as a cross-over point (0.5) in the presented analysis. In several countries such policies are accompanied with individualized approaches to activation. Very few countries combine these sorts of polices with additional employment or earnings incentives or topping up of social assistance benefits, which all together constitutes the membership score of 1.0. A complete absence of the listed government policies and measures or presence of punitive measures only would result in the membership score of 0 . The countries with activation policies that go beyond mandatory registration with PES and provide individual approach complemented with certain incentives have been assigned the score of 0.67 ("mostly" but not "fully" in the set of members). Accordingly, if the country cases have mandatory registration with PES but do not enforce it, or they do not have general activation schemes but provide specific measures linked to active labor market polices, they would score 0.33 in the set. These criteria for the calibration of measures present a quantitative assessment of degree of set membership in a rather qualitative area of research.

\subsubsection{The fuzzy-set procedure}

In this section we set out the basic principles of any fuzzy-set analysis. The core of the fuzzy set analysis presented in this study will be the explanation of necessary and sufficient conditions leading to a lower poverty outcome. After the careful calibration, the analysis proceeds with the identification of necessary conditions or, more specifically, the conditions that must be present for the outcomes to occur. For example, high share of government spending on social protection could be considered as a necessary condition for the occurrence of low level of poverty among social assistance recipients. But, it cannot guarantee this outcome. The necessity test will be passed each time the analysis demonstrates that instances of the outcome $Y$ constitute a subset of instances of a condition $X$ (Ragin, 2000, 2008; Rihoux \& Ragin, 2009 ). Rihoux and Ragin (2009) formally express consistency that indicates necessity as:

Consistency $\left.\left(Y_{i} \leq X_{i}\right)=\sum\left(\min \left(X_{i}, Y_{i}\right)\right) / \sum\left(Y_{i}\right)\right)$ 
According to this formula, a score of 1.0 i.e. the consistency would be equal to 1.0 if all outcome values are less than or equal to their corresponding relevant condition values. The necessity test is done for all the conditions applied in the analysis, as well as their negations.

Next in the analysis is to conduct the fuzzy set truth table procedure. This procedure is, in essence, the analysis of sufficiency. In the fuzzy set analysis, truth table rows represent $2^{\mathrm{k}}$ causal arguments based on logically possible combinations of conditions involved in the analysis. ${ }^{10}$ In any logically possible combination, each case can have only one membership score greater than 0.5 which indicates that the case is more in than out of the causal combination.

The remaining analytic step involves the assessment of each combination's consistency, namely identifying causal combinations of $X$ that are subsets of the outcome Y. The corresponding formula (Rihoux \& Ragin, 2009) is:

Consistency $\left.\left(\mathrm{X}_{\mathrm{i}} \leq \mathrm{Y}_{\mathrm{i}}\right)=\sum\left(\min \left(\mathrm{X}_{\mathrm{i}}, \mathrm{Y}_{\mathrm{i}}\right)\right) / \sum\left(\mathrm{X}_{\mathrm{i}}\right)\right)$

This consistency shows the degree to which one set is contained within another (Ragin, 2000,2008; Rihoux \& Ragin, 2009; Schneider \& Wagemann, 2012 ). When the values of $X_{i}$ are less than or equal to their corresponding $Y_{i}$, then $X_{i}$ is contained within $Y_{i}$, and the consistency score is 1.0. Further assessment is conducted for all the combinations i.e. truth table rows that meet the frequency threshold (at least one case with greater than 0.5 membership) and the consistency threshold of not less than 0.80 .

Once these cut-off values have been determined the analysis proceeds with the process of reducing complex set-theoretic relations into a minimal formula. The process is commonly referred to as minimization procedure which gives the end output of the analysis - the solution term indicating which combination of conditions explains the outcome and at what consistency and coverage levels (Ragin, 2000,2008; Rihoux \& Ragin, 2009; Schneider \& Wagemann, 2012). The coverage explains the size of the set of sufficient condition in relation to the size of the outcome. In other words, while consistency values describe how many cases deviate from the subset pattern condition ' $X$ ' subset of outcome ' $Y$ ', coverage levels

\footnotetext{
${ }^{10}$ The number 2 refers to both presence and absence in which conditions can occur while " $k$ " represents the number of conditions.
} 
give a percentage of how much of outcome $Y$ that needs to be explained is covered by condition X (Rihoux \& Ragin, 2009).

In the fuzzy-set analysis that follows, the described procedure is repeated twice: first, involving five conditions and a consistency cut-off threshold of 0.80 , and, second, focusing on four conditions and cut-off of 0.75 . This will show some possible implications associated with changes in the number of conditions and cutoff thresholds. In line with good fsQCA practices, the search for sufficient conditions is done for both positive and negated outcomes. In carrying out the analyses, we use the fsQCA software developed by Ragin, Drass, and Davey (2006).

\subsection{Analysis of necessary conditions}

The discussion in this section starts out with a quick investigation of the data used in the analysis. Table 2.2 shows that 5 out of 12 cases are more in than out of the set of countries with low poverty rates (with scores higher than 0.5 membership score). Out of these five cases, three are the new EU member states. More interestingly, those are Estonia and Slovenia that show the lowest relative poverty rates among social assistance beneficiaries. It appears that the CEE countries perform better on the outcome indicator than the old EU member states. This is against general perception and common sense. The reasons for such outcomes rest with the fact that the applied relative poverty measure does not adequately capture actual deprivation levels in all countries or regions. This is particularly true for the new EU member states. In these countries, there is only a weak correlation between a country's level of relative poverty and the extent of material deprivation, as found by Marx \& Bosch (2007). Clearly, poverty levels are significantly underestimated in the new EU member states, but this discussion goes beyond the scope of the thesis. For the purposes of our analysis we accept the fact that, relatively speaking, some less wealthy countries count a smaller number of social assistance recipients who can be described as relatively poor.

Within our set of rather developed countries, we observe a significant level of diversity in terms of values of their gross domestic products and shares of expenditures on social protection, while the differences in the levels of social safety net development and social assistance spending are somewhat less expressed. ${ }^{11}$ As elaborated earlier, these conditions together with activation policies summarize

${ }^{11}$ Later we carry out an additional analysis of sufficient conditions excluding the level of development of social safety nets and observe how this changes our results. 
both macro-level and social assistance related factors potentially impacting on the outcome. They are employed in the fuzzy set analysis that follows.

Before proceeding with the analysis of sufficient conditions, we first involve in the analysis of necessary conditions for the outcome (the relative poverty among social assistance recipients). As a reminder, when a condition is necessary for the outcome, then none of the cases may show the outcome without the condition being present. Upon applying the necessity test, two conditions show the consistency values higher than 0.8 (Table 2.3): the level of development of social safety nets and activation and socio-professional integration. The condition with the highest consistency score in the analysis of necessary conditions is the level of development of social safety nets (0.83). ${ }^{12}$ However, this consistency level is not sufficient to speak of a necessary condition, particularly in light of the low coverage (0.51). ${ }^{13}$

Table 2.3: Analysis of necessary conditions and their negation - both for the presence and the absence of the outcome $(r p)$

\begin{tabular}{ccccc}
\hline Conditions tested & \multicolumn{2}{c}{ Outcome: rp } & \multicolumn{2}{c}{ Outcome: $\sim$ rp } \\
\hline gdp & Consistency & Coverage & Consistency & Coverage \\
$\sim$ gdp & 0.55 & 0.55 & 0.52 & 0.50 \\
ssn & 0.50 & 0.52 & 0.54 & 0.54 \\
$\sim$ ssn & 0.83 & 0.51 & 0.89 & 0.53 \\
sps & 0.24 & 0.70 & 0.19 & 0.51 \\
$\sim$ sps & 0.66 & 0.55 & 0.65 & 0.51 \\
sas & 0.41 & 0.55 & 0.43 & 0.55 \\
$\sim$ sas & 0.50 & 0.47 & 0.66 & 0.60 \\
a & 0.58 & 0.64 & 0.42 & 0.44 \\
$\sim$ a & 0.81 & 0.56 & 0.72 & 0.49 \\
\hline
\end{tabular}

Note: "gdp" stands for high gdp per capita, "ssn" for highly developed social safety nets, "sps" for the high level of government spending on social protection, and "sas" the high level of spending on social assistance, while "a" denotes strong government commitment to activation and socio-professional integration; outcome (low relative poverty among social assistance recipients) is denoted as "rp"

The next highest consistency score is reported for activation and socio-professional integration (0.81). Since the activation is of particular interest in our study, we involve in a more detailed analysis of this (close to) necessary condition. When

\footnotetext{
${ }^{12}$ A necessary condition would be the one with consistency value above 0.90 , as suggested by Ragin (2006).

${ }^{13}$ The coverage is a measure of the relevance of a necessary condition and shows how much smaller the outcome set is in relation to the condition set (Schneider \& Wagemann, 2012). Conditions that pass consistency test but with low values of coverage should not be treated as relevant necessary conditions.
} 
activation and socio-professional integration fully pass the necessity test they constitute a superset of the outcome. In other words, activation policies need to be present for the low poverty outcome to occur. As already discussed, this particular relationship between the activation polices and lower level of poverty makes sense, but it is not completely evidenced in our data. Furthermore, when we plot the outcome ( $\mathrm{Y}$ axis) and activation ( $\mathrm{X}$ axis), it becomes clear that three out of twelve country cases do not contribute to the statement of necessity (Figure 2.1). If the activation was fully a necessary condition, all cases would fall below the diagonal in the figure below. However, Sweden, Estonia, and Latvia deviate from this statement.

Figure 2.1: High activation and socio-professional integration as a necessary condition for low poverty

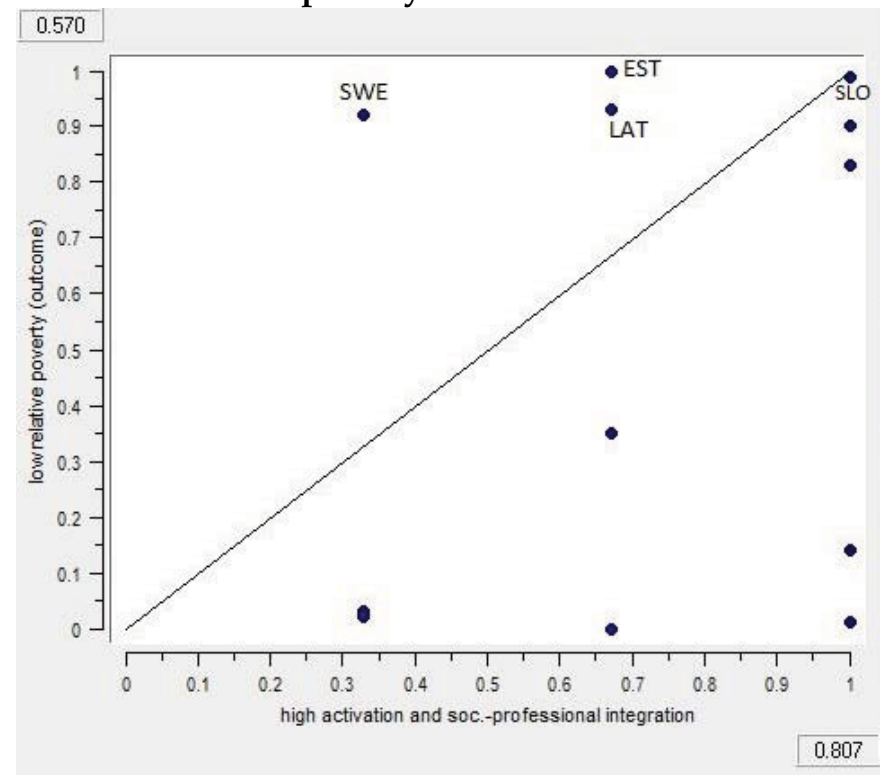

Since the focus of the overall study is on activation policies, the identified countries represent potentially interesting cases for comparative or process tracing analyses. The most recent study by Schneider and Rohlfing (2013) describes procedures for the selection of countries for process tracing studies. In this particular case, Slovenia as the most typical case should be preferably compared with Sweden as the most deviant case. However, the choice for further analysis has fallen on Estonia. We find Estonia as a good empirical instance of low relative poverty rate among social assistance recipients despite the absence of the "necessary" condition activation. 
The necessity analysis was also performed for the absence of the outcome (Table 2.3). None of the conditions passed the necessity test. The highest consistency score was recorded for the level of social safety net development yet again with very low coverage. In sum, the results of the analysis of necessary conditions suggest that none of the conditions can be described as fully necessary for the low poverty to occur.

\subsection{Analysis of sufficient conditions}

Based on the available knowledge and the discussion so far, our hypothesis pertaining to the analysis of sufficient conditions would be the following: It is a combination of wealth (expressed as GDP per capita), developed social safety nets and high spending on social protection and social assistance including activation policies that yield lower poverty outcomes among social assistance recipients.

The above is a very complex model statement which requires that all the country cases that meet the specified condition also have low poverty rates. Important noting however is that the same condition (e.g. country's wealth) may have a totally opposite effect on relative poverty which would depend on the presence of other factors. We also acknowledge that a combination of some other variables, which are not included in the model, may impact the outcome in the same way.

In order to test our hypothesis, we proceed with the analysis which entails the minimization of the truth table into solution formulas. We let the software to perform standard analyses which extract a parsimonious, intermediate, and complex (or conservative) solution. ${ }^{14}$ In the first analysis of sufficient conditions benchmarks for passing the sufficiency test involved the consistency value threshold of 0.80 and at least one case with a membership score higher than 0.5 in conjunction. The resulting distribution of cases across causal combinations is presented in Table 2.4.

\footnotetext{
14 In the parsimonious solution, any assumption in relation to logical reminders (nonobserved cases) is permitted. The intermediate solution is obtained based on "easy counterfactuals" and information provided by the researcher about the hypothesized relation between the conditions and outcome. In the complex solution term, no logical reminders are involved in the minimization procedures.
} 
Table 2.4: Distribution of cases across causal combinations and set-theoretic consistency of causal combination as subsets of low at-risk-of-poverty rate

\begin{tabular}{|c|c|c|c|c|c|c|c|}
\hline gdp & ssn & sps & sas & a & number & rp & Consist. \\
\hline 1 & 1 & 1 & 0 & 1 & 2 & 1 & 0.91 \\
\hline 0 & 1 & 1 & 1 & 1 & 1 & 1 & 0.85 \\
\hline 1 & 1 & 1 & 1 & 0 & 1 & 1 & 0.81 \\
\hline 0 & 0 & 0 & 0 & 1 & 1 & 0 & 0.72 \\
\hline 0 & 1 & 0 & 0 & 1 & 1 & 0 & 0.67 \\
\hline 0 & 1 & 0 & 1 & 1 & 1 & 0 & 0.53 \\
\hline 1 & 1 & 1 & 1 & 1 & 2 & 0 & 0.46 \\
\hline 0 & 1 & 0 & 0 & 0 & 1 & 0 & 0.45 \\
\hline 1 & 1 & 0 & 1 & 0 & 1 & 0 & 0.25 \\
\hline 0 & 1 & 1 & 0 & 1 & 1 & 0 & 0.16 \\
\hline
\end{tabular}

In the truth table above, all conjunctions that pass the established consistency test are viewed as sufficient causes for low poverty with an outcome value of 1 . On the contrary, conjunctions that are inconsistent have been assigned 0 outcome value. The complexity of causal configurations is reduced based on the available empirical information, producing the following minimal formulas (Table 2.5):

Table 2.5: Measures of fit for sufficient fsQCA solution for the outcome low relative poverty (five conditions; frequency cut-off $=1$; consistency cut-off $=0.8$ )

\begin{tabular}{|c|c|c|c|c|}
\hline $\begin{array}{l}\text { Number } \\
\text { of term }\end{array}$ & Term & Consistency & $\begin{array}{l}\text { Raw } \\
\text { Coverage }\end{array}$ & $\begin{array}{l}\text { Unique } \\
\text { coverage }\end{array}$ \\
\hline \multicolumn{5}{|c|}{ Parsimonious solution } \\
\hline 1 & $\operatorname{gdp}^{*} \sim$ sas & 0.898990 & 0.290850 & 0.261438 \\
\hline 2 & $\operatorname{sps}^{*} \sim \mathbf{a}$ & 0.532995 & 0.171569 & 0.102941 \\
\hline 3 & $\sim g d p^{*}$ sps*sas & 0.848485 & 0.183006 & 0.101307 \\
\hline \multirow{2}{*}{\multicolumn{5}{|c|}{$\begin{array}{l}\text { Note: Solution consistency }=0.77 \text {; Coverage }=0.55 \\
\text { Cases with greater than } 0.5 \text { membership in term gdp } \sim \text { sas: United Kingdom }(0.98,0.9) \text {, France } \\
(0.65,0.83) \text {; Cases with greater than } 0.5 \text { membership in term sps* a: Sweden }(0.67,0.92) \text {; Cases with } \\
\text { greater than } 0.5 \text { membership in term } \sim \text { gdp }^{*} \text { sps } s^{*} \text { sas: Slovenia }(0.62,0.99)\end{array}$}} \\
\hline & & & & \\
\hline \multicolumn{5}{|c|}{ Intermediate/Complex solution } \\
\hline 1 & $a^{*} \operatorname{sas}^{*} \operatorname{sps}^{*} \operatorname{ssn}^{*} \sim \operatorname{gdp}$ & 0.848485 & 0.183006 & 0.132353 \\
\hline 2 & $a^{*} \sim \operatorname{sas}^{*} \operatorname{sps}^{*} \operatorname{ssn}^{*} \operatorname{gdp}$ & 0.912371 & 0.289216 & 0.259804 \\
\hline 3 & $\sim a^{*} \operatorname{sas}^{*} \operatorname{sps}^{*} \operatorname{ssn}^{*} \operatorname{gdp}$ & 0.809524 & 0.138889 & 0.101307 \\
\hline \multicolumn{5}{|c|}{ Note: Solution consistency $=0.91$; Coverage $=0.55$} \\
\hline \multicolumn{5}{|c|}{ 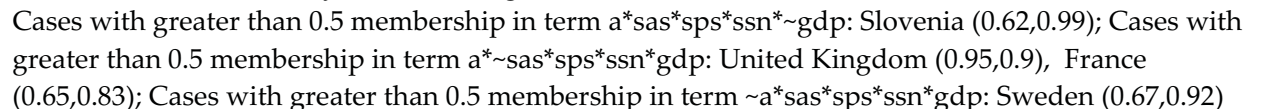 } \\
\hline
\end{tabular}


In the parsimonious solution, there are three sufficient terms for the outcome low relative poverty. Two of them involve two conditions ( $\mathrm{gdp}^{*} \sim$ sas and $\left.\mathrm{sps}^{*} \sim \mathrm{a}\right)$ while one involves three conditions ( $\left.\mathrm{gdp}^{*} \mathrm{sps}^{*} \mathrm{sas}\right)$. The overall solution consistency $(0.77)$ is not high, neither is its coverage $(0.55)$. We plot the solution term against the outcome to demonstrate that some country cases do not contribute to a positive statement of sufficiency. If the conditions (in the solution term) were perfectly sufficient for the outcome to occur, all the cases would be placed above the diagonal in presented xy-plot.

Figure 2.2: Sufficient conditions for low relative poverty

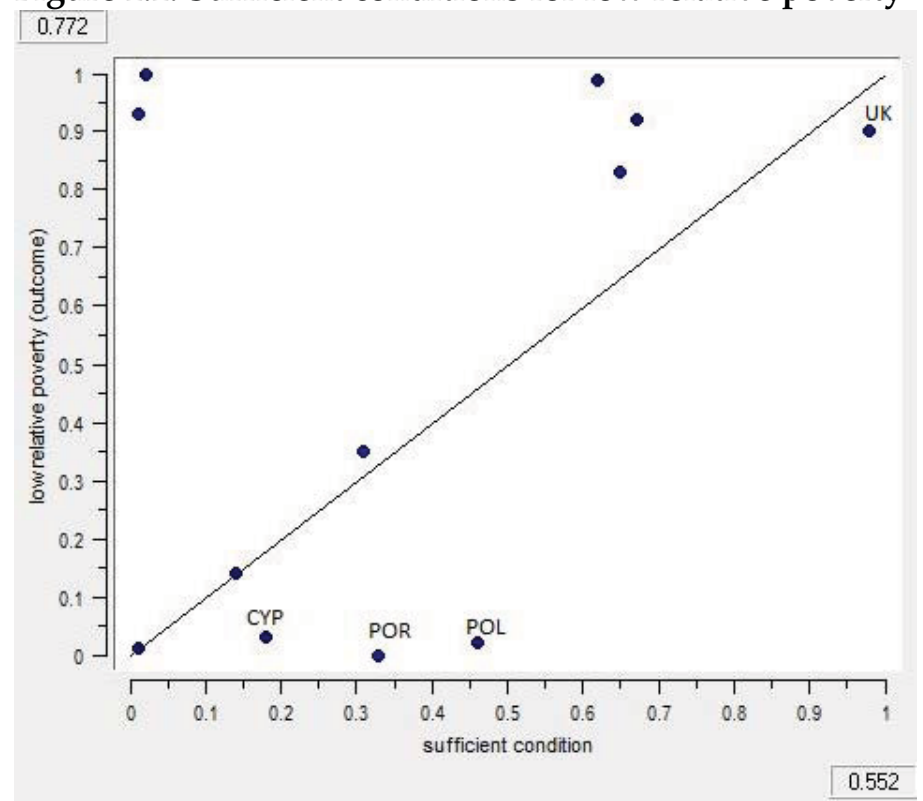

Contrary to our expectations, the analysis of sufficiency shows that it is a combination of high GDP per capita and low spending on social assistance or high social protection spending in combination with low activation or, finally, a combination of low GDP per capita and high spending on social protection and social assistance that produce low poverty rates. The obtained result, however, should not be interpreted as wrong or contradictory to the existing theoretical and empirical findings. As a reminder, this is the result of the parsimonious solution which is essentially the super-set of the intermediate (and complex) solution.

The intermediate solution is more in line with our (researcher's) expectations about the relationship between the conditions and the outcome. As such, the combinations of conditions resulting from the intermediate formula will be adopted as having the explanatory power. Formulas of the intermediate solutions, 
which are at the same time the formulas of the complex solution, are presented in Table 2.5. All three solution terms (1-3) have a rather high consistency scores $(0.85$, 0.91 , and 0.81 respectively) but they show very limited coverage. There are four (country) cases that match the membership sets represented by each formula. The overall solution consistency is 0.91 , but the coverage is only 0.55. An alternative analysis of sufficient conditions, involving a reduced number of conditions (excluding the level of development of social safety nets) and a lower consistency cut-off threshold (0.75), was carried out for exploratory purposes to test the sensitivity of our analysis to possible changes. This, in turn, produced somewhat decreased solution consistency (0.88) but increased the coverage to 0.77 . These results are reported in the Appendix 2.

While the intermediate solution formula in the example above is overwhelmingly complex, it is clear that in each solution term only one condition derails from the formula perfectly matching our expectation about the relationship between the combination of conditions and the outcome $\left(g d p^{*} S^{*} n^{*} s_{s}{ }^{*} s a s^{*} a\right.$ leading to relative poverty rate among social assistance recipients). The results also suggest that there is no single condition that is sufficient for producing the outcome on its own, but each of the condition is at the same time a necessary part of a conjunction that is, on the other side, unnecessary but sufficient for producing the outcome. Schneider \& Wagemann (2012) refer to these conditions as INUS conditions. For example, for the activation condition which is of our particular interest, this means that it is insufficient to yield low relative poverty. But, it is a necessary part of a combination of conditions that is sufficient for producing the low poverty outcome. The same finding on INUS conditions is observed in the additional analysis with the reduced number of conditions and lower consistency cut-off value (Appendix 2).

In the presented intermediate solution, there are three solution terms. The causation is conjunctional and equifinal. ${ }^{15}$ In line with our expectations, it is the combination of factors that impacts on poverty among the social assistance beneficiaries, not the isolated variables. These relevant factors combine in different ways that are represented by certain country cases. The representative of the first solution term is Slovenia where in the context of average wealth, its rather developed social safety net and high spending on social protection within which a significant share is spent on active social assistance policy, the country manages to produce low relative poverty among social assistance recipients. Its success story, from which other countries undergoing transition could learn, makes Slovenia an

\footnotetext{
${ }^{15}$ Causation is conjunctional when it is a combination of relevant conditions that generates the outcome. It is equifinal when different causal paths lead to the same outcome.
} 
interesting case for further analysis. Together with Estonia, Slovenia is selected for the comparative case study presented in Chapter 3.

The United Kingdom and France are representing the second solution term where almost all conditions are met except that the countries do not spend significant shares of their social protection budget on social assistance per se. Nevertheless they contain the low level poverty among welfare recipients. According to the third solution term, the same outcome occurs even when the activation condition is not being met. The typical representative is Sweden. Its distinctive institutional features couple with very high spending on social protection and keep the poverty rate among social assistance recipients low, which is not surprising given the country's traditional and strong commitment to providing welfare to its citizens.

All these interpretations of the empirical results are done in light of the expectations set earlier in the chapter and within a given welfare production framework. The focus was on the presence of low poverty outcomes and therefore the analysis was geared towards this particular outcome. From the solution formulas presented in the models above, we find enough support for our argument that insisting on activation policies yields better poverty results for the social assistance beneficiaries. ${ }^{16}$ Nevertheless, our findings suggest that this occurs only in combination with other conditions and in a relatively small number of cases.

\subsection{Conclusion}

The choice to adopt the fuzzy-set variant of Qualitative Comparative Analysis (QCA) for our study was made deliberately due to the fact that the number of country cases was small but still too big for a feasible in-depth analysis of all cases. Besides, the fsQCA offered headway for dealing with complex events. Hence, the approach to analysis and findings could be treated as novelty. However, they should not be adopted as absolutely conclusive. The presented analysis is rather an introduction to a broad research on social assistance and activation policies and their roles in creating better social inclusion outcomes. Further elaboration on the topic follows in subsequent chapters.

We started out the discussion with the argument that social exclusion is a complex social phenomenon. Complex causal statements in terms of necessary and

16 The absence of activation and socio-professional integration, however, would not necessarily lead to higher poverty rates. The fuzzy set analysis does not recognize this type of asymmetry. 
sufficient conditions were framed using set-theoretic relations. The analysis explored a combination of relevant conditions leading to the defined social exclusion outcome - the low at-risk-of-poverty rate among social assistance beneficiaries. The factors included in the analysis were: country's wealth, the levels of development of social safety net, spending on social protection as share of GDP and spending on social assistance from the social protection budget, as well as the countries commitment to activation policy. Particular attention was paid to the role of activation and socio-professional integration within given combinations of conditions.

The findings show that it is a combination of different factors that lead to low atrisk-of-poverty rate among social assistance recipients, which is in line with our expectations set at the beginning of our analysis. In this context, activation has a role to play but not in isolation. On the contrary, it appears to be a necessary part of a sufficient condition combining all other factors employed in the analysis. The same applies to each of the conditions included in the analysis. These results have several implications. In line with Atkinson's (1998) argument, social exclusion is the product of different events in society. Government designed welfare policies and institutions play a role in fighting social exclusion. However, these policies do not impact on social exclusion separately but rather as part of the overall social policy environments, which is also suggested by Hill and Bramley (1986). The arguments speak in favor of constructing one integrated approach for treating complex phenomena such as social exclusion.

Despite its superiority in treating causal complexity, the fsQCA offered in this chapter did not deal with any time dimension. It rather provided a snapshot for the year 2004. At the same time, poverty and social exclusion are of very dynamic nature. To gain insights in the processes leading towards certain outcomes and their developments, one would need to involve in deeper country case analyses. QCA is generally very useful in combination with case studies. Chapter 3 of this dissertation offers a comparative analysis of Estonia and Slovenia cases with the focus on their social assistance policies and poverty outcomes over time. Our analysis shows Estonia as a deviant case in the analysis of activation as a necessary condition for low poverty. Slovenia performs as a typical case in the same analysis. To some extent, this finding qualifies them for a comparative case study. However, the choice of these countries for further analysis was primarily guided by their success stories and shared past.

Another shortcoming of the presented fuzzy-set analysis is related to its inability to address multidimensional nature of social exclusion. This issue is taken forward in Chapter 4 which offers a definition of social exclusion in line with the approaches of multiple deprivation and multidimensional poverty. The quantitative analysis 
presented in Chapter 4 takes into account the domains and indicators of deprivation and offers a multidimensional measure of poverty for a single country. Throughout this process, social assistance recipients are treated as a separate group under investigation. 


\section{CHAPTER}

\section{A Closer Look At Structural and Social Assistance Specific Conditions: The Cases of Estonia and Slovenia}

\subsection{Introduction}

As noted in the fuzzy-set analysis in Chapter 2, Estonia and Slovenia seemed especially good in a closely defined sense - they scored relatively well on the poverty outcome for social assistance recipients. ${ }^{17}$ At the same time, Estonia appeared as a deviant and Slovenia as a typical case when the activation condition was plotted against the relative poverty outcome in the analysis of necessary conditions. Additionally, Slovenia showed a rather distinctive path combining social protection features that led to low relative poverty while Estonia relied on other, non-social protection factors, to produce good poverty results for social assistance recipients. ${ }^{18}$

The existing comparative literature tends to describe Estonia and Slovenia as good transition reformers with diametrically opposed approaches and outcomes (Buchen, 2005; Feldmann, 2006). This raises an interesting question: What made it possible for Estonia and Slovenia to score similarly on poverty outcomes if the circumstances that framed their anti-poverty programs appeared to be rather different? Providing answer to this question is of significant importance for countries undergoing similar economic transformations and aspiring to achieve the same low poverty goals.

While belonging to the same Central and Eastern European (CEE) region that went through the major transformation of political and socio-economic systems in the nineties, Estonia and Slovenia are often associated with opposing approaches to reforms. Estonia is commonly recognized as a radical and fast reformer while Slovenia is characterized with a rather gradual and slow approach. These are the two basic forms discussed under the Optimal Speed of Transition (OST) framework involving on one side a gradual phasing out of the old state sector and the so called "shock" or "big bang" therapy on the other (Aghion \& Blanchard,

\footnotetext{
17 The countries are of similar population size. In 2004, the population of Estonia was 1.35 million and the population of Slovenia was 2 million.

${ }^{18}$ The later discussion in this chapter will show that it was actually strong economic growth that had a positive impact on poverty outcomes. It however needs to be stressed at the outset that the impact on poverty outcomes for social assistance recipients was possible only in circumstances in which they engaged in grey economy next to receiving social assistance benefits.
} 
1994; Boeri, 1999; Castanheira \& Roland, 2000; Jurajda \& Terrell, 2000; Jurajda \& Terrell, 2008). Descriptively, Estonia and Slovenia are very different in the domains of economic restructuring, adjustment, and economic growth. Indicators pertaining to these developments will be treated in this chapter as structural conditions framing the development of the countries' social assistance policies and impacting on their poverty outcomes.

It has already been noted that social assistance policies are important instruments in the fight against poverty and social exclusion. However, the real effect of these policies has rarely been discussed in comparative research. In the case of Estonia and Slovenia, there has been little comparative analysis linking social assistance to poverty outcomes. We aim at answering the question of how social assistance programs help alleviate poverty and work inactivity. The discussion follows different policy developments and resulting outcomes across the countries and over time. The study relies on substantive literature review, secondary data, and the EU-SILC and SaMip data analysis. ${ }^{19}$ The analysis covers the period from 1991 until 2004, describing the developments from the beginning of transition until the EU accession.

The findings of our analysis suggest that Estonia and Slovenia differed substantially, both in terms of the conditions framing their policies and related poverty outcomes. In terms of poverty alleviation efforts, Slovenian social assistance program fared much better in lifting welfare recipients out of poverty. At first sight, Estonia's achievements were rather limited. Worth noting, however, is that the country made a huge leap from its initial position at the start of transition. In the context of strong post-2000 economic growth and increased job availability, Estonia managed to provide opportunities for social assistance recipients to integrate in the labor market and move out of poverty.

This chapter is organized as follows. The first part includes the description of the countries' structural changes and diverging paths within the OST framework. Next is a discussion of the resulting inequality and poverty outcomes in Estonia and Slovenia. The subsequent section offers a description of the social assistance program features. That section also explores the trends in programs' coverage, spending, generosity, adequacy, and employment requirements. It links the overall discussion back to the question of the role of social assistance in mitigating poverty and inactivity. The final section concludes.

\footnotetext{
${ }^{19}$ SaMip dataset is established by the Swedish Institute for Social Research (SOFI) at the Stockholm University and contains comparable data on social assistance.
} 


\subsection{Structural conditions framing different reform paths}

At the macroeconomic level, the dramatic fall of output at the beginning of the 1990s was regarded as the main characteristic of the transformation process in the entire region (Bar, 1994; Gomulka, 1998). In Estonia and Slovenia the magnitude and duration of the recession was different. These countries experienced two diverging paths and included modest declines and quick recovery in Slovenia and much deeper and longer recession in Estonia.

Slovenia was among the countries that had the smallest declines in the early transition years. In the first two years of transition, the fall in output was below 10 percent a year in Slovenia, while in Estonia the fall in output in a single year (1992) turned out to be above 20 percent. The shaded areas in Figure 3.1 show that despite a major downturn in the early nineties, Slovenia's economy recovered very early already in 1993; In Estonia, the recovery occurred only in the mid-1990s but the country experienced growth slowdown between 1997 and 1999. ${ }^{20}$ On balance, while in Slovenia the output growth remained rather stable throughout the post1993 period, Estonia experienced an accelerated growth in the post-2000 period.

Figure 3.1: Estonia and Slovenia: Growth rates (\%) and GNI per capita (US\$ PPP), 1991-2004

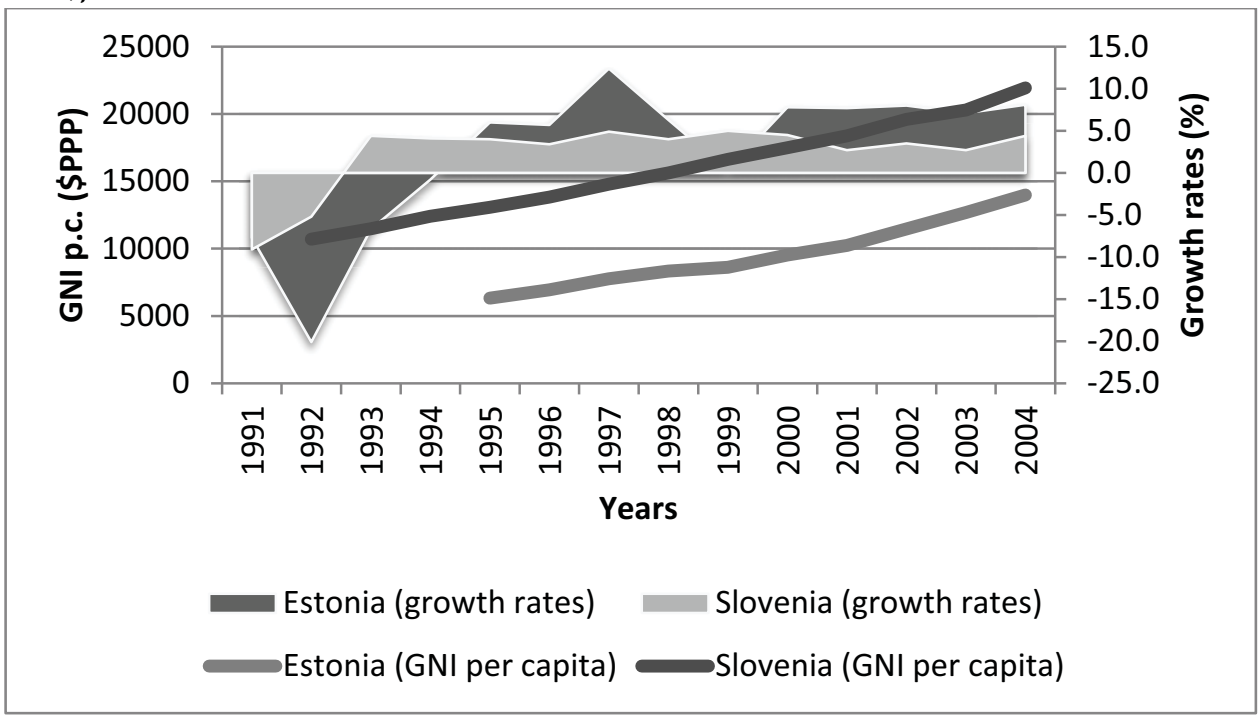

Source: Data from the World Bank's World Development Indicators Database.

20 This overlaps with the1998 Russian financial crisis which impacted on the heavily dependent Estonian economy. 
Compared to other transition economies both countries had growth rates above the regional average in the later period. A significant difference between the two countries that remained present throughout the years was the level of gross national income (GNI). As Figure 3.1 suggests, the level of Slovenia's GNI (expressed in PPPs) was consistently higher but the difference between the two countries has shrunk over time (World Bank, 2005). While the average annual growth rate of GNI per capita was 6 percent in Slovenia in the period 1995-2004, it was more than 9 percent in Estonia.

The transition process had far-reaching consequences for the standard of living of the population in both countries. The reforms included early adjustments of the labor market and changes in social spending by the governments. As a result of the economic collapse and the inherited inefficiencies associated with central planning, the labor market had to accommodate the fall in the demand for labor. The reaction of the labor market to the declining demand was evident in decreasing employment rates, raising unemployment and decreasing real wages.

Most old communist states had traditionally denied recognizing formal unemployment as a problem, but it was inevitable in the transition period. In Slovenia, poverty and unemployment were actually recognized in the socialist times, though at lower levels than in the rest of former Yugoslavia, and therefore the country developed social assistance and unemployment insurance programs early in the process.

Unemployment figures had different paths in the economies of Estonia and Slovenia. Slovenian unemployment rate peaked in the early years of transition and then stabilized at around 7.4 percent while the unemployment rate in Estonia reached 10 percent in 1996 (Vodopivec et al, 2003). With these levels of unemployment Estonia and Slovenia fared relatively well in the group of CEE countries. The countries' falling employment rates and growing unemployment were accompanied by a decline in real wages, which taken together made a significant impact on households' well-being. Additionally, certain mechanisms of labor market adjustment such as wage arrears, forced leaves, reduction in hours of work were implemented during the decline phase (Jackman,1998; Jurajda \& Terrell, 2008).

Similar to the output dynamics, the adjustment of the labor markets in Estonia and Slovenia followed rather different paths. The optimal speed of transition (OST) theory, applied in much of the research on economic transition of that time (Boeri, 1999; Castanheira \& Roland, 2000; Jurajda \& Terrell, 2000; Jurajda \& Terrell, 2008), explains the reallocation of labor from the old state-owned sector to the new private one through the speed of job destruction in the old system. The reallocation took the forms of a gradual phasing out of the old and inefficient sector in Slovenia 
and the, so called, "shock" therapy in Estonia. According to the OST theory, government policies influence job destruction in the old state sector through "push" and "pull" policies that are applied in the privatization and restructuring processes.

On the "push" side, there was a significant difference in the implementation of the privatization agenda in Estonia and Slovenia. The "push" side policies, or structural reforms, could be treated as the context factors influencing the choice and implementation of the "pull" side polices. By taking an example of social assistance provision, we later show the "pull" side of social protection responses to the restructuring processes.

The characteristics of the Slovenian early transition were the emergence of a significant share of state-owned enterprises and government control which slowed down the destruction in the "old" sector. At the end of privatization of old "socially-owned" enterprises that emerged from the specific Yugoslav "selfmanagement" regime, the private sector was yielding only 50 percent of the Slovenian GDP and employed about 50 percent of the labor force, which was among the lowest shares in the leading CEE economies (World Bank, 1999). ${ }^{21}$ It was actually the state that emerged as the major owner.

It was a rather surprising development that in a country where the state ownership had been non-existent, the state became a primary owner of the old "sociallyowned" firms. The official completion of privatization of the "socially-owned" enterprises was announced in 1997. However, enterprise subsidies and government control continued to exist. While the Slovenian government controlled enterprises heavily, that was not the case in Estonia. Estonian privatization included the elimination of exit barriers and subsidies for state enterprises as early as in 1993 (Cornelius, 1995). By 1995, almost all small-size firms and large-scale Estonian industrial enterprises were privatized. The remaining privatization agenda included only big infrastructure enterprises such as transportation, public utility, energy, and oil companies, as well as some state banks in Slovenia.

A change in the wage-setting mechanism, as another inevitable characteristic of transition, had a potentially strong impact on households' well-being. In the pretransition socialist regimes wages were usually fixed at a certain level by the state. In the process of transition, new wage-setting mechanisms reflected individual productivity and effort, which caused a raising inequality of the wage distribution

21 In the old Socialist Federal Republic of Yugoslavia from which Slovenia gained independence in 1991, property was not considered as belonging to the state but it was allegedly owned by all the citizens ("socially-owned"), namely, the broader social community. 
and impacted on income inequality among the households. Privatization of stateowned enterprises was the factor contributing to raising inequality, though the evidence in different countries is somewhat mixed (World Bank, 2005).

\subsection{Inequality and poverty outcomes in Estonia and Slovenia}

Direct consequences of the decrease in output were evidenced in higher unemployment, lower incomes, higher inequality, and greater poverty. Poverty, which together with unemployment was for the major part unrecognized unrecognized by the old socialist rule, became one of the most important challenges that the newly established economies faced. When analyzed strictly within the OST framework, the so called "shock therapy" assumes greater inequality and higher poverty rates in the early transition period. This is to be associated with the experience of Estonia. Given its gradual development path and distinctive privatization policy, Slovenia was expected to have experienced smaller inequality and poverty. The following section explores these arguments.

Income inequality that increased across transition economies was driven by raising inequality of labor earnings. In Estonia, inequality rose sharply. Gini coefficient - a standard measure of inequality - was 0.37 in 1998 (World Bank, 2005). At the same time, Slovenia had a Gini coefficient of only 0.25 , less than the EU average of 0.3. Nevertheless, these measures may underestimate the levels of inequality because of the high level of informality in the economies of the nineties and the difficulty of measuring income. In many countries social transfers and taxes played a significant role in cushioning the effect of rising wage inequality. Milanovic (1998) found that the countries where wages and government transfers increased as a share of GDP during the early years of transition, experienced a smaller increase in inequality. 22

Like in many CEE countries, over the course of the nineties, poverty landscape of Estonia and Slovenia entailed a shift from transient poverty that resulted from the output collapse to chronic long-term poverty and the emergence of vulnerable groups. According to the World Bank (2000) estimates based on the $\$ 2.15$ measure $^{23}$ there was virtually no absolute deprivation in Slovenia towards the end of the nineties, while in Estonia it was only 2.1 percent. When the line was drawn

\footnotetext{
${ }^{22}$ For these countries the Gini coefficient was 0.2. Conversely, in countries where social transfers did not offset the declining wages or where only wages or social transfers increased, the Gini increased on average by 0.1 to 0.12 points (Milanovic, 1998).

${ }^{23}$ Poverty line of $\$ 2.15$ per person per day in 1996 PPP terms; Based on Household Income and Expenditures Surveys in both Estonia and Slovenia.
} 
at the level of $\$ 4.30$ a day, the population of Estonia turned out to be much poorer with the rate of almost 20 percent (World Bank, 2005). Slovenia contained poverty close to zero.

Poverty increased in both countries in the first years of transition, but the increase was very uneven, with Slovenia managing to contain its low poverty and Estonia experiencing increasing poverty. Towards the end of the 1990s, both Estonia and Slovenia made progress with regard to the EU accession ${ }^{24}$ and the poverty analysis started focusing on relative measures of poverty and comparisons based on these measures. In 2004, Slovenia had a relative poverty rate that was well below the EU average of 15 percent. ${ }^{25}$ In comparison to Slovenia's 12 percent, the relative poverty rate in Estonia was significantly higher and at the level of 22 percent.

The divergence in absolute poverty rates between the two countries was even greater. For the analysis of absolute poverty, the threshold was set at the value of 10 euro per person per day in order to compare the absolute poverty rates across the countries. ${ }^{26}$ This threshold had been established earlier in the research of the European Center for Social Welfare Policy and Research (Lelkes \& Zólyomi, 2008). At 10 euro a day, poverty rate was below 2 percent in Slovenia and almost 40 percent in Estonia (Table 3.1). Absolute poverty turned out to be very high in other Central and Eastern European countries excluding Slovenia.

Table 3.1: At-risk-of-poverty rate at $60 \%$ of the median income and absolute poverty rate at 10 euro/day, by country, 2004

\begin{tabular}{lcccc}
\hline & $\begin{array}{c}\text { At-risk- } \\
\text { of- } \\
\text { At-risk-of-poverty rate } \\
\text { among soc.assistance } \\
\text { recipients (\%) }\end{array}$ & $\begin{array}{c}\text { poverty } \\
\text { threshold } \\
\text { (Euro) }\end{array}$ & Absolute poverty rate(\%) & $\begin{array}{c}\text { Gini } \\
\text { Coefficient }\end{array}$ \\
\hline Estonia & 22 & & & 37 \\
Slovenia & 12 & 1,611 & 1.4 & 0.36 \\
\hline
\end{tabular}

Source: Own calculation based on the EU-SILC 2005; ${ }^{27}$ World Bank's World Development Database for Gini coefficients.

\footnotetext{
${ }^{24}$ The countries started the negotiations with the EU in 1998 and joined the EU in 2004.

${ }^{25}$ Refers to the at-risk-of-poverty rate after social transfers. Slovenia's poverty rate has traditionally been low. Based on the available and comparable survey data, relative poverty rate in Slovenia was in the range of 13-15 percent in the first half of the nineties (SORS, 1996). This rate ranked Slovenia among the European countries with a relatively low poverty rate (Vidmar, 2000).

${ }^{26}$ All the nominal amounts were adjusted with the purchasing power standards.

${ }^{27}$ The year of the survey is 2005, which refers to 2004 incomes.
} 
Clearly, Estonia experienced higher inequality and poverty in the transition years. Slovenia reported low and rather stable poverty outcomes while its inequality was on the rise - from the Gini coefficient of 0.25 in the nineties to 0.31 in 2004. It goes without saying that some groups within the society have been affected more and those poorest in both countries were covered by their respective social assistance programs.

The fuzzy-set analysis has shown that the at-risk-of-poverty rates among the recipients of social assistance transfers in Estonia and Slovenia were among the lowest in the EU. ${ }^{28}$ Interestingly, Estonia recorded the lowest relative poverty rate of 14 percent in 2004, while the measure in Slovenia was 22 percent. Like in no other area that has been discussed so far, the difference between the two countries seemed rather minimal. At the same time, the relating at-risk-of-poverty rates were much higher in other countries, implying that the income of the socially excluded might have been significantly below the standard relative poverty threshold. These data, however, need to be interpreted with certain caution. Later in this discussion we will show that the social assistance programs in our two countries had a rather small coverage and poor targeting, particularly in Estonia. In addition, the EUSILC included a relatively small number of social assistance recipients' households. The calculations were done solely on income data and did not allow for any generalizations about the programs' characteristics nor their effects. In order to gain more insights in the main program's features and outcomes, these topics will be further investigated in the subsequent sections.

\subsection{Resulting social assistance designs}

The new economic circumstances called for government intervention and larger social spending. Social assistance support was almost non-existent or in its rudimentary forms in the old regimes. The old social safety net was of smaller scale and involved mainly basic subsidies and the provision of food. Hence, a system of social assistance benefits was absent or not well suited to the market economy.

Here we depict Estonia and Slovenia's social assistance programs' responses to the earlier discussed "push" factors. In Table 3.2, different policy outputs are

\footnotetext{
${ }^{28}$ At-risk-of-poverty for this group has been estimated from the EU-SILC 2005 data using the definition of social assistance as "social exclusion not elsewhere classified". At the EU level, social exclusion benefits (not elsewhere classified) assume cash transfers aimed at mitigating financial burden of a number of risk or needs of those referred to as "socially excluded" or to "those at risk of social exclusion" (European Commission, 2007).
} 
introduced under the "pull" side of the framework. They concern different trends in social assistance coverage, spending, benefit levels, and adequacy.

Table 3.2: Social assistance as a "pull" side response to the "push" side developments

\begin{tabular}{|c|c|c|}
\hline & PUSH & PULL \\
\hline ESTONIA & 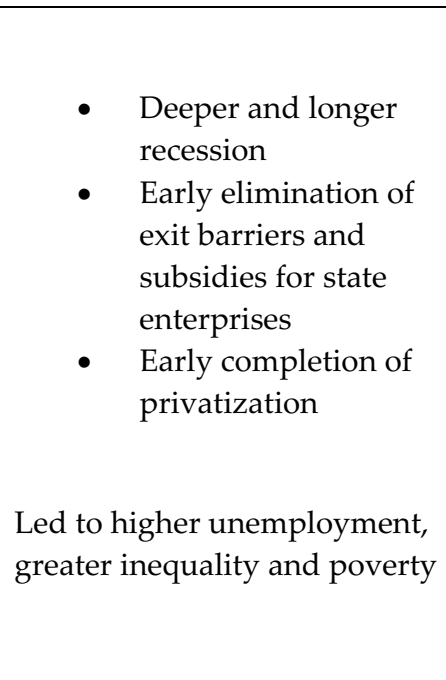 & 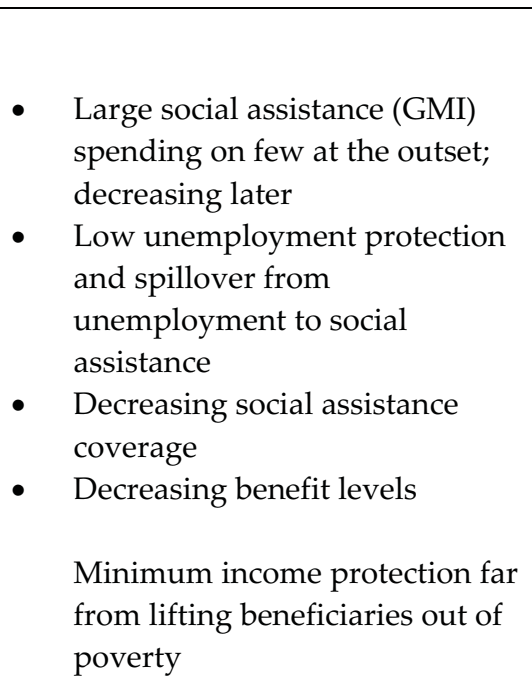 \\
\hline $\begin{array}{l}\text { gradual } \\
\text { reformer }\end{array}$ & $\begin{array}{l}\text { - } \quad \begin{array}{l}\text { Modest decline and } \\
\text { quick recovery } \\
\text { - Slow destruction of } \\
\text { old sector }\end{array} \\
\text { - } \quad \begin{array}{l}\text { High number of state } \\
\text { owned enterprises } \\
\text { and enterprise } \\
\text { subsidies } \\
\text { - Significant } \\
\text { preservation of jobs } \\
\text { in the state sector }\end{array} \\
\text { Led to smaller } \\
\text { unemployment; increased } \\
\text { inequality and contained } \\
\text { poverty }\end{array}$ & $\begin{array}{l}\text { - Small and steady increase in } \\
\text { social assistance (GMI) spending } \\
\text { High unemployment protection } \\
\text { compensation but spillover of } \\
\text { unemployed to social assistance, } \\
\text { particularly after } 1998 \\
\text { - } \quad \text { Increasing social assistance } \\
\text { coverage } \\
\text { Benefit levels decreasing in real } \\
\text { terms and increasing } \\
\text { significantly in the post-2000 } \\
\text { period } \\
\text { Early activation effort (since } \\
\text { 1998) } \\
\text { Minimum income protection } \\
\text { lifting or close to lifting } \\
\text { beneficiaries out of poverty }\end{array}$ \\
\hline
\end{tabular}


With regard to the "pull" side policies, Slovenia and Estonia differed substantially. Slovenia was (alongside with other former Yugoslav countries) an exception in the region since both unemployment insurance and social assistance benefits existed under the old socialist system. Estonia was still to develop them in the early transition years. Compared to Estonia, Slovenia had a more generous unemployment benefit scheme. In Slovenia, the unemployed were entitled to 24 months of unemployment benefits throughout the nineties; the unemployment benefits were tightened subsequently but the replacement rates stayed at the level of 60-70 percent of previous wage (Vodopivec et al., 2003). According to the same source, in Estonia the entitlement period was 6 months and the replacement rate was only 60 percent of the minimum wage. In 2001, the Estonian unemployment benefit duration was extended to 12 months. The benefit levels changed to 50 percent of the previous wage for the first 100 days and 40 percent afterwards (Vodopivec et al., 2003). At the end of the family member's entitlement to unemployment benefit, the poor Slovenian families were able to claim and receive social assistance benefits early on, whereas in Estonia a suitable social assistance scheme was developed rather late. These developments in the provision of unemployment benefits were brought out here just to reflect on the related pull side polices. The development of social assistance schemes is discussed further and in greater detail.

\subsubsection{Definition, coverage, and spending}

In this study, social assistance refers to a means-tested program ensuring guaranteed minimum income (GMI), which is being activated when all other efforts fail. Therefore, it is a final safety net aimed at avoiding severe poverty.

In Slovenia, the means-tested social assistance to the needy families was introduced already in 1979 and it was financed from the central budget. The 1992 changes to the law retained the main principles. Social assistance ("denarni dodatek" and later "denarna socialna pomoc") was offered to individuals and households without sufficient means, i.e. those with income below the guaranteed minimum income. ${ }^{29}$ In contrast to Slovenia, the social protection system in Estonia started to change in the beginning of the nineties. A new system of means-tested income support (subsistence benefit or "toimetulekutoetus") was introduced in September 1993. ${ }^{30}$ The benefits were centrally financed but local governments were

\footnotetext{
${ }^{29}$ There was also social assistance for those who were unable to work and the population older than 60 .

${ }^{30}$ It also included a housing assistance component.
} 
encouraged to grant supplementary social assistance benefits from their local budgets.

Eligibility requirements included means and asset tests in both Estonia and Slovenia. In both countries, the level of benefit equaled the difference between the prescribed income threshold - the subsistence threshold or the basic minimum income respectively - and the actual income of the individual or household. ${ }^{31}$

The maximum duration of the benefit was six months in Slovenia with the possibility of extension or renewal. In Estonia, social assistance was seen as a shortterm intervention aimed at relieving the temporary problems of individuals and was granted on a monthly basis. However, one fourth of all the recipients actually comprised those who are the long-term recipients (Trumm, 2002).

Within rather stable developments in Slovenia, the number of recipients of ablebodied social assistance recipients was consistently increasing in the nineties (Table 3.3). The average number of monthly recipients doubled in a ten year period - from around 25,000 household recipients in 1995 to over 50,000 in 2004. This was primarily due to the increasing number of the unemployed who became eligible to social assistance. After the termination of their unemployment benefits, namely, unemployment compensation and unemployment assistance, the long-term unemployed were entitled to social assistance.

Coverage and benefit levels continued to increase with the amendments to the Slovenian Social Assistance and Services Act introduced in September 2001.32

\footnotetext{
${ }^{31}$ For instance, since 1999 the Estonian subsistence threshold was EEK 500 (euro 32) for a single person per month and EEK 400 (euro 26) or 80 percent of the subsistence threshold, for each additional member. In Slovenia, the basic minimum income was SIT 45,524 (euro 191) for the first adult and SIT 31,867 (euro 134), or 70 percent of the basic minimum income, for other adults in the household. At the same time, it was SIT 13,657 (euro 57), or 30 percent of the basic minimum income, for the child (MISSOC, 2004).

${ }^{32}$ Income threshold for the entitlement increased the most - by 64 percent (Republic of Slovenia, 2003). Expressed as a share of the wage - the new amount represented 61 percent of the minimum wage and 29 percent of the average wage in the economy. The minimum income for an individual and the first person in the family increased by 30 percent. The number of financial assistance recipients increased by 31 percent in the period August 2001 - December 2002. The average level of social assistance increased by 43 percent. In December 2002, 3.6 percent of the population received social assistance. Nevertheless, the increase in the number of recipients was smaller than expected due to the newly enacted provisions of the Social Assistance and Services Act banning the right to assistance to those who had savings or property in the amount of 24 monthly minimum wages. Also, a significant number of persons had started receiving the state pension approximately at the same time (Republic of Slovenia, 2002).
} 
Contrary to the Slovenian experience, the number of social assistance recipient households in Estonia started to decrease towards the end of the nineties. While the average monthly number of recipients was 51,100 in1997 and 45,000 in 1999, it dropped to 17,900 in 2004 (Table 3.3). The primary recipients of the Estonian subsistence benefits were families with long-term unemployed or unemployed persons looking for a job, as well as the families with children. All individuals, including the long-term unemployed and non-working jobs seekers, whose income after covering the housing costs was below the subsistence level had the right to subsistence benefit since July 1997. This has influenced the structure of benefit recipients in favor of long-term unemployed persons and non-working jobs seekers who comprised 60 percent of all subsistence benefit recipients in 2000 and above 70 percent in 2004 (Ministry of Social Affairs of Estonia, 2006). 


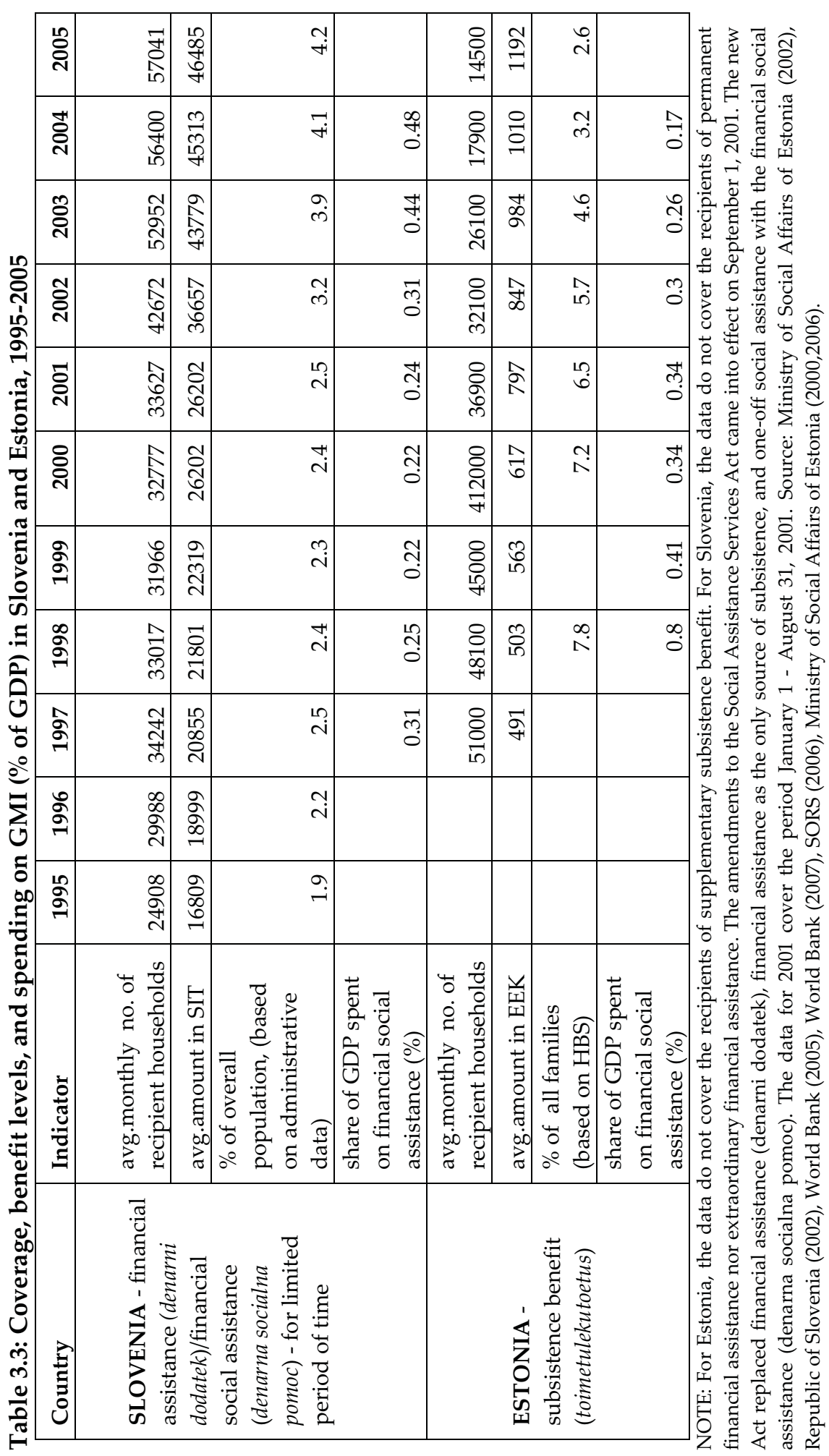


Together with the increasing number of Slovenian social assistance beneficiaries, the total expenditure on social assistance also increased in the nineties. In 1993, the share of social assistance expenditure was 0.17 percent of GDP. It increased to 0.31 percent in 1997 and stabilized around the level of 0.25 percent in 1998-1999 (Figure 3.2).

Figure 3.2: Share of GDP spending on social assistance programs (GMI), percent

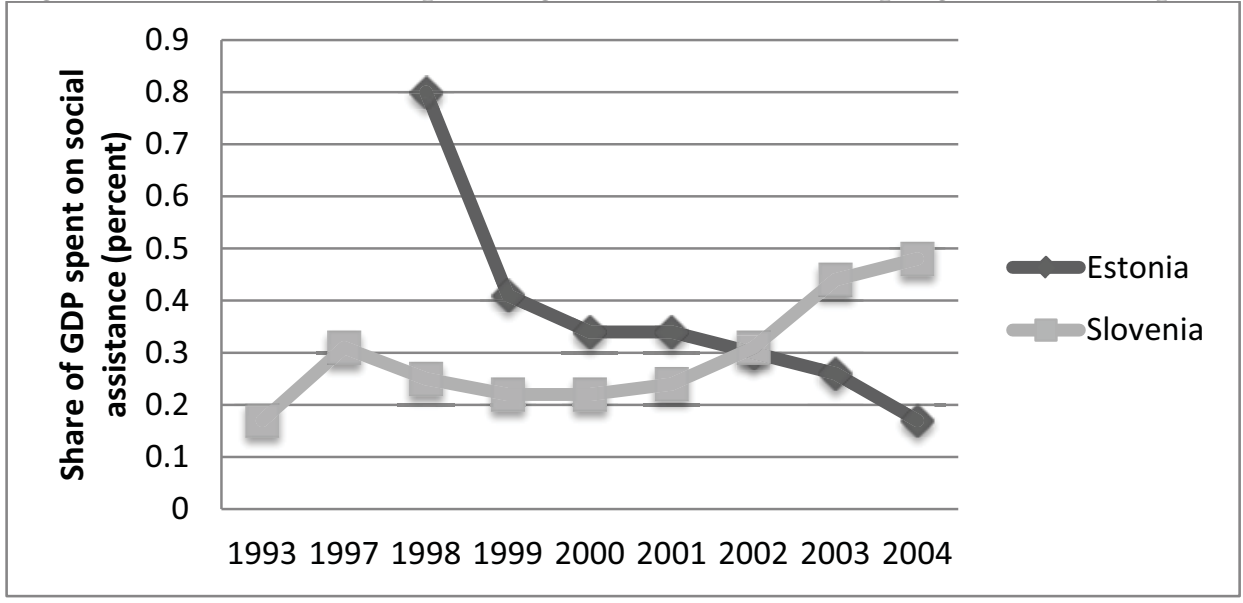

Source: Data collected from different sources (Ministry of Social Affairs of Estonia, 2002; Republic of Slovenia, 2002; World Bank, 2005; World Bank, 2007).

The trends were somewhat different in Estonia. Throughout the nineties, the level of GDP expenditure on social assistance was higher in Estonia than in Slovenia. In 1995, the number of families applying for income support grew by nearly one-third in Estonia. The budget for means-tested social assistance remained high between 1996 and 1998. However, due to the cuts in supplementary social benefits in 1999 the budget was reduced by one fifth causing a significant decrease in social assistance spending that continued in subsequent years (Trumm, 2002). ${ }^{33}$ The spending started to decline also due to the higher living standard in the population which assumed a smaller number of people living below the low established

\footnotetext{
${ }^{33}$ Interestingly, the overall social protection expenditure has been growing in Estonia at an increasing pace in the post- 2000 period. For example, the expenditure marked a yearly increase of approximately 15 percent in 2004 (Ministry of Social Affairs of Estonia, 2006). However, the increase was due to the growth of health, disability and old age benefits. Child benefits for the first child also increased significantly and the implementation of the new parental benefit started. Only the spending on subsistence benefit including housing costs actually decreased. Overall, the state provision of guaranteed minimum income remained limited.
} 
benefit threshold of 500 EEK (Ministry of Social Affairs of Estonia, 2006). The number of recipients also decreased because of the political decision to replace the cash benefit with social assistance related services (Trumm, 2006).

We can conclude that with its big-bang approach to reforms, Estonia experienced faster changes in social assistance provision and higher social spending early in the process when the number of beneficiaries was also higher. As presented the figure above, Slovenia experienced a significant and steady increase in the number of beneficiaries and social assistance spending reflecting its gradual transition to the market economy.

\subsubsection{Generosity and adequacy}

One of the first studies of the Estonia's social assistance scheme (Milanovic, 1999) described Estonia as a "concentrated" social assistance regime in which a relatively large amount of social assistance benefits were disbursed to a few households. Based on the HEIDE (Household Expenditure and Income Data for Transition Economies) data from 1995, Milanovic found that only a small proportion of the Estonian population received social assistance (excluding housing costs) due to the relatively low level of administratively established poverty threshold. In Slovenia, social assistance benefits were at much higher levels reflecting both the wealth of the society and the government's dedication to such a program, but it was still of a small coverage (Stropnik \& Stanovnik, 2002). In both countries, the level of meanstested social assistance varied depending on the household composition.

While social assistance was a relatively important source of income for the poorest segments of the population, the expert opinion in both countries was that the programs suffered from a number of imperfections limiting the direct and indirect impact on poverty alleviation. The agreements on the levels of social assistance benefits were made based on political decisions and they did not have much in common with the assessment of a food or commodity basket necessary for meeting the basic needs. The minimum income covered only costs of low nutrition, without meeting the other basic needs. Social assistance benefits could not really lift many beneficiaries out of poverty, though the experiences in the two countries were rather different.

We proceed with the analysis of social assistance benefit generosity and adequacy based on the SaMip data providing information about social assistance benefits for European countries. The data cover the period from 1995 until 2005. SaMip contains information on hypothetical family types and their benefit levels. Social 
assistance benefits are calculated for a single person, a one-parent family, and a two-parent family types.

The first insight in social assistance benefits that are standardized for wage and price developments, with the year 1995 as the baseline for comparisons, reveals that both Estonia and Slovenia experienced dramatic changes in real benefit levels over the observed period. As shown in Figure 3.3, social assistance significantly eroded relative to wages. The reduction was at the level of more than 50 percent over the ten year period. This indicates that the income of social assistance recipients was continuously lagging behind the general income growth in these societies. On the other side, social assistance benefits managed somewhat to keep up with prices. This was particularly expressed in Estonia owing to its mechanism of regular government adjustment of the subsistence level.

Figure 3.3: Social assistance (yearly amount for a single person) indexed for wages and prices in Estonia and Slovenia, 1995-2005 (index 1995=100)

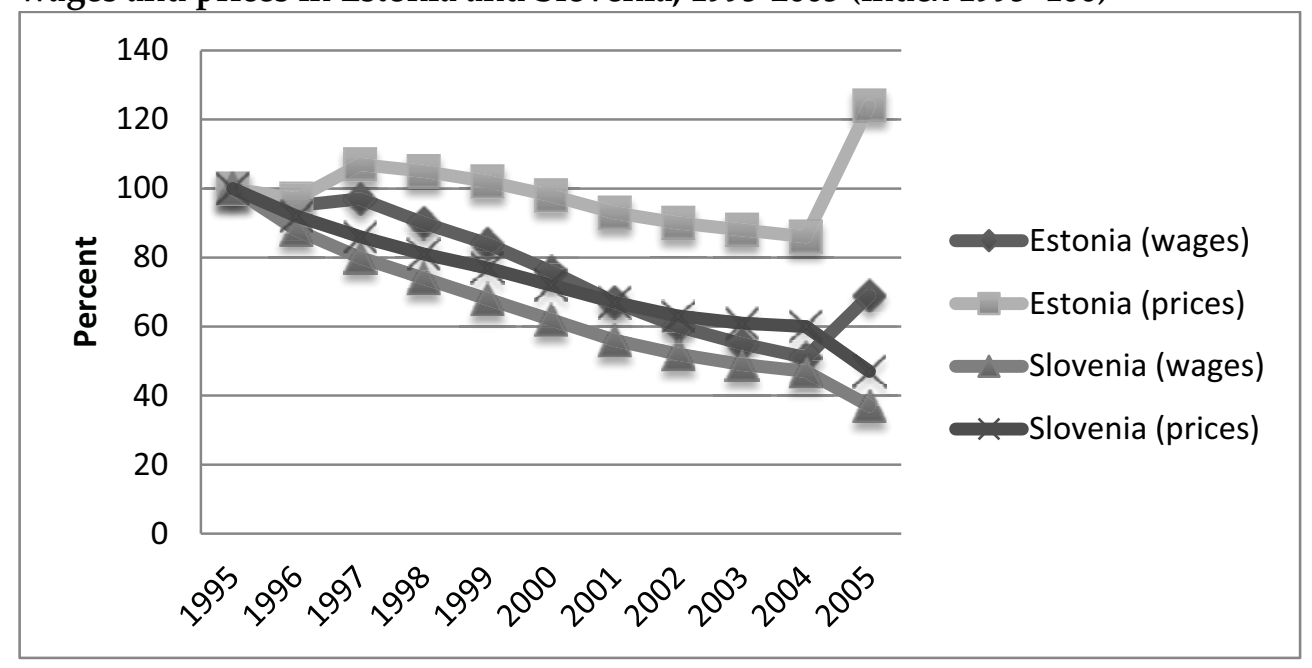

Source: SaMip data (2008).

Most governments use some form of price indexation and that was certainly the case in both Estonia and Slovenia. In Estonia, there was no automatic indexation. Benefits were adjusted on a regular basis by the government decision. In Slovenia, adjustments were done once a year (January), by taking into account the consumer price index for the previous calendar year. Wages continued to grow faster than prices and the later Slovenian strategy of indexing benefits to the cost of living 
proved to be successful. The most notable exception for Estonia was observed at the end of the ten year period. In 2004-2005, the benefits grew much sharper than the wages and prices. A similar development, though to a much smaller extent, was observed in 1996-1997. In Slovenia, the developments were rather opposite and contributed to the erosion of social assistance benefits.

Throughout reform process the countries have changed indexation rules. Firstly, since the 2001 changes to the Social Assistance and Services Act, the level of social security in Slovenia was set at a more adequate level. The new basic minimum income level, as the income level deemed to cover minimum needs, was derived from a food basket meeting the needs of the 40 percent of Slovenian households at the lower end of income distribution. Nevertheless, while both governments changed formal indexation procedures in order to strengthen the recipients' purchasing power, they failed to keep up with the general wage growth. This is usually detrimental to poverty alleviation efforts. In the circumstances as depicted above, poverty reduction objective of social assistance became less effective over time. It would be therefore interesting to examine to what extent social assistance was offered at levels that enabled recipients move out of poverty.

In order to calculate social assistance adequacy rates, the data from SaMip were combined with income distribution data from the Luxembourg Income Study (LIS). ${ }^{34}$ The ratio of social assistance to the median income is used to reflect the adequacy of social assistance. Equivalized income is used to standardize income across households of different size and needs and as such is included in the SaMip dataset (Nelson, 2009). ${ }^{35}$ The ratio was compared to different poverty thresholds, such as 50 or 60 percent of the median income. As described earlier, households with below 60 percent of the country median income are considered to live in poverty. Benefits were calculated for a single person, one-parent and two-parent families. ${ }^{36}$

The minimum income protection indicator, which includes social assistance standard rates and other benefits such as housing supplements and similar, was used to explore whether the countries provide minimum income that is close to the established poverty threshold. As shown in Figure 3.4 below, the minimum income rate appears to be above the threshold of 60 percent of the median income in the

\footnotetext{
${ }^{34}$ LIS contains harmonized national micro-level income data, from which equivalized median income is computed.

35 The applied equivalence scale is the square root of household size.

${ }^{36}$ Nelson (2009) found that hardly any of the European countries provides social assistance above the EU poverty threshold. Furthermore, he argued that social assistance adequacy rate in almost all the European transition economies were significantly below "the 60 percent poverty threshold" in 2000.
} 
case of two family types in Slovenia. For lone parents ${ }^{37}$ and four-member families, the minimum income was provided at the levels higher than the poverty threshold. This suggests that the minimum income benefit was able to lift the recipients out of relative poverty. For single persons, the average minimum income rate was around the established threshold of 50 percent of the median income.

Figure 3.4: Adequacy of minimum income protection for single persons, lone parents, and families

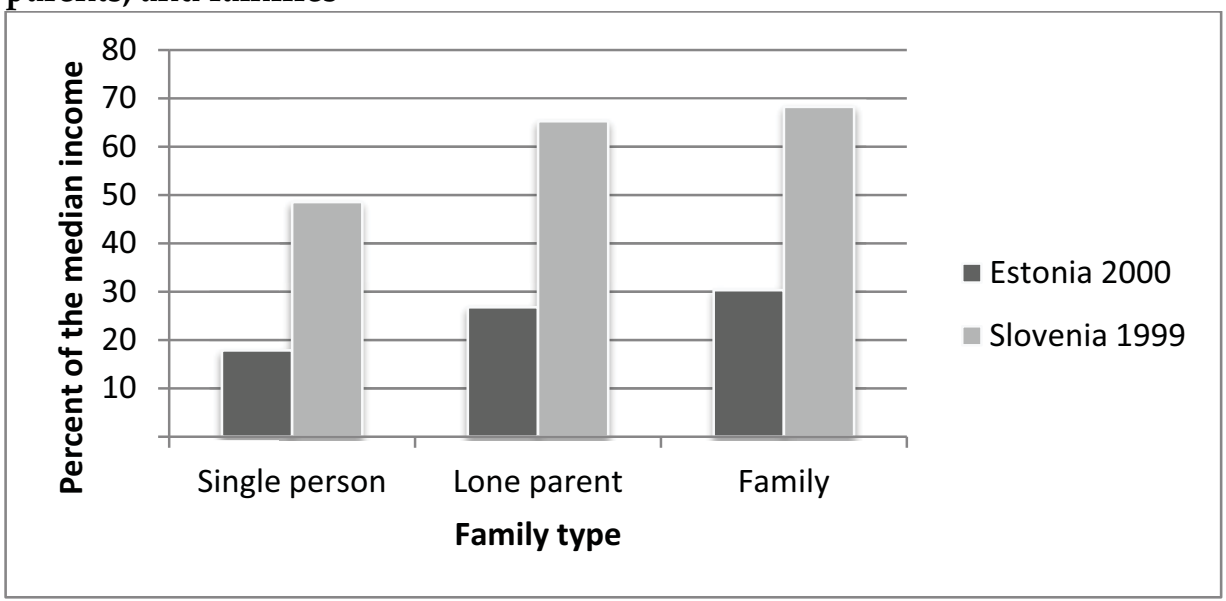

NOTE: Adequacy=(Equivalized Minimum Income Protection/Equivalized Median Income for Total Population)*100 (Square Root Scale).

Source: SaMip data (2008).

In contrast to Slovenia, the rather successful example of providing benefits above the poverty threshold, the findings for Estonia suggest that social assistance was far from providing adequate protection against poverty. In Estonia, the benefit levels were in the range of 20 to 30 percent of the median income. However, the data also suggest that for all three family types in Slovenia, the trend in adequacy rate was slightly decreasing and could be described a consequence of continuously declining benefits.

While raising serious concerns for policy makers and providing cross-country comparable data on the level of minimum income protection, the presented family type studies and similar hypothetical model-family simulations suffer from a range of imperfections in their attempt to establish a proper link between social

\footnotetext{
${ }^{37}$ Lone-parent families received a supplement of 0.3 of the minimum income. This part of analysis focuses on the year 2000 due to the limited availability of data in the dataset.
} 
assistance and poverty outcomes. The general disadvantage of the approach is that it does not account for the discrepancy between the government established social assistance eligibility thresholds and national poverty lines, nor the family/household size, coverage by different program schemes, characteristics of different institutional arrangements, and take-up rates. For these reasons such analyses do not allow for broad generalizations about the level and the kind of social protection in a country. Nonetheless, these findings are indicative. By adding certain institutional features to the analysis the study of social assistance becomes even more encompassing. The following section touches upon the part of social assistance programs that concerns work, training, education, and social activation of beneficiaries.

\subsubsection{Social Assistance and Activation}

Incentives to take on paid employment that were introduced towards the end of the 1990s had an aim to increase self-responsibility and social inclusion, and possibly compensate for the erosion of social assistance benefits. This has become a priority of the European Union as a means of securing a relative position of the groups with the lowest income.

A closer cooperation between Slovenian centers for social work ${ }^{38}$ and employment services with regard to social assistance beneficiaries and their employment needs was established in 1998. A new eligibility criteria pertaining to the beneficiary's active role in solving his or her problem was introduced. The beneficiary was now obliged to sign a contract with the center for social work and was required to undertake a more active approach to the solution of the problem, be it a job seeking activity in order to find employment or involvement in a medical treatment for drug addicts and similar. Social assistance claimants were expected to be registered with the employment services. The centers for social work were in charge of checking their status at the employment offices. Once a recipient, a person had a priority in the government run training and employment programs. In principle, the stricter eligibility rules introduced in 1998 assumed that all those who were capable to work had to prove that they were actively seeking jobs as a condition for entitlement to unemployment benefit or social assistance. With the 2001 legislative amendments, social assistance levels substantially increased and provisions were made stricter with regard to the responsibilities and obligations of the persons applying for and receiving financial assistance.

\footnotetext{
${ }^{38}$ Centers for social work are deconcentrated branch offices of the Ministry of Labor, Family and Social Affairs in charge of social assistance delivery.
} 
Estonia was somewhat lagging behind with the enforcement of work related obligations. However, since 2002 the Estonian local governments had the right to refuse to pay subsistence benefit to working age individuals who did not work or study and who had repeatedly refused suitable work offers (Trumm, 2006). The same applied to those who did not participate in social rehabilitation programs organized by the municipality. Also, the Estonian government financed a number of measures targeted at increasing labor market inclusiveness. More specifically, it focused on increasing the competitiveness of risk groups in the labor market (Ministry of Social Affairs of Estonia, 2007).

In addition to the already discussed obligations on the side of the social assistance recipients, the subsequent changes in the Slovenian policy concerned the introduction of measures such as subsidized employment of social assistance beneficiaries. On the one side, the benefit recipients were entitled to both counseling and support within the social welfare system and a preferential treatment with regard to the inclusion in active employment policy programs. On the other side, the employer was entitled to a subsidy in the amount 12 times basic minimum income equaling SIT 546,288 or Euro 2,290 in the case of employment of social assistance recipient for 24 months within a three year period (MISSOC, 2004). However, the most remarkable change, with potentially significant impact on social assistance program, was actually observed in the area of unemployment insurance. The duration of unemployment benefits in Slovenia was halved to 12 months and the general emphasis now was on active labor market measures such as subsidized employment, self-employment, public works, and training. In the area of social assistance, services that were provided included more intensive guidance, advisory work, and the orientation to work activation for the ablebodied recipients of social assistance. The number of service providers, including the non-government and private organizations, increased under the amended Social Assistance and Services Act and reached the level of approximately 2,000.

In the beginning, Estonia was somewhat behind in terms of its dedication to activation policies. Certain ideological and value-oriented factors restricted the implementation of activation policy measures. According to Trumm (2006), the ruling right-wing government was in favor of the concept of "negative freedom" meaning that an individual cannot be forced into anything because the individual is free to do nothing. By the same token, the social assistance recipient cannot be forced into workfare program or a similar activity as it could be seen as a restriction of basic human rights. This has, however, changed with the new concept of social welfare introduced in 2004. It involved a close case management of social assistance beneficiaries. Since then, activation has become one of the priority measures in the fight against poverty and social exclusion, supported at the same time by strong economic growth and increased jobs availability. 
Despite all the listed positive achievements of the Estonian and Slovenian social protection systems in ensuring financial transfers and social services to the population, a certain level of poverty and exclusion from the labor market remained to exist in the countries. Important noting is that poverty risks were associated not only with the financial status of individuals but also with the employment status of the household as a whole. Box 3.1 provides basic data on work intensity of Estonian and Slovenian households.

\title{
Box 3.1: Work intensity of Estonian and Slovenian households, 2004
}

\begin{abstract}
The EU-SILC indicator on work intensity (WI) is often applied in the analysis of the households' work activity status. Work intensity reflects the share of the total number of months worked within the given number of working months in the income reference period (Eurostat 2007). In the dataset, work intensity is coded for the following four categories: $\mathrm{WI}=0$ corresponds to jobless households; $\mathrm{WI}=1$ corresponds to full-year work of all working age individuals in the households; $0<\mathrm{WI}<0.5$ corresponds to less than half-a-year; and, $0.5 \leq \mathrm{W}<1$ to more than half-a-year but less than full-year work for some or all household members. For the purpose of this study, the households are classified as the social assistance recipient ${ }^{39}$ and the non-recipient households.

The percentage of social assistance recipient households who were involved in work activity for a full year in 2004 is striking. In the figure below, the full-year work activity is indicated by the black line.With 50 percent, this share was particularly high in Estonia as it is at the level of work intensity of non-recipient households. This percentage was also much higher than the EU average for the recipient households. In Estonia, the majority of work active households belonged to the category of half-a-year to full-year activity of household members - more than 70 percent. In Slovenia, the share of fully active recipient households was significantly lower - below 20 percent. However, more than 40 percent of the Slovenian recipient households were involved in work activity between half a year and a full year, represented by the gray line in the figure.
\end{abstract}

\footnotetext{
${ }^{39}$ Refers to the recipients of social exclusion n.e.c., as such classified in the EU-SILC.
} 


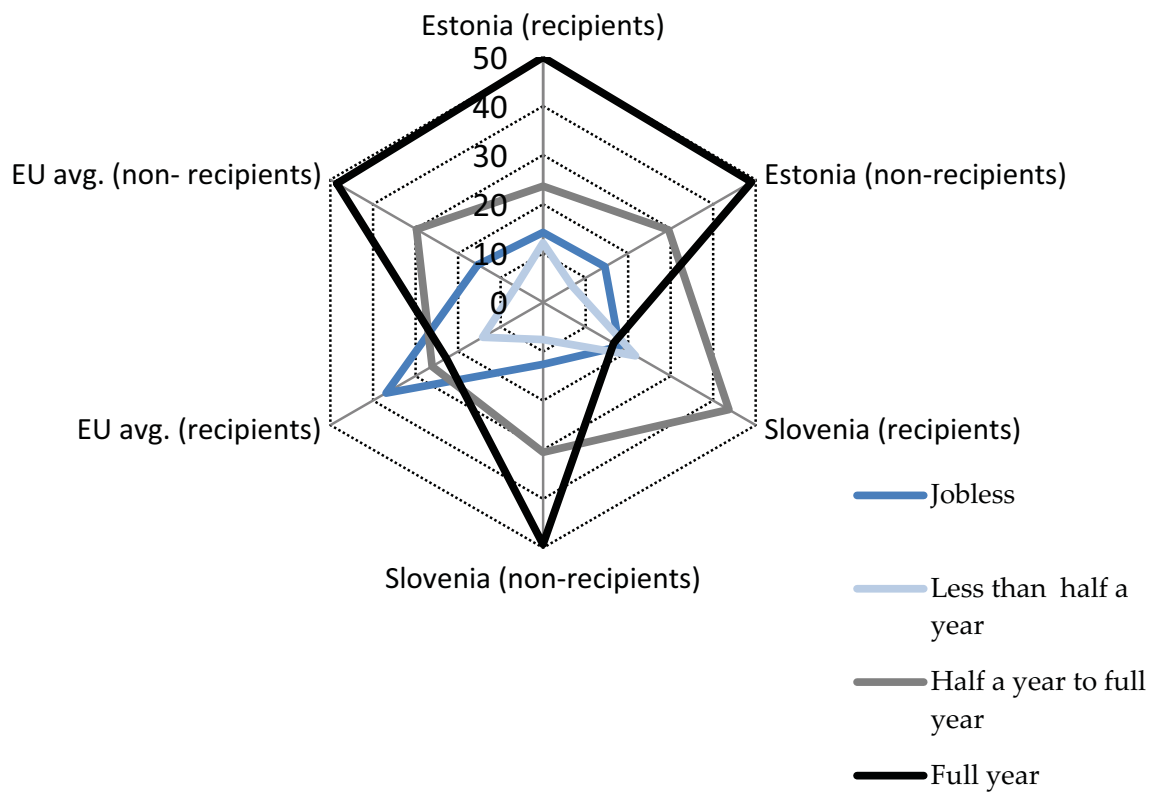

Source: Author's own calculation based on EU-SILC 2005.

Overall, the share of jobless social assistance recipient households was significantly smaller in Estonia and Slovenia compared to the EU. The difference is less expressed for the category of non-recipients. The percentages of those who were active for less than half-a-year period were rather equal across the observed cases except for the recipient households in Slovenia. On balance, work intensity of the Estonian social assistance recipient households was much more expressed relative to the Slovenian one. This is partially to be attributed to the favorable macroeconomic conditions, positive employment trends, and the renewed focus on work activation of welfare recipients. After the years of slowdown in economic growth in the early 2000s, the pace of economic activity increased toward 2004. The Estonian strong economic growth has evidently translated into employment gains and greater involvement of welfare recipients in the labor market.

The presented discussion gives some indication about the complex relationship between welfare and work. On the one hand, higher levels of work activity among 
social assistance recipients could be a consequence of certain employment incentives embedded in the government social assistance and labor market programs. On the other, they can be a pure product of a strong economic performance offering jobs to all. Moreover, increased activity might simply reflect a high level of informality of work among welfare recipients, with no particular relation to the official employment incentives. Perhaps, it also signals the existence of a significant share of the working poor. However, the latter is not the topic of this study and will not be further explored. Our aim here was to stress the importance of treating different-level factors in the assessment of numerous and intertwined processes, as well as to shed light on the existing scope for activation of social assistance recipients.

\subsection{Conclusion}

The aim of the discussion in this chapter was to provide a through explanation of various conditions leading to low relative poverty among social assistance recipients in Estonia and Slovenia. In addition to the fuzzy-set analysis of causal complexity presented in Chapter 2, the discussion of this chapter follows the developments over time. The countries' social assistance programs were treated in-depth to highlight their actual roles in mitigating poverty.

The findings of this chapter show rather stable developments in Estonia and Slovenia, but in quite opposite directions. Deep structural changes in Estonia contributed to already high inequality and poverty. The country's wealth and gradual approach to transition helped Slovenia contain inequality and poverty. Slovenia expanded its social assistance program primarily by setting the new basic minimum income threshold, altering the equivalence scales, and by insisting on activation of beneficiaries early in the process. On balance, it managed to protect its citizens in the period of economic decline and improve their standards of living in good times. On the other side, the Estonian social assistance scheme was procyclical, shrinking in the period of economic decline. That represented a clear derail from the OST framework. Under this concept, the country experiencing fast and radical restructuring is expected to expand its social protection programs. Generally, Estonia did not provide full protection of citizens and its poverty outcomes were less favorable. Contrary to the Slovenian experience, social assistance cash benefit in Estonia was not able to assist people move out of poverty over time. Nevertheless, high employment creation and Estonia's commitment to work activation of social assistance recipients in the times of strong economic growth yielded improved poverty and work activity outcomes. 
The presented analysis supports some of the findings of the preceding fuzzy-set analysis. To begin with, it is certainly a combination of different factors that leads to low poverty outcomes for social assistance recipients. Sometimes, it is the social assistance program specificities that play more important role in alleviating poverty - as proven in the case of Slovenia. Other times, poverty and exclusion are successfully tackled by means of strong economic performance - as shown in the case of Estonia. The impact of the context factors in combination with activation played an instrumental role in Estonia. The relationship between these factors, that are exogenous to social assistance and the low poverty rate appear to be causally much deeper than perhaps thought.

Lots of discussion in Chapter 2 and Chapter 3 has been dedicated to revealing the factors that lead to 'at-risk-of-poverty rate' unidimensionally defined as the social exclusion outcome indicator. The next chapter expands the analysis and puts forward the discussion on multidimensional nature of social exclusion. Within this context, the study further investigates the main areas of deprivation among social assistance recipients and possible policy responses to them. 


\section{CHAPTER}

\section{Defining and Measuring the Multi-Dimensional Nature of Social Exclusion: The Case of Serbia ${ }^{40}$}

\subsection{Introduction}

In Chapter 2 and Chapter 3, the analysis revolved around a single social exclusion outcome - relative poverty - and selected EU countries. Social exclusion is, however, of multidimensional nature and will be further analyzed as such. Meanwhile, Serbia provided a good unexplored case with significant EU aspiration and social inclusion agenda, for which the data were available from the newly established UNDP/UNICEF social exclusion database (2010). This created an excellent opportunity for a comprehensive analysis of social exclusion - the concept per se, its operationalization, and measurement.

There is no one straightforward definition of social exclusion. Many authors (Atkinson \& Davoudi, 2000; Coates, Farnsworth \& Zulauf, 2001; Marlier, Atkinson, Cantillon, \& Nolan, 2007; Silver \& Miller, 2003) agree that it is a process that prevents certain individuals from participating fully in relevant social, economic, cultural, and political aspects of life. Social exclusion can be defined as the "inability to participate" (UNDP, 2011). It is a complex phenomenon that includes many dimensions. Many attempts have been made to define and measure the multidimensional nature of social exclusion (Alkire, 2008; Alkire \& Foster 2007, 2011; Atkinson and Davoudi 2000; Marlier, et al. 2007; Ravallion, 2011; Sen 2000; Silver and Miller, 2003; UNDP, 2011). In the European context, these research efforts were mainly driven by the common European Union (EU) policy and adoption of the Open Method of Coordination (OMC) involving the definition of a set of objectives on poverty and social exclusion for the EU as a whole.

This chapter seeks to contribute to the development of a context-specific social exclusion index using the case of Serbia. Moreover, as a country-wide single index tends to blur the situation of specific groups (UNDP, 2011), we analyze how social exclusion outcomes differ by population groups. We are especially interested in welfare recipients, the extent and areas of their exclusion. Previous attempts to define and measure social exclusion in Serbia have been limited. The existing

${ }^{40}$ Joint analysis with Franziska Gassmann. 
analyses by Baronijan and Cvejic (2010) and Government of Serbia (2010) are based on the Living Standard Measurement Survey (LSMS) and Household Budget Survey (HBS) data respectively, which are not specifically designed for social exclusion analyses.

The conceptual underpinnings for this chapter are based on the approaches of multiple deprivation and multidimensional poverty. The advantage of shifting emphasis from single dimensions, such as income or expenditure, to a multidimensional framework is manifold. First, breaking down social exclusion into different dimensions highlights the broad areas of exclusion. Secondly, these dimensions and the carefully selected indicators per dimension often reinforce each other and create space for the analysis of multiple deprivations. Finally, such a breakdown makes the concept of social exclusion more concrete and measurable. As a result, social exclusion can be explained through various dimensions and offered as a single headcount measure.

The literature does not provide a unique solution for the construction of the multidimensional social exclusion index. The social exclusion measure proposed in this chapter follows the UNDP adaptation of Alkire and Foster's $(2007,2011)$ work on multidimensional poverty measures. Building on the newly developed UNDP (2011) measure of social exclusion defined for the purpose of cross-country comparisons, the proposed chapter makes contribution in different ways. We make the selection of deprivation indicators context-specific. What is regarded as social exclusion in one country depends largely on the general level of social and economic development, which varies considerably across countries. Therefore, we raise the question of the ability of the proposed set of UNDP indicators to satisfactorily reflect the situation in Serbia. A number of indicators included in the UNDP-developed measure of social exclusion, or, more precisely, 13 out of 24 indicators have been altered or completely replaced in our analysis to better reflect country-specific circumstances. We opt for the use of the national social exclusion indicators that have already been defined in the official document by the Government of Serbia (Government of Serbia 2010) and apply this approach as a guiding principle throughout the process of selection of indicators. In the final step, we offer an index of multi-dimensional social exclusion.

The chapter is structured as follows. The next section summarizes existing approaches to social exclusion. The third section provides the rationale for the selection of country-specific indicators. The data and methodology used to measure multidimensional social exclusion are described in section four. Section five presents the results of the analysis including the discussion of the key patterns of deprivation, multidimensional index of social exclusion, and links between monetary and non-monetary deprivations. The final section concludes. 


\subsection{Relevant approaches to social exclusion}

In its contemporary sense, the term "social exclusion" appeared in the French literature and practice of the 1970s with the rising concern for the well-being of marginalized groups ${ }^{41}$ that were excluded from the social protection system (Atkinson \& Davoudi, 2000; Coates et al., 2000; Silver \& Miller, 2003). In the mid1970s, the poor in Europe were described as individuals and families whose income, goods, and access to public and private services were so small that excluded them from the minimum acceptable way of living.

The concept of social exclusion emerged in the European Union in the 1980s and 1990s with the manifestation of significant economic, technical, and social changes, often accompanied by growing poverty and unemployment (Atkinson \& Davoudi, 2000; Silver \& Miller, 2003). The concept of poverty measured as insufficiency of financial resources was no longer adequate enough as it did not include the emerging forms of exclusion, such as, for example, the exclusion from the labor market or education opportunities. In 1992, the European Commission concluded that the "social exclusion" concept is more encompassing than "poverty" since it covers the multidimensional nature of deprivation. Today, EU's social policy focus is on social inclusion and reflects an attempt to analyze and respond to poverty as a broad and complex phenomenon.

The concept of social exclusion in Europe is clearly different from the notion of disadvantage in the U.S. where disadvantage is conceptualized in terms of poverty measured as financial insufficiency rather than the non-realization of citizenship rights. In Europe, any reference to disadvantage assumes a broader concept of social exclusion. When defining social exclusion, the EU refers to "a process whereby certain individuals are pushed to the edge of society and prevented from participating fully by virtue of their poverty, or lack of basic competencies and lifelong learning opportunities, or as a result of discrimination. This distances them from job, income and education opportunities as well as social and community networks and activities. They have little access to power and decision-making bodies and thus often feeling powerless and unable to take control over the decisions that affect their day to day lives" (European Commission, 2004, p.8). The EU social exclusion concept reflects a move from treating poverty as income insufficiency and related inequality to include the social, cultural and political

\footnotetext{
${ }^{41}$ In 1974, Rene Lenoir came up with a phrase "les exclus" to describe those who are excluded from French welfare state system protection.
} 
dimensions of exclusion, expanding, thus, the framework for the non-monetary aspects of deprivation.

There are numerous definitions and interpretations of social exclusion, most closely related ones being discussed here. Within the social rights tradition, social exclusion is defined as non-realization of rights in the labor market but also as the denial of rights of social citizenship i.e the right to the minimum standard of living defined broadly to include minimum level of income, housing, education, and health protection. Extensions to this type of definition include the denial of other social political and civil rights of citizens and their inability to participate in the society. Stressing the rights-based approach, UNDP, therefore, defines social exclusion as the denial of basic civil and social rights, but also as non-accessibility to the political and legal systems to execute the rights (UNDP, 2011). Other international agencies apply the definitions used either by the EU or the UNDP. As Coates et al. (2001) noted early in the discussion, the definitions of social exclusion range from slightly re-naming poverty to the more comprehensive ones focusing on the lack or inability of participation in the society.

Obviously, social exclusion has been tied to the idea of citizenship rights over the past two decades. These rights are viewed through the realization or denial of economic and social benefits and services, education, legal processes, decision making, and similar. However, the existence of rights does not necessarily guarantee fairness, justice, well-being, or the respect for citizens. In Europe, exclusion was framed to explain the inability to exercise basic social rights of citizens to a minimum standard of living and participation and integration in the society (Silver \& Miller, 2003). With the changing face of poverty, a growing number of individuals have become excluded from full citizenship. Expansion of social exclusion was recognized as a threat to social cohesion in the EU. Hence, the citizenship approach represented that necessary link between social and economic policy and politics. Social exclusion is understood as the denial or non-realization of citizenship rights through institutions, such as the labor market, welfare and family networks, and, promotion of civic integration through the various parts of the legal and political systems. This was described as a rather unique attempt to finally locate the causes of social exclusion (Atkinson \& Davoudi, 2000).

In a similar vein, Sen (2000) views social exclusion as a result of negative factors affecting the freedom to undertake activities that a person would choose. It occurs because of a deliberate policy or practice and in that case it should be treated as 'active exclusion'. When it is the result of complex societal processes without deliberate actions to exclude, social exclusion should be treated as 'passive exclusion'. In either form, exclusion may result in reduced human capabilities in one or more fields in life. This is described as 'capability failures' by Sen, with 
exclusion playing a critical role. The remedy is to adopt polices targeted at the disadvantaged groups that are affected the most.

In Sen's terminology, unemployment or low take-up of welfare benefits by one group of people such as the Roma is to be treated as active exclusion because it occurs due to the specific formal obstacles such as the lack of identification documents, which is often the case in Serbia. The resulting capability deprivation i.e. the lack of access to basic rights and services stemming from their status, comprise the capability failure. However, if, for example, unemployment results from complex processes within the society with no specific decisions involved, such as structural changes resulting in high unemployment rate, this is to be perceived as passive exclusion.

Clearly, social exclusion is the result of factors and processes that are either in the control or beyond the control of the individual. It can be a product of direct or indirect discriminatory policies, rules and behaviours, regulations, policies and the ways they are implemented, against an individual or groups in a given society. Social exclusion is directly linked to human rights as it takes the forms of denials of basic human rights related to participation in economic, social, cultural, and political life. This approach to social exclusion has provided a framework for the analysis of social exclusion that is rather comprehensive and multidimensional.

\subsection{Selection of country-specific indicators}

The process of building a multidimensional social exclusion measure is subject to many assumptions and value judgments (Alkire, 2002, 2008; Robeyns, 2006). The initial steps here involve the selection of appropriate indicators for each dimension of social exclusion. In this section we describe the approach to the selection of social exclusion indicators for Serbia. In the group of post-socialist countries selected for the UNDP analysis, Serbia and FYROM Macedonia stand out as countries with significant EU integration aspirations. Given that the topics around social exclusion are very high on the EU agenda, it would be of critical importance to develop a set of appropriate country-specific indicators this early in the process. With the adequate set of indicators, which build upon both common EU and nationally agreed indicators, the levels and dynamics of exclusion could be accurately measured and monitored.

The existing literature does not provide a unique measure of social exclusion. The EU, the World Bank, the Organization for economic Cooperation and Development (OECD), the United Nations (UN), and others, use various measures in their 
analyses of poverty, inequality, or multiple deprivations. There has been a little consensus in developing a common measure of social exclusion. The EU has gone furthest in this process and defined a set of common indicators for monitoring poverty and social exclusion over time and across its member states. The agreed indicators, known as "Laeken indicators" cover poverty, inequality, access to labor markets, access to health care and education, housing standards, material deprivation, and child well-being. In the context of the Europe 2020 strategy, the European Council adopted a headline target on social inclusion in 2010. This indicator combines three sub-indicators: the at-risk-of-poverty rate, severe material deprivation, and people living in households with very low work intensity. The main data source for all these indicators is the Statistics on Income and Living Conditions (SILC) Survey. ${ }^{42}$

In this chapter we focus on the three dimensions of social exclusion already identified by the UNDP (2011): economic exclusion; exclusion from health, education and other services; and, exclusion from participation in civic and social life and networks. The selection of the three dimensions is in line with the UNDP understanding that certain processes within societies push some individuals to the margins of society and deny their full participation in economic, social, political, and cultural life. We follow the logic that the indicators should be grouped in a limited number of dimensions and that the indicators should be used as indicative of their underlying dimension.

The first step in the analysis is reviewing the indicators selected by the UNDP (2011) in its cross-country comparison. These indicators are presented in the first column of Table 4.1.

We view the UNDP choice as an "absolute" set of indicators, determining a minimum standard which is applicable across countries as diverse as Serbia, Kazakhstan, FYROM Macedonia, Moldova, Ukraine, or Tajikistan. These countries are at very different levels of social and economic development. From the national perspective, the indicators and their cut-off thresholds may therefore not be appropriate, especially if we consider social exclusion having a rather relative connotation. The country context, its level of development, and the norms and values of the society determine the national understanding of social exclusion, and as such the necessary ingredients for a person to fully participate in society. ${ }^{43}$

\footnotetext{
42 The SILC survey adopting EU methodology for monitoring poverty and social exclusion was piloted in Serbia in 2012.

${ }_{43}$ The underlying relative poverty concept refers to standards and values defined for the particular society in which an individual lives and which differ across countries and over time. See for example Marlier et al. (2007) for the discussion of relative poverty or Roelen,
} 
Table 4.1: Lists of dimensions and indicators of multidimensional social exclusion

\begin{tabular}{|c|c|}
\hline UNDP-defined indicators & $\begin{array}{l}\text { Proposal for Serbia-specific indicators } \\
\text { (changes highlighted) }\end{array}$ \\
\hline \multicolumn{2}{|l|}{ Economic exclusion dimension } \\
\hline $\begin{array}{l}\text { Inequality: At-risk-of-poverty rate ( } 60 \\
\text { percent of median equivalent } \\
\text { expenditures in a country) }\end{array}$ & $\begin{array}{l}\text { Poverty and Inequality: } \\
\text { At-risk-of-poverty rate ( } 60 \text { percent of median } \\
\text { equivalent expenditures) }\end{array}$ \\
\hline $\begin{array}{l}\text { Subjective basic needs: In the past } 12 \\
\text { months the household has not been able to } \\
\text { afford three meals a day, or pay bills } \\
\text { regularly, or keep the home adequately } \\
\text { warm, or buy new clothes and shoes }\end{array}$ & $\begin{array}{l}\text { Material deprivation - basic: } \\
\text { Not being able to afford two out of five } \\
\text { items in the past } 12 \text { months: three meals a } \\
\text { day, pay bills regularly, keep the home } \\
\text { adequately warm, buy new clothes and } \\
\text { shoes, pay for a week's long vacation away } \\
\text { from home }\end{array}$ \\
\hline $\begin{array}{l}\text { Employment: Being unemployed or a } \\
\text { discouraged worker }\end{array}$ & $\begin{array}{l}\text { Employment: } \\
\text { Being unemployed or a discouraged worker }\end{array}$ \\
\hline $\begin{array}{l}\text { Financial services: Lack of access to a bank } \\
\text { account on one's own name }\end{array}$ & $\begin{array}{l}\text { Financial services: } \\
\text { Lack of access to a bank account on one's } \\
\text { own name }\end{array}$ \\
\hline $\begin{array}{l}\text { Material deprivation-housing: The } \\
\text { household cannot afford a bed for every } \\
\text { member of the household }\end{array}$ & $\begin{array}{l}\text { Material deprivation - housing: The } \\
\text { household cannot afford a bed for every } \\
\text { member of the household }\end{array}$ \\
\hline $\begin{array}{l}\text { Material deprivation-amenities: } \\
\text { Household needs a washing machine, } \\
\text { freezer or microwave but cannot afford } \\
\text { one }\end{array}$ & $\begin{array}{l}\text { Material deprivation - amenities: } \\
\text { Household needs but cannot afford two out } \\
\text { of five items such as a TV, car, washing } \\
\text { machine, refrigerator, phone, stove }\end{array}$ \\
\hline $\begin{array}{l}\text { Material deprivation-ICT: Household } \\
\text { needs a computer or internet but cannot } \\
\text { afford one }\end{array}$ & $\begin{array}{l}\text { Material deprivation - ICT: } \\
\text { Household needs a computer or internet but } \\
\text { cannot afford one }\end{array}$ \\
\hline $\begin{array}{l}\text { Overcrowding: Household with less than } \\
6 \mathrm{~m}^{2} \text { per person }\end{array}$ & $\begin{array}{l}\text { Overcrowding: } \\
\text { Household with less than } 10 \mathrm{~m}^{2} \text { per person }\end{array}$ \\
\hline
\end{tabular}

Gassmann, and de Neubourg (2009a) for their country-specific and multidimensional approach to child poverty. 


\begin{tabular}{|c|c|}
\hline \multicolumn{2}{|c|}{ Exclusion from health, education and other services dimension } \\
\hline $\begin{array}{l}\text { Public utilities: Household with no } \\
\text { running water or sewerage system }\end{array}$ & $\begin{array}{l}\text { Public utilities: } \\
\text { Household with no running water or } \\
\text { sewerage system }\end{array}$ \\
\hline $\begin{array}{l}\text { Public utilities: Household heats with } \\
\text { wood or with no heating device }\end{array}$ & $\begin{array}{l}\text { Education: } \\
\text { Low educational achievements - basic } \\
\text { school and less }\end{array}$ \\
\hline $\begin{array}{l}\text { Education: Low educational achievements } \\
\text { (basic schooling) and early school leavers }\end{array}$ & $\begin{array}{l}\text { Education: } \\
\text { Household could not afford to buy school } \\
\text { materials for every child in the past } 12 \\
\text { months }\end{array}$ \\
\hline $\begin{array}{l}\text { Education: Household could not afford to } \\
\text { buy school materials for every child in the } \\
\text { past } 12 \text { months }\end{array}$ & $\begin{array}{l}\text { Health care: } \\
\text { Not having health insurance }\end{array}$ \\
\hline $\begin{array}{l}\text { Education: Household with young } \\
\text { children not in school or pre-school }\end{array}$ & $\begin{array}{l}\text { Health care: } \\
\text { Household could not afford or could } \\
\text { seldom afford medication that individual or } \\
\text { household needed in the past } 12 \text { months }\end{array}$ \\
\hline $\begin{array}{l}\text { Health care: Household could not afford } \\
\text { medication or dental checks for every } \\
\text { child in the past } 12 \text { months }\end{array}$ & $\begin{array}{l}\text { Health care: } \\
\text { Medical needs not being met due to the } \\
\text { distance to doctor's office/hospital/medical } \\
\text { center }\end{array}$ \\
\hline $\begin{array}{l}\text { Health care: Medical needs not being met } \\
\text { by the health care system }\end{array}$ & $\begin{array}{l}\text { Social welfare services: } \\
\text { Lack of access to social work providers } \\
\text { (providing social assistance, health, or } \\
\text { educational activities) }\end{array}$ \\
\hline $\begin{array}{l}\text { Social infrastructure: Lack of } \\
\text { opportunities to attend events due to } \\
\text { distance (lack of transportation) }\end{array}$ & $\begin{array}{l}\text { Public infrastructure: } \\
\text { Lack of bus stop and shops in the } \\
\text { settlement }\end{array}$ \\
\hline \multicolumn{2}{|c|}{ Exclusion from civic and social life and networks dimension } \\
\hline $\begin{array}{l}\text { Social capital: Rare or infrequent social } \\
\text { contact with family or relatives }\end{array}$ & $\begin{array}{l}\text { Social capital: } \\
\text { Rare or infrequent social contacts with } \\
\text { family/relatives }\end{array}$ \\
\hline Social capital: Rare social contact with & Social capital: \\
\hline
\end{tabular}




\begin{tabular}{|c|c|}
\hline friends & $\begin{array}{l}\text { Rare social contact with friends or } \\
\text { acquaintances (e.g. work colleagues) }\end{array}$ \\
\hline $\begin{array}{l}\text { Social capital: Lack of support networks } \\
\text { that could help in the event of emergency }\end{array}$ & $\begin{array}{l}\text { Social capital: } \\
\text { Lack of support networks that could help in } \\
\text { the event of emergency }\end{array}$ \\
\hline $\begin{array}{l}\text { Social participation: In the past } 12 \text { months } \\
\text { the household has not been able to afford } \\
\text { inviting friends or family for a meal or } \\
\text { drink at least once a month }\end{array}$ & $\begin{array}{l}\text { Social participation: } \\
\text { In the past } 12 \text { months the household has not } \\
\text { been able to afford inviting friends or } \\
\text { family for a meal or drink at least once a } \\
\text { month or travel to family celebrations/for } \\
\text { family events }\end{array}$ \\
\hline $\begin{array}{l}\text { Civic participation: No participation in } \\
\text { political/civic activities }\end{array}$ & $\begin{array}{l}\text { Social participation: } \\
\text { In the last three months the household did } \\
\text { not participate in any cultural event } \\
\text { (theatre, museums, concerts, etc.) }\end{array}$ \\
\hline $\begin{array}{l}\text { Social participation: The household has } \\
\text { not been able to afford to buy books, } \\
\text { cinema or theatre tickets in the past } 12 \\
\text { months }\end{array}$ & $\begin{array}{l}\text { Civic participation: } \\
\text { Not having access to TV news in the } \\
\text { language you normally speak at home }\end{array}$ \\
\hline $\begin{array}{l}\text { Civic participation: Inability to vote due to } \\
\text { lack of eligibility or distance to polling } \\
\text { station }\end{array}$ & $\begin{array}{l}\text { Civic participation: } \\
\text { Inability to vote due to lack of eligibility } \\
\text { (registration irregularities and other) or } \\
\text { distance to polling station }\end{array}$ \\
\hline $\begin{array}{l}\text { Civic participation: No } \\
\text { participation/membership in associations, } \\
\text { teams or clubs }\end{array}$ & $\begin{array}{l}\text { Civic participation: } \\
\text { No participation/membership in associations, } \\
\text { teams or clubs }\end{array}$ \\
\hline
\end{tabular}

Moreover, the national (and individual) perception is partly driven by how people perceive each other and how they are perceived by different groups. Therefore, the discussion needs to take into account the given society, its norms and values. In our approach, we emphasize this rather relative concept - exclusion within a given country can be well assessed by comparing the circumstances of an individual or group relative to others in the same context. Therefore, we modify certain indicators in order to render the indicators meaningful at the country level. 
The choice of indicators is guided by the established set of nationally defined indicators (Government of Serbia, 2010) and data availability. In the development of a set of indicators that is more reflective of the in-country circumstances, we relied heavily on the nationally agreed set of social exclusion indicators (Government of Serbia, 2010). In its document "Monitoring of Social Inclusion in Serbia" the Government of Serbia provides lists of national indicators selected on the basis of literature review, empirical evidence, and expert opinions. The process of concluding the list of social exclusion indicators was carried out in a participatory manner. The national indicators are offered in addition to the selected Laeken indicators. This made it possible for the analysis to explore connections between conventional definitions of social exclusion and countryproposed indicators. In addition, it provided a venue to reflect on patterns of social exclusion concerning particular groups within society.

The following is the reasoning behind the selection of particular indicators and how they differ with regard to the indicators already identified by the UNDP.

\subsubsection{Economic exclusion dimension}

Economic exclusion is usually characterized by inequality in incomes and poverty. Unemployment is often a contributing factor. Furthermore, if status of unemployment lasts long many individuals stop looking for a job. Lack of financial resources and limited access to financial services leave the individuals and household's basic material needs unmet. Therefore, under the economic exclusion dimension the indicators reflect at-risk-of-poverty rate, access to employment and financial services, as well as access to necessities and amenities that the households need but cannot afford.

For poverty and inequality measure we use at-risk-of-poverty rate indicator, conventionally defined as the share of people with expenditures below 60 percent of the median expenditures in the country and applied by the UNDP in their analysis. However, with regard to the material deprivation indicators, we apply a modification of material deprivation measures, both in the choice of indicators and when deciding on the cut-off thresholds. At the EU level, material deprivation is defined as non-voluntary inability to afford some items considered by most people to be desirable or even necessary to lead an adequate life. Material deprivation rate measures the percentage of the population that cannot afford to pay their rent, mortgage or utility bills; to keep their home adequately warm; to face unexpected expenses; to eat meat or proteins regularly; to go on holiday; a television set; a refrigerator; a car; and a telephone. In line with the UNDP choice, the material deprivation indicators presented in the table above are divided into four groups 
(basic, amenities, housing, and ICT). However, for the basic material deprivation rate and material deprivation in amenities, we offer new definitions and cut-off points.

UNDP uses the indicator of subjective basic needs to explain basic material deprivation reflected in the failure of the household to afford three meals a day, or pay the bills regularly, or keep the home adequately warm, or buy new clothes and shoes over 12 months. In addition to these four items, our basic material deprivation indicator also includes the ability to afford one week long vacation, which is in line with the EU list of material deprivation items and a common lifestyle of the Serbian population. This indicator is positively correlated with the other constitutive indicators of the economic exclusion dimension and appears as a good proxy of financial shortcomings. For material deprivation in amenities (durables), we select five items most frequently possessed by the average Serbian household - a TV set, car, washing machine, refrigerator, phone, and stove. The selection is based on the findings from the national Household Budget Survey (Government of Serbia 2010). Besides, basic material deprivation rate and material deprivation in amenities are now defined as the enforced lack of at least two of the selected five items per indicator. In order to exclude taste and lifestyle preferences, "the enforced lack" refers to people who would like to possess the items but cannot afford them. The cut-off threshold of two, which considers person as excluded in a given indicator if he/she cannot afford at least two items out of five, reliably reflects the relative nature of social exclusion.

Another indicator describing material living conditions relates to housing. The list of national social exclusion indicators (Government of Serbia 2010), suggests the use of $8-10 \mathrm{~m}^{2}$ per household member measure for the estimates of the level of overcrowding. The $10 \mathrm{~m}^{2}$ measure has already been applied in the research of social exclusion in Serbia by Baronian and Cvejic (2010). For this reason, we replace the UNDP defined overcrowding measure ("Household with less than $6 \mathrm{~m}^{2}$ per person") and apply $10 \mathrm{~m}^{2}$ per household member for the overcrowding indicator. The adopted definition is less strict but more reflective of the actual housing situation in Serbia.

The other five indicators within the economic exclusion dimension remain identical to the UNDP list of indicators. The reasons for sticking to the above described set of indicators is the degree of penetration of the selected items in the Serbian society, confirmed in the national documents and, more important, in ordinary living patterns common to a majority of the population. Frequency controls on existing data were also performed to give us an indication of the presence of the particular item in the society. 


\subsubsection{Exclusion from health, education and other services}

The exclusion from health, education, and other services dimension encompasses a list of indicators that reflect accessibility and affordability to education, health, social services, and utilities. This section examines exclusion from public utility services by looking at household's access to running water and sewage system. Within education domain, the emphasis is on the measure of educational achievements and school materials affordability. For the health care indicators, the focus is on the discrepancy between the needs and health care utilization influenced by the lack of insurance, financial sources, or physical distance. Social work and counselling services are of critical importance for the excluded or those at risk of being excluded. Ideally, social work services should be equally distributed at local levels. It is essentially the access to providers of educational, health, and social assistance services that will be examined under this dimension. Additionally, the public infrastructure indicator will look at the availability of basic infrastructure such as bus stops and shops in a given settlement.

Firstly, we abandon the indicator on heating defined by UNDP ("Household heats with wood or with no heating device") since heating with wood is common for the subsection of the population living in rural areas and as such cannot be used as an indicator of deprivation or social exclusion for the general population. The issue here would be if someone cannot heat his or her house, but these responses are not available in the existing dataset. The data, however, confirm that there are no households without any heating device.

In education indicators, we stick to the commonly accepted definitions of education attainment and affordability as they provide precise measures of deprivations. The indicators involve the measures of low educational achievements in terms of completed basic education or less and inability to afford school materials for children. We drop the UNDP applied indicator estimating the share of households with young children who are not in school or pre-school as these data were not available to us in the obtained dataset.

Two indicators of health care services offered by the UNDP were dropped on the basis of inappropriateness for the analysis of general social exclusion. The first one ("Household could not afford medication or dental checks for every child in the past 12 months") was deleted as it focused on children only. Instead, we proposed a similar indicator covering the general population: "Household could not afford or could seldom afford medication that individual or household needed in the past 12 months". Also, based on the existing evidence, the failure to cover the costs of medicines when needed appears to be one of the main challenges faced by the 
poorest segments of the population (Petrovic, 2009) and as such needed to be explored further. The definition of the UNDP's second health care indicator is rather vague: "Medical needs not being met by the health care system" and could not be found in the dataset and related questionnaire. In our study, we put forward two new indicators linked to the accessibility of health care services to all. Despite the declarative universal health coverage, a significant and alarming number of individuals remains uninsured. Based on the HBS data, 6 percent of the Serbian population does not have health insurance (Government of Serbia, 2010). Therefore, we propose the indicator on health insurance coverage, which is at the same time listed as the national social exclusion indicator. The second national indicator on health care service accessibility addresses the inability of households to meet medical needs due to the distance to the health facility. Moreover, the findings of the national Institute of Public health suggest that due to these reasons the medical needs of the poorest 20 percent of the population remain largely unmet (Government of Serbia, 2010).

Data on social welfare services utilization are rarely compiled in the literature, yet in the Serbian circumstances they tend to blur the real level of service accessibility given its broad administrative coverage (World Bank, 2006). We propose measuring the non-accessibility of social assistance, health, or educational services at local level. The survey respondents were asked to look at the list of organizations providing social services related to social assistance, health and education in their settlements. Those who responded that none of these services was provided, were labelled as not having the access.

Finally, the UNDP defined social infrastructure indicator measuring the "lack of opportunities to attend events due to distance (lack of transportation)" was replaced by the more general one dealing with public infrastructure broadly defined. Lack of bus stops and shops in a given area certainly prevents people from participating in social and economic life. At the same time, it is the lack of public transportation and socio-economic infrastructure including schools, primary health centers, shops, and jobs, which are listed among the items under the "quality of life in the residential area" indicator of the Government of Serbia (2010).

In total, six out of eight indicators in the exclusion from health, education, and other services dimension are replaced to better reflect the circumstances around service provision in Serbia. We find these changes of quite significant importance since these services are typically more demanded by those who are at risk of being excluded. 


\subsubsection{Exclusion from civic and social life and networks}

The third dimension titled exclusion from civic and social life and networks covers indicators that reflect deprivation in social contacts and access to cultural, political, and social events. They focus largely on respondents' inability to actively participate in social, cultural and political life.

Exclusion from social participation is defined as a single social exclusion dimension in the national review of social exclusion indicators (Government of Serbia, 2010). According to Government of Serbia (2010), social participation dimension contains nine indicators covering broad areas of cultural and political participation, access to the judiciary system, prevalence of domestic violence, and subjective assessments of social exclusion. Due to the data constraints only five of the nationally agreed indicators reflecting social and civic participation are used in our analysis. They include: social contacts with family/relatives; contacts with friends and work colleagues; affordability of inviting friends and family for a meal or drink once a month or to travel to family events; participation in cultural events such as concerts, theatre plays and visits to museums; and, participation in associations, teams or clubs. With regard to the UNDP choice of indicators, two indicators in this group have been altered to include contacts with work colleagues and visits to family events and better reflect the national choice of items in this dimension.

The indicators defining contacts with family/relatives, support networks, participation in associations, as well as the inability to vote due to non-eligibility or distance to the polling station were retained from the UNDP list of indicators.

The remaining indicator of civic participation involves the measure of accessibility of TV news in the language people usually speak at home. Measuring the access to TV news in different languages is of significant importance in multi-ethnic settings. The existing data confirm presence of various ethnic groups in the Serbian society. The demographic profile of social exclusion survey participants, including the disaggregation by ethnic background, is provided in Table 4.2.

\subsection{Methodology and data}

Once the indicators had been identified a principal component analysis (PCA) of the indicators of the social exclusion index was run to check the robustness of the index. The 24 indicators of the index were subject to PCA using SPSS version 15 (see Scree plot and the explanation of the procedure in the Appendix 3). The results 
of this analysis support the use of the 24 indicators in the construction of the social exclusion index. They confirm that many components were actually needed and that their combination explained the variance.

Robustness checks are carried out to ensure that each individual indicator is important for the explanation of the social exclusion index, but also that the indicators are not strongly correlated. The relationship between indicators was investigated using Pearson product-moment correlation coefficient. The individual correlation coefficients are reported in Table A2.1 in the Appendix 3.

Next in our analysis was to identify those who are multidimensionally deprived. Despite Ravallion's (2011) criticism of collapsing the multiple dimensions into one index that cannot capture all what is important in a particular setting, the social exclusion measure proposed in this chapter applies the UNDP (2011) approach of multidimensional poverty. However, particular attention was paid to developing a credible set of dimensions and indicators of deprivation most relevant to a specific country context and the analysis of different groups within the given country (Serbia). Besides, Alkire and Foster's (2007) dual cut-off approach allows for a twostep process for the identification of the multidimensional poor. Firstly, it is identified whether a person is deprived with respect to a given indicator ('within indicator cut-off'). The second step ('across indicators cut-off') identifies those who are socially excluded by counting the number of indicators across the given dimensions in which a person is deprived. The analysis employs the 24 deprivation indicators within three dimensions of social exclusion (Table 4.1).

Another argument against the single multidimensional index refers to how dimensions and indicators should be weighted in the index construction (Ravallion, 2011). Each of the 24 indicators has equal weight as they are considered to be of relatively equal importance in measuring social exclusion. This is possible when there is no evidence that the importance of individual indicators is overly different (Atkinson, Cantillon, Marlier \& Nolan, 2002). Each respondent is classified as "socially excluded" or "not excluded" depending on the number of deprivations the individual or his/her household experiences. The deprivation scores are first summed to identify the multidimensionally excluded. The individual is multidimensionally excluded if it is deprived in at least 9 indicators. The cut-off was established at the level of 9 which is in line with the UNDP approach. The established threshold is close to one third of the indicators and equal to 3 deprivations per dimension, or deprivation across at least 2 dimensions. ${ }^{44}$

\footnotetext{
${ }^{44}$ See below for a sensitivity analysis for the number of indicators.
} 
The selected indicators and the applied approach should be understood just as a starting point in an effort to best describe the country circumstances with respect to social exclusion. As with other definitions of multidimensional exclusion and poverty (UNDP, 2011), the presented social exclusion index suffers from drawbacks coming primarily from the data constraints. Firstly, the indicators cover both outputs (e.g. educational achievements) and inputs (e.g. not being able to afford school material). Secondly, careful judgements were needed to address missing data (e.g. the levels of expenditure). Lastly, the analysis does not reflect the intra-household inequalities. Despite all these shortcomings, the approach outlined above provides scope for a comprehensive multidimensional analysis of social exclusion.

The resulting measures of social exclusion are derived from a simple count of indicators of exclusion. This approach could be questioned as it is based on the assumption that each indicator has the same importance in terms of social exclusion. However, the context-specific requirements proposed in this chapter control for the selection of appropriate indicators. The advantage of this approach is in depicting social exclusion in a way which reflects the national context and as such reflects the relative nature of social exclusion.

\section{Data}

The data used for the creation of the social exclusion index for Serbia stem from the publicly available UNDP/UNICEF social exclusion dataset (2010) ${ }^{45}$. These survey data provide suitable information on the scope and determinants of social exclusion. The survey was carried out in six countries - Serbia, FYR Macedonia, Moldova, Ukraine, Kazakhstan, and Tajikistan with an identical questionnaire in all the countries (UNDP, 2011). In this chapter, we use the data for Serbia only. Sampling was based on multistage random sampling. Serbia was first stratified into six administrative regions (Belgrade, Vojvodina, Western Serbia, Central Serbia, Eastern Serbia and Southern Serbia) and further by residential and ethnic characteristics of population within each region. The list of voting stations was used for random selection of sampling points as a starting point. The random walk method was used for household selection. ${ }^{46}$. The selection of respondents was based on the "next birthday" principle.

\footnotetext{
${ }^{45} \mathrm{http}$ //europeandcis.undp.org/poverty/show/DEAD2A6F-F203-1EE9-B97DD75685658B6A

${ }^{46}$ In this approach, the selection starts from the assigned starting point and moves to each third or fourth address onwards. The selected address is on the left-hand side of the interviewer's route. In apartment buildings of up to four floors, the selected household is the fifth one; in the higher buildings the selected household lives in every tenth apartment.
} 
According to the UNDP (2011) documentation, the field work was implemented in November-December 2009. The information was collected on the level of household or respondent only. Certain characteristics such as age, gender, education and activity status were included for all household members. It is further assumed that the respondent's answers are representative for all household members. The working sample for Serbia included 865 respondents who represented 2,874 household members. In cases where observations on the 24 indicators were missing, the respondents were excluded from the dataset. The final dataset for the construction of the multidimensional social exclusion index for Serbia involved the sample of 2,401household members. The average number of members per household was 3.2.

Table 4.2 presents the demographic profile for all individuals living in surveyed households. Men comprise 50.4 percent and women 49.6 percent. The women are slightly underrepresented as the official statistics suggests a larger share of females relative to males. ${ }^{47}$ The majority (52.6 percent) lives in urban areas, which is in line with official statistics.

Most of the people are of active population age. 42.9 percent is employed by the state or private firms while almost 7 percent is self-employed or involved in a production cooperative. Many declare themselves as unemployed. The level of unemployment is very high in Serbia. The share of 18.7 percent of unemployed survey participants corresponds to the 2009 official unemployment rate of 17.4 percent ${ }^{48}$. Nonetheless, these percentages are not directly comparable due to methodological difference in measuring the unemployment rates across different surveys. Another 18.7 percent is retired and 7.2 percent still in education. Consequently, the main source of income for 61.7 percent of the surveyed individuals is income from earnings. For 14 percent it is the old-age pension, while for 2.4 percent the main source of income is social benefit transfer (social assistance, caregivers' allowance, or other welfare transfers).

\footnotetext{
${ }^{47}$ According to the official RSO (Republican Statistical Office) estimates there were 51.4 women and 48.6 men in 2009

(Source: http://webrzs.stat.gov.rs/WebSite/Public/PageView.aspx?pKey=163).

48 Source: October 2009 Labor Force Survey, The Republican Statistical Office of Serbia (http://webrzs.stat.gov.rs/axd/drugastrana.php?Sifra=0018\&izbor=odel\&tab=152)
} 
Table 4.2: Demographic profile for all individuals

\begin{tabular}{|c|c|c|}
\hline & $\begin{array}{c}\text { Number of } \\
\text { observations }\end{array}$ & Percentage \\
\hline \multicolumn{3}{|l|}{ By sex } \\
\hline Male & 1,209 & 50.4 \\
\hline Female & 1,192 & 49.6 \\
\hline \multicolumn{3}{|l|}{ By age } \\
\hline $15-29$ & 634 & 26.4 \\
\hline $30-49$ & 994 & 41.4 \\
\hline $50+$ & 773 & 32.2 \\
\hline \multicolumn{3}{|l|}{ By settlement type } \\
\hline Urban & 1,264 & 52.6 \\
\hline Rural & 1,137 & 47.4 \\
\hline \multicolumn{3}{|l|}{ By activity status } \\
\hline Employed in state or private firm & 1,029 & 42.9 \\
\hline Self-employed and members of a production cooperative & 162 & 6.8 \\
\hline In education & 173 & 7.2 \\
\hline Unemployed & 450 & 18.7 \\
\hline Retired & 449 & 18.7 \\
\hline Other & 138 & 5.7 \\
\hline \multicolumn{3}{|l|}{ By completed years of education } \\
\hline Basic education or less (grade 1 to 8 ) & 562 & 23.4 \\
\hline Secondary education (grade 1 to 4 )) & 1,383 & 57.6 \\
\hline $\begin{array}{l}\text { Vocational education following secondary education / } \\
\text { college }\end{array}$ & 213 & 8.9 \\
\hline University degree (BA, MA, PhD) & 243 & 10.2 \\
\hline \multicolumn{3}{|l|}{ By main source of income } \\
\hline Earnings from work & 1,481 & 61.7 \\
\hline Pension (old-age) & 337 & 14 \\
\hline Pension (disability, military, and other) & 100 & 4.2 \\
\hline $\begin{array}{l}\text { Social assistance, caregivers' allowance, and similar } \\
\text { welfare transfers }\end{array}$ & 57 & 2.4 \\
\hline $\begin{array}{l}\text { Other income (savings, assets, stipends, remittances, and } \\
\text { other) }\end{array}$ & 64 & 2.6 \\
\hline Does not know & 216 & 9 \\
\hline NA and missing & 146 & 6.1 \\
\hline \multicolumn{3}{|l|}{ By ethnic background } \\
\hline Serbian & 2,050 & 85.4 \\
\hline Roma & 30 & 1.2 \\
\hline Hungarian & 117 & 4.9 \\
\hline Other or refuse to answer & 204 & 8.5 \\
\hline Total & 2,401 & 100 \\
\hline
\end{tabular}

Source: Author's own calculation using UNDP/UNICEF Social Exclusion Dataset 2010.

Note: Data represent sample distribution and are not weighted. 
Almost 60 percent of individuals have secondary level education. Those with basic school or less comprise 17.4 percent; 20 percent have a college or university degree. More than 85 percent of individuals in the sample are Serbian. The second largest group is of Hungarian background. Other ethnic groups included the Montenegrins, Roma, and Albanian. ${ }^{49}$

\section{$4.5 \quad$ Results}

This section summarizes key patterns of deprivation and presents the findings on multidimensional social exclusion across different groups. We also explore the link between monetary and non-monetary deprivations and whether monetary poverty has the power to predict other kinds of deprivations.

\subsubsection{Key patterns of deprivation}

Table 4.3 shows deprivation rates for the each social exclusion indicator. The results are presented for the total sample and disaggregated by location (urban/rural) and benefit recipient status, though the analysis of social benefit recipients involves a very small sample. ${ }^{50}$ Nevertheless, this part of analysis aims to contribute to a better understanding of the types and levels of deprivation among those who are traditionally at a greater risk of exclusion. Moreover, recent studies have shown a deterioration in living conditions and a downward trend with respect to job availability for the group of social benefit recipients. The drop was especially significant in the informal market where the majority of social benefit recipients work (Matkovic et al., 2010). In total, 118 individuals or 4.9 percent of all respondents reported receiving any non-contributory social transfers (including, for example, child allowances). Despite the relatively small number of observations for this group, the findings are indicative of their social exclusion status. The urban/rural division is motivated by the discrepancy in their poverty rates (Government of Serbia, 2010; Matkovic et al., 2010; Republican Statistical Office, 2010).

\footnotetext{
49 Some respondents declared themselves as Muslim, which would normally be treated as a religious affiliation.

50 "Social benefits" refer to "social assistance, caregivers' allowance and similar welfare transfers". It excludes child allowances, various types of pensions, stipends, and other income (earnings, savings, financial support from family and friends, support form NGOs and similar).
} 


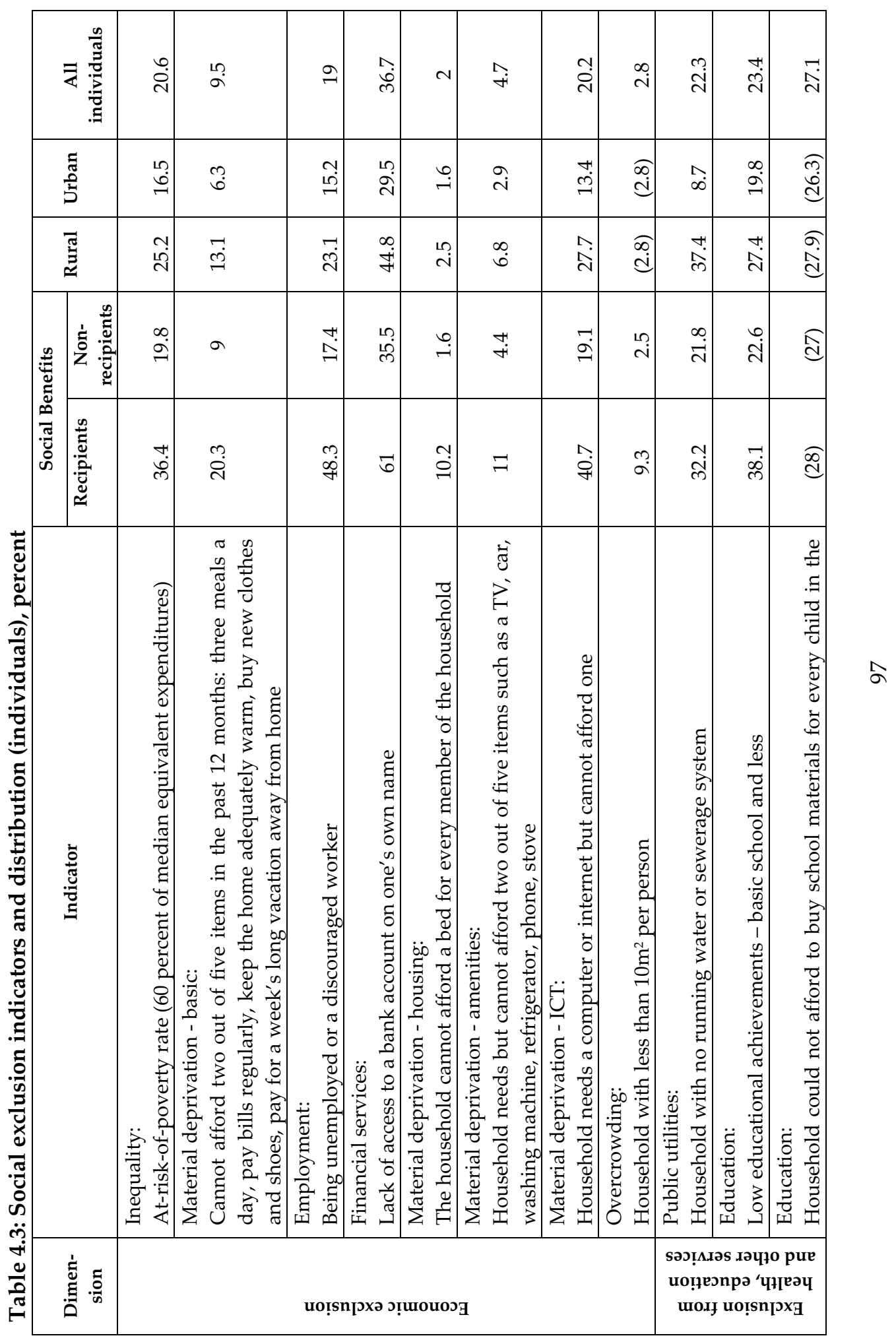




\begin{tabular}{|c|c|c|c|c|c|c|c|c|c|c|c|}
\hline & $\infty$ & $\approx$ & $\stackrel{\llcorner}{\underset{H}{H}}$ & $\frac{1}{4}$ & $\stackrel{\sigma}{\grave{N}}$ & $\stackrel{0}{\sigma}$ & $\stackrel{L}{\infty}$ & $\stackrel{1}{2}$ & + & $\stackrel{\infty}{\text { ஸे }}$ & กี \\
\hline & ตें & $\stackrel{\check{\sigma}}{\rightleftharpoons}$ & $\stackrel{\sharp}{\Lambda}$ & नें & $\stackrel{+}{+}$ & $\begin{array}{l}\infty \\
\stackrel{0}{-}\end{array}$ & $\begin{array}{l}10 \\
\infty \\
\infty\end{array}$ & $\begin{array}{l}-\infty \\
\stackrel{\infty}{0} \\
\stackrel{=}{0}\end{array}$ & 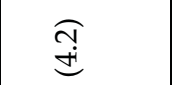 & 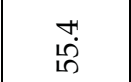 & $\stackrel{\overbrace{}}{\overbrace{}}$ \\
\hline & $\begin{array}{l}0 \\
\stackrel{0}{-}\end{array}$ & $\stackrel{\triangle}{+}$ & $\stackrel{1}{\mathrm{~N}}$ & $\begin{array}{l}\text { เి } \\
\text { டิ }\end{array}$ & $F$ & $\infty$ & $\begin{array}{l}\widetilde{10} \\
\infty \\
\infty\end{array}$ & $\begin{array}{l}\widehat{\Omega} \\
\stackrel{ }{=}\end{array}$ & $\begin{array}{l}\text { क्र } \\
\text { ल्र }\end{array}$ & $\stackrel{+}{\wedge}$ & 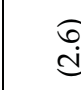 \\
\hline & $\stackrel{2}{\Lambda}$ & ब̊. & $\stackrel{\ddot{m}}{\oplus}$ & 尽 & $\stackrel{m}{\sim}$ & $\stackrel{\overparen{\sigma}}{\overparen{\sigma}}$ & $\underset{\infty}{\infty}$ & ڤ్ర & $\stackrel{n}{m}$ & రె & $N$ \\
\hline & $\begin{array}{l}0 \\
\infty \\
\rightarrow\end{array}$ & $\stackrel{\overparen{L}}{\stackrel{\rho}{\rightleftharpoons}}$ & $\begin{array}{l}\text { Lे } \\
\text { ले }\end{array}$ & 旅 & $\vec{m}$ & $\begin{array}{l}\widetilde{\sigma} \\
\stackrel{\oplus}{\rightleftharpoons} \\
=\end{array}$ & تُ & તิ & $\underset{0}{n}$ & $\stackrel{\infty}{\infty}$ & ڤे \\
\hline \multirow[t]{2}{*}{ 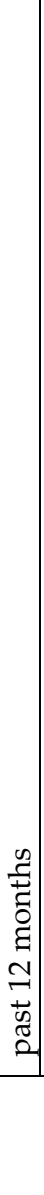 } & 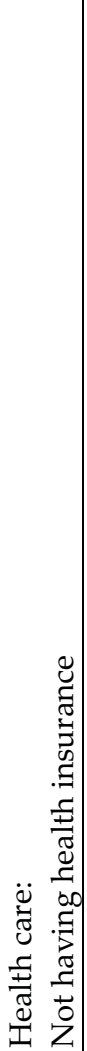 & 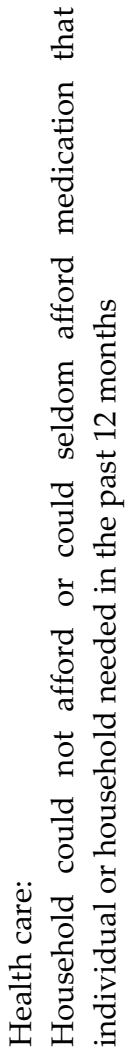 & 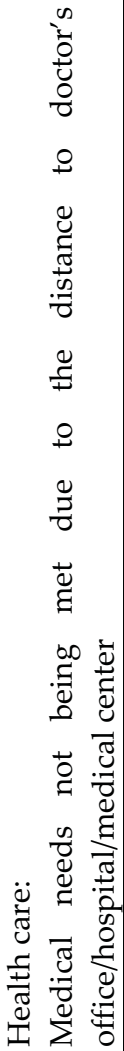 & 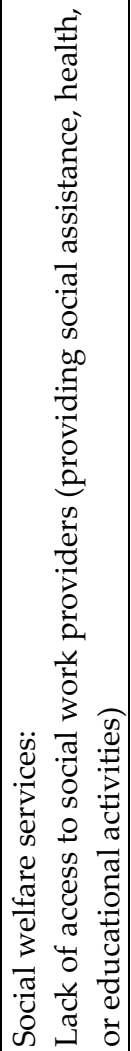 & 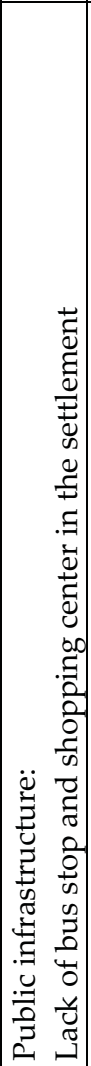 & 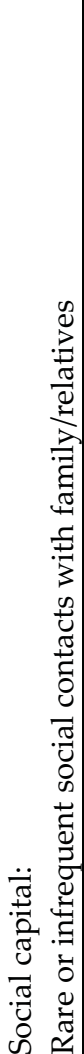 & 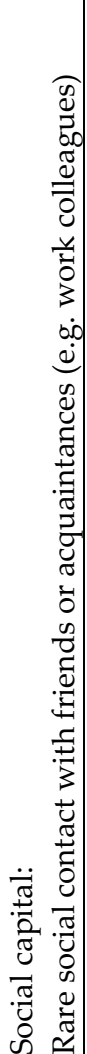 & 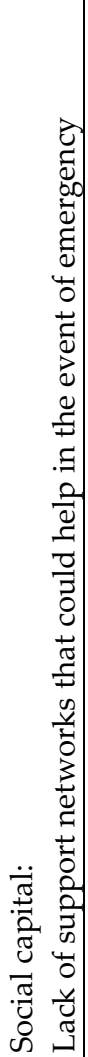 & 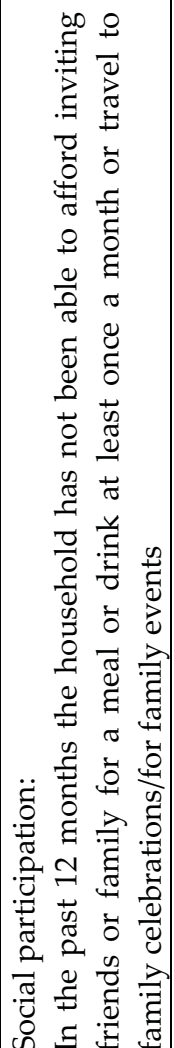 & 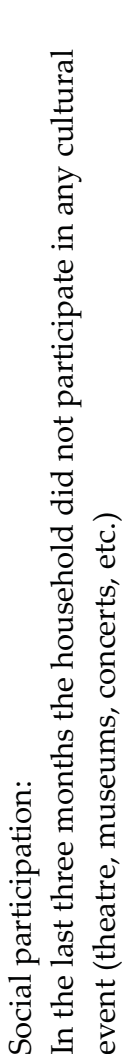 & 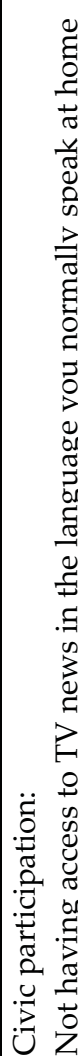 \\
\hline & & & & & & & & u u & 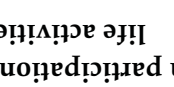 & woxy uo & $n_{\left[x x_{3}\right.}$ \\
\hline
\end{tabular}




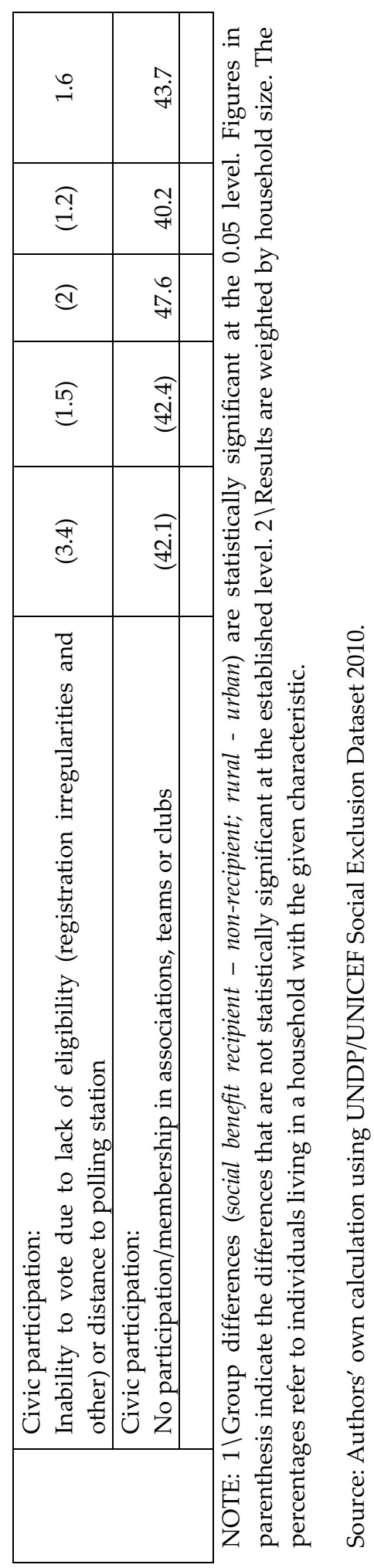


Indicators of economic exclusion show that more than 20 percent of surveyed individuals live in relative poverty. For the purpose of this analysis, relative poverty is defined as living in households where expenditures are below the threshold of 60 percent of median equivalent expenditures. We also note that the resulting poverty rate is significantly higher than the national relative poverty rate of 13.6 percent estimated on the basis of the Household Budget Survey (HBS) data (Republican Statistical Office, 2010). ${ }^{51}$ Nevertheless, this suggests that significant shares of individuals in Serbia live in households that are relatively poor. The headcount index of absolute poverty was 6.9 percent in 2009 (Republican Statistical Office, 2010). Relative poverty goes hand in hand with the deprivation situations. The data further suggest that living in rural or benefit recipient households increases the deprivation risk by almost two and three times respectively, except for the deprivation in housing indicators where rural and urban households do not differ substantially. Overall, Table 4.3 reveals much higher incidence of deprivation for social benefits recipients and people living in rural households. Across the board and except for some indicators in the exclusion from health, education, and other services dimension, social benefit recipients are worse off.

The incidence of exclusion in the dimension encompassing health, education and other services is highest, particularly for the people in rural households. For most indicators in this dimension, the incidence is well above 20 percent. Deprivation in a number of indicators is related to non-accessibility of running water, sewage, social services, public infrastructure and non-affordability of books. The level of exclusion from health care services is relatively low. Nonetheless, more than 8 percent of the surveyed population does not enjoy health insurance. Significantly higher shares of people in rural households do not have health insurance nor can they access health facilities easily due to the distance. Conversely, urban households struggle relatively more often to afford medication that the household needs.

In the domain of social and civic participation, people experience significant exclusion across three indicators. Lack of support networks that could help in the event of emergency should perhaps be observed in the context of rare and infrequent contacts with family and friends. The share of individuals excluded in the latter two indicators is significantly higher for the welfare recipients. The same applies to exclusion from networks that could help in the event of emergencies.

\footnotetext{
51 Both surveys use the relative poverty threshold that is established at the level of 60 percent of median expenditures per adult equivalent. However, the annual sample of HBS involves a larger sample of roughly 4,400 households. It collects detailed data on income and expenditures and as such is more representative. This means that relative poverty is overestimated in the UNDP/UNICEF survey.
} 
Overall, the surveyed individuals are largely excluded from participation in cultural events and membership in different types of associations. It appears that these two indicators are driving the results of the presented analysis. The high incidence rates indicate that non-participation may reflect a common lifestyle or individual preference and it raises the question of whether these two indicators of social and civic participation should be retained in the analysis. ${ }^{52}$

Generally, the group of social benefits recipients has much higher rates of deprivation and exclusion. Social benefit recipients receive the amounts of state financial transfers that hardly ever lift them and their households out of poverty. This leaves them with limited financial resources to spend. As expected, more than 36 percent of them are considered relative poor. Financial insufficiency causes their basic needs such as food, clothing, housing, and social interactions remain unmet. At the level of 20 percent, the incidence of basic material deprivation among social benefits recipients is 2.5 times higher than the average for all survey participants. Material deprivation in housing conditions show 4-5 times higher results. This puts them in need of greater support from different networks. However, in the case benefit recipients, support is often lacking.

The share of social benefit recipients who are considered deprived in the access to financial services is 61 percent compared to 37 percent on average, while 27 percent of them are excluded based on the lack of support networks. Paradoxically, those who are in greater need of social services, often find themselves unable to access social and health facilities. More than 50 percent of benefit recipients do not have access to social work providers due to the lack of providers. The same share does not access health facilities due to the distance. In this case, the rate of deprivation is twice higher than it is in general households. Besides, the share of benefit recipients excluded from health insurance is at disturbing 19 percent.

Low education and unemployment are significant determinants of social exclusion. The survey data revealed that 38 percent of social benefit recipients completed primary school or less. In general, the level of education is very low and the same measure for all individuals shows the rate of 23 percent. Similarly, at the level of 20 percent for all observed individuals and 48 percent among benefit recipients, it appears that unemployment leads to further deprivations and even more limited participation in civic and social activities.

\footnotetext{
52 If we exclude these two indicators of social and civic non-participation, the multidimensional index of social exclusion drops to under 5 percent for the cut-off threshold of 9 indicators. The decrease is relatively smaller for the subgroup of social benefit recipients for which the index decreases from 32 to 21 percent. We decided to keep these indicators to better reflect on the magnitude of exclusion faced by the most vulnerable group.
} 
Finally, the key patterns for members of different groups suggest that those living in rural areas and in social benefit recipient households are economically deprived and their utilization of health, education, and other services is principally low. As noted earlier, they are also constrained in the third dimensions and experience limited possibilities of participating in social and civic life. The presented results suggest that both sub-groups, particularly the social benefit recipients, appear rather vulnerable.

\subsubsection{Multidimensional index of social exclusion}

The construction of the multidimensional social exclusion index follows the approach described in the methodology section. The "socially excluded" are identified by counting the number of indicators in which a person is deprived. For the social exclusion index, the cut-off point is established at the level of 9 deprivations, allowing for the exclusion in at least 2 dimensions. Based on the data analysis for Serbia, 9.7 percent of the individuals are socially excluded in at least 9 indicators. Socially excluded persons face on average 10.6 deprivations out of 24 . Individuals living in rural areas have higher social exclusion rates (15.7 percent). However, the highest risk for multidimensional social exclusion have individuals living in social benefit recipient households. One out of three is excluded in at least 2 dimensions.

Figure 4.1: Social exclusion index for Serbia based on different cut-off thresholds $(8,9$, or 10 deprivations), total and by different groups, percent

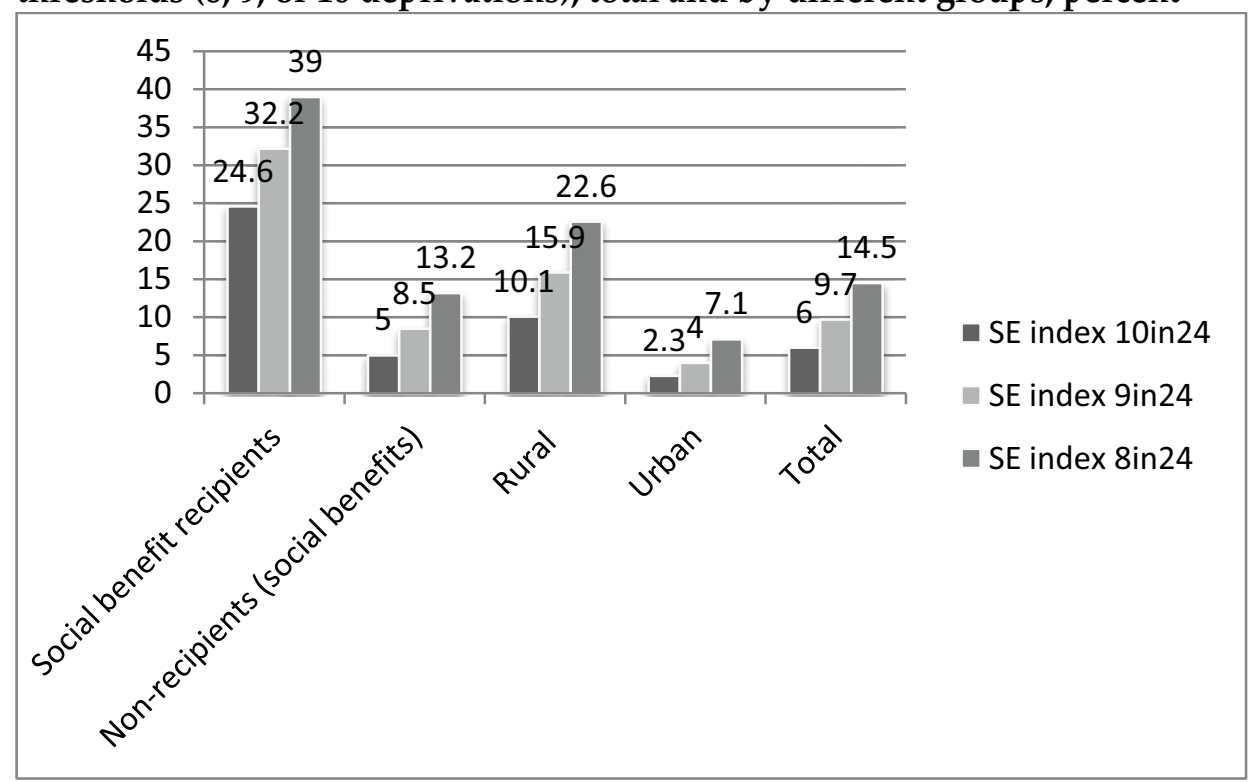

Source: Authors' own calculation using UNDP/UNICEF Social Exclusion Dataset 2010. 
As shown in Figure 4.1, setting the cut-off threshold at a different level immediately affects the level of social exclusion, but it does not change the group rankings. As such the results are robust to changes in cut-off thresholds.

Figure 4.2 presents the contribution of each dimension to the total score of deprivations (outer ring) and the social exclusion index (inner ring). In order to define the contribution of any single dimension to the overall index, we first calculate the number of those who are socially excluded and at the same time deprived in a given indicator. For each indicator, we then calculate its share in the total number of observations. These percentage contributions of the indicators comprising a given dimension are then summed to reflect the overall contribution of the dimension.

As suggested earlier, in terms of the number of deprivations per dimension, it is economic exclusion that contributes least in the total number of deprivations (28 percent). Exclusion from civic and social life contributes with 35 percent while exclusion from health, education, and other services contributes most (37 percent) to the total score of deprivations. If we, however, look at the contribution of each dimension to the overall social exclusion index, we find an even larger contribution of the exclusion from health, education, and other services dimension (40 percent).

Figure 4.2: The contribution of each dimension to the total score of deprivations (outer ring) and the social exclusion index (inner ring)

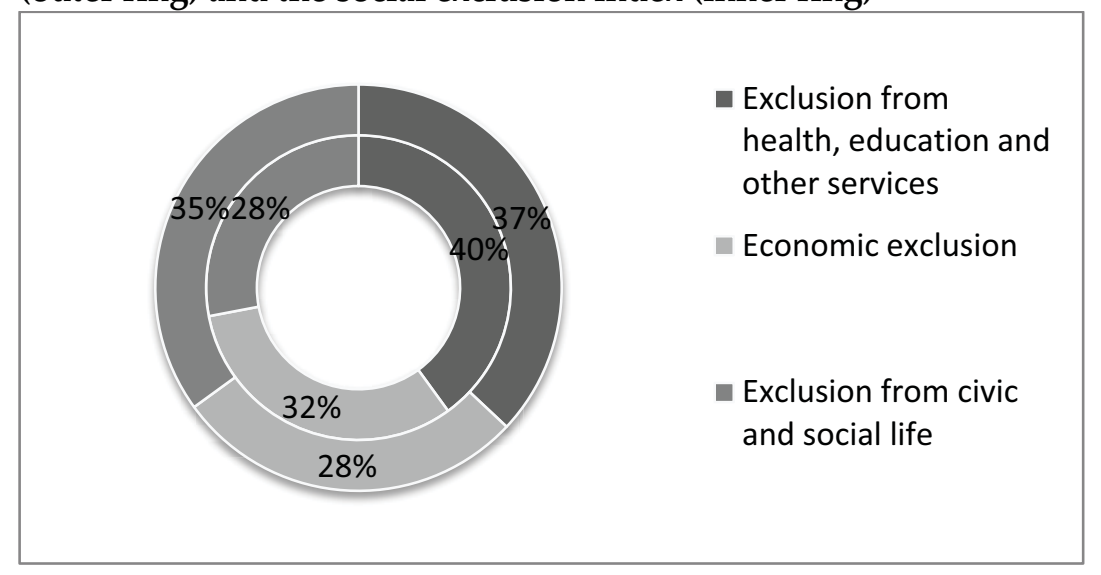

Source: Authors' own calculation using UNDP/UNICEF Social Exclusion Dataset 2010.

Economic exclusion is not the only contributing factor to social exclusion but it significantly impacts on the results. Its contribution in the overall social exclusion 
index for Serbia is 32 percent. While the results confirm that many people are excluded from civic and social life, the contribution of this dimension to the social exclusion index is smallest (28 percent). The presented results suggest that all three dimensions of exclusion should be jointly analyzed while some policy priorities should be given to the areas that contribute most to social exclusion.

\subsubsection{Monetary and non-monetary deprivation}

The discussion in the previous section confirms that economic exclusion alone is not able to explain social exclusion outcomes and that all three dimensions contribute to social exclusion to a varying degree. We also learned that insufficiency of resources, which belongs to the economic dimension, may lead to further deprivations and unmet needs. This, however, needs to be further explored. In this section we bring the analysis down to the level of specific indicators belonging to different dimensions and their overlaps. We investigate the link between monetary and non-monetary deprivations, but also whether monetary poverty can substitute for or even explain other social exclusion indicators.

The implicit assumption in the monetary approach to poverty is that individuals and households with income (or expenditures) above the poverty line can buy everything that is needed in order to meet their basic needs while those with money below the poverty line cannot. The first part of this assumption has often been criticized on the grounds of limited consumer sovereignty or supply constraints, particularly in developing countries (Roelen, Gassmann, \& de Neubourg, 2009b). In our analysis, we assume that not everything can be explained by lack of money. For example, people are monetary poor and labor market deprived (unemployed and discouraged) to the same extent if we consider each indicator separately (Table 4.3). The question is to what extent these two groups are overlapping. The aim of this section is to explore in more detail the links between the indicators of monetary and non-monetary-deprivation.

Table 4.4 provides information on monetary poverty incidence and the overlaps between non-monetary deprivations and monetary poverty.

The selection of indicators in Table 4.4 is based on the characteristics of those who are at greater risk of poverty in Serbia. Namely, they are highly unemployed and with low educational attainment (Matkovic et al., 2010, Republican statistical Office, 2008). The remaining three indicators of exclusion from services and social participation are chosen based on their relative importance and differing 
deprivation results across these indicators. The results are presented for the three groups under analysis. The third column in Table 4.4 indicates the overlaps between the selected non-monetary indicators and monetary poverty. The overlaps are rather limited and range between 24 percent and 46 percent for all individuals. For example, the share of individuals who report not having health insurance and who are at the same time monetary poor is 30 percent. For rural and social benefit sub-groups the overlaps raise up to 36 percent and 58 percent respectively

Table 4.4: Monetary and non-monetary deprivation (all individuals), percent

\begin{tabular}{|c|c|c|}
\hline Social exclusion indicator & $\begin{array}{c}\text { Share of } \\
\text { individuals } \\
\text { who are } \\
\text { deprived }\end{array}$ & $\begin{array}{c}\text { Share of } \\
\text { individuals } \\
\text { who are also } \\
\text { monetary poor }\end{array}$ \\
\hline \multicolumn{3}{|l|}{ Total } \\
\hline Monetary poverty & 21 & 100 \\
\hline No health insurance & 8 & 30 \\
\hline Lack of access to social work providers & 47 & 24 \\
\hline Low educational achievements & 23 & 32 \\
\hline Being unemployed or a discouraged worker & 19 & 24 \\
\hline Not inviting friends or family nor attending family events & 4 & 46 \\
\hline \multicolumn{3}{|l|}{ Rural } \\
\hline Monetary poverty & 25 & 100 \\
\hline No health insurance & 11 & 27 \\
\hline Lack of access to social work providers & 60 & 27 \\
\hline Low educational achievements & 27 & 34 \\
\hline Being unemployed or a discouraged worker & 23 & 26 \\
\hline Not inviting friends or family nor attending family events & 4 & 63 \\
\hline \multicolumn{3}{|l|}{ Social benefit recipients } \\
\hline Monetary poverty & 36 & 100 \\
\hline No health insurance & 19 & 41 \\
\hline Lack of access to social work providers & 50 & 42 \\
\hline Low educational achievements & 38 & 36 \\
\hline Being unemployed or a discouraged worker & 48 & 42 \\
\hline Not inviting friends or family nor attending family events & 10 & 58 \\
\hline
\end{tabular}

Source: Authors' own calculation using UNDP/UNICEF Social Exclusion Dataset 2010. 
Further in our analysis is the explanation of the importance of lack of money for selected indicators representing each of the three dimensions of social exclusion. We run binary logistic regression for five dependent variables referring to:

i) the health insurance status,

ii) social participation,

iii) the possession of a bank account,

iv) having a support network in case of emergency, and

v) basic material deprivation. ${ }^{53}$

The odds ratios and levels of significance are reported in Table 4.5. Full regression analyses output tables are provided in the Appendix 4 of this chapter.

First, we perform direct logistic regression to assess the impact of the number of factors, including monetary poverty, on the likelihood that respondents would report not having health insurance. The dependent variable is categorical and takes the values of 1 (not having health insurance) and 0 (having health insurance). The model contains 12 independent or predictor variables, all except one (household size) being binary variables (Table 4.5).

With regard to the first regression, seven independent variables made a unique statistically significant $(\mathrm{p}<.05)$ contribution to the model. The strongest predictor of reporting lack of health insurance is unemployment, recording odds ratio of 4.4. This indicates that respondents who are unemployed are more than 4 times more likely to report not having health insurance than those who are employed, controlling for all other factors in the model. Other types of activity such as home work or temporary or permanent inactivity and basic material deprivation, with odds ratios of 2, are also powerful predictors of not having health insurance. Similarly, individuals living in rural households and those with primary education or less are 1.5 times more likely to report the lack of health insurance. The odds ratios of 0.18 for the retired persons is less than 1 , indicating that those respondents are less likely to report the same result, if we take into account all other factors.

\footnotetext{
${ }^{53}$ In the applied Forced Entry Method approach, all predictor variables have been tested in one block. This applies to all five regression models. The full models containing all predictors are statistically significant.
} 
Table 4.5: The predictors of reporting deprivation across five areas and recorded odds ratios

\begin{tabular}{|c|c|c|c|c|c|}
\hline Variable & $\begin{array}{l}\text { no health } \\
\text { insurance }\end{array}$ & $\begin{array}{l}\text { no social } \\
\text { participation }\end{array}$ & $\begin{array}{l}\text { no bank } \\
\text { account }\end{array}$ & $\begin{array}{l}\text { no help in } \\
\text { emergency }\end{array}$ & $\begin{array}{l}\text { basic } \\
\text { material } \\
\text { deprivation }\end{array}$ \\
\hline Rural & $1.486^{* *}$ & $0.652^{*}$ & $1.332^{* * *}$ & $0.806^{*}$ & $1.85^{* * *}$ \\
\hline (ln)household size & 0.95 & $0.296^{* * *}$ & $1.36^{* * *}$ & 0.849 & 0.825 \\
\hline Child in household & 0.683 & $2.133^{* *}$ & 0.924 & 0.884 & 0.87 \\
\hline Elderly in household & 0.765 & 0.827 & 1.177 & $1.537^{* * *}$ & $1.855^{* * *}$ \\
\hline $\begin{array}{l}\text { Primary education or } \\
\text { less }\end{array}$ & $1.485^{* *}$ & $1.683^{* *}$ & $2.699^{* * *}$ & $2.111^{* * *}$ & $1.652^{* * *}$ \\
\hline $\begin{array}{l}\text { Post-secondary } \\
\text { education }\end{array}$ & 0.91 & 0.538 & $0.447^{* * *}$ & $0.573^{* * *}$ & 0.678 \\
\hline Unemployed $^{* * * *}$ & $4.428^{* * *}$ & $2.973^{* * *}$ & $5.584^{* * *}$ & $1.956^{* * *}$ & $2.014^{* * *}$ \\
\hline Retired $^{* * * *}$ & $0.184^{* * *}$ & $2.747^{* * *}$ & 0.964 & $1.582^{* * *}$ & $1.672^{* *}$ \\
\hline $\begin{array}{l}\text { Other (home work or } \\
\text { temporary or permanent } \\
\text { inactivity) }\end{array}$ & $2.04^{* *}$ & $2.742^{* *}$ & $3.491^{* * *}$ & 1.135 & 1.603 \\
\hline Social assistance receipt & 1.184 & $1.907^{*}$ & 1.258 & 1.31 & $1.885^{* *}$ \\
\hline $\begin{array}{l}\text { Basic material } \\
\text { deprivation }\end{array}$ & $1.971^{* * *}$ & $3.265^{* * *}$ & $1.52^{* * *}$ & $1.895^{* * *}$ & \\
\hline Being at-risk-of-poverty & $1.563^{* *}$ & $1.833^{* *}$ & $1.504^{* * *}$ & $1.467^{* * *}$ & $1.463^{* *}$ \\
\hline Constant & 0.045 & 0.037 & 0.18 & 0.136 & 0.044 \\
\hline Cox Snell R square & 0.075 & 0.057 & 0.201 & 0.083 & 0.058 \\
\hline Nagelkerke R square & 0.175 & 0.199 & 0.274 & 0.138 & 0.123 \\
\hline $\begin{array}{l}\text { Percentage of cases } \\
\text { correctly classified }\end{array}$ & 91.9 & 96 & 72.9 & 82.8 & 90.5 \\
\hline Number of observations & 2401 & 2401 & 2401 & 2401 & 2401 \\
\hline
\end{tabular}

NOTE: ${ }^{*}$ significant at $10 \%,{ }^{* *}$ significant at $5 \%,{ }^{* * *}$ significant at $1 \%$

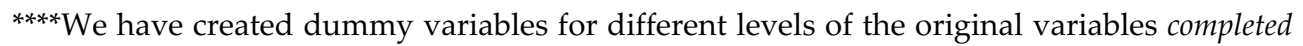
education and activity status. The levels that are not coded are secondary level education and employed respectively. These are the categories to which all other categories are compared.

Source: Authors' own calculation using UNDP/UNICEF Social Exclusion Dataset 2010.

In the next model we examined the effect of certain factors on the likelihood of reporting lack of social participation. The lack of social participation assumes that the household was not able to afford inviting friends or family for a meal or drink at least once a month or to travel to family celebrations or family events. The most powerful predictor of reporting this type of non-participation is basic material 
deprivation. The data suggest that the respondents who are materially deprived are almost 3 times more likely to report not participating in different events with family and friends than those who are not deprived, controlling for all other factors. As in the previous model, those who are the unemployed, retired, home workers or other rather inactive population are much more likely to report not having the aforementioned types of social interaction. For example, the unemployed are almost 3 times more likely to be excluded from social participation. So far, the status of unemployment appears to be the strongest predictor of deprivation across other areas, if we control for all other variables in the models. Further analyses reveal that the unemployed are more than 5 times more likely to report the lack of a bank account and 2 times more likely to report basic material deprivation or not having support in case of emergency.

The remaining two variables with generally significant predictive power concern different households' characteristics. Interestingly, the presence of a child in the household does not increase social participation of the same household. On the contrary, those who have one or more children in the household are 2 times more likely to report the lack of social participation. On the other side, the odds ratio of 0.3 for the household size indicates that for every increase in household size respondents are less likely to report not participating in social events with their families and friends. It is then possible that rather large households involve in greater interactions with family and friends.

In this section of the analysis we pay particular attention to the role of monetary poverty in assessing the chances to report deprivation in other areas. With the odds ratio of 1.6, the at-risk-of-poverty indicator is able to predict the lack of health insurance pretty well. This indicates that those who are monetary poor are 1.6 times more likely to report not having health insurance, if we control for all other variables. When this measure of relative poverty (based on expenditures) was replaced by the equivalent household expenditures it turned out that with an increase in equivalent household expenditure the respondents are 0.6 times less likely to report the absence of health insurance. Both money-metric measures appear to play an important predictive role. Additionally, those who are poor are 1.8 times more likely to report lacking social participation. Similarly, the relative poor are 1.5 times more likely to report deprivation in accessing financial services/having a bank account, emergency help, as well as basic material deprivation.

The findings on the predictive importance of monetary poverty suggest that being at-risk-of-poverty predicts well the deprivations in other areas, but it does not appear to be the strongest predictor variable in the analyzed models. Clearly, while monetary poverty has certain predictive ability, it is actually the status of being 
unemployed that powerfully increases the likelihood of deprivation across the other areas. Therefore, besides addressing monetary poverty, tackling unemployment is perhaps the key to reducing deprivation in particular areas and as such an interesting topic for further research.

Earlier in this section we concluded that the overlap of individuals being deprived in any of the listed non-monetary indicators and being monetary poor rarely goes beyond 50 percent (Table 4.4). This indicates that policies targeted to those who are monetary poor might not cover a significant share of people who are simultaneously experiencing deprivation in non-monetary areas. When we couple this information with the later finding on the strong predictive power of unemployment, we conclude that any discussion on policy responses requires attention to both financial security and labor market integration. More generally, the limited overlaps between indicators, their diverse and significant predictive ability, and group specificities call for policy responses that need be carefully and cross-sectorally designed or, at least, greatly coordinated in order to cover all those areas impacting on social exclusion outcomes.

\subsection{Conclusion}

The primary aim of the chapter was to develop a context-specific social exclusion index by analyzing the case of Serbia. This required a careful deliberation about social exclusion dimensions and relevant indicators. The analysis was further enriched by gaining insights in how much each of the dimension contributes to the overall index of social exclusion. At the level of individual indicators, we examined the link between monetary and non-monetary deprivations and the importance of monetary poverty in the explanation of different deprivations. Within this context we paid particular attention to the sub-group of social benefit recipients who are traditionally more at risk of poverty and exclusion.

The conceptual underpinnings for this chapter were found in the approaches of multiple deprivation and multidimensional poverty. In the process of building the multidimensional index of social exclusion, the initial steps involved the selection of 24 indicators for each of the 3 dimensions of social exclusion. Our choice of indicators was guided by the established set of nationally defined indicators for Serbia. In our view, this was necessary since deprivations are shaped by different social-economic contexts and various country-specific determinants at work.

The resulting measures of social exclusion come from a simple count of the number of deprivations that an individual is experiencing. The individual is 
multidimensionally excluded if he or she is deprived in at least 9 indicators or 2 dimensions. The findings show that almost 10 percent of persons in Serbia are socially excluded. Additionally, the results are presented for four groups urban/rural and social benefit recipient/non-recipient people. They confirm relatively higher levels of exclusion for individuals living in rural and benefit recipient households. The benefit recipients appear to be particularly vulnerable. The main characteristics of this group, forms of their exclusion, and the possibility for their greater inclusion in the society are further explored in Chapter 5.

Additional findings of our analysis show that while exclusion from health, education, and other services contributes most to the overall social exclusion all three dimensions play significant role in the explanation of exclusion. The analysis of the link between monetary and non-monetary deprivations reveals that the overlaps are of rather limited magnitude, which indicates that different facets of social exclusion cannot be solely explained by the lack of money. Furthermore, the analysis of the relative importance of specific predictor variables confirms that while monetary poverty plays important role it is actually the status of unemployment which significantly increases the likelihood of deprivation in other areas. Together, these findings have important policy implications calling for crosssectoral measures to address social exclusion in Serbia. One such policy option is discussed in the next chapter. 


\section{CHAPTER}

Addressing Social Exclusion through Work Activation:

Taking into Account Subjective Well-Being of Social Assistance

Recipients $^{54}$

\subsection{Introduction}

The study has so far highlighted a number of aspects related to social exclusion. Since our focus is on social benefit recipients, the extent, and areas of their deprivations, as well as the possibilities for their greater inclusion, in this chapter we extend our scrutiny of this group - its socio-economic characteristics and positions in the labor market. We also put forward the application of subjective well-being (SWB) measures in the analysis of the effects of a specific public policy. We believe that subjective assessments of the quality of life may have significant impact on people's lives, their integration in the society, and decision makers' responses.

The program under analysis is the Public Works Program in Serbia. We explore whether and how activation of social assistance recipients through public works impacts on their subjective well-being. Additionally, we explore the link between SWB outcomes and social inclusion. Taking into account the findings from previous analyses focusing on Serbia (Bonin \& Rinne, 2006; Arandarenko \& Krstic, 2008; Petrovic, 2011; Petrovic, 2013), complemented with the results of the analyses presented in Chapters 2 through 4 of this thesis, we reveal to what extent the work activation provides better social inclusion outcomes for social assistance recipients.

SWB refers to people's assessments of their lives and includes both measures of cognition and measures of affect. Perceptions of well-being appear to be more complex than what is captured by objective indicators identified in relation to societal contexts (Diener \& Suh, 1997). For example, forced unemployment is bad for social assistance recipients who are capable to work and labor market indicators will indicate the kind and extent of it. In contrast, from a subjective wellbeing perspective it would be important to know whether and how individuals' moods and life satisfaction are affected by the state of employment or

\footnotetext{
${ }^{54}$ Based on two separate studies that have been published as Petrovic, M. (2013). Subjective Well-Bing, Activation Policies, and the Inclusion Agenda. In C. Ruggeri Laderchi \& S. Savastano (Eds.), Poverty and Exclusion in the Western Balkans - New Directions in Measurement and Policy (117-132), New York: Springer and Petrovic, M. (2011). Social Assistance and activation: In search of inclusive policy options, Belgrade: CLDS/MDG Achievement Fund.
} 
unemployment, which in turn may explain some of their actions. In sum, both kinds of measures are needed to understand human well-being and to make informed policy decisions.

There is a considerable amount of work on the topic of subjective well-being both in psychology and economic science (see Diener ,1984; Diener, Suh \& Oishi, 1997; Frey \& Stutzer, 1999, 2002; Layard, 2006; Van Praag \& Ferrer 2004; Veenhoven, 1991, 2000, 2004; Kahneman \& Krueger 2006). Despite an extensive literature on poor people's perceptions of poverty, particularly in low income countries (e.g. the comprehensive Voices of the Poor study by Narayan et al. (2000), ) and the work of the Well-being in Developing Countries Research group (Camfield, 2006), the subjective well-being of the poor and socially excluded has been largely absent in theoretical discussions and research explanations of poverty and social exclusion in the European context. This study starts bridging this gap by focusing on the perceptions of able-bodied working age social assistance beneficiaries about the effects of their public work engagement.

The findings of our study indicate that work experience is beneficial for the participants even if it does not lead to their immediate employment. For example, the participation in the public work program increases the participants' employability judged by the level of "qualifications and skills" and "chances for employment". It also reduces the mental cost of being unemployed and increases the participants" "self-confidence" and "social contacts". We find these findings important for understanding the role of activation in the social inclusion agenda.

The chapter is structured as follows. We first present the approaches to determining individuals' quality of life i.e. their well-being or ill-being. Next, we place the overall discussion in the context of work engagement of social assistance recipients through Public Works Program in Serbia. In the subsequent section, we discuss different approaches to measuring subjective well-being of the unemployed poor. We further analyze the subjective well-being outcomes and highlight specific conditions that impact on recipients' better integration in the labor market and society in general. This is covered in the sections discussing the linkages between SWB, employability, and social inclusion. Finally, we offer the summary presentation of findings and discuss possible policy implications.

\subsection{Conceptualizing subjective well-being}

Providing a better understanding of different aspects of social exclusion is important, but it should not be viewed as the end-goal (Sen, 2000). Similarly, 
reducing social exclusion does not necessarily improve the people's life. What is often missing in the reviews of social exclusion literature is the whole discussion on enhancing the quality of life while improving social inclusion outcomes.

There are several philosophical approaches to determining individuals' quality of life. For example, normative ideals such as religious or philosophical systems (Diener \& Suh, 1997) can determine the characteristics of a good life. The approach dominant in economic thinking is based on utility and satisfaction of preferences. A different approach, rooted in behavioral science, defines quality of life in terms of people's experience of their subjective wellbeing (SWB). The forthcoming discussion of dimensions of subjective well-being of social assistance recipients has clearly been absent in theoretical discussions and research explanations of poverty and social exclusion.

As earlier noted, Sen (2000) argues for the need for people to be given capabilities or opportunities to lead a decent life. He also points out that for both individuals and households the way the capabilities are transformed into values may differ. He makes a distinction between "capabilities" and "functionings" (what people actually do and experience and which constitute "capability"). However, he avoids offering a detailed account of substantial values which would operationalize his approach. This is, however, done by the prominent theorist Martha Nussbaum (2001) who provided a list of separate values or ten basic capabilities that should be applicable to all democracies. These include the following areas: life; bodily health; bodily integrity; imagination, senses, and thought; emotions; practical reason; affiliation; other species; play, and, control over one's environment. And while Nussbaum's list has been contested by Sen (2005) on the grounds of its precision or weighting which should be context-specific, her approach points to a number of values which we would expect to describe (subjective) well-being.

There has been a long and non-conclusive discussion about 'domains' or 'dimensions' of subjective well-being (Alkire, 2002). In our study, we focus on the most critical dimensions of subjective well-being of the unemployed poor. Towards that end, we rely on rather conventional definition of dimension. Dimension is usually defined as one of the constituting aspects of a given situation, in this case subjective well-being, which co-exists with other aspects.

Although the literature recognizes numerous lists of well-being, values, and human needs, those have been developed in response to varying theoretical and empirical questions (see for example Alkire 2002 for a comprehensive discussion on different approaches). For the purpose of our study, the discussion focuses primarily on two relevant pioneering studies of subjective well-being. One defines 
the 'domains' of subjective well-being (Cummins, 1996) and the other the personal assessments of the poor people (Narayan et al., 2000).

In order to define seven domains of subjective well-being, Cummins (1996) surveyed theoretical and empirical literature on the 'quality of life'. The seven domains included material well-being, health, productivity, intimacy/friendship, emotional well-being, safety, and community. The question relating to subjective well-being would usually ask how satisfied is the person with 'domain', referring to material well-being, health, social ties, and similar. Cummins identified 1,500 articles relating to 'quality of life' and subsequently developed five criteria for the inclusion of the data on quality of life for the study. The selected 32 studies yielded 173 names of 'domains' for the indicators of 'quality of life'. Finally, each of the named domains was classified into one of his seven domain categories for the general population presented in Table 5.1.

In their cross-cultural study of the values of 20,000 poor people only, Narayan et al. (2000) explored how the poor define poverty and wellbeing. The analysis focused on how people define well-being or a good quality of life and ill-being or a bad quality of life. Particular aim was to understand poor people's definition of wellbeing, but also their understanding of the concept of vulnerability, risk, and social exclusion. Without surprise, the poor defined 'well-being' as multidimensional phenomenon in a similar vain to Cummins' (1996) understanding of subjective well-being. The qualitative analysis under the study resulted in the defined components of 'well-being' and 'ill-being' that are common across 23 countries. According to this study, well-being has been divided into following components: material, bodily, social, and psychological well-being, security, and freedom of choice and action. ${ }^{55}$

Concerning the SWB dimensions of the unemployed poor, it appears that specific definitions of the poor people's subjective well-being or ill-being relating to various life domains have been rarely described in the academic literature. Bonin and Rinne (2006) made an attempt in that regard.

\footnotetext{
55 According to the same source, the components of ill-being as perceived by the same respondents included: material lack and want, physical ill-being, bad social relations (exclusion, rejection, isolation and loneliness), insecurity (vulnerability, worry and fear), powerlessness and helplessness, and psychological ill-being (humiliation, shame, anguish and grief).
} 
Table 5.1: Dimensions of subjective well-being (SWB)

\begin{tabular}{lll}
$\begin{array}{l}\text { Domains of SWB } \\
\text { (Cummins, 1996) }\end{array}$ & $\begin{array}{l}\text { Well-being according to the Voices } \\
\text { of the Poor (Narayan et al., 2000) }\end{array}$ & Dimensions of SWB ${ }^{56}$ \\
\hline Material well-being & $\begin{array}{l}\text { Material well-Being: Having enough } \\
\text { - Food } \\
\text { - }\end{array}$ & Fssets \\
& - Work
\end{tabular}

Health

Productivity

Intimacy/Friendship

Emotional well-being

Safety

Community

Bodily well-being: being and appearing well
Health status

Personal qualifications and skills

Desire to find a job

Chances to find a regular job

Social contacts

Social well-being

- Being Able to Care for, Bring up, Marry and Settle Children

- Self-Respect and Dignity

- Peace, Harmony and Good Relations in the Family and the

- Community

Psychological well-being: Peace of Mind, Happiness and Harmony

Security

- Civil Peace

- A Physically Safe and Secure Environment

- Personal Physical Security

- Lawfulness and Access to Justice

- Security in Old Age

- Confidence in the Future

Self-confidence

Freedom of choice and action

Source: Own adaptation based on Cummins (1996), Narayan et al. (2000) and Bonin and Rinne (2006).

${ }^{56}$ Based on Frey \& Stutzer (2002) defined items of personal happiness; Adapted by Bonin \& Rinne (2006) for the study of the disadvantaged participants of active labor market program 
Table 5.1 shows subjective well-being dimensions as defined by Bonin and Rinne (2006). They judged the effects of a specific active labor market program on measures of subjective well-being involving the following dimensions: family income situation, health status, personal qualifications and skills, desire to find a job, chances to find a job, social contacts, and self-confidence. The program under evaluation was the Beautiful Serbia program, an ad hoc public-work type of operation supported by the Government of Serbia and donors, which provided training and temporary employment to disadvantaged population. Given its relevance, the Bonin and Rinne's (2006) approach has been adopted to guide our analysis of subjective well-being outcomes of social assistance recipients who participated in the government's public works program.

\subsection{Context: Linking social assistance with public works}

The existing literature suggests that public works programs are usually designed to make income transfers in return for work done. They have two distinct types of impact: income transfers in return for services provided by unskilled workers who are employed and, most often, infrastructure construction or rehabilitation (Datt \& Ravallion, 1994; Devereux, 2002; Subbarao, 1997). The most common targeting technique used for these programs includes self-targeting - the benefit is set low so that only the poorest are attracted to take up employment. Usually, such targeting methods help reduce leakages and help increase coverage but where poverty is related to structural causes such as exclusion of certain ethnic groups, this method may not be the most adequate in reaching the poorest. Theoretically, wage rates are set low to facilitate self-targeting and greater number of beneficiaries.

As a rather new government-run program, the Serbian Public Works Program is set as a conventional public work activity with most of the features described above. ${ }^{57}$ The program targets 'hard-to-place' categories of the unemployed who are registered at the national employment agency and aims at increasing their employability and employment. Note however that in addition to providing employment, public work programs have additional objectives such as increasing participants' competitiveness in the labor market, gaining additional knowledge

\footnotetext{
${ }^{57}$ The program was introduced in 2006 and since then it provided temporary employment and low pay to around 5,000 individuals yearly. Those were the neediest unemployed who are primarily unskilled workers. The targeting method involved self-targeting but also a purposeful inclusion of the poor representatives of the Roma minority as a measure of their social inclusion. The pay rate was set at the level of the minimum wage. The programs also entailed learning component in the form of off- and on-the-job training. Training and work components combined lasted between 6 and 12 months.
} 
and skills, and mitigating negative consequences of participants' socio-economic status. These objectives are officially adopted by the government, as such integrated in the public works program, and can be easily seen to aim to increase the "employability" of beneficiaries.

Social assistance recipients were one but not the only group targeted by the public works program. ${ }^{58}$ In our study, social assistance refers to the Financial Social Assistance (FSA) program - "materijalno obezbedjenje" or "novcana socijalna pomoc $^{\prime \prime 9}$ - run by the Government of Serbia ${ }^{60}$. The FSA is the main guaranteed minimum income program in the country and it is aimed at individuals and households with an income below the administratively established social welfare threshold. The main characteristics of the Serbian social assistance program and its beneficiaries are presented in the Appendix 5.

In 2008, the year to which our analysis refers, 263 projects were approved by the Government which enabled employment for 5,315 individuals (Vlada Republike Srbije, 2009). Project activities covered three broad areas: social, humanitarian, and cultural activities; public infrastructure; and environment protection projects. A total of 650 million dinars or 0.02 percent of GDP was allocated by the Government for these activities. The overall expenditure on active labor market programs, of which public works were only a small part, comprised only 0.1 percent of GDP. The study analyzing the impact of the public works program estimated that as low as 1.4 percent of all participants turn out to be employed six months after the termination of the program (Arandarenko \& Krstic, 2008). In terms of social assistance recipients' involvement and their employment prospects, the outcomes were no different and maybe even worse. For them, the public work activity represented a temporary income-support program. On the positive side, it was a rare opportunity for them to involve in any kind of formal employment.

It is paradoxical that without work experience social assistance beneficiaries hardly get a job, yet without employment they cannot gain any experience when their activation is low on the agenda. ${ }^{61}$ Judging from the pure economics perspective, their labor market integration and social inclusion prospects are grim. However, this is not always the case and hardly the only truth. This chapter seeks to explore

\footnotetext{
${ }^{58}$ The program also included the disadvantaged groups such as the Roma, refugees, youth, the disabled, women, persons older than 50, and other long-term unemployed.

${ }^{59}$ New term in use since April 2011.

${ }^{60}$ It is financed and delivered by the Ministry of Labor and Social Policy through the Centers for Social Work (CSWs).

${ }^{61}$ In 2008, the Public Works Program was the only official program involving the activation of social assistance beneficiaries.
} 
personal experiences of public work participants and explain various dimensions and measures of well-being.

\subsection{Measuring subjective well-being of deprived groups}

The literature presents two broad approaches to the analysis of subjective wellbeing. One is to focus on summary measures of wellbeing, generally captured by single-item or multiple-item questions in surveys. Single item questions on life satisfaction or happiness are usually framed as following: "Taking things all together, how satisfied/happy are you with your life these days?" Individuals' satisfaction may also be captured by multiple-item questions. Box 5.1 shows examples of questions used in both types of approaches. Usually, the respondents are asked to grade the level of their satisfaction/happiness on a scale, for example, from 1 to 5 or 1 to 7 (Diener et al., 1997).

\section{Box 5.1: Examples of questions related to life satisfaction or happiness}

The University of Michigan's Survey Research Center (SRC) and the National Opinion Research Center (NORC):

Taken all together, how would you say things are these days - would you say that you are very happy, pretty happy, or not too happy?

The World Value Survey:

Taken all together, how happy would you say you are: very happy, quite happy, not very happy, not at all happy?

Eurobarometer Survey:

On the whole are you very satisfied, fairly satisfied, not very satisfied, or not at all satisfied with the life you lead?

Satisfaction With Life Scale (introduced by Ed Diener et al (1997).; answers rated on a scale 1-7 from "strongly agree" to "strongly disagree"):

In most ways my life is close to ideal.

The conditions of my life are excellent.

I am satisfied with my life.

So far I have gotten the important things I want in life.

If I could live my life over, I would change almost nothing. 
Alternatively, different domains over which SWB is defined are identified, and those are analyzed separately. As already noted, Cummins (1996) surveyed theoretical and empirical literature on the quality of life to identify the relevant domains for an analysis of the general population. The seven domains he identified included material well-being, health, productivity, intimacy/friendship, emotional well-being, safety, and community (Table 5.1). In his approach questions relating to subjective well-being would usually ask how satisfied one person is with 'domain'. In our study we follow this second approach since it appears to be the most useful in providing policy relevant information on the performance of a specific policy program, though we tailor it to the specific group of respondents we have in mind.

The literature offers limited examples of SWB analysis for subgroups of the population. A notable exception is a study by Bonin and Rinne (2006), focusing on SWB of disadvantaged groups. They evaluated the effects of a specific active labor market program based on its impact on measures of subjective well-being of the beneficiaries. Building on the Frey and Stutzer's (2002) discussion of items of personal happiness and the psychic and social cost associated with unemployment, Bonin and Rinne (2006) developed a set of domain measures for assessing subjective well-being outcomes (Table 5.1). These include family income situation, health status, personal qualifications and skills, desire to find a job, chances to find a regular job, social contacts, and self-confidence. Answers are rated on a scale: strongly improved, somewhat improved, stayed more or less the same, somewhat deteriorated, strongly deteriorated. The responses in the Bonin and Rinne's (2006) study were captured in a survey.

The analysis presented in this study uses a variant of Bonin and Rinne's (2006) approach which has already been applied in Serbia. However, we implement it through qualitative tools or, more specifically, through in-depth interviews. While the most frequent method of measuring SWB is through survey analysis it was not possible in this case as there were no survey data available nor it was possible to carry out an ad hoc survey due to budget and time constraints. Instead, the respondents' judgments have been captured in face-to-face interviews. We wanted to be able to distinguish individual perceptions about different changes in their lives and for this reason we opted for in-depth interviews rather than focus groups. We assumed that the focus group format would add little over individual interviews if not all the participants would actively engage in the discussion. We found that social assistance recipients would not feel comfortable talking openly in a group about their family or income situations nor they would be free to express their feelings in a group setting. 


\subsection{Data and Method}

Data for this study come from the qualitative analysis of semi-structured in-depth interviews with social assistance recipients and other disadvantaged people who participated in two separate public works projects in 2008. In total, 26 interviews were conducted. The presented analysis is part of a broader qualitative study on social assistance recipients' experiences with work engagement through public works. ${ }^{62}$

In order to focus and streamline the data gathering process, the study benefited from pre-structured qualitative data collection and analysis. The research questions were well specified prior to the field work. The case outline, including conceptual framework and a defined set of specific questions with regard to subjective wellbeing dimensions, had been developed and included in the in-depth interview guide before any data were collected. ${ }^{63}$ A purposive sample was applied in the selection process. In line with Berg's (1998) reasoning, this strategy required special knowledge and expertise about a certain group under investigation. Since time for the data collection was limited, advanced planning for respondents' selection and within-case sampling was necessary. Access to the public works participants was ensured through the official government registry.

To ensure territorial diversity in terms of geographical location, size of the town and its level of development, but also the diversity in types of public work activities performed, the interviews were carried out in two towns: Ada (Vojvodina province) and Kragujevac (Central Serbia). In both towns public work activities were planned and implemented in close cooperation of local authorities, public firms, and non-governmental organizations. The public work activities in Ada included mainly infrastructure and environment protection projects. The activities in Kragujevac focused more on provision of social services, namely, the types of care provision that could be performed in the homes of service beneficiaries - the, so called, home care services.

In total, 26 in-depth interviews were conducted - 20 with social assistance recipients and 6 with non-recipient participants. There were 15 women and 11 men among the respondents from different backgrounds: urban, semi-urban, rural, and Roma settlements. The age ranged from 18 to 60 years. Most of the interviewees (16) completed only primary education while two young non-recipients had a university degree. Additional key requirements of the approach was to ensure the right balance between people receiving social assistance for longer periods of time and those who were rather new recipients.

\footnotetext{
${ }^{62}$ See Petrovic (2009) for more information on the study.

${ }^{63}$ See the Interview Guide in the Appendix 6.
} 
The interviews were conducted face-to-face during February 2009. This meant that for some respondents they took place shortly after the completion of their work engagement in public works. In all the cases, the timing of the interview corresponded to the period of one to six months from the completion of their work. Interviews conducted in the offices of the public work implementation agency and lasted 50 minutes on average. All the interview participants were provided with detailed information about the study and the type of interview they were participating in. The interviews were recorded, while confidentiality was guaranteed.

First raw field notes were coded without being previously transcribed. Notes were subsequently transformed into write-ups. The missing information, unclear data, and quotes were added by using the transcribed text. The data were entered directly in the earlier designed concept note by using the Word processor and writing accompanying analytic text. The conclusions drawn from the data were compared with those of Bonin and Rinne (2006) in which the same dimensions of subjective well-being were explored using the survey data.

The questions in the interviews were aimed at gaining insights in the participants' overall experiences with public works and covered three broad categories: beneficiaries' experiences with different types of assistance and support that they receive, the experience of direct participation in public works, and their experience with social services in general. While this qualitative approach entailed a broader set of questions related to overall experiences with public works, the analysis in this chapter focuses only on the findings revealing the impact of work engagement on social assistance beneficiaries and their subjective well-being outcomes.

The primary interest of the study was to obtain responses to the questions concerning particular dimensions of life that provide insights on how the respondents' personal situations had changed over time. The respondents were asked to compare their situation at the time of the interview with the one before the public work program came into effect. More precisely, the interviews entailed a self-assessment of changes concerning family income situation, health status, personal qualifications and skills, desire to find a job, chances to find a regular job, social contacts, and self-confidence. These items have already been identified in the literature as determinants of personal happiness (Bonin \& Rinne, 2006; Frey \& Stutzer, 2002). The analysis in this chapter entails a summary of positive and negative assessments per each item.

Before drawing conclusions on the findings, the study examined the extent to which each of the domains is related to subjective well-being. At variance with Bonin and Rinne (2006) we omitted a discussion on the link between personal 
health ratings and happiness as the close correlation between these dimensions made it impossible to attribute causality in our data. In addition, the analysis of changes in income takes into account the trends of adaptation (Bonin \& Rinne, 2006; Layard, 2006) which might result in a temporary impact only. ${ }^{64}$

\subsection{Findings}

As discussed above, the data collected through in-depth interviews provide us with an opportunity to analyze impacts of formal work engagement on different dimensions of quality of life, including the social assistance recipients' own assessment of their well-being. Studying this rather narrow definition of SWB relating to work activation helps us gain a greater understanding of specific conditions that might influence welfare recipients' better integration in the labor market and their social inclusion in general.

\subsubsection{The livelihoods of social assistance respondents and public work participation}

To put in context respondents' perceptions on their wellbeing and the extent to which public works' participation affected it, we first consider the respondents' livelihood strategies and the role that different programs, from which they benefited, played in them. Respondents were, for example, asked to describe the kinds of support they were benefiting from, with the aim to learn about their own and the status of their families in general. In addition, we wanted to gain insights in their coping mechanisms.

For social assistance recipients, the main survival strategy is based on a combination of income sources (Matkovic et al., 2010). Respondents in our study generally illustrated their survival strategies with a great deal of disappointment. The social assistance benefit was usually described as a minimal benefit that covers only basic needs (bread, basic groceries, and, very often, utility payments). Child allowance was considered another equally important and stable source of income for families with children. ${ }^{65}$ It was not surprising to learn that for social assistance recipients 'stability of resources' mattered a lot as the assistance and support of extended family was almost non-existent, the role of non-governmental sector limited to a few cases, and informal jobs were only occasional. Practically, all the participants interviewed admitted that they worked in the informal economy. In

\footnotetext{
${ }^{64}$ According to adaptation theory, people first react strongly to new circumstances but they return to their original position over time.

${ }^{65}$ Child allowance benefits are also provided at very low levels.
} 
the informal work engagement activities they include agricultural and construction works, garden maintenance, cleaning jobs, singing, and similar.

In contrast with their description of their usual livelihood strategies, the respondents were very enthusiastic in the explanation of their work experience and income earned in the public work. They describe the earned income as a matter of pride and happiness relative to the situation in which they receive official support. Prompted to compare the overall feelings associated with the receipt of social assistance with the one of earning money through formal employment, the respondents often provided arguments in favor of official work engagement:

"I feel as if, if this work continues, I am useful in this society. Why do I feel useful in the society? Because I also pay social contributions. Am I expressing myself well?...It means I am useful! So, it means that I am providing assistance for someone else. Let the social assistance exist, but it should be given to those who really need assistance, who are not able to work. I think that's what the Government should do. But, we the young, we should work. Okay, not all the people are well educated, but I think, for example, we all have our own qualification. Why wouldn't I be able to clean the streets? Why wouldn't I clean the street - it's a respectful job and I can earn decently?!?"

(male, 32 years)

At the time of interviews, most of the respondents were registered as unemployed. Only three interview participants, including one social assistance recipient, retained employment status after the completion of the public work project. In terms of labor market achievements, this outcome could be described as rather disappointing. This is particularly true for the group of social assistance recipients since only one of them managed to find a formal job following the public work engagement. One third of former welfare beneficiaries had already re-applied to social assistance program, the other third claimed unemployment benefits, while the rest of them found themselves in some kind of limbo awaiting the decision on "the beginning of a new public work".

For a great majority of them, employment through public works was the first official employment that followed after years of "waiting" or searching for a job. Interestingly, one respondent was offered employment through public works after being registered as unemployed for more than 22 years. Most of them had to wait for the formal employment opportunity between 10 and 20 years. The overall impressions about employment were exceedingly positive. Some of them are presented in Box 5.2. 


\section{Box 5.2: Social assistance recipients' impressions about work engagement}

"Oh, it was the first official stamp in my worker's booklet!!! After so many years...I felt very well...This work gave me a lot..."

"When I received the first salary, I think...it was for me as if I was flying... Look at it from this side: not a single sick leave day, nothing, it was an incentive to get up and go to the work place... You work...You have a job..."

"When I receive social assistance, I feel very useless. In general...Personally...I don't feel comfortable, because the assistance should be receiving those who can't work. Those are the disabled and the elderly. They should receive social assistance. And we? We are young and we should work. So that even for the others... The others should also benefit and we should benefit. It's mutual... If we work for a firm, the employer...He should also benefit, and we should be fine. So, we get the money and they get the job done...I feel very bad when I have to wait to receive 4,000-5000...when I work, I get 15,000 and I could plan. Both my husband and I used to work. I feel more confident, important, and useful..."

At the individual level, the experience of work engagement had a significance of mental stability, personal satisfaction, and pride. At the family level, besides financial security, the formal work experience had impacted on improved mood, mental health, and "peace at home" as presented in Box 5.3.

\section{Box 5.3: Perceptions about the impact of work activity on mental health}

"When there was the public work, the atmosphere at home was very nice...Otherwise...We are all sick, nervous..."

"First of all, the family mood is at a higher level. Why? When I don't work, it has a negative mental effect, on all of us, you understand...When, for example, I have monthly earnings, my spouse as well, we get the money and schedule how we are going to spend it. The overall atmosphere in the family is better immediately."

"...My daughter had been sad all day long. I didn't know what to say. I told her that I got fired. I felt uncomfortable and very very useless and sad, both because of her and because of our family. And, because of the society in general..."

Except for the non-recipients with university degrees, for all other respondents the earnings from the public works appeared to be a significant work incentive and a source of satisfaction. The minimum wage, received by majority of them, was described as financial resource "paid on time" which allows them to "plan the financing of their needs". "Stability and security" of earnings are usually described as the most important factors influencing their decision to opt for formal employment with a minimum wage rather than informal activity that could 
eventually yield higher income. The older respondents also stress the importance of paying social contributions and meeting the requirements for pension. ${ }^{66}$

\subsubsection{Subjective well-being and employability}

The employment probability for social assistance recipients is generally very low. Public works provide temporary employment only, but they are also expected to raise the participants' competitiveness in the labor market, thus increasing their chances for employment. However, only one public work participant among those formerly receiving social assistance was employed three months after the completion of the public work. Note that according to the latest findings (Petrovic, 2011) the share of social assistance recipients who found employment after public work's participation is 6.8 percent, which is significantly higher than the employment rate of 1.4 percent, found for all public works' participants in 2007 (Arandarenko \& Krstic 2008). Despite this relatively positive development for social assistance recipients, their labor market outcomes remain generally unfortunate. In this light, it is interesting to examine the impact of the program on employability, a key element of the activation agenda.

With regard to the employability, the discussion in our analysis centers on respondents perceptions about qualifications and skills acquired, as well as on the chances to find a new employment. Public works appeared to have a strong positive effect on qualifications and skills of social assistance recipients, signaling that the training component of public works programs had a rather positive impact: "I believe that I acquired some knowledge. Both as a brick layer and other stuff...We did all sorts of things there." Prompted to assess the change, the participants almost unanimously singled out the acquired qualifications and skills as the biggest positive achievement from public works: "Really, it increased, my knowledge has increased. You learn when you work with people and you learn how to work with them...I don't want to lie. There were things that I didn't know how to do and I learned."

To a significant number of respondents training activities were provided as part of their public work engagement. The duration of training varied from few days of on-the-job training to a month long certified training programs in specialized institutions. This could partially be the reason why many of them would like to perform exactly the same activity in the future. For most of them, those were the only training obtained and the first skills and qualifications acquired in their life.

\footnotetext{
${ }^{66}$ Public pension system in Serbia functions as a pay-as-you-go scheme.
} 
The additional quantitative analysis of activation and labor market prospects for social assistance recipients showed that only 8 percent of them had participated in a training program during their lifetime (Petrovic, 2011). ${ }^{67}$ This study further confirmed that for one third of social assistance recipients who participated in public works those were actually the qualifications and skills acquired in the public work that helped them find new employment (Petrovic, 2011).

With regard to the chances for employment, the opinions were more diverse. Participants older than 50 years, but sometimes also the younger ones, expressed significant doubts in their chances to find a new job. This is very often supported by anecdotal evidence about potential employers who are more interested in younger workforce (Box 5.4).

\section{Box 5.4: Perceived changes with regard to chances for employment}

"I don't know, son...It all depends...it depends on other people as well...Is there anyone ready to give me some job and pay for my contributions...I just want the same...It's all the same, the chances are not that big, but still it all depends..."

"I've been looking for a job from December 'til now. I haven't found, I mean, I've found but...I was at one place. They had been looking for a worker. I went there. Took a seat. We talked this and that...And, then, they said...up to 30 years of age. And, I am 32. We talked for half an hour. The man said: «Well, you are too old for this». I was supposed to work in storage. What shall I say? I couldn't say anything. I spent half an hour there, we talked, I thought there will be something out of this since we had been talking for half an hour. But, he said up to 30 years of age. What can I say? I didn't want to believe in what I had just heard."

"The first thing they asked me was : "How old are you? " and "How many kids do you have?»"

"I think that the chances to find a new employment are bigger. I have some work experience now and I have a stamp in the worker's booklet. It should be easier...I hope..."

"My chances should be bigger now, but you never know...Still, I hope. I hope and expect some better days. I already told you about that certificate...I know a bit more now than before...should help..."

\footnotetext{
${ }^{67}$ These data stem from an ad hoc survey of the recipients of financial social assistance (FSA) geared to identify their labor market status, educational attainment, job search activities, and access to cross-sectoral referral system (See the questionnaire in Appendix 7). The sample for the analysis consisted of 868 FSA recipient households or 1,652 household members. It is a two-tier stratified sample that reflects the national situation. The structure followed the household structure of FSA recipients obtained from the administrative data of the Ministry of Labor and Social Policy. The unit of observation is an individual in the age group 15 to 64 years old (working age population). Data were collected for the territory of Serbia according to the Nomenclature of Units for Territorial Statistics (NUTS) level 2 (Region of Belgrade, Vojvodina, Sumadija and Western Serbia, Southern and Eastern Serbia).
} 
Additionally, some respondents made rather short but very optimistic statements in favor of their chances for future employment. It was particularly evident among the participants for whom the work in public works was the first involvement in the formal labor market. Moreover, for many of them the inclusion in the labor market was perceived as a first sign and important instrument for greater inclusion in the society.

\subsubsection{Subjective well-being and social inclusion}

Social inclusion is usually defined as the process that prevents people from becoming excluded and provides them with the opportunities for greater participation in the society. In other words, for social assistance recipients who are capable to work this can be done by improving their income situation through increased social transfers but also, and more important, by providing adequate employment opportunities and participation in different aspects of social and civic life. However, social inclusion is not only about labor market integration but involves social exchange at a qualitatively new level, as well as participation in different aspects of social and civic life as discussed in Chapter 4. Our interviews allowed us to explore the level of social contacts and established confidence for social exchange under the notion of social inclusion.

In our study, personal contacts, established at work place, represented one of the core reasons for the very high subjective assessment of social contacts. Very often, it was the established level of self-confidence that enabled the participants to increase the level of their social interaction. The level of self-confidence marked a significant increase, particularly among the former social assistance beneficiaries. This was usually coupled with their willingness to look for a new job, the level of which has also dramatically increased. However, important mentioning here is that in the absence of formal employment opportunities, the able-bodied social assistance recipients very often undertake activities in the informal economy, and, therefore, rarely make a proper distinction between jobs in the formal market and activities in the informal one. This has significant implications for their selfassessments of the willingness or readiness to look for a job and accept an offer. However, it should not undermine the general social integration effects of their activation, the support for which is found in the assessment below (Box 5.5). 


\section{Box 5.5: Perceived changes with regard to the level of social contacts}
"Yes, I am in contact with people and I better understand them."
'I know more people now and I am in better contact with people because of the public work. In the past, even if they were looking for a worker, they didn't know who to contact. Now, if she decides to do something with the garden, she knows that you work that and that you are free after work. She gives me a call: "Would you please come? I have one tree that needs to be pulled out.» Or any other job around the house...It means, I know more people and they offer me jobs. And, in general, I have more contacts with people."
"My social contacts are much better. I've met more people, which opens the door..."
"Oh, yes, definitely. The circle is bigger...Both friends and others...And nice communication and better words...everything..."

Social assistance beneficiaries feel more and better heard after their work activation. The number of contacts as well as their position in the society has increased. Their work is valued. They feel accepted and more integrated:

"I felt nice and free, and I felt that they accepted me in the society. That's the fact. Here, in our municipality, they accepted me very well. All of them, without exception: the president, manager, to start with the highest positions... and all the others. They respected me and there was no discrimination. Somehow, it felt like a second family to me."

(female, 35 years)

These kinds of responses comprised the core of changes along the social inclusion line. The question on social inclusion was not posed explicitly. Rather, it was assumed that people would most probably answer the questions about different aspects of social exclusion and inclusion when telling about other experiences.

\subsubsection{Participation in pubic work and overall subjective well-being}

As noted earlier, the respondents' assessment of their participation in public works consisted of descriptions on whether their personal situation had changed following the completion of the work. In our analysis we focused on individuals' perceptions about their willingness to search for a job, changes in their family income, personal qualifications and skills, the chances for new employment, and the level of self-confidence and social contacts. 
In sum, the public work employment has positively affected the level and kind of social assistance recipients' subjective well-being. The strongest positive effect concerned the qualifications and skills acquired in public works, possibly due to the well-designed and implemented training components. Also, the frequency and quality of social contacts did improve with the increased integration in other areas such as labor market. It seems that the positive effects on these aspects of life were larger than the objective outcome of being unemployed, as perceived by the program participants. For them, there are factors other than employment that impact on their well-being. These findings are in line with Bonin and Rinne's (2006) study.

Public works are generally not being found very effective in terms of labor market impacts. In the case of Serbia, this has been supported in Arandarenko and Krstic's (2008) analysis of active labor market policies. I our study, however, we explored a number of broader dimensions of impacts which suggest that public works have important positive impacts on subjective well-being and social inclusion of social assistance recipients. This is particularly the case for older groups of recipients, as confirmed later in the study of Petrovic (2011).

According to Petrovic (2011), public works activities have the strongest positive effect on prime age (30-49) and older (50-64) individuals. However, older individuals are more likely to be involved in public programs and to be referred to other institutions for additional assistance compared to young people. The figures show that up to now, young people have been rather neglected. A relatively small number of young social assistance beneficiaries participated in any kind of training outside formal education. Still, they are more willing to return to education (11 percent) or participate to training programs (60 percent) (Figure A5.4 in the Appendix 5).

Important noting is also an interesting observation related to the levels of positive experiences. Across the board, social assistance beneficiaries grade their experiences very high even when their basic needs remain unmet. This, however, is in line with context theories which claim that the factors influencing SWB vary across individuals and time (Diener et al., 1997). How good or bad people judge life events is based on circumstances in which they live and events they experience. For the group of social assistance recipients included in this qualitative analysis, those were rather harsh life circumstances to start with and any improvement on SWB dimensions was graded relatively high.

Overall, the presented findings on significant impact of work engagement on certain aspects of life (e.g. increased qualifications and skills, broadened social contacts, and built self-confidence for greater social exchange) increase our 
understanding of subjective well-being of the poor. They also set the stage for greater policy actions leading to increased activation and social inclusion of welfare recipients. The explained effects may have serious policy implication if discussed together with conventional economic performance indicators, as both kinds of measures are needed to understand well-being and to make informed decisions.

\subsection{Conclusion}

We started out the chapter with the argument that the focus on subjective wellbeing (SWB) measures is relevant from the perspective of both people who are involved in a particular public program and a decision maker who seeks to improve individual welfare by offering active forms of support. At the same, the objective was not to undermine the role of conventional economic indicators but to stress the importance of using SWB measures in addition to them. We focused the analysis on social assistance recipients as we wanted to contribute to better understanding of subjective well-being of the poor who got a chance to work and, therefore, explore the possibilities for future activation of this group of welfare recipients and their greater inclusion in the society.

Based on our qualitative analysis, we concluded that the positive effects of work engagement on subjective well-being of social assistance recipients appear to be very strong. The evidence is strongest in relation to their perceptions about the level of attained qualifications and skills and social contacts. In addition, the program has impacted on individual welfare by strengthening job desire and selfconfidence. Hence, the activation has worked towards the overall integration in the society. This evidence speak in favor of further work activation of social assistance beneficiaries.

Some of the findings presented in this chapter have later been confirmed in a broader quantitative analysis of financial social assistance recipients in Serbia (Petrovic, 2011). The results of this study suggest the positive impact of qualifications and skills acquired in public works on finding a new job. They also reveal higher willingness of social assistance recipients compared to other public works' participants to involve in employment activity. Additionally, the findings point to a number of important areas that need to be taken into account by policy makers in designing an adequate set of activation measures.

Subjective well-being measures applied in our study proved to be valuable in investigating quality of life, its dimensions, and the overall understanding of social 
inclusion outcomes. On balance, subjective well-being measures can be used to explore the areas that may be neglected in traditional economic analyses. However, they are often difficult to interpret and they cannot be used as the only values guiding public policies (Marlier et al. 2007). Nevertheless, considerations always need to be made to include them in the lists of indicators measuring deprivation and social exclusion. 


\section{CHAPTER}

\section{Conclusions}

\subsection{Summary of findings}

To address the main research question on the role of activation policies in yielding better social inclusion outcomes, we approached it from a macro-level focusing on social and economic factors shaping countries' social policies and related outcomes. Additionally, we involved in a close-up micro-level study which is entirely country-specific. Together these approaches provided a powerful and detailed account of intertwined processes impacting on social exclusion and social inclusion of social assistance recipients. We summarized the findings of each step of the analysis.

\subsubsection{Activation as a necessary or sufficient condition for better poverty outcomes}

We started out with the argument that social exclusion is a complex social phenomenon. Complex causal statements in terms of necessary and sufficient conditions were framed using set relations. We explored possible combinations of relevant conditions leading to the defined social exclusion outcome - the low atrisk-of-poverty rate. The analysis was done across twelve EU countries. We were particularly interested in the role of activation and socio-professional integration of social assistance recipients within given combinations of factors. In line with our expectations, the analysis has demonstrated that strong activation and socioprofessional integration policies contributed to yielding better poverty outcomes among welfare recipients. Nevertheless, the findings suggest that activation alone is neither necessary nor sufficient condition for the occurrence of lower poverty levels. In other words, activation is insufficient but necessary part of a condition consisting of certain macroeconomic environments and respective social protection systems, and as such contributes to better outcomes for welfare beneficiaries.

How activation features in different contexts and in relation to poverty outcomes is thoroughly explained in the case studies of Estonia and Slovenia. Furthermore, the experience of these countries shows that sometimes it is the social assistance program, framed by different context factors, that plays more important role in alleviating poverty (Slovenia). In this case, the activation of social assistance recipients interacts as part of the on-going social protection efforts. Other times, 
poverty and exclusion are successfully tackled by means of strong economic performance offering jobs to all, not solely in the formal labor market (Estonia). Here, the activation comes into play because of the increased labor demand.

From the unidimensional definition of social exclusion focusing on relative poverty outcomes we moved towards a more encompassing explanation of its multidimensional nature. In this process, social exclusion has been framed to explain the inability to exercise basic rights of citizens to a minimum standard of living but also some broader forms of non-participation in the society.

\subsubsection{Multidimensional nature of social exclusion}

Another aim of our study was to look deeper into multidimensional nature of social exclusion and to develop a context-specific social exclusion index by analyzing the case of Serbia. This required a careful deliberation about social exclusion dimensions and relevant indicators, as well as the analysis of each specific contribution to the overall index of social exclusion. At the level of individual indicators, we examined the link between monetary and non-monetary deprivations and the importance of monetary poverty in the explanation of other deprivations. Within this context we paid particular attention to the sub-group of social benefit recipients who are traditionally more at risk of poverty and exclusion.

The findings show that almost every tenth person in Serbia is socially excluded. The results are presented for four groups - urban/rural, social benefit recipient/non-recipient individuals - and they confirm relatively higher levels of exclusion for individuals living in rural and benefit recipient households. The findings further suggest that while exclusion from health, education, and other services contributes most to the overall social exclusion all three dimensions play significant role in the explanation of exclusion. The analysis of the link between monetary and non-monetary deprivations revealed that the overlaps are of rather limited magnitude, which indicates that many forms of social exclusion cannot be explained by the lack of money only. Furthermore, the analysis of the relative importance of specific predictor variables showed that monetary poverty plays important role, but it is actually the status of unemployment that significantly increases the likelihood of deprivation in other areas.

The presented perspective on social exclusion surly shows its multidimensional character. It confirms that "there are distinct capabilities and functioning's that we have reason to value" (Sen, 2000, p.4-5), and as such it provides the venue for exploring different approaches to addressing deprivations. 


\subsubsection{The link between activation, subjective well-being, and social inclusion outcomes}

Next in our study was the application of subjective well-being measures to the analysis of a specific public policy. We explored whether and how activation of social assistance recipients through public works impacts on their subjective wellbeing outcomes and what is its link to social inclusion goals. The program under analysis was the Public Works Program in Serbia.

The applied qualitative analysis of the data obtained from semi-structured indepth interviews focused on the changes in different dimensions of subjective well-being. We took into account the periods before and after the public work activity. Despite the low employment rate of participants after the completion of the program, the qualitative analysis revealed significant positive impact of work engagement on subjective well-being of social assistance recipients. The evidence is strongest in relation to their positive perceptions about the level of acquired qualifications, skills, and social contacts. In addition, the program has impacted on individual welfare by strengthening job desire and self-confidence.

As a consequence of participation in a work activity, the frequency and level of social contacts improve; Social assistance beneficiaries improve in self-confidence and given a voice in society. The number of contacts as well as their position increases with their participation in the labor market. Their work is valued. They feel accepted and more integrated. These kinds of assessment comprise the core of changes along the social inclusion line. In this particular case activation appears to play an important role in addressing social exclusion and providing better social inclusion outcomes.

\subsubsection{Two important pathways for reaching the social inclusion goal}

Activation and work-related conditionality tied to the receipt of social assistance impact on the balance between rights and obligations. Nevertheless, this renewed approach of welfare to work does not necessarily reduce the quantity or the quality of social assistance (Lodemel \& Trickey, 2000). Clearly, it can be perceived as a means of reducing existing rights and freedoms, but also as a provision of enhanced opportunities to join the labor market and better integrate in the society. Obviously, this is highly dependent on the design of a specific program.

In the presented study we explored a number of dimensions of impacts involving both objective labor market and subjective well-being measures. In our view, there are at least two pathways that explain the interaction between activation and social inclusion. They are depicted in Figure 6.1. 
Table 6.1: Two pathways for reaching the social inclusion goal through activation

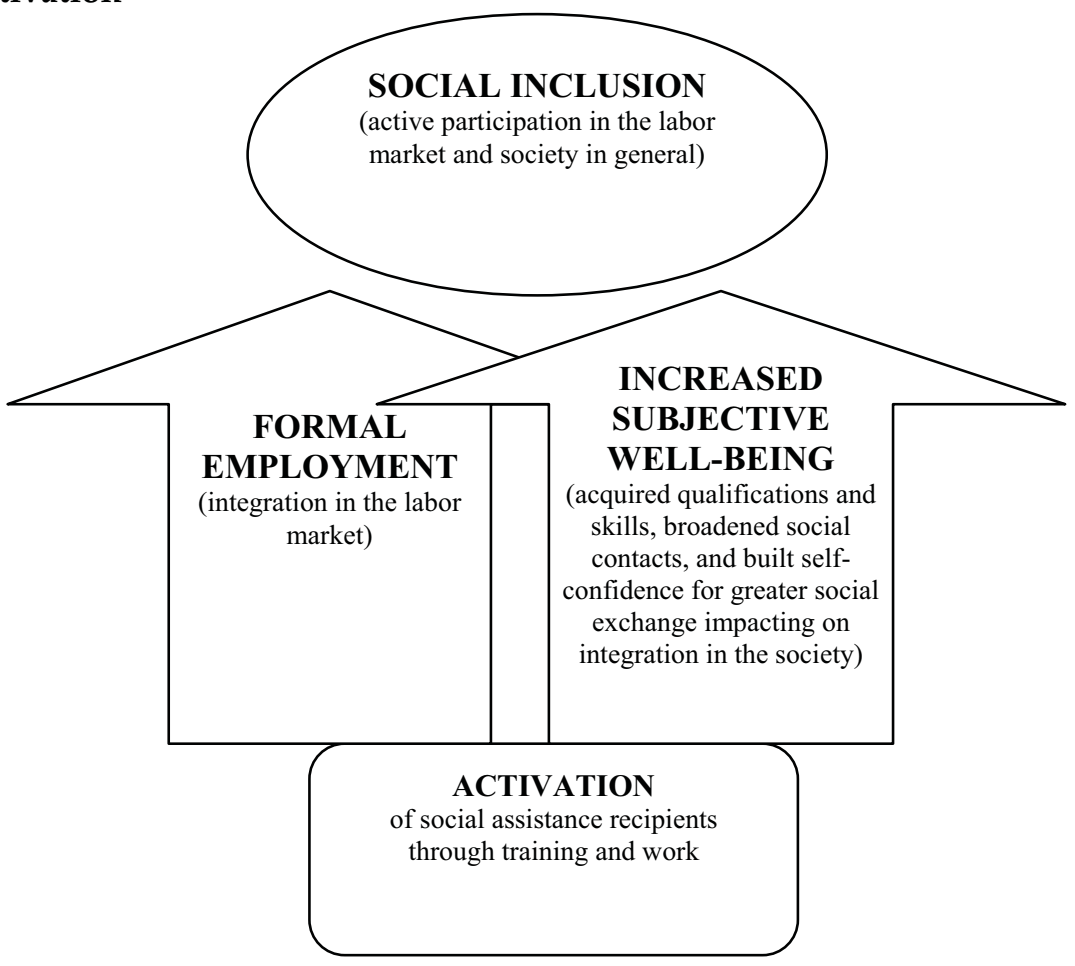

On the one side, social inclusion is expected to occur through direct formal employment. However, the available literature suggests that activation through temporary work engagement (such as public works) is generally not very effective in terms of formal employment outcomes. In our study we acknowledge that very few social assistance beneficiaries find employment following the completion of the public work activity. On the other hand, and as shown in our study, there is a significant impact of public work engagement on particular aspects of life such as acquiring qualifications and skills, broadening social contacts, and building selfconfidence for greater social exchange. This discovery not only increases our understanding of subjective well-being of the poor and their prospects, but also establishes the necessary link between activation, subjective well-being, and social inclusion.

While the overall finding suggests that activation through public works has important positive impact on subjective well-being and social inclusion of social assistance recipients, we allow for differences in judgments about the general effectiveness of public work programs. How the program is viewed certainly 
depends on a number of factors ranging from the program design, institutional arrangements, processes, and expected outcomes. Our aim in this study was only to stress the importance of gauging the perceptions of program participants and discuss the effects on their well-being in relation to social inclusion outcomes.

\subsection{Limitations of the study}

Each step of our study has provided a deep understanding of the topic researched, but each analysis also suffers from a number of drawbacks. They are highlighted here to reflect on possible areas for future research.

Despite its superiority in treating causal complexity, the offered fuzzy-set analysis was not tailored to deal with time dimensions. At the same time, poverty and social exclusion are of very dynamic nature. To gain through insights in the processes leading towards defined outcomes, one would need to involve in deeper country case analyses. In our study we manage to cover only three country cases in greater detail.

Another shortcoming of the presented fuzzy-set analysis relates to its inability to examine the multidimensional nature of social exclusion due to data limitations for the observed period. This issue is, however, addressed in a separate chapter offering a definition of social exclusion for Serbia in line with the approaches on multiple deprivations and multidimensional poverty and relying on the data from a survey that was purposefully designed to study social exclusion outcomes.

The results on the multidimensional measure of social exclusion (i.e. the index of social exclusion) are presented for four groups - urban/rural and social benefit recipient/non-recipient individuals and households. They confirm relatively higher levels of exclusion for individuals living in rural and benefit recipient households. The benefit recipients appear to be particularly vulnerable. However, due to the small number of observations, these findings are rather indicative and cannot serve the purpose of wider generalization. Therefore, this limitation has been compensated by the analysis of additional qualitative and quantitative data. Further research on this topic would certainly benefit from recipient booster surveys.

Subjective well-being measures are generally used to explore the areas that may be neglected in traditional economic analyses. The subjective well-being measures applied in our study proved to be valuable in investigating quality of life and social inclusion outcomes for social assistance recipients. The explained effects 
have serious policy implication and should always be examined together with conventional economic indicators as both kinds of measures are needed to understand well-being and to make informed decisions. However, the interactions between activation and social inclusion are rather contextual. Additional studies of larger scale would be needed to unravel more of the dimensions and factors potentially impacting social inclusion (rather than social exclusion) outcomes.

\subsection{Policy implications}

The findings of our study set the stage for greater policy actions leading to an increased activation and social inclusion of welfare recipients. There are several policy implications stemming from the results of the study.

In general terms, social exclusion is a product of different events in society and government-designed welfare policies and institutions, such as social assistance and activation, play a significant role in fighting social exclusion and increasing social inclusion. These policies do not impact in isolation but rather as part of the overall social policy environments and, therefore, require one integrated approach for treating deprivation and enhancing inclusion.

In terms of specific policy responses aimed at decreasing social exclusion and increasing inclusion, the measures need to be designed and implemented across different sectors. For example, the analysis of the relative importance of specific variables confirmed that monetary poverty plays important role, but it is actually the status of unemployment that significantly increases the likelihood of deprivation in other areas. Applied to the case of social assistance recipients, this means that the policy response should involve an adequate financial transfer, but also a provision of opportunities in the labor market, and forms of integrated labor market and social service delivery which is often missing, as confirmed by the presented analysis.

When we reduce the discussion to the Serbia case only, the evidence speak in favor of further work activation of social assistance beneficiaries who are capable to work. They point to the existence of activation potential among social assistance beneficiaries, possibly even higher than shown by the data. Judging from the main characteristics of social assistance recipients and the extent and areas of exclusion, there appears to be substantial scope to improve both their educational and employment outcomes. 
Social assistance recipients have remarkably low levels of educational attainment. At the same time, they are reluctant to return to formal education and hardly ever they get referred to education and training programs. Nevertheless, many young people appear to be relatively more willing to return to education or participate in training program, if given the opportunity. In terms of employment potential, the findings also suggest a positive impact, but it is unevenly distributed across age groups. Hence, any discussion about activation potential and related policy options needs to be age sensitive. In Serbia, for example, the public works program has developed a targeting approach focused on adult and older social assistance recipients and it should be retained as such. For the younger cohorts other approaches need to be considered. One possible policy option would be a systematic return to mainstream education or involvement in training programs geared to increase their employment prospects. The other possible approach would be their participation in subsidized employment programs. 


\section{Bibliography}

Adema, W. (2006). Social Assistance Policy Development and the Provision of a Decent Level of Income in Selected OECD Countries. Retrieved December 20, 2006, from Organization for Economic Development and Cooperation Web site: http://www.oecd.org/els

Aghion, P., \& Blanchard, O. (1994). On the Speed of Transition in Central Europe, Macroeconomics Annual, 9: 283-320.

Alkire, S. (2002). Dimensions of human development. World Development, 30(2), 181-205.

Alkire, S. (2008). Choosing Dimensions: The Capability Approach and Multidimensional Poverty. In N. Kakwani \& J. Silber (Eds.), The Many Dimensions of Poverty (pp. 89-119). New York (NY): Palgrave Macmillan.

Alkire, S. \& Foster, J. (2007). Counting and Multidimensional Poverty Measurement. Retrieved December 10, 2009, from Oxford Poverty and Human Development Initiative Web site: http://www.ophi.org.uk/pubs/OPHI_WP7.pdf

Alkire, S. \& Foster, J. (2011). Understandings and Misunderstandings of Multidimensional Poverty Measurement. Retrieved December 10, 2011, from Oxford Poverty and Human Development Initiative Web site:http://www.ophi.org.uk/wpcontent/uploads/ophi-wp43.pdf

Arandarenko, M., \& Krstić, G. (2008). Analiza uticaja politike zapošljavanja i aktivnih mera tržišta rada u Republici Srbiji 2003-2007. Retrieved March 1, 2010, from Government of Serbia Web site: http://www.inkluzija.gov.rs/wpcontent/uploads/2009/10/Analiza-uticaja-politike-zaposljavanja-i-APTR.pdf

Askonas, P., \& Stewart, A. (2000). Social Inclusion: Possibilities and Tensions. London: Palgrave.

Atkinson, A. (1998). Social Exclusion, Poverty and Unemployment in Exclusion, Employment and Opportunity. CASEpaper. Center for Analysis of Social Exclusion, London School of Economics, London.

Atkinson, A. (2003). Multidimensional Deprivation: Contrasting Social Welfare and Counting Approaches. Journal of Economic Inequality, 1(1), 51-65. 
Atkinson, A., Cantillon, B., Marlier, E. \& Nolan, B. (2002). Social Indicators: The EU and Social Inclusion, Oxford: Oxford University Press.

Atkinson, A.,B., \& Micklewright, J. (1992). Economic Transformation in Eastern Europe and the Distribution of Income. Cambridge, UK: Cambridge University Press.

Atkinson, R. \& Davoudi, S. (2000). The Concept of Social Exclusion in the European Union: Context, Development and Possibilities. Journal of Common Market Studies, 38 (3), 427-48.

Barr, N., (Ed.). (2005). Labor markets and social policy in Central and Eastern Europe: the accession and beyond. Washington (DC): The World Bank.

Barr, N., \& Harbison, R. (1994). Overview: Hopes, Tears, and Transformation. In Barr, N.(Ed.), Labor Markets and Social Policy in Central and Eastern Europe. New York: Oxford University Press.

Barrett, G., F. (2000).The effect of educational attainment on welfare dependence: Evidence from Canada. Journal of Public Economics, 77(2): 209-232.

Baronijan, H. \& Cvejic, S. (2010). Social Exclusion in Serbia, 2002-2007, As the Phenomenon of Multiple Deprivation. Paper presented at the World Bank International Conference on Poverty and Social Inclusion in the Western Balkans, Brussels, Belgium.

Berg, B. (1989). Qualitative research methods for social science. Boston (MA): Allyn and Bacon.

Boeri, T. (1999). Transition with Labour Supply. William Davidson Institute Working Paper Number 274.

Boeri, T., \& Terrell, K. (2002). Institutional determinants of labor reallocation in transition, Journal of Economic Perspectives, 16(1): 51-76.

Bonin, H., \& Rinne, U. (2006). Beautiful Serbia. Retrieved December 1, 2008, from Institute for the Study of Labor Web site: http://ftp.iza.org/dp2533.pdf

Braithwaite, J., Grootaert, C.,\& Milanovic, B. (2000). Poverty and Social Assistance in Transition Countries. New York: Palgrave Macmillan. 
BTI (2006). The Bertelsmann Transformation Index, Retrieved December 9, 2008, from Bertelsmann Transformation Index Web site: http://www.bertelsmanntransformation-index.de/en/

Buchen, C. (2005). East European Antipodes: Varieties of Capitalism in Estonia and Slovenia, Prepared for the Pre-Publication Conference "Varieties of Capitalism in Post-Communist Countries" at Paisley University on 23-24 September 2005.

Burchardt, T., Le Grand, J. \& Piachaud, D. (2002), Introduction, Understanding Social Exclusion. Oxford: Oxford University Press.

Cameron, A. (2006). Geographies of welfare and exclusion: social inclusion and exception, Progress in Human Geography, 30: 396-404.

Camfield, L. (2006). The why and how of understanding 'subjective' wellbeing: Exploratory work by the WeD group in four developing countries. Retrieved December 1, 2008, from Wellbeing in Developing Countries Research: www.welldev.org.uk/research/workingpaperpdf/wed26.pdf

Carcillo, S., \& Grubb, D. (2006). From inactivity to work: The role of active labour market policies, SEM Working Paper no. 36, OECD: Paris.

Castanheira, M., \& Roland, G. (2000). The Optimal Speed of Transition: A General Equilibrium Analysis, International Economic Review, 41(1): 219-39.

Clark, A.,E. \& Oswald, A.,J. (1994), Unhappiness and Unemployment, Economic Journal 104: 648-659.

Coady, G., \& Hoddinott, J. (2002). Targeting outcomes redux. FCND Discussion Paper No. 144.

Coates, A., Farnsworth, K. \& Zulauf, M. (2001). Social Exclusion and Inclusion: Partnerships for Neighborhood Regeneration in London, Social Science Research Paper No.15, South Bank University, October 2001.

Cornelius, P. (1995). Unemployment During Transition: The Experience in the Baltic Countries, Communist Economies and Economic Transformation, 7 : 445 -464.

Council of the European Union (2002). Fight Against Poverty and Social Exclusion: Common Objectives for the second round of national Action Plans, SOC 508. 
Council of the European Union (2005), Joint Report on Social Protection and Social Inclusion, Brussels, Belgium.

Council of the European Union (2006), Joint Report on Social Protection and Social Inclusion, Belgium, Brussels.

Cox, R.,H. (1998). The Consequences of Welfare Reform: How Conceptions of Social Rights are Changing, Journal of Social Policy, 27(1): 1-16.

Crouch, C. (2003). Institutions Within Which Real Actors Innovate, In Mayntz, R. \& W. Streeck (Eds.) Die Reformierbarkeit der Demokratie, Frnakfurt/New York: Campus.

Cummins, R.A. (1996). Domains of life satisfaction: An attempt to order chaos. Social Indicators Research, 38(3), 303-328.

Cummins, R.A. (2000a). Personal income and subjective well-being: A review. Journal of Happiness Studies, 1 (2), 133-158.

Cummins, R.A. (2000b). Objective and subjective quality of life: An interactive model. Social Indicators Research, 52 (1), 55-72.

Dahl, E., \& Lorentzen, T. (2003). Explaining Exit to Work among Social Assistance Recipients in Norway: Heterogeneity or Dependency? European Sociaological Review, 19(5): 519-536.

Datt, G., \& Ravallion, M. (1994). Income gains for the poor from public works employment: Evidence from two Indian villages. LSMS Working Paper Number 100, Washington D.C.: The World Bank.

Devereux, S. (2002). From workfare to fair work: The contribution of public works and other labour-based infrastructure programmes to poverty alleviation. Geneva: ILO.

Diener, E. (1984). Subjective well-being. Psychological Bulletin, 95, 542-575.

Diener, E., \& Suh, E. (1997). Measuring quality of life; Economic, social, and subjective indicators. Social Indicators Research, 40(1-2), 189-216.

Diener E., Suh, E., \& Oishi, S. (1997). Recent findings on subjective well-being. Indian Journal of Clinical Psychology, 24, 25-41. 
DfID (2005). Social Transfers and Chronic Poverty: Emerging Evidence and the Challenge Ahead. Retrieved March 20, 2008, from Department for International Development Web site: http://www.dfid.gov.uk/pubs/files/social-transfers.pdf

Dropping, J.A., Hvinden, B.,\&Vik. K. (1999). Activation Policies in The Nordic Countries, In Kautto, M., Heikkilla, M., Hvinden, B., Marklund, S., \& N. Ploug (Eds.) Nordic Social Policy: Changing welfare States. London/New York: Routledge.

Estevez-Abe, M., Iversen, T. \& Soskice, D. (2001), Social Protection and the Formation of Skills: A Reinterpretation of the Welfare State. In Hall, P.,A.,\& D. Soskice (Eds), Varieties of Capitalism: The Institutional Foundations of Comparative Advantage. Oxford: Oxford University Press.

European Commission (1992). Towards a Europe of Solidarity: Intensifying the Fight Against Social Exclusion, Fostering integration. COM (92) 542, Brussels: European Commission.

European Commission (1998). Non-Monetary Indicators of Poverty and Social Exclusion - Final Report, Luxembourg: OOPEC.

European Commission (2000). Communication from the Commission: Building an Inclusive Europe. Brussels: European Commission.

European Commission (2004). Joint Report on Social Inclusion. Retrieved April 24, 2008, from European Commission web site: ec.europa.eu/employment_social/socprot/soc-incl/joint_rep_en.htm

European Commission (2006). Communication from the Commission to the Council. The European Parliament, The European Economic and Social Committee and the Committee of the Regions Concerning a Consultation on Action at EU Level to Promote the Active Inclusion of the People Furthest from the Labor Market. COPM(2006)44 final, Brussels, 8.2.2006.

European Commision (2007). Description of SILC user database variables: Crosssectional and Longitudinal. Version 2005.4 from 15-09-07.

European Commission (2007). Efficiency and Effectiveness of Social Spending. Achievements and challenges. Background note for the informal ECOFIN of 4-5 April 2008, Directorate-General for Economic and Financial Affairs, Brussels, ECFIN/E3(2007)/REP/50604. 
European Commission (2008). Social inclusion. Retrieved December 20, 2008, from European Commission Web site: http://ec.europa.eu/employment_social/spsi/poverty_social_exclusion_en.htm

Europeans Social Network (2006). Social and Employment Activation. Retrieved December 20, 2010, from European Social Network Web site: www.esn-eu.org/getdocument/index.htm?id=142

European Union (2000). Charter of Fundamental Rights of the European Union. Retrieved March 20, 2008, from European Union Web site: http://eurlex.europa.eu/LexUriServ/site/en/oj/2000/c_364/c_36420001218en00010022 .pdf

Eurostat (2007). Description of SILC user database variables: Cross-sectional and longitudinal, Version 2005.4 from 15-09-07, European Commission, Brussels.

Eurostat (2008). Living conditions and social protection statistics. Retrieved December 20, 2008, from European Commission Web site: http://epp.eurostat.ec.europa.eu/statistics_explained/index.php/Living_conditions _and_social_protection_introduced

Feldmann, M. (2006). Emerging Varieties of Capitalism in Transition Countries: The Case of Wage Bargaining in Estonia and Slovenia, Comparative Political Studies, 39: 829-854.

Fischer, A., M. (2008). Resolving the Theoretical Ambiguities of. Social Exclusion with reference to Polarisation and Conflict. Retrieved December 20, 2011, from London school of Economics and Political Science Web site: www2.lse.ac.uk/internationalDevelopment/pdf/WP90.pdf

Förster, M.,F, \& Mira d'Ercole, M. (2005). Income distribution and poverty in OECD countries in the second half of the 1990s, OECD Social, Employment and Migration Working Paper 22, Paris.

Frey, B., \& Stutzer, A. (1999). Happiness, economy and institutions. The Economic Journal, 110 (466), 918-938.

Frey, B., \& Stutzer, A. (2002). Happiness and economics: How the economy and institutions affect human well-being. Princeton: Princeton University Press. 
Gomulka, S. (1998). Output: Causes of the Decline and the Recovery, In Boone, P., Gomulka, S., \& R. Layard (eds.) Emerging from Communism. Cambridge (MA): The MIT Press.

Government of Serbia (2010). Monitoring of Social Inclusion in Serbia. Belgrade: Government of Serbia.

Government of Serbia. (2011). First National Report on Social Inclusion and Poverty Reduction in the Republic of Serbia The Status of Social Exclusion and Poverty Trends in the Period 2008 - 2010 and Future Priorities, Office of the Deputy Prime Minister, Belgrade.

Gustafsson, B, Muller, R., Negri, N., \& Voges, W. (2002). Paths Through (and Out of) Social Assistance. In Saraceno, C. (Eds.) Social Assistance Dynamics in Europe. National and Local Poverty Regimes. The Policy Press: Bristol.

Hagfors, R., \& Kajanoja, J. (2007). The Welfare State, Inequality and Social Capital, presented at the conference on "Risk \& Rationalities", Queens' College, Cambridge, 29-31 March 2007.

Hall, P.,A., \& Soskice D. (2001). An Introduction to the Varieties of Capitalism', In Hall, P.,A, \& D. Soskice (Eds), Varieties of Capitalism: The Institutional Foundations of Comparative Advantage. Oxford: Oxford University Press.

Haltiwanger, J.,C., \& Vodopivec, M. (2002). Gross worker and job flows in a transition economy: An analysis of Estonia, Labour Economics, 9(5): 601-630.

Haltiwanger, J.,C., \& Vodopivec, M. (2003). Worker flows, job flows and firm wage policies: An analysis of Slovenia, Economics of Transition, 11(2): 253-290.

Ham J.,C., Svejnar, J., \& Terrell, K. (1998). Unemployment and the Social Safety Net during Transitions to a Market Economy: Evidence from the Czech and Slovak Republics, The American Economic Review, 88(5): 1117-1142.

Herrmann, P., Tausch, A., Heshmati, A., \& Bajalan, C., S.,J., (2008). Efficiency and Effectiveness of Social Spending. IZA Discussion Paper No. 3482.

Hill, M., \& Bramley, G. (1986). Analyzing Social Policy. Oxford: Blackwell.

Holzmann, R., \& Jorgensen, S. (2001). Social Risk Management: A New Conceptual Framework for Social Protection, and Beyond, International Tax and Public Finance, 8(4): 529-556. 
Hvinden, B. (1999). Activation: A Nordic Perspective, Linking Welfare and Work, Dublin: European Foundation for the Improvement of Living and Working Conditions.

Hyman, D., N., (1999). Public Finance, A contemporary Application of Theory to Policy. Orlando (FL): The Dryden Press.

International Labour Organization (2000). World Labor Report: Income Security and Social Protection in a Changing World, GB.279/ESP/7279th Session, November 2000, Committee on Employment and Social Policy, Geneva.

International Labour Organization. (2011). Serbia FSA recipient dataset, Sub-regional Office for Central and Eastern Europe, Budapest.

Jackman, R. (1998), Unemployment and Restructuring, In Boone, P., Gomulka, S., \& R. Layard (eds.) Emerging from Communism. Cambridge (MA): The MIT Press.

Jurajda, S., \& Terrell, K. (2000). Optimal Speed of Transition: Micro Evidence from the Czech Republic, William Davidson Institute Working Papers Series 355, William Davidson Institute at the University of Michigan Stephen M. Ross Business School.

Jurajda, S., \& Terrell, K. (2008). Job Reallocation in Two Cases of Massive Adjustment in Eastern Europe, World Development, 36(11): 2144-2169.

Kahneman, D. \& Krueger, A.B. (2006). Developments in the Measurement of Subjective Well-Being.Journal of Economic Perspective, 20(1), 3-24.

Kapstein, E., \& Milanovic, B. (2003). Income and Influence, Social Policy in Emerging Market Economies, W. E. Upjohn Institute.

Keedman, W. (1998). Of Nets and assets: Effects and impacts of employment-intensive programmes - a review of ILO experience. Geneva: ILO.

Kingdon, G.G., \& Knight, J. (2006). Subjective Well-Being Poverty vs. Income Poverty and Capabilities Poverty, Journal of Development Studies, 42(7): 1199-1224.

Klugman, J., Micklewright, J.,\& Redmond, G. (2002). Poverty in the transition: social expenditures and the working-age poor, CEPR Discussion Paper 3389. 
Kuivalainen, S. (2004). Production of Last Resort Support: A Comparison on Social Assistance Schemes in Europe with the Notion of Welfare Production and the Concept of Social Right, LIS Working paper No 397.

Kvist, J. (2007). Fuzzy Set Ideal Type Analysis, Journal of Business Research, 474-481.

Layard, R. (2006). Happiness and public Policy: A challenge to the profession. The Economic Journal, 116(510), C24-33.

Lelkes, O., \& Zólyomi, E. (2008). Poverty Across Europe: The Latest Evidence Using the EU-SILC Survey, European Centre for Social Welfare Policy and Research Policy Briefs.

Levitas, R. (2000). What Is Social Exclusion? In Gordon D. \& P. Townsend (Eds.), Breadline Europe. The Measurement of Poverty (357-83). Bristol: The Policy Press.

Levitas, R., Pantazis, C., Fahmy, E., Gordon, D., Lloyd, E. \& Patsios, D. (2007). The multidimensional analysis of social exclusion. Retrieved December 20, 2008, from Social Exclusion Task Force Web site:

http//:www.cabinetoffice.gov.uk/social_exclusion_task_force/publications/research /multidimensional.asp

Lindert, P. (1996). What Limits Social Spending? Explorations, Economic History 33(1): 1-34.

Lodemel, I., \& Trickey, H. (2000). An Offer You Can't Refuse. Bristol: The Policy Press.

Lucas, R., Diener, E., \& Suh, E. (1996). Discriminant validity of well-being measures. Journal of Personality and Social Psychology, 71(3), 616-628.

Mahoney, J., \& Snyder, R. (1999). Rethinking Agency and Structure in the Study of Regime Change, Studies in Comparative International Development 34 (2): 3-32.

Manning, N. (2004). Diversity and Change in Pre-Accession Central and Eastern Europe Since 1989, Journal of European Social Policy, 14(3): 211-232.

Marlier, E., Atkinson,A.B., Cantillon, B., \& Nolan, B. (2007). The EU and Social Inclusion, Facing the Challenges. Bristol: The Policy Press. 
Marx, I. \& Bosch, Van den, K. (2007). On poverty measurement in an Enlarged EU context: conventional and alternative approaches, CEIES Proceedings 34., Luxembourg: Eurostat.

Matkovic, G., Mijatovic, B., \& Petrovic, M. (2010). Impact of the financial crisis on the labor market and living condition outcomes in Serbia, Belgrade: CLDS.

Milanovic, B. (1998). Income, Inequality, and Poverty during the Transition from Planned to Market Economy. Washington (DC): The World Bank.

Miles, M, \& Huberman, M. (1994). Qualitative data analysis: an expanded sourcebook (2nd ed.). Thousand Oaks (CA): Sage Publications.

Ministry of Labor, Family and Social Affairs (2000), National Program to Fight Poverty and Social Exclusion, Government of Slovenia, Ljubljana.

Ministry of Social Affairs of Estonia (2000). Social Sector in Figures, Tallinn, Estonia.

Ministry of Social Affairs of Estonia (2002). Social Sector in Figures, Tallinn, Estonia.

Ministry of Social Affairs of Estonia (2004). Social Sector in Figures, Tallinn, Estonia.

Ministry of Social Affairs of Estonia (2006). Social Sector in Figures, Tallinn, Estonia.

Ministry of Social Affairs of Estonia (2007). European Social Fund in Estonia, Tallinn, Estonia.

MISSOC (2004), Mutual Information System on Social Protection in the European Union, Retrieved December 20, 2008, from European Commission Web site: http://ec.europa.eu/employment_social/missoc/db/public/compareTables.do?lang= en

Morel, S. (1998). American workfare versus French insertion policies: An application of Common's theoretical framework, Paper presented at Annual Research Conference of the Association for Public Policy and Management, New York, United States of America.

Musgrave, R.,A., \& Musgrave, P. (1975). Public Finance in Theory and Practice. New York: McGraw-Hill.

Narayan, D., Chambers, R., Shah, M. K., \& Petesch, P. (2000). Voices of the poor: Crying out for change, New York: Oxford University Press for the World Bank. 
Nelson, K. (2008a). SaMip Documentation, Swedish Institute for Social Research, Stockholm, Sweden.

Nelson, K. (2008b). SaMip Variables and Code Book, Swedish Institute for Social Research, Stockholm, Sweden.

Neslon, K. (2009). Social Assistance and Minimum Income Protection in the EU: Vulnerability, Adequacy, and Convergence, Luxembourg Income Study Working paper Series, Working paper No. 511.

Neubourg de, C., Castonguay J. \& Roelen, K. (2006). Social Safety Nets and Targeted Social Assistance: Lessons from the European Experience, Maastricht, the Netherlands: University of Maastricht, Maastricht Graduate School of Governance.

Novak, M. (1997). HDSE Report on Slovenia, Social Cohesion and Quality of Life. Retrieved December 20, 2009, from Council of Europe Web site: http://www.coe.int/t/e/social_cohesion/hdse/2_hdse_reports/1_country_reports/K_ Report $\% 20 S L O V E N I A . a s p$

Nussbaum, M.,C. (2000). Women and Human Development: The Capabilities Approach. Cambridge: Cambridge University Press.

Organization of Economic Cooperation and Development (2008). Growing Unequal? Income Distribution and Poverty in OECD Countries. Paris: OECD.

Organization of Economic Cooperation and Development (2012). On the Relevance of Relative Poverty for Developing Countries, Working Paper No.314. Paris: OECD.

Petrovic, M. (2009). Aktivacija korisnika MOP-a u Srbiji: Proi pecat u radnoj knjizici, Izvestaj za Tim za socijalno ukljucivanje i smanjenje siromastva, Kabinet potpredsednika Vlade za evropske integracije,Vlada Republike Srbije, Srbija.

Petrovic, M. (2011). Social Assistance and activation: In search of inclusive policy options, Belgrade: CLDS/MDG Achievement Fund.

Petrovic, M. (2013). Subjective Well-Bing, Activation Policies, and the Inclusion Agenda. In C. Ruggeri Laderchi \& S. Savastano (Eds.), Poverty and Exclusion in the Western Balkans - New Directions in Measurement and Policy (117-132), New York: Springer. 
Pierson, P. (1996). The new Politics of the Welfare State. World Politics, 48 (2): 14379.

Ragin, C. (1987). The Comparative Method. Moving Beyond Qualitative and Quantitative Strategies. Berkeley: The University of California Press.

Ragin, C. (2000). Fuzzy-Set Social Science. Chicago: The University of Chicago Press.

Ragin, C. (2006). Set Relations in Social Research: Evaluating Their Consistency and Coverage. Political Analysis, 14: 291-310.

Ragin, C. (2008). Redesigning social inquiry: Fuzzy set and beyond. Chicago: The University of Chicago Press.

Ragin, C., \& Davey, S. (2009). fs/QCA [Computer Program], Version 2.5. Tucson: University of Arizona.

Ragin, C., Drass, K.,A., \& Davey, S. (2006) Fuzzy-Set/Qualitative Comparative Analysis 2.0. Tucson, Arizona: Department of Sociology, University of Arizona.

Ravallion, M. (2011). On multidimensional indices of poverty. World Bank Policy Research Working Papers No. 5580, Washington, DC, February 2011.

Republic of Slovenia (2002). Report on the realization of the program of the fight against poverty and social exclusion, Ljubljana.

Republic of Slovenia (2003). Joint Memorandum on Social Inclusion of Slovenia, Brussels.

Republic of Slovenia (2005). First annual report on the implementation of the national action plan on social inclusion - NAP/inclusion 2004 - 2006, Ljubljana.

Republican Statistical Office. (2008). Living standards measurement study Serbia 20022007. Retrieved March 1, 2009, from Government of Serbia Web site: www.inkluzija.gov.rs/wp-content/uploads/2011/09/Book.pdf

Republican Statistical Office (2010). Profil siromastva u Republici Srbiji, Belgrade, Serbia.

Rihoux, B., \& Grimm, H. (Ed.). (2006). Innovative Comparative Methods for Policy Analysis: Beyond the Quantitative-Qualitative Divide. New York: Sage Publications. 
Rihoux, B., \& Ragin, C. (Ed.). (2009), Configurational Comparative Methods: Qualitative Comparative Analysis (QCA) and Related Techniques. New York: Sage Publications.

Robeyns, I. (2006), The Capability Approach in Practice. Journal of Political Philosophy, 14, 351-376.

Roelen, K., Gassmann, F., \& de Neubourg, C. (2009a). Child poverty in Vietnam providing insights using a country-specific and multi-dimensional model. Social Indicators Research, 98 (1), 129-145.

Roelen, K., Gassmann, F., \& de Neubourg, C. (2009b). Making Poverty Analyses Richer - Multidimensional poverty research for policy design. In K. Boyser, C. Dewilde, D. Dierckx \& J. Friedrichs (Eds), Between the Social and the Spatial Exploring Multiple Dimensions of Poverty and Social Exclusion (pp. 35-56), Ashgate Publishing.

SaMip Data-set (2008). Documentation, Version: 1.3.4 Beta, Swedish Institute for Social Research, Sweden.

Schneider, C.Q., \& Rohlifing, I. (2013). Combining QCA and Process

Tracing in Set-Theoretic Multi-Method Research. Sociological Methods

Research. Retrieved August 20, 2013 from SAGE Journals Web site: http://smr.sagepub.com/content/early/2013/03/21/0049124113481341.abstract

Schneider, C.,Q., \& Wagemann, C. (2006). Reducing Complexity in Qualitative Comparative Analysis (QCA): Remote and Proximate Factors and the Consolidation of Democracy, European Journal of Political Research 45(5):751-786.

Schneider, C., Q., \& Wagemann, C. (2010). Standards of good practice in Qualitative Comparative Analysis (QCA) and fuzzy sets. Comparative Sociology, 9:1-22.

Schneider, C., Q., \& Wagemann, C. (2012). Set-Theoretic Methods: A User's Guide for Qualitative Comparative Analysis and Fuzzy Sets in Social Science. Cambridge: Cambridge University Press.

Schulte, B. (2002). A European definition of poverty: the fight against poverty and social exclusion in the member state of the European Union, In Townsend, P., \& D. Gordon (Eds.), World Poverty: New policies to defeat an old enemy (119-145). Bristol: The Policy Press. 
Sen, A.K. (1976). Poverty: An Ordinal Approach to Measurement. Econometrica, 44, 219-231.

Sen, A.K. (1985). Commodities and Capabilities. Oxford: Oxford University Press.

Sen, A.K. (1999). Development As Freedom. New York: Knopf.

Sen, A.K. (2000). Social Exclusion, Concept, Application, and Scrutiny, Social Development Papers No. 1, Asian Development Bank, June 2000.

Sen, A.K. (2005). Human Rights and Capabilities, Journal of Human Development, 6(2): 151-

Silver, H. \& Miller, S.M. (2003). Social Exclusion: The European Approach to Social Disadvantage. Indicators, 2 (2), 1 -17.

Stiglitz,J. (2000). Economics of the Public Sector, New York: W.W.Norton.

SORS (1996). Poverty Analysis, Statistical Office of the Republic of Slovenia, Ljubljana.

SORS (2006). Rapid Reports, Social Protection, No. 143 from July 31, 2006, Statistical Office of the Republic of Slovenia, Ljubljana.

Soskice, D. (1999). Divergent Production Regimes: Coordinated and Uncoordinated Market Economies in the 1980s and 1990s. In Herbert, K., Lange., P., Marks, G., \& J.D. Stephens, (Eds.), Continuity and Change in Contemporary Capitalism (101-134). Cambridge: Cambridge University Press.

Stropnik, N., \& Stanovnik, T. (2002). Combating Poverty and Social Exclusion - Volume 2, A Case Study of Slovenia, Budapest: International Labour Office.

Stutzer, A. (2001). The role of social work norms in job searching and subjective well-being, IZA Discussion Paper, 300.

Subbarao, K. (1997). Public works as an anti-poverty program. American Journal of Agricultural Economics, 79, 678-683.

Todman, L. (2004). Reflections on Social Exclusion: What is it? How is it different U.S. conceptualizations of disadvantage? And, why might Americans consider integrating it into U.S. social policy discourse? Retrieved December 20, 2009, from University of Milan Web site:

http://www.uic.edu/cuppa/cityfutures/papers/webpapers/cityfuturespapers/sessio n2_3/2_3reflections.pdf 
Townsend, P. (1979). Poverty in the United Kingdom. Harmondsworth: Penguin Books.

Trumm, A. (2002). Structural shifts in providing social assistance: Response to changing living conditions in Estonia. Fafo-paper 2002:1.

Trumm, A. (2005). Poverty in Estonia. Overview of main trends and patterns of poverty in the years 1996-2002, Fafo-report 497. Oslo, Fafo 2005.

Trumm, A. (2006). Recent developments of Estonia's social protection system, Background Paper Prepared for the EU 8 Social Inclusion Study, World Bank; University of Tartu.

UNDP (1998). Human Development Report Slovenia, Institute of Macroeconomic Analysis and Development.

UNDP (2011). Beyond transition - Towards Inclusive Societies, Regional Human Development Report, Regional Bureau for Europe and CIS, Bratislava, Slovakia.

UNDP/UNICEF (2010) Social Exclusion Dataset 2010, Retrieved December 9, 2001, from http://europeandcis.undp.org/poverty/show/DEAD2A6F-F203-1EE9B97DD75685658B6A

Van Praag, B., \& Ferrer, A. (2004). Happiness quantified: a satisfaction calculus approach. Oxford: Oxford University press.

Veenhoven, R. (1991). Is happiness relative? Social Indicators Research, 24, 1-34.

Veenhoven, R. (2000). Freedom and happiness: A comparative study in 46 nations in the early 1990's. In Diener, E., \& E.M. Suh (Eds.), Culture and subjective wellbeing (pp. 257-288). Cambridge (MA): MIT press.

Veenhoven, R. (2004). Subjective measures of well-being. WIDER Discussion Paper, 2004/07.

Veugelers, J., \& Magnan, A. (2005). Conditions of Far-Right Strength in Contemporary Western Europe: An Application of Kitschelt's Theory, European Journal of Political Research (44): 837-860.

Vidmar, A. K.(2000). Social Exclusion and Poverty in Slovenia, University of Ljubljana, presented at the conference on "New Governence" and the Social Dimension of Enlargement, Brussels, 18 October 2000. 
Vodopivec, M. (1998). Transition from Cash Benefit to Work: The Case of Slovenia, Empirical Economics, 23, 177-202.

Vodopivec, M., Wörgötter, A., \& Raju D. (2003). Unemployment Benefit Systems in Central and Eastern Europe: A Review of the 1990s, Social Protection Discussion Paper, 310, Washington (DC): World Bank.

Vlada Republike Srbije (2009). Izvestaj o realizaciji javnih radova od interesa za Republiku Srbiju u 2008. godini. Beograd, Srbija.

Wagemann, C., \& Schneider, C.,Q., (2010). Qualitative Comparative Analysis (QCA) and Fuzzy-Sets: Agenda for a Research Approach and a Data Analysis Technique. Comparative Sociology, 9:376-396.

Wagener, H.,J. (2002), The Welfare State in Transition Economies and Accession to the EU, West European Politics, 25(2): 152-174.

Wilensky, H., L. (1975). The Welfare State and Equality, Berkeley/Los Angeles/London: University of California Press.

World Bank (1996). Estonia Living Standards During the Transition: A Poverty Assessment, Washington (DC): The World Bank.

World Bank (1999), Slovenia: Economic Transformation and EU Accession: Main Report, Washington (DC): The World Bank.

World Bank (2000), Making transition work for everyone: Poverty and inequality in Europe and Central Asia. Washington DC, The World Bank.

World Bank, (2001), Attacking Poverty, World Development Report 2000/2001. World Bank (DC): World Bank and Oxford University Press.

World Bank (2005a), Growth, Poverty, and Inequality: Eastern Europe and the Former Soviet Union, Washington DC, The World Bank.

World Bank (2005b), Labor Markets and Social Policy in Central and Eastern Europe: The Accession and Beyond, Washington DC, The World Bank.

World Bank (2006). Serbia Social Assistance and Child Protection Note, Washington (DC): The World Bank. 
World Bank (2007). Social Assistance in Central Europe and the Baltic States, Washington (DC): The World Bank.

World Bank (2008). 2005 International Comparison Program: Tables of final results, Washington (DC): The World Bank.

World Bank (2010), World Development Indicator Database, Retrieved December 20, 2008, from World Bank Web site: http://data.worldbank.org/data-catalog/worlddevelopment-indicators. 


\section{APPENDICES}

\section{Appendix 1: Short overview of GMI schemes}

Table A1.1 Guaranteed minimum income (GMI) scheme statutory basis, willingness to work, activation and socio-professional integration, by countries

\begin{tabular}{|c|c|c|}
\hline Country & $\begin{array}{l}\text { Program name and } \\
\text { applicable statutory basis }\end{array}$ & $\begin{array}{l}\text { Willingness to work; Activation and } \\
\text { socio-professional integration }\end{array}$ \\
\hline $\begin{array}{l}\text { Czech } \\
\text { Republic }\end{array}$ & $\begin{array}{l}\text { Social Assistance Benefit } \\
\text { (Dávky sociální péče).Act } \\
\text { No } 463 / 91 \text { on Minimum } \\
\text { Living Standard (Zákon o } \\
\text { životním minimu).Act No } \\
482 / 91 \text { on Social Need (Zákon } \\
\text { o sociální potřebnosti). }\end{array}$ & $\begin{array}{l}\text { Willingness to work is a condition for } \\
\text { entitlement, with the exception of children } \\
\text { under } 18 \text { and adults over } 65 \text { years } \\
\text { (recipients of the pension). } \\
\text { Social work with individuals or families } \\
\text { precedes the grant of benefit. }\end{array}$ \\
\hline Cyprus & 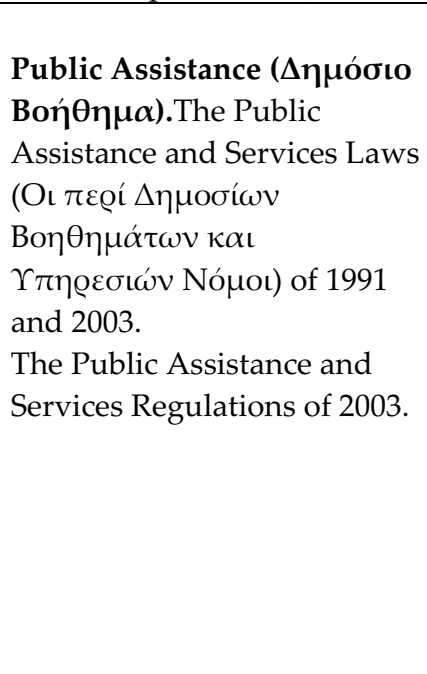 & $\begin{array}{l}\text { Taking into account personal and family } \\
\text { circumstances, healthy persons of } \\
\text { working age are expected to seek work. } \\
\text { An amount of up to CYP } 500 \text { ( } € 862) \text { may } \\
\text { be granted for training or professional } \\
\text { equipment for the claimant or a } \\
\text { dependant. } \\
\text { When determining the benefit as } \\
\text { differential amount, earnings from work } \\
\text { of the applicant and his/her dependants of } \\
\text { CYP } 20 \text { ( } € 34) \text { per month are not taken into } \\
\text { account. For single parents, this discount } \\
\text { amounts to CYP } 100 \text { ( } € 172 \text { ) or } 50 \% \text { of } \\
\text { their income, whichever is higher. For } \\
\text { persons with disabilities, CYP } 100 \text { ( } € 172) \\
\text { per month are not taken into account. }\end{array}$ \\
\hline Estonia & $\begin{array}{l}\text { Subsistence benefit } \\
\text { (toimetulekutoetus).Social } \\
\text { Welfare Act } \\
\text { (Sotsiaalhoolekande seadus) } \\
\text { 1995. }\end{array}$ & $\begin{array}{l}\text { Persons of working age who are without a } \\
\text { job must be registered as unemployed at } \\
\text { the labor market office. They must accept } \\
\text { a suitable job offer or participation in } \\
\text { rehabilitation or education programs } \\
\text { arranged by the local municipality. } \\
\text { Rehabilitation or education programs } \\
\text { arranged by the local municipality. } \\
\text { Since } 2002 \text {, the local municipality may } \\
\text { refuse to grant the benefit to those capable } \\
\text { of work and aged between } 18 \text { and }\end{array}$ \\
\hline
\end{tabular}




\begin{tabular}{|c|c|c|}
\hline & & $\begin{array}{l}\text { retirement age, who are neither working } \\
\text { nor studying and have repeatedly refused, } \\
\text { without due cause, offers of suitable work } \\
\text { or participation in rehabilitation or } \\
\text { education programs arranged by the local } \\
\text { municipality. }\end{array}$ \\
\hline Germany & $\begin{array}{l}\text { Sozialhilfe.Federal Social } \\
\text { Assistance Act } \\
\text { (Bundessozialhilfegesetz) of } \\
23 \text { March 1994.Social Code } \\
\text { (Sozialgesetzbuch), Book XII, } \\
\text { by the Act to integrate social } \\
\text { assistance legislation into the } \\
\text { Social Code (Gesetz zur } \\
\text { Einordnung des } \\
\text { Sozialhilferechts in das } \\
\text { Sozialgesetzbuch) of } 27 \\
\text { December 2003. }\end{array}$ & $\begin{array}{l}\text { Persons capable of working must be } \\
\text { prepared to carry out all work offered to } \\
\text { them, within reason. } \\
\text { A part of the earnings from work is not } \\
\text { taken into account for the calculation of } \\
\text { social assistance payments. It is possible to } \\
\text { pay a benefit for } 12 \text { months to recipients } \\
\text { of social aid who take up an employment } \\
\text { as an encouragement for them to take up a } \\
\text { new job. Back to work assistance (Hilfe } \\
\text { zur Arbeit):In order to encourage people } \\
\text { to take up work it is possible to offer an } \\
\text { employer allowance or other appropriate } \\
\text { means (e.g. hiring-out of labor or } \\
\text { temporary employment } \\
\text { contracts).Creation of jobs as regular } \\
\text { employment relationships (employment } \\
\text { contracts which are liable to social } \\
\text { insurance - social assistance fund may } \\
\text { cover the costs), creation of additional jobs } \\
\text { and jobs which are of benefit to the public } \\
\text { (employment relationships subject to } \\
\text { social insurance legislation or } \\
\text { compensation for additional expenditure } \\
\text { without employment contract). Co- } \\
\text { operation with the labor offices. In case } \\
\text { the beneficiary refuses to take up } \\
\text { reasonable work, the standard rate } \\
\text { (Regelsatz) allowance shall be reduced } \\
\text { imperatively by } 25 \% \text { and further } \\
\text { reductions to follow. Counseling and } \\
\text { support should help to prevent and } \\
\text { overcome the need of social assistance. }\end{array}$ \\
\hline France & $\begin{array}{l}\text { Revenu Minimum } \\
\text { d'Insertion (RMI).Social } \\
\text { action and Family Code } \\
\text { (Code de l'action sociale et de } \\
\text { la famille), articles L. 262-1 } \\
\text { and following. }\end{array}$ & $\begin{array}{l}\text { Beneficiaries must be available for } \\
\text { training, integration, or employment } \\
\text { activities on the basis of an integration } \\
\text { contract. Integration contract (Contrat } \\
\mathrm{d}^{\prime} \text { insertion) and Guaranteed minimum } \\
\text { resources (Revenu Minimum d'Insertion, } \\
\text { RMI): }\end{array}$ \\
\hline
\end{tabular}




\begin{tabular}{|c|c|c|}
\hline & & $\begin{array}{l}\text { During the contract period, the person } \\
\text { concerned receives minimum income } \\
\text { (SMIC) corresponding to the number of } \\
\text { hours worked. During the whole contract } \\
\text { period, this person continues to receive } \\
\text { the Guaranteed minimum resources } \\
\text { (Revenu Minimum d'Insertion, RMI) from } \\
\text { which the aid paid to the employer is } \\
\text { deducted (amount guaranteed only for an } \\
\text { individual). }\end{array}$ \\
\hline Latvia & $\begin{array}{l}\text { Guaranteed Minimum } \\
\text { Income Benefit (Pabalsts } \\
\text { garantētā minimālā } \\
\text { ienākuma līmeņa } \\
\text { nodrošināšanai).Law on } \\
\text { Social Services and Social } \\
\text { Assistance (Sociālo } \\
\text { pakalpojumu un sociālās } \\
\text { palīdzības likums) of } 31 \\
\text { October 2002. }\end{array}$ & $\begin{array}{l}\text { Unemployed beneficiaries capable of } \\
\text { work are obliged to register at the State } \\
\text { Employment Service, seek work and } \\
\text { accept suitable offers of work. } \\
\text { Acceptance of medical treatment and } \\
\text { rehabilitation (for example in the case of } \\
\text { alcohol or drug abuse) and participation } \\
\text { in measures promoting employment (for } \\
\text { example retraining, paid temporary } \\
\text { community jobs etc). } \\
\text { If the recipient has started to work, the } \\
\text { benefit is granted for further } 3 \text { months } \\
\text { (from the following month after the } \\
\text { person has informed about getting a job) } \\
\text { with a decreasing rate of } 75 \%, 50 \% \text { and } \\
25 \% \text { of the granted amount. }\end{array}$ \\
\hline Luxemburg & $\begin{array}{l}\text { Revenu Minimum Garanti. } \\
\text { Law of } 29 \text { April 1999, } \\
\text { creating a guaranteed } \\
\text { minimum income (revenu } \\
\text { minimum garanti). }\end{array}$ & $\begin{array}{l}\text { Persons need to be ready to participate in } \\
\text { active measures. } \\
\text { An integration allowance (indemnité } \\
\text { d'insertion) is granted when the } \\
\text { beneficiary signs an integration contract } \\
\text { (contrat d'insertion), takes part in an } \\
\text { integration activity and accepts any job } \\
\text { assigned by the employment } \\
\text { administration. }\end{array}$ \\
\hline Poland & $\begin{array}{l}\text { Social Assistance (Opieka } \\
\text { społeczna).Law on Social } \\
\text { Assistance (Ustawa o } \\
\text { pomocy społecznej) of } 12 \\
\text { March } 2004 .\end{array}$ & $\begin{array}{l}\text { All those capable of work must be } \\
\text { available for work, training or socio- } \\
\text { professional integration and be registered } \\
\text { with the labor office. } \\
\text { A small number of special measures } \\
\text { targeted at social assistance recipients and } \\
\text { linked to active labor market policies. }\end{array}$ \\
\hline Portugal & $\begin{array}{l}\text { Social insertion income } \\
\text { (Rendimento social de } \\
\text { inserção). Law } 13 / 03 \text { of } 21 \\
\text { May 2003. Statutory Order }\end{array}$ & $\begin{array}{l}\text { These measures are part of the social } \\
\text { integration program which, in conjunction } \\
\text { with the benefit, seeks to create favorable } \\
\text { conditions for the socio-professional }\end{array}$ \\
\hline
\end{tabular}




\begin{tabular}{|c|c|c|}
\hline & 283/03 of 8 November 2003. & $\begin{array}{l}\text { integration of the recipient and his family } \\
\text { members. }\end{array}$ \\
\hline Slovenia & 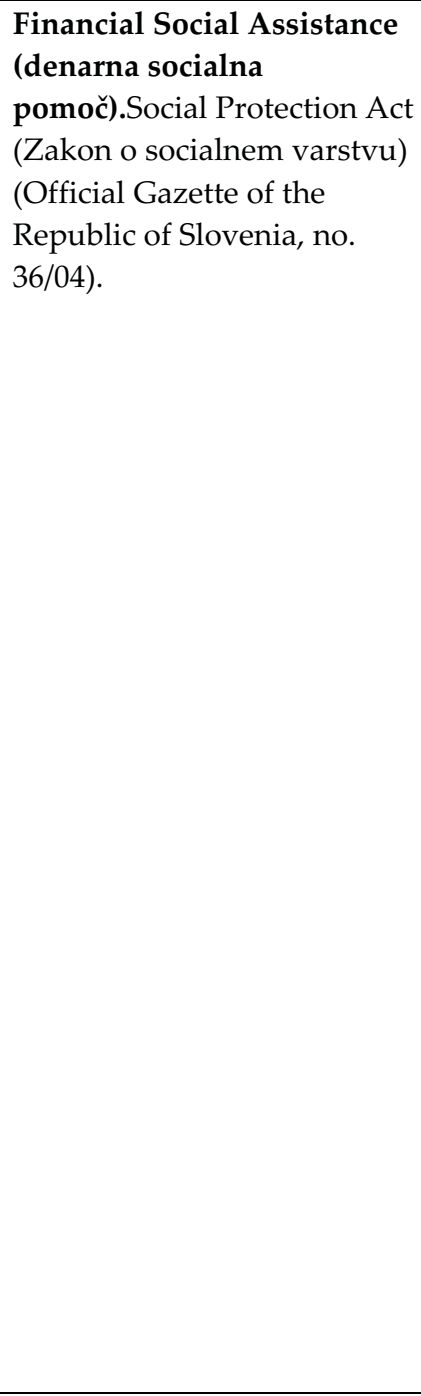 & $\begin{array}{l}\text { In principle everyone is obliged to } \\
\text { support him or herself through work. } \\
\text { Participation in an active employment } \\
\text { program must be considered before } \\
\text { granting assistance benefit. Entitlement } \\
\text { maybe linked to signing a contract with } \\
\text { the Social Work Centre (Center za } \\
\text { socialno delo), which places obligations } \\
\text { on the beneficiary to resolve his/her social } \\
\text { problems (rehabilitation, health treatment, } \\
\text { etc.). } \\
\text { Counseling and support in order to help } \\
\text { prevent and overcome the need for social } \\
\text { assistance (Social assistance services). A } \\
\text { closer link between Social Work Centers } \\
\text { and employment agencies was established } \\
\text { in } 1998 \text {. } \\
\text { A contract may be signed between the } \\
\text { Social Work Centre (Center za socialno } \\
\text { delo) and the beneficiary in which the } \\
\text { beneficiary agrees to actively resolve his } \\
\text { social problems. } \\
\text { Persons entitled to Financial Social } \\
\text { Assistance (denarna socialna pomoč) have } \\
\text { a preference of inclusion in active } \\
\text { employment policy programmes. } \\
\text { The employer is entitled to the subvention } \\
\text { of } 12 \times \text { Basic Minimum Income = SIT } \\
546,288 \text { ( } € 2,290 \text { ), if employ for an } \\
\text { indefinite period persons who was } \\
\text { entitled to Financial Social Assistance } \\
\text { (denarna socialna pomoč) at least } 24 \\
\text { months in last } 3 \text { years. }\end{array}$ \\
\hline Sweden & $\begin{array}{l}\text { Ekonomiskt bistånd.Law of } \\
\text { January } 2002 .\end{array}$ & $\begin{array}{l}\text { Everybody is bound to support him- or } \\
\text { herself first, and must try to get a job with } \\
\text { a sufficient salary at all times, as long as } \\
\text { he/she is able to work. } \\
\text { No general scheme. Social assistance for } \\
\text { persons capable to work linked to active } \\
\text { labor market measures in order to achieve } \\
\text { gainful employment. }\end{array}$ \\
\hline
\end{tabular}




\begin{tabular}{|c|c|c|}
\hline $\begin{array}{l}\text { United } \\
\text { Kingdom }\end{array}$ & $\begin{array}{l}\text { Income Support. Income } \\
\text { Support (General) } \\
\text { Regulations, } 1987 . \\
\text { Social Security } \\
\text { Administration Act } 1992 .\end{array}$ & $\begin{array}{l}\text { Not a condition for Income Support. } \\
\text { Personal Advisers meetings are } \\
\text { compulsory. Persons capable of working } \\
\text { are entitled to income based Jobseekers' } \\
\text { Allowance rather than Income Support. } \\
\text { Income disregards: } \\
\text { In calculating Income Support, earnings of } \\
\text { GBP } 5 \text { ( } € \text { 7.41) per week for single } \\
\text { claimants and GBP } 10 \text { ( } € \text { 15) per week for } \\
\text { couples are disregarded. Certain groups } \\
\text { qualify for a higher disregard of GBP } 20 \text { (€ } \\
\text { 30) per week e.g. lone parents, the sick } \\
\text { and the disabled. New Deal for Lone } \\
\text { Parents: Personal Adviser meetings are } \\
\text { compulsory for lone parents. They are } \\
\text { also compulsory for existent claimants. } \\
\text { Service provides advice and help to find } \\
\text { lone parents work. Other measures: } \\
\text { Development of the tax and benefit } \\
\text { systems aims to ensure that people are } \\
\text { better off working and are not } \\
\text { discouraged from increasing earnings. } \\
\text { Income Support ("run-on") is paid to lone } \\
\text { parents for two weeks after beginning } \\
\text { work if they have moved off benefit. Also } \\
\text { Housing Benefit and Council Tax Benefit } \\
\text { are extended for } 4 \text { weeks. For claimants of } \\
\text { IS/JSA receiving help with mortgage } \\
\text { interest, there is a run-on of } 4 \text { weeks. The } \\
\text { Working Tax Credit - an in-work tax } \\
\text { credit aimed at making work pay for } \\
\text { people and families with or without } \\
\text { children. Other measures include help } \\
\text { with rent through Housing Benefit (HB) } \\
\text { and Council Tax Benefit (CTB) once the } \\
\text { person is in work if they are on low pay. }\end{array}$ \\
\hline
\end{tabular}

NOTE: All presented GMIs include income and assets tests. Income not taken into account often involves family and child protection benefits, other social welfare benefits, and fees from activation and socio-professional integration. Rules vary by countries. More detailed descriptions are provided in the MISSOC database. Source: MISSOC, 2004. 


\section{Appendix 2: fsQCA with alternative consistency and cut-off values}

Table A2.1 Distribution of cases across causal combinations and set-theoretic consistency of causal combination as subsets of low at-risk-of-poverty rate (four conditions; frequency cut-off $=1$; consistency cut-off $=0.75$ )

\begin{tabular}{|c|c|c|c|c|c|c|}
\hline gdp & sps & sas & a & number & rp & Consist. \\
\hline 1 & 1 & 0 & 1 & 2 & 1 & 0.90 \\
\hline 0 & 1 & 1 & 1 & 1 & 1 & 0.85 \\
\hline 1 & 1 & 1 & 0 & 1 & 1 & 0.81 \\
\hline 0 & 0 & 0 & 1 & 2 & 1 & 0.76 \\
\hline 0 & 0 & 1 & 1 & 1 & 0 & 0.53 \\
\hline 0 & 0 & 0 & 0 & 1 & 0 & 0.51 \\
\hline 1 & 1 & 1 & 1 & 2 & 0 & 0.46 \\
\hline 1 & 0 & 1 & 0 & 1 & 0 & 0.25 \\
\hline 0 & 1 & 0 & 1 & 1 & 0 & 0.16 \\
\hline
\end{tabular}

Table A2.2 Measures of fit for sufficient fsQCA solution for the outcome low relative poverty (four conditions; frequency cut-off $=1$; consistency cut-off $=0.75$ )

\begin{tabular}{|c|c|c|c|c|}
\hline $\begin{array}{l}\text { Number } \\
\text { of term }\end{array}$ & Term & Consistency & $\begin{array}{c}\text { Raw } \\
\text { Coverage }\end{array}$ & $\begin{array}{l}\text { Unique } \\
\text { coverage }\end{array}$ \\
\hline \multicolumn{5}{|c|}{ Parsimonious/Complex solution } \\
\hline 1 & $\operatorname{gdp}^{*} \sim$ sas & 0.898990 & 0.290850 & 0.254902 \\
\hline 2 & $\operatorname{sps}^{*} \sim a$ & 0.532995 & 0.171569 & 0.101307 \\
\hline 3 & $\sim \operatorname{sps} *$ sas*a & 0.758065 & 0.230392 & 0.214052 \\
\hline 4 & $\sim \operatorname{gdp}{ }^{*} \mathrm{sps}^{*}$ sas & 0.848485 & 0.230392 & 0.101307 \\
\hline \multicolumn{5}{|c|}{$\begin{array}{l}\text { Note: Solution consistency }=0.82 \text {; Coverage }=0.77 \\
\text { Cases with greater than } 0.5 \text { membership in term gdp* } \sim \text { sas: United Kingdom }(0.98,0.9) \text {, France } \\
(0.65,0.83) \text {; Cases with greater than } 0.5 \text { membership in term sps* } \sim \text { a: Sweden }(0.67,0.92) \text {; Cases with } \\
\text { greater than } 0.5 \text { membership in term } \sim \text { sps }^{*} \sim \text { sas }^{*} \text { a: Estonia }(0.67,1) \text {, Latvia }(0.67,0.93) \text {; Cases with greater } \\
\text { than } 0.5 \text { membership in term } \sim \text { gdp }^{*} \text { sps }^{*} \text { sas: Slovenia }(0.62,0.99)\end{array}$} \\
\hline \multicolumn{5}{|c|}{ Intermediate solution } \\
\hline 1 & $a^{*} \sim$ sas $^{*} \sim$ sps $^{*} \sim g d p$ & 0.755435 & 0.227124 & 0.217320 \\
\hline 2 & $a^{*}$ sas $^{*}$ sps $^{*} \sim \operatorname{gdp}$ & 0.848485 & 0.183006 & 0.130719 \\
\hline 3 & $a^{*} \sim \operatorname{sas}^{*} \operatorname{sps}^{*} \operatorname{gdp}$ & 0.903061 & 0.289216 & 0.258170 \\
\hline 4 & $\sim \mathbf{a}^{*} \operatorname{sas}^{*} \operatorname{sps}^{*} \operatorname{gdp}$ & 0.809524 & 0.138889 & 0.101307 \\
\hline \multicolumn{5}{|c|}{$\begin{array}{l}\text { Note: Solution consistency }=0.88 \text {; Coverage }=0.77 \\
\text { Cases with greater than } 0.5 \text { membership in term } \mathrm{a}^{*} \sim \mathrm{sas}^{*} \sim \mathrm{sps}^{*} \sim \text { gdp: Estonia }(0.67,1) \text {, Latvia }(0.67,0.93) \text {; } \\
\text { Cases with greater than } 0.5 \text { membership in term } \mathrm{a}^{*} \mathrm{sas}^{*} \mathrm{sps}^{*} \sim \text { gdp: Slovenia }(0.62,0.99) \text {; Cases with } \\
\text { greater than } 0.5 \text { membership in term } \mathrm{a}^{*} \sim \operatorname{sas}^{*} \mathrm{sps}^{*} \text { gdp: United Kingdom }(0.97,0.9), \text { France }(0.65,0.83) \text {; } \\
\text { Cases with greater than } 0.5 \text { membership in term } \sim \mathrm{a}^{*} \operatorname{sas}^{*} \operatorname{sps}{ }^{*} \text { gdp: Sweden }(0.67,0.92)\end{array}$} \\
\hline
\end{tabular}




\section{Appendix 3: Initial Factor Method and correlation matrix}

Figure A3.1. Initial Factor Method: Principal components scree plot of eigenvalues

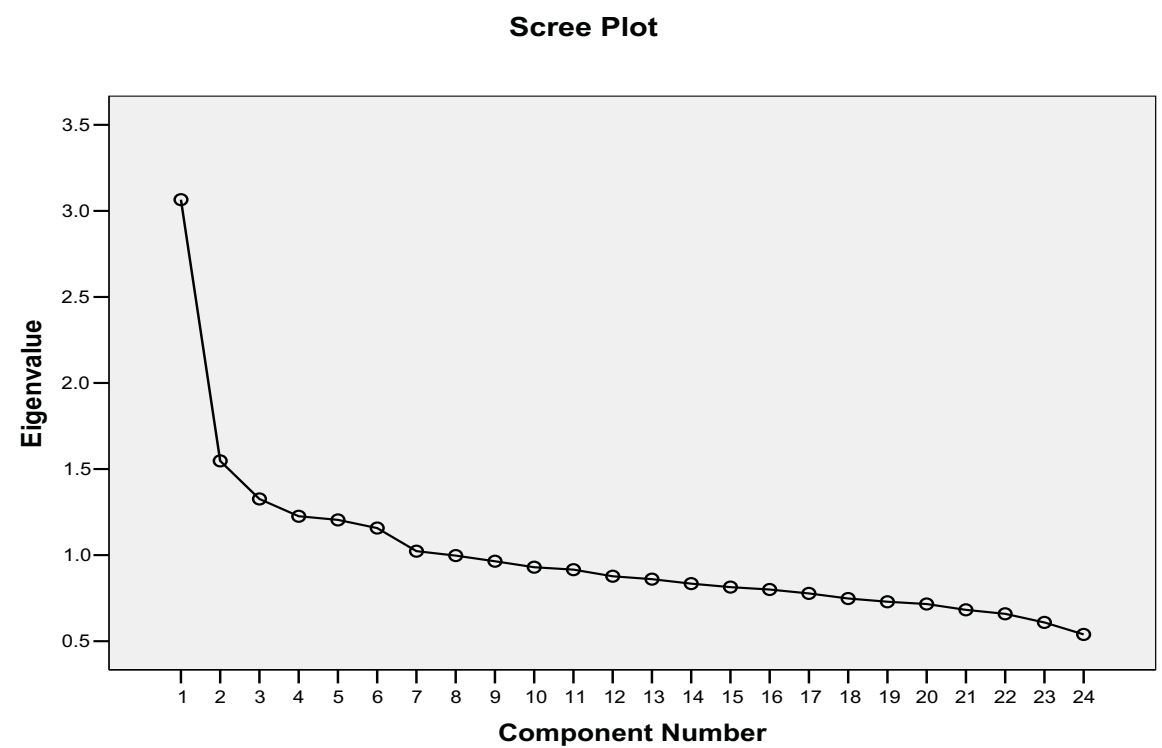

NOTE: The suitability of data for factor analysis was assessed prior to performing PCA. The Kaiser-Meyer-Oklin value was 0.74 , exceeding the recommended value of 0.6 , and Bartlett's Test of Sphericity reached statistical significance. PCA revealed the presence of seven components with eigenvalues exceeding 1 . An examination of the scree plot showed that there was no obvious single break in the plot that separates the meaningful components from the trivial components. Instead, the scree plot displayed three breaks, with the last two breaks after the components six and seven, following which the eigenvalues started to level off. It was decided to retain six components for further analysis. The results of Parallel Analysis ${ }^{68}$ also showed six components with eigenvalues exceeding the corresponding criterion values for a randomly generated data matrix of the same size (24 indicators x 2401 respondents). The six component solution explained 40 percent of the variance. There was a weak correlation between the six factors.

${ }^{68}$ Monte Carlo PCA for Parallel Analysis. 


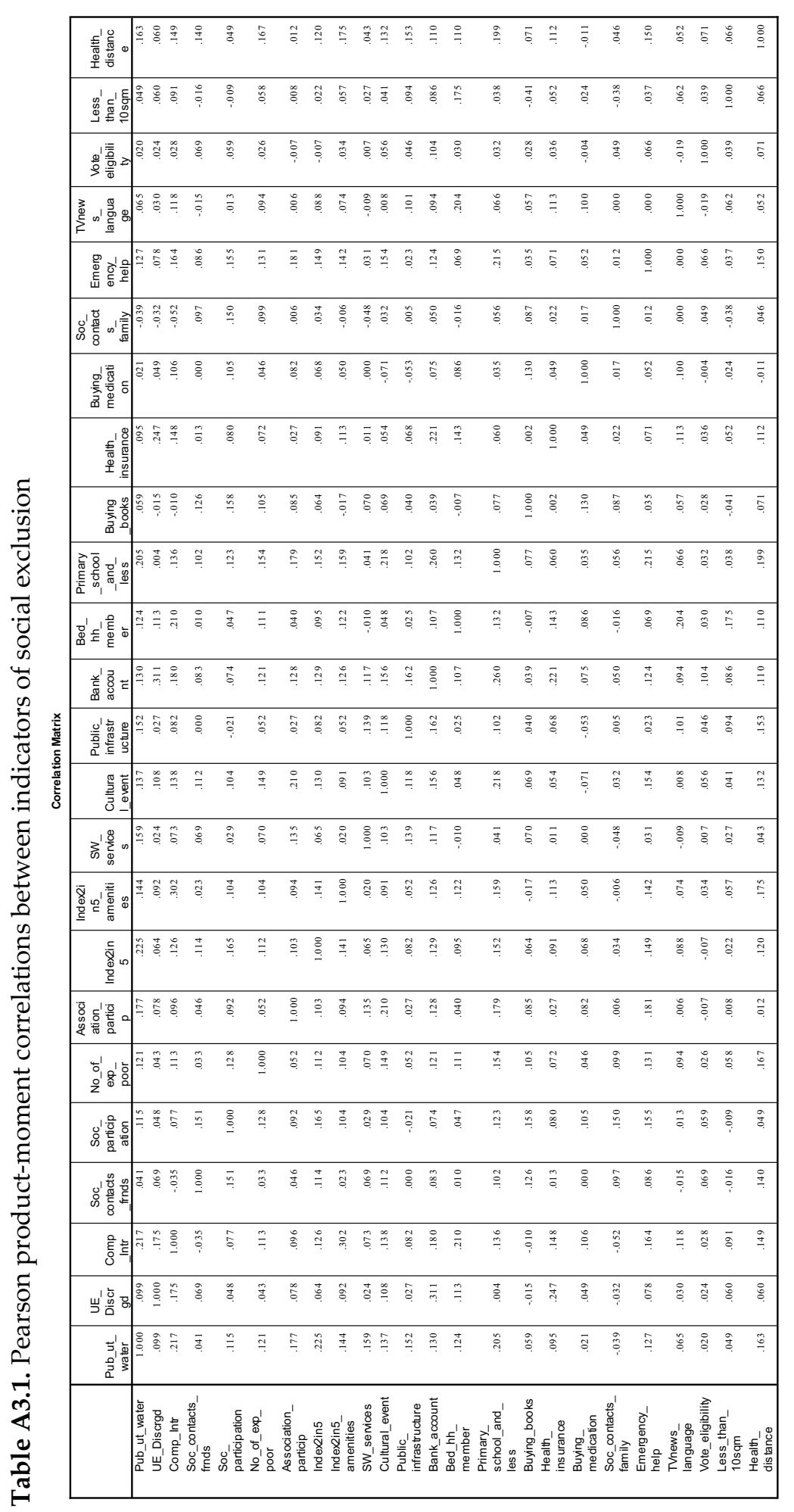




\section{Appendix 4: Logistic regression outputs for dependent variables referring to}

\section{different areas of deprivation}

Table A4.1. Logistic regression predicting likelihood of reporting lack of health insurance

\begin{tabular}{|c|c|c|c|c|c|c|}
\hline \multirow[b]{2}{*}{ Variable } & \multirow[b]{2}{*}{$B$} & \multirow[b]{2}{*}{ S.E. } & \multirow[b]{2}{*}{ Wald } & \multirow[b]{2}{*}{$d f$} & \multirow{2}{*}{$\frac{\text { Sig. }}{(p)}$} & \multirow{2}{*}{$\begin{array}{l}\text { Odds } \\
\text { Ratio }\end{array}$} \\
\hline & & & & & & \\
\hline Rural & 0.396 & 0.167 & 5.633 & 1 & 0.018 & 1.486 \\
\hline (ln)household size & -0.051 & 0.19 & 0.073 & 1 & 0.787 & 0.95 \\
\hline Child in household & -0.381 & 0.2 & 3.611 & 1 & 0.057 & 0.683 \\
\hline Elderly in household & -0.268 & 0.22 & 1.476 & 1 & 0.224 & 0.765 \\
\hline Primary education or less ${ }^{*}$ & 0.395 & 0.189 & 4.391 & 1 & 0.036 & 1.485 \\
\hline Post-secondary education* & -0.094 & 0.245 & 0.147 & 1 & 0.701 & 0.91 \\
\hline Unemployed & 1.488 & 0.174 & 72.872 & 1 & 0 & 4.428 \\
\hline Retired* & -1.695 & 0.458 & 13.676 & 1 & 0 & 0.184 \\
\hline $\begin{array}{l}\text { Other (home work or temporary or } \\
\text { permanent inactivity) }\end{array}$ & 0.713 & 0.299 & 5.681 & 1 & 0.017 & 2.04 \\
\hline Social assistance receipt & 0.169 & 0.275 & 0.376 & 1 & 0.54 & 1.184 \\
\hline Basic material deprivation & 0.678 & 0.221 & 9.435 & 1 & 0.002 & 1.971 \\
\hline Being at-risk-of-poverty & 0.446 & 0.184 & 5.895 & 1 & 0.015 & 1.563 \\
\hline Constant & -3.093 & 0.25 & 153.427 & 1 & 0 & 0.045 \\
\hline
\end{tabular}

NOTE: *We have created dummy variables for different levels of the original variables completed education and activity status. The levels that are not coded are secondary level education and employed respectively. These are the categories to which all other categories are compared.

Source: Authors' own calculation using UNDP/UNICEF Social Exclusion Dataset 2010. 
Table A4.2. Logistic regression predicting likelihood of reporting 'lack of social participation' 69

\begin{tabular}{|c|c|c|c|c|c|c|}
\hline Variable & $B$ & S.E. & Wald & $d f$ & Sig. & $\begin{array}{l}\text { Odds } \\
\text { Ratio }\end{array}$ \\
\hline Rural & $\begin{array}{r}- \\
0.428\end{array}$ & 0.233 & 3.367 & 1 & 0.067 & 0.652 \\
\hline (ln)household size & $\begin{array}{r}- \\
1.218 \\
\end{array}$ & 0.256 & 22.678 & 1 & 0 & 0.296 \\
\hline Child in household & 0.758 & 0.333 & 5.19 & 1 & 0.023 & 2.133 \\
\hline Elderly in household & $\begin{array}{r}- \\
0.189 \\
\end{array}$ & 0.296 & 0.41 & 1 & 0.522 & 0.827 \\
\hline Primary education or less* & 0.52 & 0.248 & 4.39 & 1 & 0.036 & 1.683 \\
\hline Post-secondary education* & $\begin{array}{r}- \\
0.621\end{array}$ & 0.423 & 2.15 & 1 & 0.143 & 0.538 \\
\hline Unemployed $^{*}$ & 1.09 & 0.315 & 11.984 & 1 & 0.001 & 2.973 \\
\hline Retired* & 1.011 & 0.353 & 8.218 & 1 & 0.004 & 2.747 \\
\hline $\begin{array}{l}\text { Other (home work or temporary or } \\
\text { permanent inactivity) }\end{array}$ & 1.009 & 0.445 & 5.139 & 1 & 0.023 & 2.742 \\
\hline Social assistance receipt & 0.645 & 0.364 & 3.14 & 1 & 0.076 & 1.907 \\
\hline Basic material deprivation & 1.183 & 0.254 & 21.621 & 1 & 0 & 3.265 \\
\hline Being at-risk-of-poverty & 0.606 & 0.239 & 6.445 & 1 & 0.011 & 1.833 \\
\hline Constant & $\begin{array}{r}- \\
3.288 \\
\end{array}$ & 0.329 & 100.174 & 1 & 0 & 0.037 \\
\hline
\end{tabular}

NOTE: *We have created dummy variables for different levels of the original variables completed education and activity status. The levels that are not coded are secondary level education and employed respectively. These are the categories to which all other categories are compared.

Source: Authors' own calculation using UNDP/UNICEF Social Exclusion Dataset 2010.

69 "Lack of social participation" refers to the following indicator: In the past 12 months the household has not been able to afford inviting friends or family for a meal or drink at least once a month or travel to family celebrations/family events. 
Table A4.3. Logistic regression predicting likelihood of reporting lack of access to a bank account

\begin{tabular}{|c|c|c|c|c|c|c|}
\hline Variable & $B$ & S.E. & Wald & $d f$ & $\frac{\text { Sig. }}{(p)}$ & $\begin{array}{l}\text { Odds } \\
\text { Ratio }\end{array}$ \\
\hline Rural & 0.286 & 0.099 & 8.391 & 1 & 0.004 & 1.332 \\
\hline (ln)household size & 0.308 & 0.116 & 6.984 & 1 & 0.008 & 1.36 \\
\hline Child in household & -0.079 & 0.12 & 0.429 & 1 & 0.513 & 0.924 \\
\hline Elderly in household & 0.163 & 0.125 & 1.716 & 1 & 0.19 & 1.177 \\
\hline Primary education or less* & 0.993 & 0.118 & 71.312 & 1 & 0 & 2.699 \\
\hline Post-secondary education* & -0.805 & 0.149 & 29.033 & 1 & 0 & 0.447 \\
\hline Unemployed* & 1.72 & 0.126 & 186.766 & 1 & 0 & 5.584 \\
\hline Retired* & -0.037 & 0.152 & 0.058 & 1 & 0.809 & 0.964 \\
\hline $\begin{array}{l}\text { Other (home work or temporary or } \\
\text { permanent inactivity) }\end{array}$ & 1.25 & 0.206 & 37.008 & 1 & 0 & 3.491 \\
\hline Social assistance receipt & 0.229 & 0.225 & 1.041 & 1 & 0.308 & 1.258 \\
\hline Basic material deprivation & 0.418 & 0.161 & 6.741 & 1 & 0.009 & 1.52 \\
\hline Being at-risk-of-poverty & 0.408 & 0.12 & 11.592 & 1 & 0.001 & 1.504 \\
\hline Constant & -1.716 & 0.149 & 131.819 & 1 & 0 & 0.18 \\
\hline
\end{tabular}

NOTE: *We have created dummy variables for different levels of the original variables completed education and activity status. The levels that are not coded are secondary level education and employed respectively. These are the categories to which all other categories are compared.

Source: Authors' own calculation using UNDP/UNICEF Social Exclusion Dataset 2010. 
Table A4.4. Logistic regression predicting likelihood of reporting lack of support networks that could help in the event of emergency

\begin{tabular}{|c|c|c|c|c|c|c|}
\hline Variable & $B$ & $S . E$ & Wald & $d f$ & $\frac{\text { Sig. }}{(p)}$ & Odds \\
\hline Rural & -0.216 & 0.12 & 3.239 & 1 & 0.072 & 0.806 \\
\hline (ln)household size & -0.163 & 0.131 & 1.552 & 1 & 0.213 & 0.849 \\
\hline Child in household & -0.123 & 0.153 & 0.654 & 1 & 0.419 & 0.884 \\
\hline Elderly in household & 0.43 & 0.141 & 9.346 & 1 & 0.002 & 1.537 \\
\hline Primary education or less* & 0.747 & 0.13 & 33.136 & 1 & 0 & 2.111 \\
\hline Post-secondary education* & -0.557 & 0.191 & 8.523 & 1 & 0.004 & 0.573 \\
\hline Unemployed* & 0.671 & 0.149 & 20.277 & 1 & 0 & 1.956 \\
\hline Retired* & 0.459 & 0.17 & 7.25 & 1 & 0.007 & 1.582 \\
\hline $\begin{array}{l}\text { Other (home work or temporary or } \\
\text { permanent inactivity)* }\end{array}$ & 0.126 & 0.249 & 0.257 & 1 & 0.612 & 1.135 \\
\hline Social assistance receipt & 0.27 & 0.231 & 1.362 & 1 & 0.243 & 1.31 \\
\hline Basic material deprivation & 0.639 & 0.163 & 15.294 & 1 & 0 & 1.895 \\
\hline Being at-risk-of-poverty & 0.383 & 0.134 & 8.217 & 1 & 0.004 & 1.467 \\
\hline Constant & -1.995 & 0.17 & 137.536 & 1 & 0 & 0.136 \\
\hline
\end{tabular}

NOTE: *We have created dummy variables for different levels of the original variables completed education and activity status. The levels that are not coded are secondary level education and employed respectively. These are the categories to which all other categories are compared.

Source: Authors' own calculation using UNDP/UNICEF Social Exclusion Dataset 2010. 
Table A4.5. Logistic regression predicting likelihood of reporting basic material deprivation

\begin{tabular}{|c|c|c|c|c|c|c|}
\hline \multirow[b]{2}{*}{ Variable } & \multirow[b]{2}{*}{$B$} & \multirow[b]{2}{*}{ S.E. } & \multirow[b]{2}{*}{ Wald } & \multirow[b]{2}{*}{$d f$} & \multirow{2}{*}{$\begin{array}{l}\text { Sig. } \\
(p)\end{array}$} & \multirow{2}{*}{$\begin{array}{l}\text { Odds } \\
\text { Ratio }\end{array}$} \\
\hline & & & & & & \\
\hline Rural & 0.615 & 0.155 & 15.825 & 1 & 0 & 1.85 \\
\hline (ln)household size & -0.193 & 0.165 & 1.371 & 1 & 0.242 & 0.825 \\
\hline Child in household & -0.14 & 0.199 & 0.493 & 1 & 0.483 & 0.87 \\
\hline Elderly in household & 0.618 & 0.172 & 12.827 & 1 & 0 & 1.855 \\
\hline Primary education or less ${ }^{*}$ & 0.502 & 0.165 & 9.234 & 1 & 0.002 & 1.652 \\
\hline Post-secondary education* & -0.389 & 0.251 & 2.406 & 1 & 0.121 & 0.678 \\
\hline Unemployed $^{*}$ & 0.7 & 0.191 & 13.463 & 1 & 0 & 2.014 \\
\hline Retired $^{*}$ & 0.514 & 0.22 & 5.472 & 1 & 0.019 & 1.672 \\
\hline $\begin{array}{l}\text { Other (home work or temporary or } \\
\text { permanent inactivity) }\end{array}$ & 0.472 & 0.287 & 2.695 & 1 & 0.101 & 1.603 \\
\hline Social assistance receipt & 0.634 & 0.258 & 6.052 & 1 & 0.014 & 1.885 \\
\hline Being at-risk-of-poverty & 0.38 & 0.164 & 5.379 & 1 & 0.02 & 1.463 \\
\hline Constant & -3.134 & 0.23 & 185.759 & 1 & 0 & 0.044 \\
\hline
\end{tabular}

NOTE: *We have created dummy variables for different levels of the original variables completed education and activity status. The levels that are not coded are secondary level education and employed respectively. These are the categories to which all other categories are compared.

Source: Authors' own calculation using UNDP/UNICEF Social Exclusion Dataset 2010. 


\section{Appendix 5: Financial Social Assistance (FSA) program in Serbia and key characteristics of its beneficiaries}

\section{New features of the financial social assistance (FSA) program in Serbia}

FSA (financial social assistance) or MOP (materijalno obezbedjenje)/NSP (novcana socijalna pomoc) benefit is the main social assistance program in Serbia. ${ }^{70}$ It is a means-tested benefit for poor individuals and households which is financed and delivered by Ministry of Labor and Social Policy (MLSP) through Centers for Social Work (CSW). FSA is aimed at individuals and households with an income below the minimum social welfare threshold that is administratively established. It fills the gap between the household's income and the administrative threshold adjusted for the household size. In addition to the income test, FSA eligibility criteria also involve an asset test.

In 2011, the Republic of Serbia adopted a new Law on Social Welfare which significantly changed the FSA benefit levels and coverage, particularly for beneficiaries living in multi-member households and in the households with members who are unable to work. In addition, the social welfare law placed a new emphasis on activation so that the FSA recipients are expected to become more active in addressing their own problems.

With the enactment of the new law, the FSA benefit is set at a higher level and calculated based on a new equivalence scale aligned to the modified OECD scale (1 for the first adult, 0.5 for the second and each additional adult, and 0.3 for the child). For households without capable to work members, the law provides for a 20 percent benefit increase. The maximum number of eligible members was raised from five to six, while the maximum benefit duration of nine months for households where the majority of members is able to work remained unchanged. The land ownership threshold was increased from 0.5 to 1 hectare for households with members who are unable to work. The definition of individuals "not capable to work" also changed to include college and university students, pregnant women, and those providing care to disabled family members.

The new law also places emphasis on activation of FSA recipients through education, training, employment and community based work. For the first time, the Law on Social Welfare prescribes that an individual who is capable to work has

${ }^{70} \mathrm{MOP}$ and NSP refer to the same program. The program changed the name with the adoption of the new Law on Social Welfare (April 2011). 
the right, as well as the obligation, to participate in activities leading to his/her inclusion in society. The law gives the possibility to the CSWs to sign agreements with beneficiaries for their activation (individual activation plans) and with other service providers such as the National Employment Service.

The number of FSA recipients has been on the rise since the enactment of the new law. Administrative data show that 215,490 individuals $(83,470$ households) or almost 3 percent of the total Serbian population received FSA in April 2012.

\section{Key characteristics of the population receiving financial social assistance (FSA) ${ }^{71}$}

In Serbia, more women than men are FSA recipients - 52.2 percent and 47.8 percent, respectively. Table A5.1 below shows that the majority of recipients are in the age group 30 to 49 years of age (41.8 percent), followed by over one third of recipients in the age cohort 50 to 64 years of age. Young people 15 to 19 years old represent 27.1 percent of all FSA beneficiaries. Single-members households represent 36.4 percent of all recipient households. Two- and three-member households represent 22.2 percent and 16.7 percent of all recipients, while the share of four- and five-member households is 12.9 and 7.7 percent, respectively. Households with six members and more account for 4.1. percent of the total.

Over 65 percent of all FSA recipients live in urban areas. Southern and Eastern Serbia has the larger share of FSA recipients (39.6 percent) and Belgrade the lowest (7.9 percent). This is in line with poverty estimates that indicate lower poverty rates in Belgrade compared to other Serbian regions (Republican Statistical Office, 2008).

In terms of educational outcomes, over two third of FSA recipients have primary education or less, nearly twice the share found for the overall population (30 percent). Among these, nearly 6 percent never went to school and 14.9 percent did not complete compulsory education. Only 38 percent of FSA beneficiaries has secondary education, compared to over 70 percent recorded for the Serbian population (Government of Serbia, 2011). Approximately 2 percent of FSA beneficiaries have university education.

\footnotetext{
${ }^{71}$ Based on the Serbia FSA recipient dataset (International Labor Organization, 2011).
} 
Table A5.1. Main characteristics of FSA population, percent

\begin{tabular}{|l|c|}
\hline Sex & 47.8 \\
\hline Men & 52.2 \\
\hline Women & 27.1 \\
\hline Age group & 41.8 \\
\hline 15-29 years old & 31.1 \\
\hline 30-49 years old & \\
\hline $50-64$ years old & 65.7 \\
\hline Settlement type and region & 34.3 \\
\hline Urban & 7.9 \\
\hline Non-urban ${ }^{72}$ & 23.2 \\
\hline Belgrade & 29.3 \\
\hline Vojvodina & 39.6 \\
\hline Sumadija and Western Serbia & 35.5 \\
\hline Southern and Eastern Serbia & 1.0 \\
\hline Educational attainment & 1.1 \\
\hline No education & 14.9 \\
\hline Incomplete primary education & 41.8 \\
\hline Primary education (8 grades) & \\
\hline Secondary education & \\
\hline College education & \\
\hline University & \\
\hline & \\
\hline
\end{tabular}

Source: Petrovic (2011).

Around 43 percent of FSA recipients also enjoy other types of social transfers. The largest overlap is between the FSA and child allowances, with around 94 percent of FSA recipient households also receiving child allowance and 5 percent receiving caregivers' allowance, with no significant difference among the various groups (Figure A5.1). Other types of transfers (one-off payments, parental allowances and student bursaries) are less common. None of the respondents received humanitarian aid in the reference period.

72 "Non-urban" corresponds to "Other" areas ("Ostalo" in the Serbian language) in the official statistics and includes non-urban and sub-urban areas. 
Figure A5.1. FSA combined with other social transfers, percent

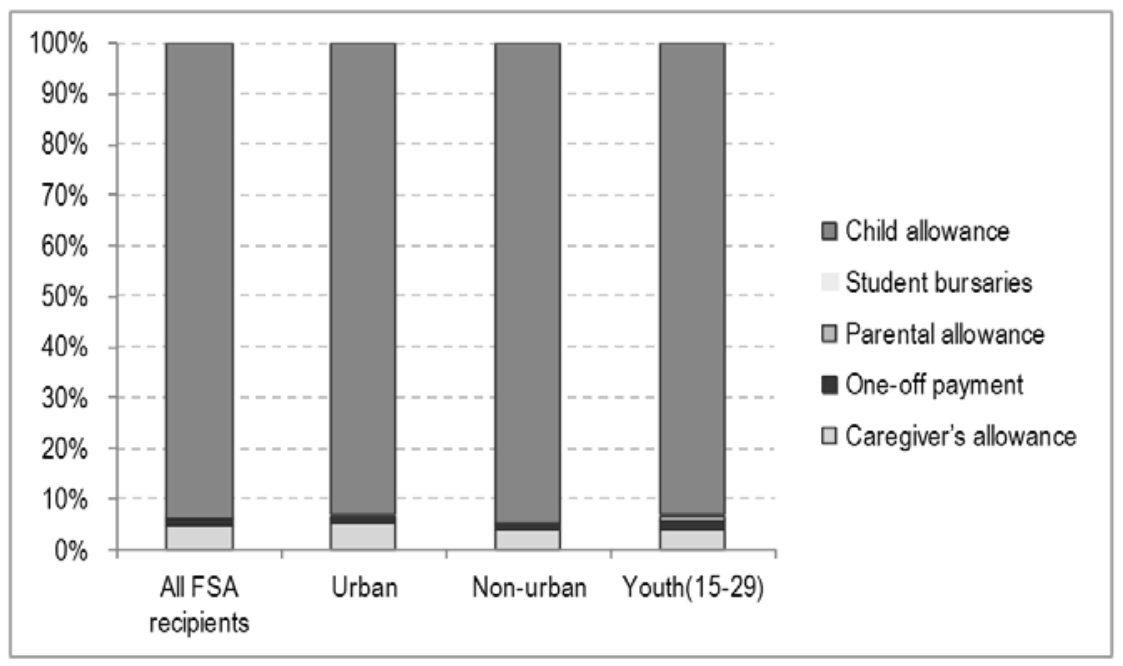

Source: Petrovic (2011).

The average duration of the benefit is 4.4 years, with women more likely to remain longer on the benefits compared to men (4.7 and 4 years, respectively). Over 6 percent of households had been receiving the FSA benefit for more than 10 years, 19 percent for over 5 years. Only 10 percent had been on benefits for less than a year. This indicates that for many individuals and households the lack of resources is a long-term problem from which it is difficult to escape.

Over one fifth of all FSA recipients come from families that were themselves on social assistance. This share is significantly higher for individuals living in nonurban areas and in Sumadija and Western Serbia. A relatively smaller share of FSA recipients in Southern and Eastern Serbia comes from beneficiary families, despite the fact that this region has currently the largest share of FSA recipients. One possible explanation is that a significant number of poor individuals living in this region became eligible following the 2004 amendments of the Law on Social Welfare, namely after the setting of a single eligibility threshold for the whole country. ${ }^{73}$

The survey data also report the subjective assessment of recipients on the level of needs covered by the FSA benefit. For over 97 percent of respondents, the benefit covers only half or less of their needs. Over 80 percent deems that only one third of

\footnotetext{
${ }^{73}$ According to the previous social welfare law, the FSA eligibility thresholds were set at municipal level on the basis of the average salary in the given municipality. When the threshold was unified, the number of FSA recipients in municipalities with low salaries and low eligibility thresholds increased.
} 
their needs is covered, with roughly the same percentage being satisfied through own production. The average amount that is perceived to be needed is 29,756 Serbian dinars (RSD), approximately 1.5 times the minimum wage. ${ }^{74}$

\section{Employment history}

The figures of the survey indicate that only 3 percent of FSA recipients is employed, with 44 percent working in the formal economy and 56 percent involved in various kinds of informal activities.

Over 55 percent of working age FSA recipients have prior work experience, men more than women (61 percent and 44 percent respectively), with an average length of employment of 12 years. Only 17.2 percent of young people - including those in school at the time of the survey - have prior work experience.

Over half of FSA recipients was dismissed, either due to bankruptcy/closure of the enterprise or for other reasons (Table A5.2). This is particularly the case for beneficiaries 50 years of age and older. The composition of FSA recipients appears to be shifting towards individuals who lost their jobs during the transition to a market economy, given the relatively higher number of new FSA beneficiaries with prior formal work history. For roughly 28 percent of beneficiaries employment ceased due to the temporary/seasonal character of the job, while 6 percent left work due to illness or disability.

Table A5.2. Reasons for losing the job, percent

\begin{tabular}{|l|c|c|c|c|c|c|}
\hline \multirow{2}{*}{ Reasons } & \multicolumn{3}{|l|}{ Sex } & \multicolumn{3}{l|}{ Age groups } \\
\cline { 3 - 8 } & Total & Male & Female & $\mathbf{1 5 - 2 9}$ & $\mathbf{3 0 - 4 9}$ & $\mathbf{5 0 - 6 4}$ \\
\hline Dismissed (including bankruptcy) & 55.6 & 58.2 & 52.3 & 27.8 & 48.3 & 68.9 \\
\hline The job was temporary or seasonal & 27.8 & 27.1 & 28.7 & 65.8 & 33.8 & 13.7 \\
\hline Own illness or disability & 5.7 & 6.2 & 5.0 & 2.6 & 7.3 & 4.7 \\
\hline $\begin{array}{l}\text { Other personal and family reasons } \\
\text { Looking after children or } \\
\text { incapacitated adults }\end{array}$ & 1.7 & 1.3 & 2.2 & 0.0 & 1.6 & 2.2 \\
\hline
\end{tabular}

Source: Petrovic (2011).

\footnotetext{
74 The net minimum wage in Serbia in the same period was 17,136 dinars, while the FSA ranged from 6,552 dinars for single member household to 17,690 dinars for households with two adults and four children.
} 
Over 65 percent of young beneficiary lost their job due to its temporary/seasonal duration, confirming that temporary work is the predominant form of employment for young people in Serbia. Around 3 percent of beneficiaries had to leave work due to personal or family reasons (including care responsibilities).

As regard the type of work FSA recipients carried in the past, only 2 percent were employed in jobs organized by the local self-government. Of these, 55 percent had an employment contract, while 45 percent received a lump-sum payment for the work performed. Men were more likely to be involved in such jobs compared to women. A higher share of FSA recipients (4.7 percent), however, participated to public works.

The percentage of FSA recipients who found employment after participating to a public work program is 6.8 percent, which is higher than the employment rate found for all public works' participants - 1.4 percent in 2007 according to Arandarenko and Krstic (2008). Men are more likely to participate to a public work program compared to women (6.1 percent and 3.4 percent, respectively). Likewise, the percentage of individuals in the prime age (30-49 years old) and older cohort (50-64) engaged in public work is higher than that of young people (6 percent, 5.8 percent and 4 percent, respectively).

One third of FSA recipients who participated in public works think they have gained the skills needed to find a new job, while approximately one half considered the salary level of public works as a good enough incentive to work.

Only 6.2 percent of all FSA beneficiaries would work rather than remain on benefits, if offered works at a salary equal to the FSA amount (Table A5.3). However, recipients that participated to public works are much more likely to opt for work compared to other groups of beneficiaries (27 percent). The same applies to individuals living in single and two-member households compared to beneficiaries of larger households.

The low availability to work is not surprising for at least two reasons. First, the work alternative was offered at a salary level equal to the social assistance benefit, which is often much lower than the statutory minimum wage. ${ }^{75}$

The younger cohort is less available to work at low wages compared to other age groups. This points to a reservation wage mechanism among young beneficiaries. Second, since a considerable share of beneficiaries does not have any prior work experience, they are unaware of all the advantages associated with being productively employed. Public work participants, who had the opportunity to have a job and earn a salary, seem to be more willing to work. The figures suggest

\footnotetext{
75 The level of the social assistance benefit depends on the size of the household - the lower the number of family members the smaller the benefit.
} 
that there is a core 6.8 percent of FSA recipients who are willing and available to work for a salary level equal to the amount of social assistance. ${ }^{76}$

Table A5.3. FSA recipients opting to work rather than remain on benefits, percent

\begin{tabular}{|c|l|}
\hline Total FSA recipient who would work & 6.2 \\
\hline Total FSA recipients, excluding students & 6.8 \\
\hline Beneficiaries 15-29 years old (excluding students) & 6.1 \\
\hline Beneficiaries 30-49 years old & 6.7 \\
\hline Beneficiaries 50-64 years old & 7.6 \\
\hline Beneficiaries who participated in public works & 26.7 \\
\hline Beneficiaries who did not participate in public works & 5.2 \\
\hline Beneficiaries living in single-member households & 9.2 \\
\hline Beneficiaries living in two-member households & 7.1 \\
\hline
\end{tabular}

Source: Petrovic (2011).

Beneficiaries who would opt for work do so mainly to secure a minimum old age pension. This is why the older cohort of FSA recipients is more likely to opt for work than other age groups (Figure A5.2). Other important reasons for opting to work is the need to have a productive role in society (do not want charity) and the opportunity to gain work experience necessary to find better jobs. This is particularly the case for over a third of young people.

76 This share would probably have been higher had the survey been carried out of season, e.g. in the period of the year when there are larger numbers of FSA recipients able and willing to work. 
Figure A5.2. Main reasons for opting to work, percent

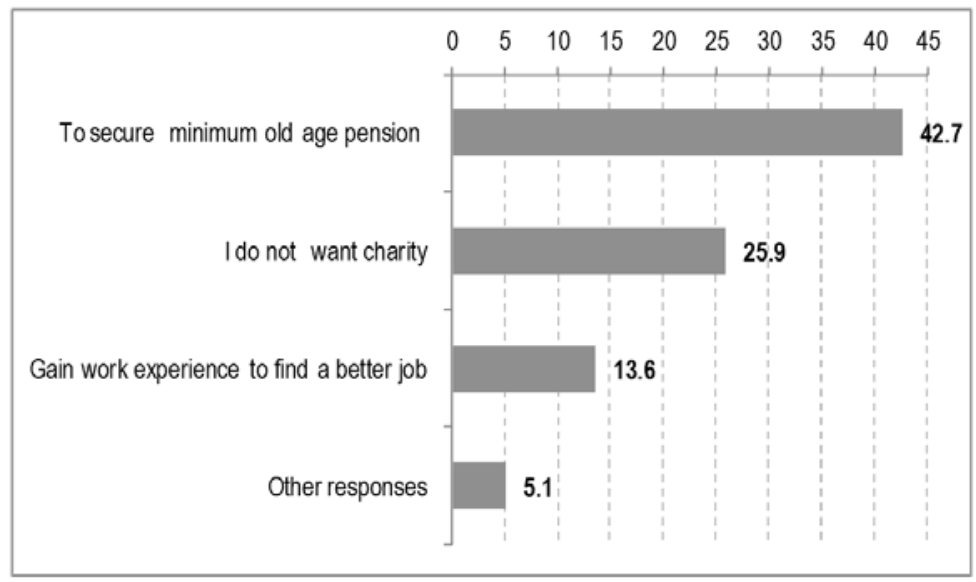

Source: Petrovic (2011).

Figure A5.3 below shows the main (perceived) obstacles that FSA beneficiaries face in taking up work. Nearly half of respondents indicate the lack of jobs as the main constraint, followed by poor health (17 percent). Given the high and rising unemployment rates recorded in Serbia since the onset of the global economic crisis in 2008, the high share of respondents pointing to low labor demand as the main obstacle is not surprising. However, a contributing factor may be the workers' discouragement effect, as many FSA recipients are long-term unemployed and they may have lost confidence in ever being able to find a job.

Figure A5.3. Main obstacles to work, percent

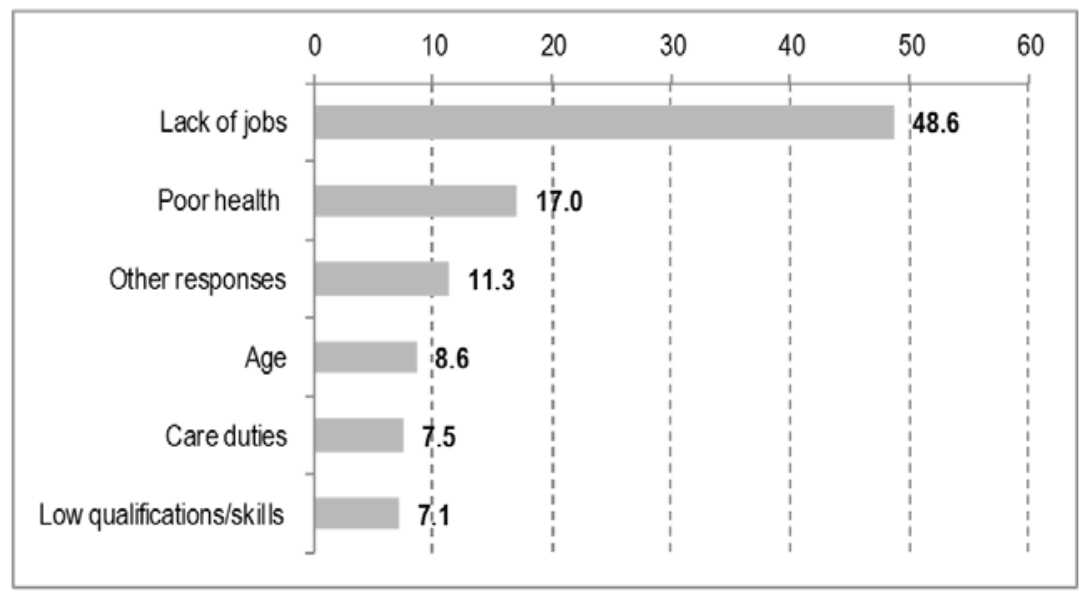

Source: Petrovic (2011). 
Age is also a significant constraint, especially for older beneficiaries (aged 50 years old and over). An almost equal share of FSA recipients (over 7 percent) find lack of qualifications and care responsibilities as the as the main obstacles to work.

\section{Job search and return to education}

Around three quarters of all FSA recipients are registered with the National Employment Service (NES). ${ }^{77}$ However, only 41 percent were looking for a job in the four weeks preceding the survey, with men being more active (47 percent) than women (35 percent). The younger cohort (15-29) is the most active in job search. If we compare these figures with the reasons for not looking for a job or with the share of referrals, it is clear that many FSA beneficiaries have lost hope of ever finding work and the system does not encourage them to be more active.

Among FSA recipients registered with NES, the main reason for not searching for a job is illness or disability and care duties (Table A5.4). Based on the figures presented so far, it is difficult to find a reasonable explanation of such high shares of FSA recipients (43 percent) claiming to be unable to work due poor health or disability. A significant share of recipients (19 percent) have care responsibilities (looking after children or disabled adults).

Most young FSA recipients registered with the employment service were not searching for a job due to care responsibilities (43 percent), with a much smaller share not searching for a job due to poor health (14 percent of young beneficiaries compared to 43 percent among FSA recipients). Less than 2 percent were discouraged workers compared to over 16 percent found among the overall recipient population. These results suggest that the potential for activation lies mostly with the younger group.

One third of FSA recipients registered with the employment service - but not looking for a job - would accept a job offer. However, 4.3 percent of beneficiaries to whom a job was offered, rejected it. Nearly 60 percent would be available to start work within two weeks. The reasons for not being available within the two weeks period range from maternity leave to illness and school attendance (Table A5.4). These results overlap to some extent with the previous figures, except in that here personal and family reasons prevail over illness or disability.

\footnotetext{
77 Those who are not registered include students, pensioners, as well as persons who are temporarily or permanently unable to work for any other reason.
} 
Table A5.4. Reasons for not looking for a job (beneficiaries registered with the NES), percent

\begin{tabular}{|l|c|c|}
\hline Reasons for not looking for a job & $\begin{array}{c}\text { All } \\
\text { recipients }\end{array}$ & Youth \\
\hline Illness or disability & 43.4 & 13.9 \\
\hline In education or training & 1.1 & 6.7 \\
\hline Looking after children or disabled adults & 18.7 & 42.8 \\
\hline Lost hope in finding a job & 15.9 & 1.9 \\
\hline Other personal or family reasons & 13.4 & 17.2 \\
\hline Reasons for not being available to work & & \\
\hline Personal or family reasons (including maternity leave) & 52.5 & 76.8 \\
\hline Illness or disability & 46.5 & 18 \\
\hline In education or training & 0.9 & 5.2 \\
\hline Reasons for visiting the employment service & & \\
\hline Complying with the obligation to report regularly & 67 & 60.5 \\
\hline Consultations on the individual employment plan & 6.3 & 2.6 \\
\hline Need additional information (vacancies, measures) & 7.3 & 11.7 \\
\hline Consultations for intake into employment programs & 0.9 & 2.2 \\
\hline
\end{tabular}

Source: Petrovic (2011).

The high share of beneficiaries unable to work (over 40 percent) is in line with the incidence of FSA recipients involved in case management, pointing to objective reasons preventing recipients from being active in the labor market. Again, young recipients are less likely to indicate illness or disability as the reason for not being available for work (18 percent compared to 47 percent).

One way to gauge the level of individual job search activity is to look at the frequency with which FSA recipients registered with the employment service visit their case workers and for which reasons. Only 3 percent of FSA beneficiaries visit NES offices on a monthly basis. Most beneficiaries (77 percent) visit the NES offices every three months and the remaining 20 percent once every six months. These visits are mainly related to compliance with the formal obligation to report (67 percent), while 7 percent of beneficiaries visit the employment offices to have information on job vacancies or on their individual employment plan. Young people seem to be more active in requesting additional information. 
Jobs search activity is closely related to educational background and personal attitudes, including the individual's willingness to engage in education, training or employment. Only 3 percent of all FSA beneficiaries are willing to return to the formal education system, with young people more prone to return to education (10.6 percent) compared to other groups (Figure A5.4)

Figure A5.4 Willingness to return to education or participate to a training program, percent 78

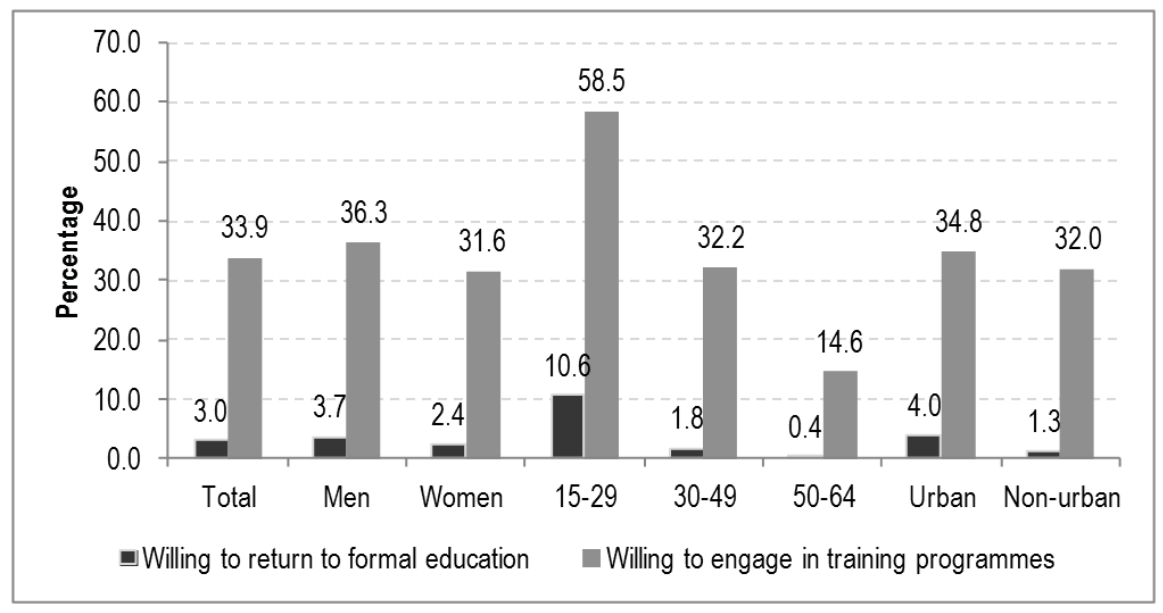

Source: Petrovic (2011).

The share of FSA recipients who participated in a training program at any time is 8 percent. For some respondents, training was provided as part of the public work program. The duration of training varied from few days (on-the-job) to a one month-long certified training program (organized by a training institution). For most beneficiaries, these programs represent the only qualification ever gained. The data further suggest that 34 percent of FSA recipients would be willing to participate in training programs. Among those who participated in public works, the share is ten percentage points higher. Overall, the number of individuals interested in training programs is significantly higher than those interested in returning to formal education. Nearly 60 percent of young beneficiaries are willing to attend training courses, but only 11 percent would return to school.

Approximately 32 percent of beneficiaries in the age group 30-49 years old and 15 percent of those over 50 years of age would be willing to participate to training

\footnotetext{
${ }^{78}$ Figures for the 15-29 age group exclude students.
} 
programs. The main reason for hesitation to return to school or participate in a training program is age (Tables A5.5 and A5.6).

Table A5.5. Main reasons for not returning to school, percent

\begin{tabular}{|c|c|c|c|c|c|c|c|c|}
\hline \multirow[b]{2}{*}{ Reasons } & \multirow[b]{2}{*}{ Total } & \multicolumn{2}{|l|}{ Sex } & \multicolumn{3}{|c|}{ Age group } & \multicolumn{2}{|c|}{ Settlement } \\
\hline & & Men & Women & $\begin{array}{l}15- \\
29\end{array}$ & $\begin{array}{l}30- \\
49\end{array}$ & $\begin{array}{l}50- \\
64\end{array}$ & Urban & $\begin{array}{l}\text { Non } \\
\text { urban }\end{array}$ \\
\hline Has to earn a living & 19.1 & 21.9 & 16.6 & 22.9 & 24.3 & 10.3 & 19.1 & 19.0 \\
\hline Too old & 48.0 & 48.6 & 47.5 & 2.0 & 40.1 & 80.4 & 49.2 & 45.8 \\
\hline $\begin{array}{l}\text { Education is } \\
\text { inadequate and does } \\
\text { not help to find a job }\end{array}$ & 1.4 & 1.9 & 0.9 & 1.2 & 2.1 & 0.6 & 1.4 & 1.3 \\
\hline School is too far & 0.2 & 0.3 & 0.1 & 0.0 & 0.4 & 0.0 & 0.2 & 0.2 \\
\hline $\begin{array}{l}\text { Education is too } \\
\text { expensive }\end{array}$ & 17.1 & 17.7 & 16.6 & 50.2 & 17.3 & 1.2 & 16.4 & 18.5 \\
\hline $\begin{array}{l}\text { Care of children or } \\
\text { other family member }\end{array}$ & 7.0 & 0.9 & 12.4 & 15.8 & 8.3 & 1.2 & 7.0 & 7.0 \\
\hline Other reasons & 7.2 & 8.7 & 5.9 & 7.8 & 7.6 & 6.4 & 6.7 & 8.1 \\
\hline
\end{tabular}

Source: Petrovic (2011).

Over 19 percent of FSA beneficiaries state the need to earn a living as ground for refusing to return to formal education. However, only 3 percent claim to be employed. This indicates that many FSA beneficiaries grossly misreport their real labor market status..$^{79}$ Around 17 percent of recipients are not available to return to formal education as it is too expensive. Interestingly, over half of young respondents consider education too expensive.

The main obstacle to participate to training programs is age (over 50 percent of beneficiaries consider themselves too old). Approximately 20 percent of respondents deem that attending a training program would not help them in finding a job, while 17 percent are not even aware that such possibility exists. The most worrisome finding, however, is the fact that over 44 percent of young people are unaware of training opportunities. ${ }^{80}$

\footnotetext{
${ }^{79} \mathrm{Or}$, alternatively, that many use "work" as an excuse for not returning to school.

${ }^{80}$ This fact would need to be explored further in the subsequent surveys.
} 
Table A5.6. Main reasons for not participating to training programs, percent

\begin{tabular}{|l|c|c|c|c|c|c|c|c|}
\hline \multirow{2}{*}{ Reasons } & \multirow{2}{*}{ Total } & \multicolumn{3}{l|}{ Sex } & \multicolumn{2}{l|}{ Age group } & \multicolumn{2}{l|}{ Settlement } \\
\cline { 3 - 9 } & & Men & Women & $\begin{array}{l}\mathbf{1 5 -} \\
\mathbf{2 9}\end{array}$ & $\begin{array}{l}\mathbf{3 0 -} \\
\mathbf{4 9}\end{array}$ & $\begin{array}{l}\mathbf{5 0 -} \\
\mathbf{6 4}\end{array}$ & Urban & $\begin{array}{l}\text { Non } \\
\text { urban }\end{array}$ \\
\hline Too old & 50.5 & 50.2 & 50.7 & 2.7 & 46.3 & 75.2 & 50.7 & 50.1 \\
\hline $\begin{array}{l}\text { Training not helpful } \\
\text { for job search }\end{array}$ & 19.3 & 20.1 & 18.7 & 27.3 & 22.8 & 12.3 & 19.6 & 18.8 \\
\hline $\begin{array}{l}\text { Unaware of this } \\
\text { possibility }\end{array}$ & 17.4 & 15.8 & 18.8 & 44.0 & 19.0 & 4.5 & 16.5 & 19.1 \\
\hline Other reasons & 12.7 & 13.8 & 11.8 & 26.0 & 11.8 & 8.0 & 13.1 & 12.0 \\
\hline
\end{tabular}

Source: Petrovic (2011).

When conditionality is factored in, opinions shift considerably (Figure A5.5). Approximately 19 percent of FSA beneficiaries would return to the formal education system and over 34 percent would participate to a training program if refusal is conditioned to benefit reduction or termination. Young people, again, are more prone to return to education (23 percent) compared to other groups. Young people and prime age individuals are more likely to participate to a training program, if conditionality is applied, while there are no significant differences for people living in urban and non-urban areas.

Figure A5.5. Willingness to return to education/participate to training (with conditionality), percent 81

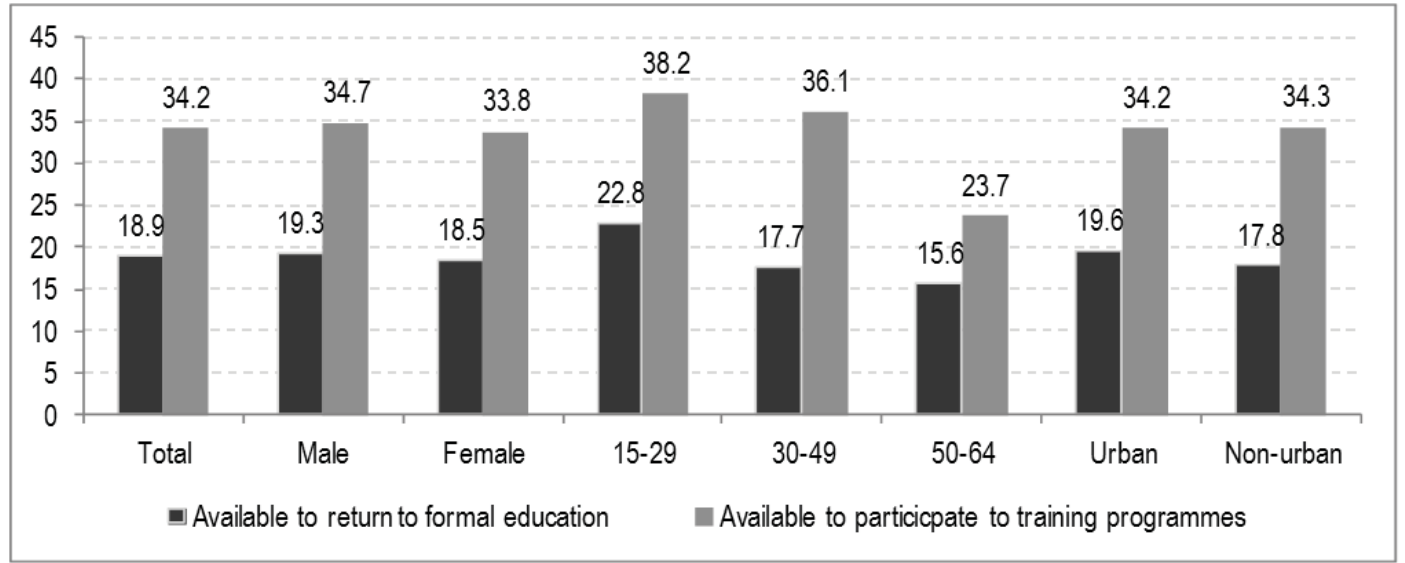

Source: Petrovic (2011).

${ }^{81}$ The data on return to formal education exclude students. 
Generally, FSA beneficiaries -except to some extent the younger cohort-have little interest in returning to formal education, with cost being an important factor. When these findings are compared to the low educational achievements of FSA recipients, a significant gap emerges between what beneficiaries are willing to undertake and what they would actually need.

The solution may lie in training programs, where the beneficiaries' interest is higher even without conditionality. However, a significant number of FSA recipients do not believe that the participation in training programs would lead to a job, while others are concerned about costs and the possibility to combine training activities with work.

\section{Referrals}

The level of cooperation among social assistance, employment, education and local self-government institutions is still rather limited. Despite the clear need for enhanced cooperation, the incidence of referrals from the employment service to the social service and vice versa is low -3 percent and 0.5 percent, respectively (Figure A5.6).

Figure A5.6. Referrals between employment and social services, percent ${ }^{82}$

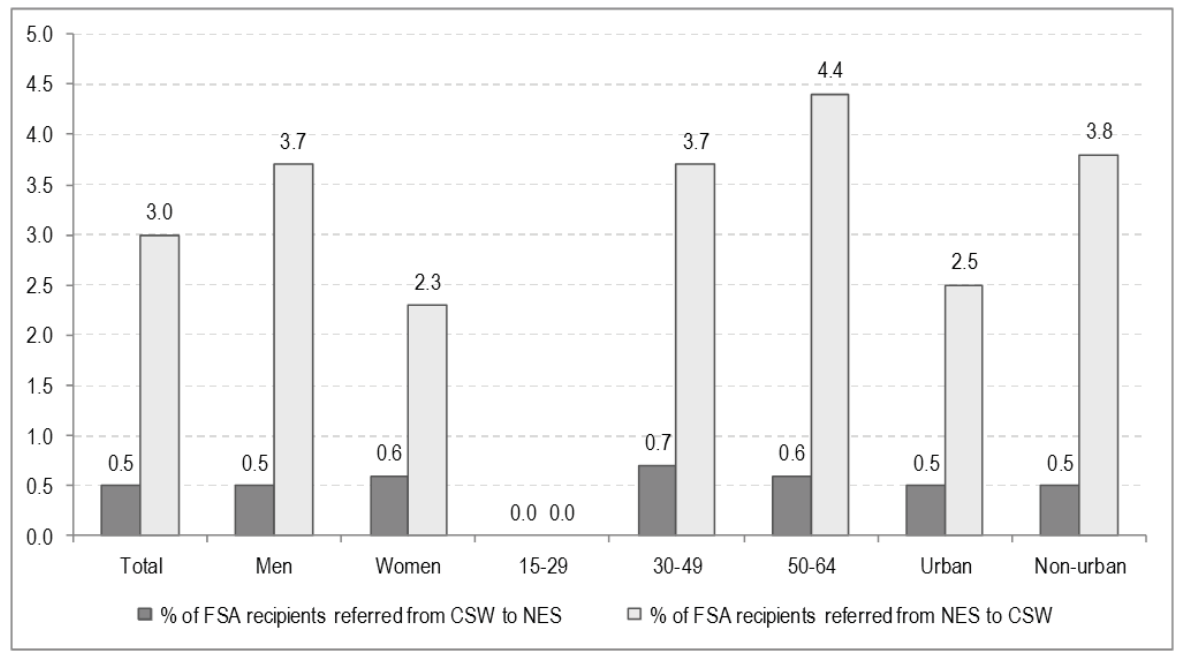

Source: Petrovic (2011).

${ }^{82}$ The data for 15-29 age group exclude those who are in formal education. 
Even when only beneficiaries registered with the employment service are taken into consideration, the results do not change significantly $(0.7$ percent referred from social to employment services and 3.7 percent from employment to social services). Young people are not involved in referrals as many are still in education. However, youth outside the formal education system appear to be neglected.

At the same time, the share of those referred to formal education by the CSW, NES and other institutions is 4 percent. A relatively higher number of referred persons is older than 50, living in Belgrade or Vojvodina (Figure A5.7). The survey did not enquire about the timeframe of the referral. Therefore, it is possible that individuals in the older cohort (with the largest number of referrals) were referred some time ago as redundant workers after the expiry of the unemployment benefits. Interestingly, a much smaller share of FSA recipients was referred to training programs (2.7 percent) and mostly individuals in the 30-49 age group (3.2 percent). ${ }^{83}$

Figure A5.7 Referrals to education and training, percent

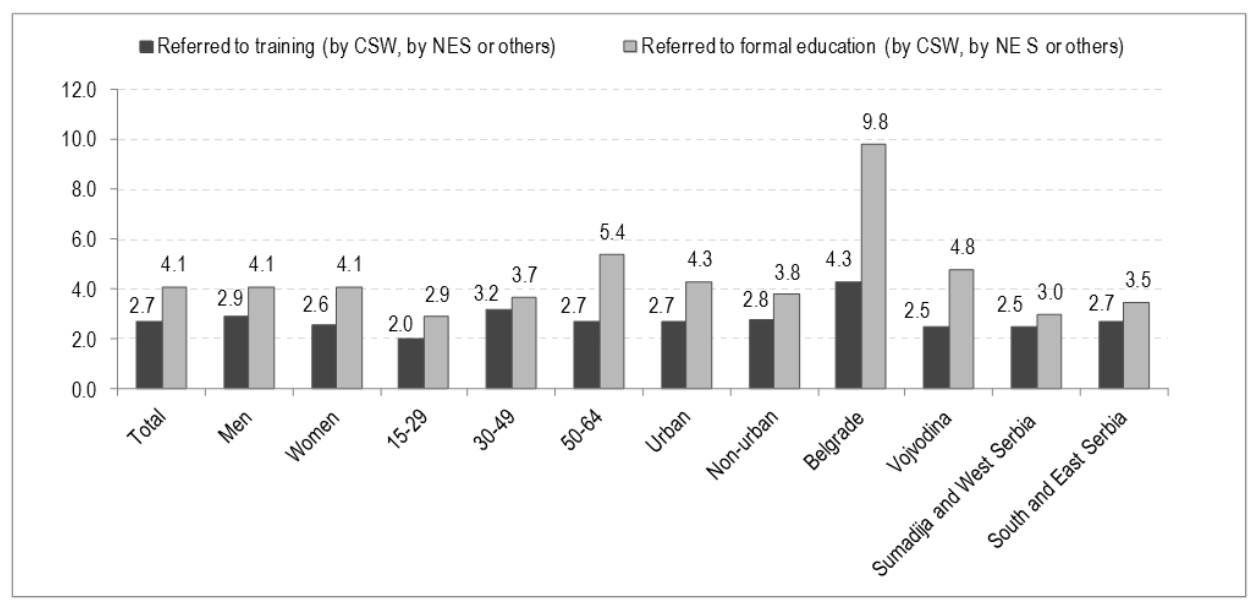

Source: Petrovic (2011).

Related to this is the relatively high share of FSA recipients involved in case management in the centers for social work. As mentioned, FSA recipients facing only a lack of financial resources are not included in case management. Yet, nearly 30 percent of respondents claim to be included, meaning that these are individuals facing multiple problems. Hence, one would expect high shares of referral to other ${ }^{83}$ In absolute terms, this figure is more than double the number of the referrals for the 15-29
age group. 
service providers. Instead these range between 1 and 4 percent, with young people grossly underrepresented. A possible explanation of this occurrence may be the implementation modalities used so far by CSWs. Case workers in the CSWs have yet to recognize their role in referring clients to the NES, since all those able to work are obliged to register with the NES to access FSA benefits. Also, a considerable share of FSA recipients face a number obstacles in finding and retaining employment and the challenge is to detect those who can be targeted with activation services. However, there is no particular reason that would limit referrals to education and training programs, aside maybe the availability of suitable programs. Nevertheless, there is room to broaden the scope of referrals. 


\section{Appendix 6: In-depth interview guide (Public Works Program in Serbia)}

\section{THE EXPERIENCE OF FSA RECIPIENTS WITH PUBLIC WORK ENGAGEMENT}

\section{In-depth Interview Guide}

I want to thank you for participating in this interview today. My name is and I would like to talk with you about your experience of participating in the public works program. The purpose of this interview is to gain insights in the overall experience of formal work engagement, but also to assess the level of social support provided, identify further needs and pitfalls for future work activation. The findings the interviews conducted with you and your colleagues can serve to develop further interventions in the social protection area.

The interview should take around one hour. I will be recording the session because I do not want to miss any of the valuable information that you will provide. I will be taking some notes during the session, if you do not mind. I cannot write fast enough and that is the reason why I want also to record the session.

Your responses will be kept confidential, which means that I will share them only with other members of our research team. Any information presented in our study will not identify you as respondent. If you do not feel comfortable talking about certain aspects of your life you do not have to talk about them. You can stop and end this interview at any time.

Do you have any questions with regard to what I just explained?

Are you willing to participate in this interview and our research?

By signing this paper you give your consent. 
I would like to start with a set of questions about the type of assistance and support that you receive. Next, we will talk about your experience of participating in the public work program. At the end, I will ask you to tell me your opinion about social services in general.

\section{$\underline{\text { I Social assistance and other types of support }}$}

1 How long have/had you been receiving MOP? (If the respondent does not receive MOP ask if he/she is officially employed)

2 What is the level of MOP and how much of your family needs does it cover?

3 Does your family/household receive any other benefit (one-time municipal payment, child allowance, and similar)?

4 Do you enjoy any other support (by extended family, church, NGO sector etc.)?

5 Do you or any member of your household perform agricultural activities, seasonal or any other work?

6 Do you produce food for your own/your family consumption?

7 How do you make ends meet? Please elaborate.

8 How do you feel about receiving support by the state (and others) instead of meeting the needs from your earnings from formal employment? Please compare the current situation to the one when you were employed.

\section{Experience with the public work activity}

- Had you had any work experience or regular employment before you engaged in the public work?

- How did you become a participant in the public work? Please describe the process.

- For how long did you participate in the public work?

- What kind of activity did you perform?

- Did you have any training for the job that you performed in the public work?

- What was your salary?

- What (if any) additional costs were covered (e.g. transportation cost, child care, and similar)?

- Do you feel that you acquired any additional skills in public works that might help you find a new job? Which ones? 
- Was the income earned a good enough incentive for you to work/continue to work? If not, what would be the appropriate amount?

- Have you found or have you been offered a new job?

- What actions have you undertaken to find a new job?

- Would you engage in a formal work activity again? If you could choose, what would be the kind of work activity that you would like to perform?

- Is there any particular reason (or a combination of reasons) because of which you would not accept a job offer (e.g. the decision to perform agricultural or seasonal activity rather that getting a regular job)?

- What is your overall impression about your public work participation? What have been (if any) the effects of work on your personal/life of your family/household? How do you feel about all of this?

Note to the interviewer: prompt the respondents with additional questions and please make sure that they provide answers to each of the following:

- If you compare your situation at the time of the interview with the one before the public work came into effect, did it improved significantly, stayed more or less the same, or has it deteriorated with regard to: -the level of self-confidence?

-the desire to find a job?

- personal skills and qualifications?

- the chances to find a job?

- the family income situation?

- social contacts?

- Did you stop receiving MOP during the time you participated in the public work?

- Did you apply for MOP after the completion of the public work?

- Did you have to submit all the documents again?

- Did you experience any problems re-submitting your MOP application?

\section{$\underline{\text { III Social services in general }}$}

- Are you informed about the kinds of services that you are entitled to as a MOP recipient (counseling services in CSW and NES, referrals to training, education and similar)?

- How often do you go to the National Employment Service office? What do you do there (talk with the employment counselor, look at the board with job posts, etc.)?

- Do you have an individual employment plan? 
- Have you ever been offered training/ additional education/ employment by the NES or other institution? Did it happen during the last year?

- Do you feel that there is a need for the introduction of such programs? Which one in particular? Why would it be useful?

- What else would contribute to improving your own position in this society?

Note to the interviewers: You are in charge of recording basic socio-demographic data (agel sex/ marital status/ household structurel level of education/ work activity/ place of residence/ housing conditions) and some specific information about the respondent and his family (if easily available and/or observable) such as alcohol or drug related problems, and similar. These questions can be asked and responses noted at any point during the interview i.e. whenever you find it appropriate.

Do you have any remaining questions at the end of our session?

Let me inform you that on the basis of information that you and others gave us, we will draft a report and submit it to the government for further discussions.

Thank you again for your time and for participating in this interview. 
Appendix 7: Questionnaire (Survey on FSA) 
REPUBLIC OF SERBIA

Statistical Office of the Republic of Serbia

Official Statistics Law

„Official Gazette

of Republic of

Serbia", no.

$104 / 2009$.

Survey Code: 019050

Survey on FSA (MOP/NSP), July 2011

Monitoring period - July 7-14, 2011

\section{IDENTIFICATION DATA}

SURVEY PERIOD

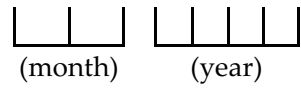

REGIONAL UNIT

(Unit name)

$\bigsqcup$

MUNICIPALITY

(name of municipality)

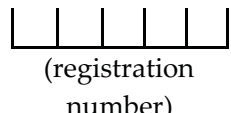

ENUMERATION

AREA

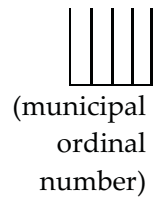

APARTMENT

(enumeration area ordinal number)

HOUSEHOLD

(apartment ordinal number)

NAME AND SURNAME OF THE HOUSEHOLD HEAD

STREET AND NUMBER

NEIGHBORHOOD 


\begin{tabular}{|c|c|c|c|c|}
\hline DEMOGRAPH & C FEATURES & & & \\
\hline & Respondent & Date of Birth & & \\
\hline Respondent No. & Name Surname & Day & Month & Year \\
\hline 0 & 1 & 2 & 3 & 4 \\
\hline 01 & & L & 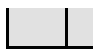 & \\
\hline 02 & & & & \\
\hline 03 & & L & & \\
\hline 04 & & & & \\
\hline 05 & & & | & \\
\hline 06 & & & & \\
\hline 07 & & & & \\
\hline 08 & & & & \\
\hline
\end{tabular}

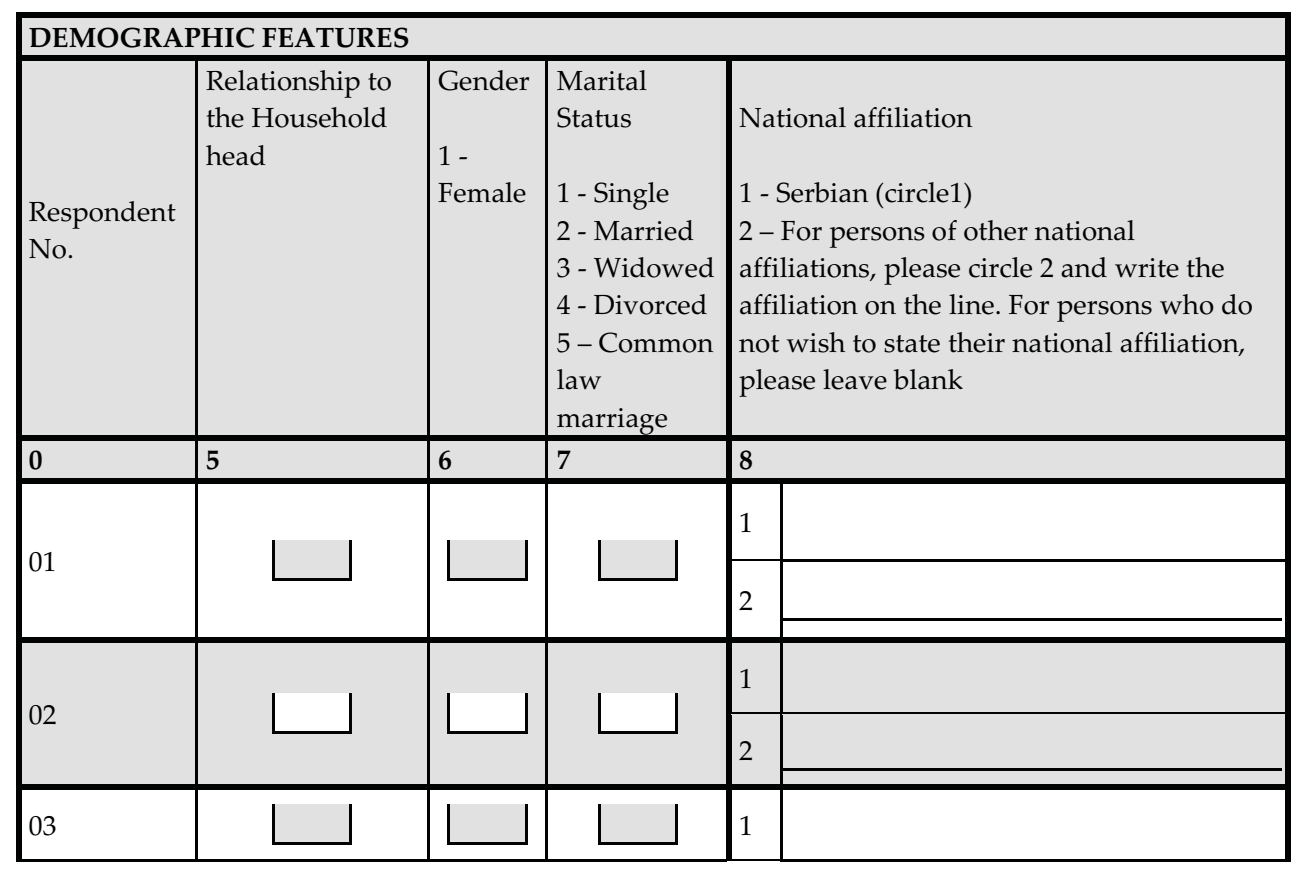




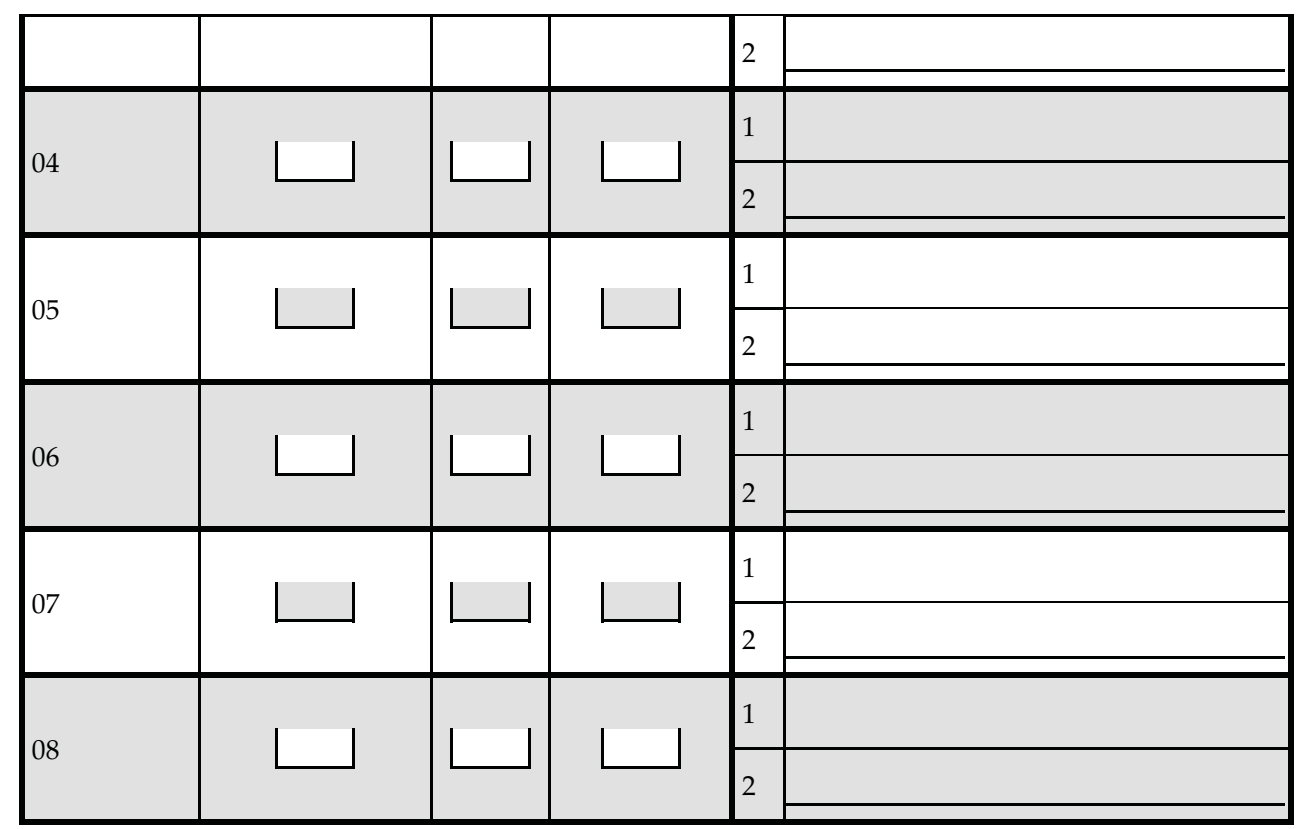

\section{Relationship to the Household head}

1 - Household head

2 - Household head's spouse (husband/wife)

3 - Household head's children (or children of the spouse)

4 - Household head's parents (or parents of the spouse)

5 - Household head's grandparents(or grandparents of the spouse)

Household head's grandparents(or grandparents of the spouse
6 - Household head's grandchildren (or grandchildren of the spouse)

7 - Household head's son-in-law or daughter-in-law (or spouse's son-in-law/daughter-in-law)

8 - Other relatives of the Household head (or relatives of the spouse)

9 - Others 


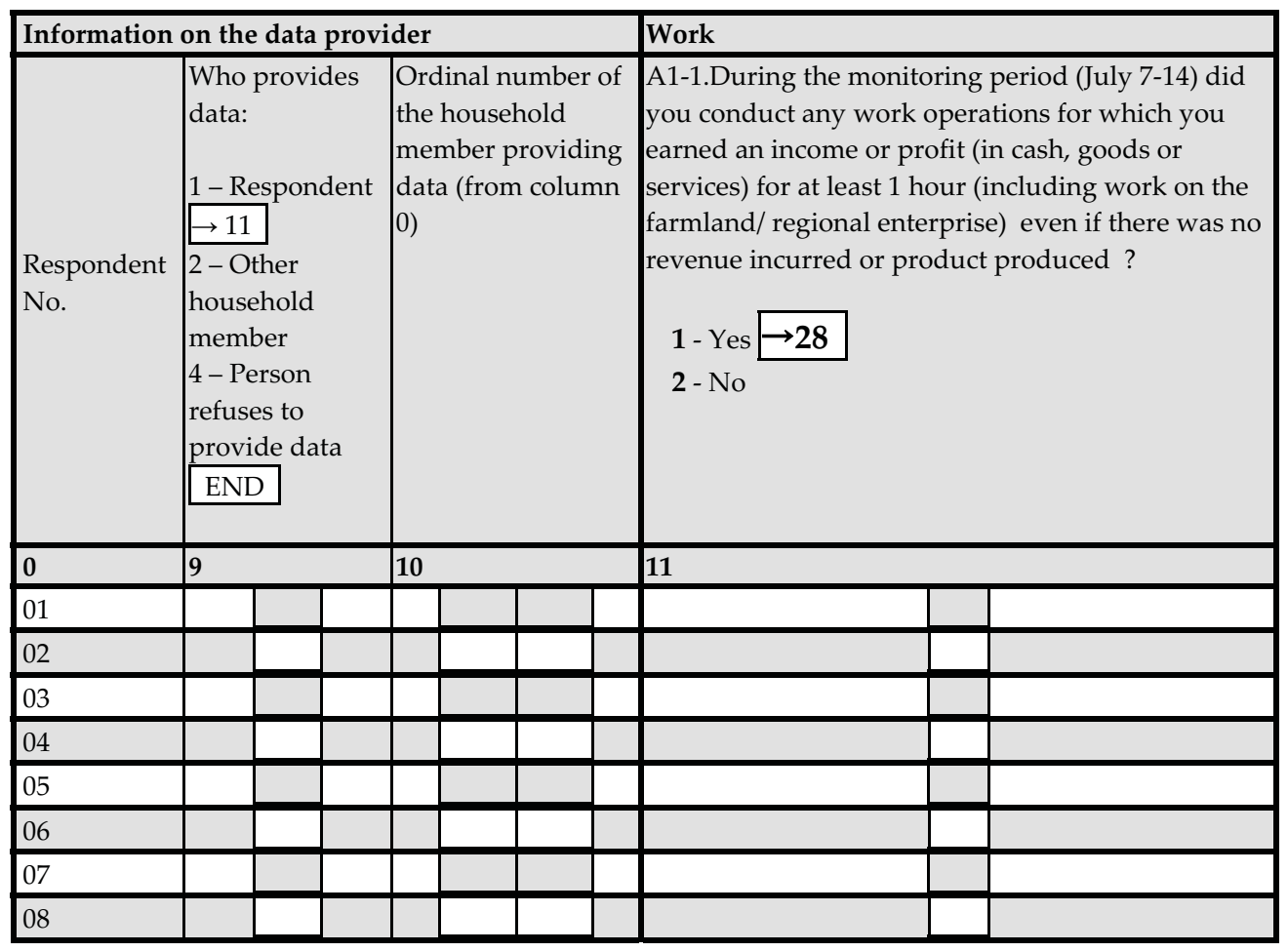




\section{Status}

\begin{tabular}{|c|c|c|c|c|}
\hline $\begin{array}{l}\text { Respondent } \\
\text { No. }\end{array}$ & $\begin{array}{l}\text { could generate income } \\
\text { (in cash, goods or } \\
\text { services) or did you } \\
\text { build a house for sale } \\
\text { or lease in the future? } \\
\begin{array}{l}1 \text { - Yes } \rightarrow 28 \\
2 \text { - No }\end{array}\end{array}$ & $\begin{array}{l}\text { agricultural field } \\
\text { owned by a member } \\
\text { of your family on } \\
\text { which the owner } \\
\text { generates income or } \\
\text { profit? } \\
\mathbf{1} \text { - Yes } \rightarrow \mathbf{2 8} \\
\mathbf{2} \text { - No }\end{array}$ & $\begin{array}{l}\text { hunting, picking } \\
\text { products such as } \\
\text { snails, mushrooms, } \\
\text { firewood, } \\
\text { herbs...etc? } \\
\qquad \begin{array}{r}\text { 1-Yes } \\
\text { 2- No } \rightarrow\end{array}\end{array}$ & $\begin{array}{l}1 \text { - Yes, the } \\
\text { products are } \\
\text { completely or } \\
\text { partially sold } \\
2-\text { No, } \rightarrow 28 \\
6 \text { mpletely used up } \\
\text { in the household }\end{array}$ \\
\hline 0 & 12 & 13 & 14 & 15 \\
\hline 01 & & & & \\
\hline 02 & & & & \\
\hline 03 & & & & \\
\hline 04 & & & & \\
\hline 05 & & & & \\
\hline 06 & & & & \\
\hline
\end{tabular}

A1-2. During the monitoring period did you devote time to launching your own business, professional business practice or starting a farm from which your household could generate income (in cash, goods or services) or did you build a house for sale

ing period did you perform any unpaid work activities in the company as part of the professional business practice or did you work on an agricultural field owned by a member of your family on which the owner generates income or profit?

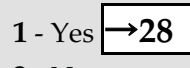

2 - No

A 1-4. During the A 1-5. Did you

monitoring period completely or were you engaged in partially sell the agricultural production (on your own or someone else's farmland), did you take up fishing, hunting, picking products such as snails, mushrooms, firewood, aforementioned product (where you were engaged in the production or collection)?

\section{collection)?}

products are completely or partially sold

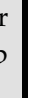

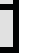




\begin{tabular}{|l|c|c|c|c|}
\hline 07 & $\bigsqcup$ & $\square$ & $\bigsqcup$ & $\vdots$ \\
\hline 08 & $\square$ & $\square$ & $\square$ & $\square$ \\
\hline
\end{tabular}

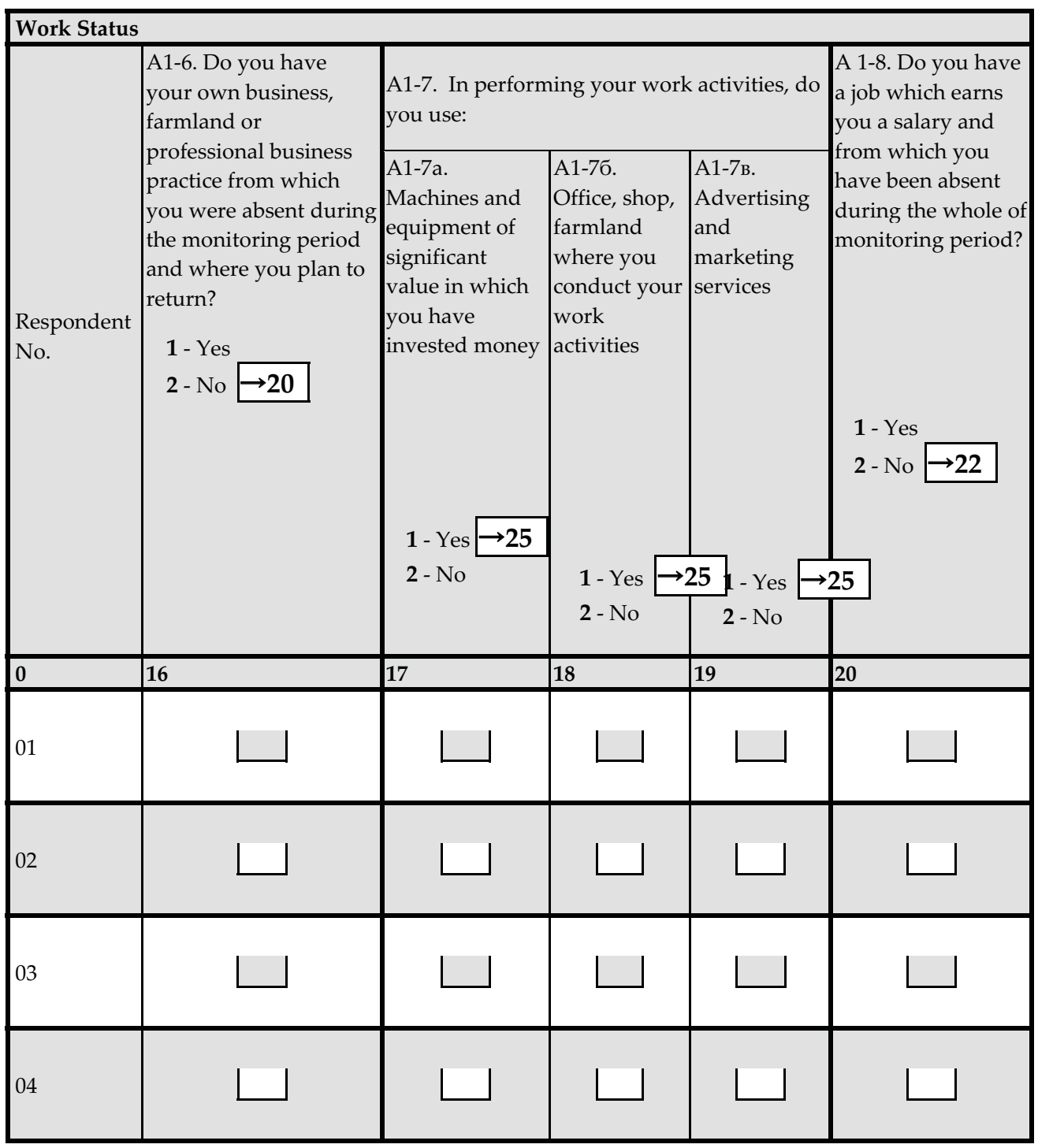




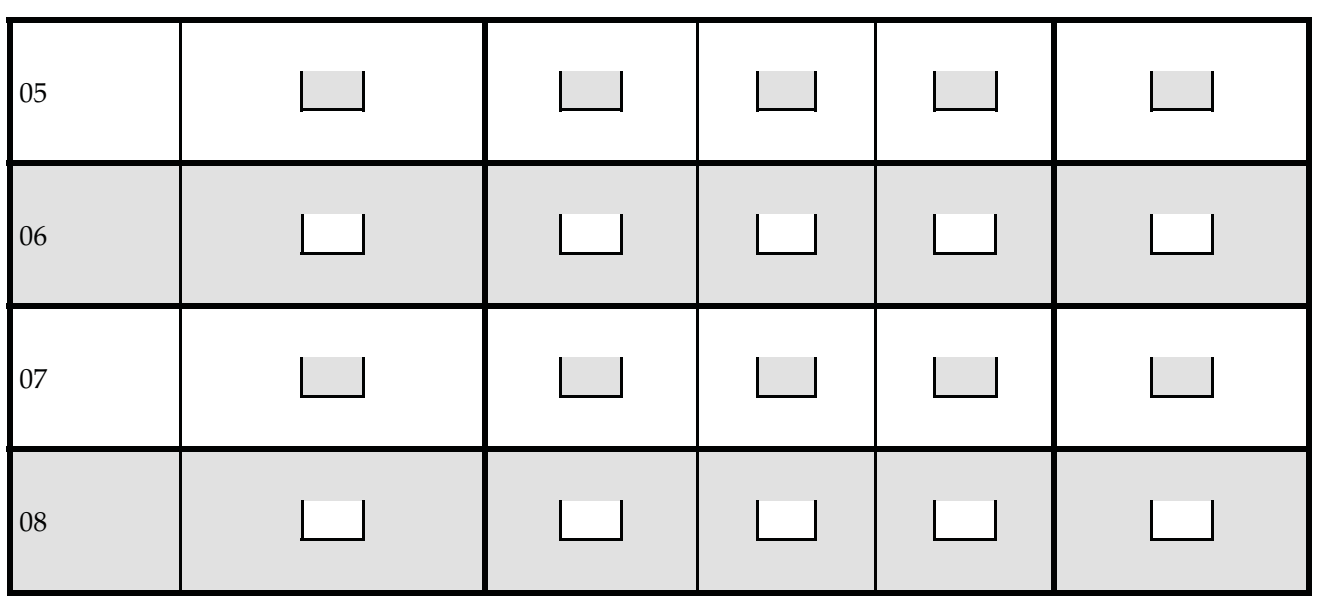

\begin{tabular}{|c|c|c|c|c|c|}
\hline \multicolumn{6}{|l|}{ Work Status } \\
\hline $\begin{array}{l}\text { Respondent } \\
\text { No. }\end{array}$ & $\begin{array}{l}\text { A1-9. Is there a } \\
\text { guarantee / security } \\
\text { that you may } \\
\text { return to your job } \\
\text { after the leave } \\
\text { period ends (you } \\
\text { have a contract or } \\
\text { an agreement for } \\
\text { conducting the } \\
\text { job)? } \\
\qquad \begin{array}{l}\mathbf{1} \text { - Yes } \rightarrow 25 \\
\mathbf{2} \text { - No }\end{array}\end{array}$ & $\begin{array}{l}\text { A1-10. Do you have } \\
\text { an unpaid job in the } \\
\text { company, farmland or } \\
\text { professional business } \\
\text { practice owned by a } \\
\text { member of your } \\
\text { household from which } \\
\text { you have been absent } \\
\text { during the monitoring } \\
\text { period? } \\
\mathbf{1} \text { - Yes } \\
\mathbf{2} \text { - No } \rightarrow \mathbf{2 4}\end{array}$ & $\begin{array}{l}\text { A1-11. Does the } \\
\text { household } \\
\text { member who } \\
\text { you work for } \\
\text { have an } \\
\text { obligation to } \\
\text { accept your } \\
\text { return to work? } \\
\text { 1-Yes } \rightarrow 25 \\
2 \text { - No }\end{array}$ & \begin{tabular}{|l}
$\begin{array}{l}\text { A1-12. Why } \\
\text { didn't you work } \\
\text { during the } \\
\text { monitoring } \\
\text { period? } \\
1 \text { - Absence or } \\
\text { temporary } \\
\text { termination of } \\
\text { work operations } \\
\text { pon employer's } \\
\text { hitiative (layoff) } \\
2 \text { - Military } \\
\text { service } \rightarrow 33 \\
3 \text { - Seasonal } \\
\text { break on } \\
\text { seasonal jobs } \\
4 \text { - Other (they } \\
\text { did not work or } \\
\text { have a job from } \\
\text { which they were } \\
\text { absent during } \\
\text { the monitoring } \\
\text { period) } \rightarrow 33\end{array}$
\end{tabular} & $\begin{array}{l}\text { A1-13. } \\
\text { Reasons } \\
\text { for being } \\
\text { absent } \\
\text { from } \\
\text { work }\end{array}$ \\
\hline 0 & 21 & 22 & 23 & 24 & 25 \\
\hline 01 & & & & & \\
\hline 02 & & & & & \\
\hline
\end{tabular}




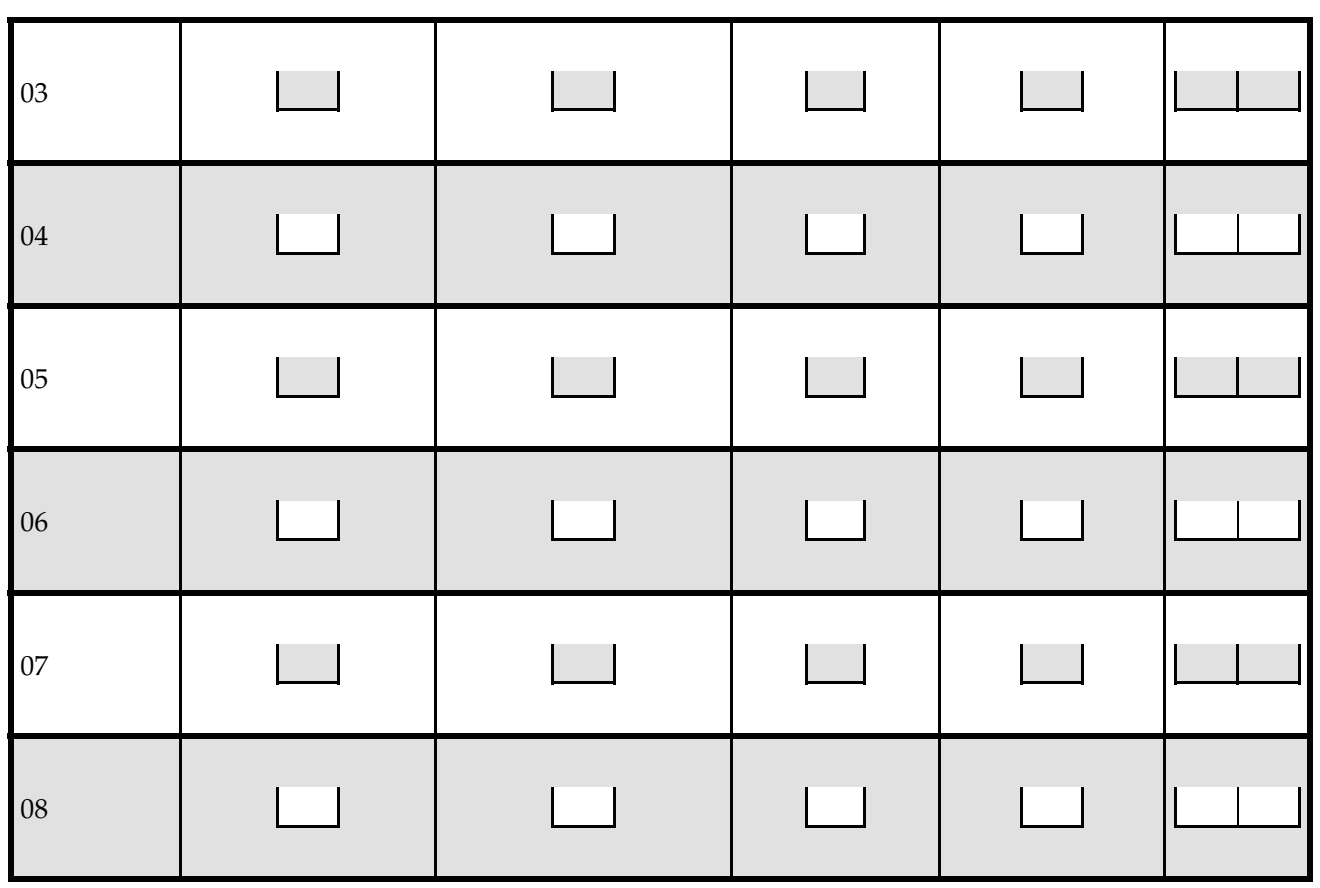

Reasons for being absent from work

01 - Poor weather conditions

02 - Reduced work scope for technical or economic reasons

03 - Strike

04 - Education or training

05 - Illness, injury or temporary disability
06 - Maternity leave

07 - Parental leave /child care

08 - Annual leave, state or religious holiday

09 - Paid leave

10 - Seasonal break

11 - Other (private reasons)

\begin{tabular}{|l|l|l|l|}
\hline Work status & $\begin{array}{l}\text { Main job } \\
\text { of leave(date from the } \\
\text { last working day to } \\
\text { the planned return- } \\
\text { to-work day) }\end{array}$ & $\begin{array}{l}\text { A1-15. What is } \\
\text { your total monthly } \\
\text { income which you } \\
\text { receive during } \\
\text { your leave from } \\
\text { work? }\end{array}$ & $\begin{array}{l}\text { Municipality or a foreign } \\
\text { country in which you do } \\
\text { your job }\end{array}$ \\
$\begin{array}{ll}\text { Nospondent } \\
1-\text { Three months or } \\
\text { less } \rightarrow 28\end{array}$ & $\begin{array}{l}\text { Circle: } \\
2-\text { More than three } \\
\text { months } \\
3-\text { You have no } \\
\text { intention of returning } \\
1-\text { No income } \\
2-\text { Less than } 50 \% \\
\text { of the regular } \\
\text { income } \\
3-50 \% \text { or more of }\end{array}$ & $\begin{array}{l}\text { P- Municipality on the } \\
\text { territory of Serbia } \\
2-\text { Foreign country }\end{array}$ \\
$\begin{array}{ll}\text { Please write on the line the } \\
\text { name of the municipality if }\end{array}$ \\
\hline
\end{tabular}




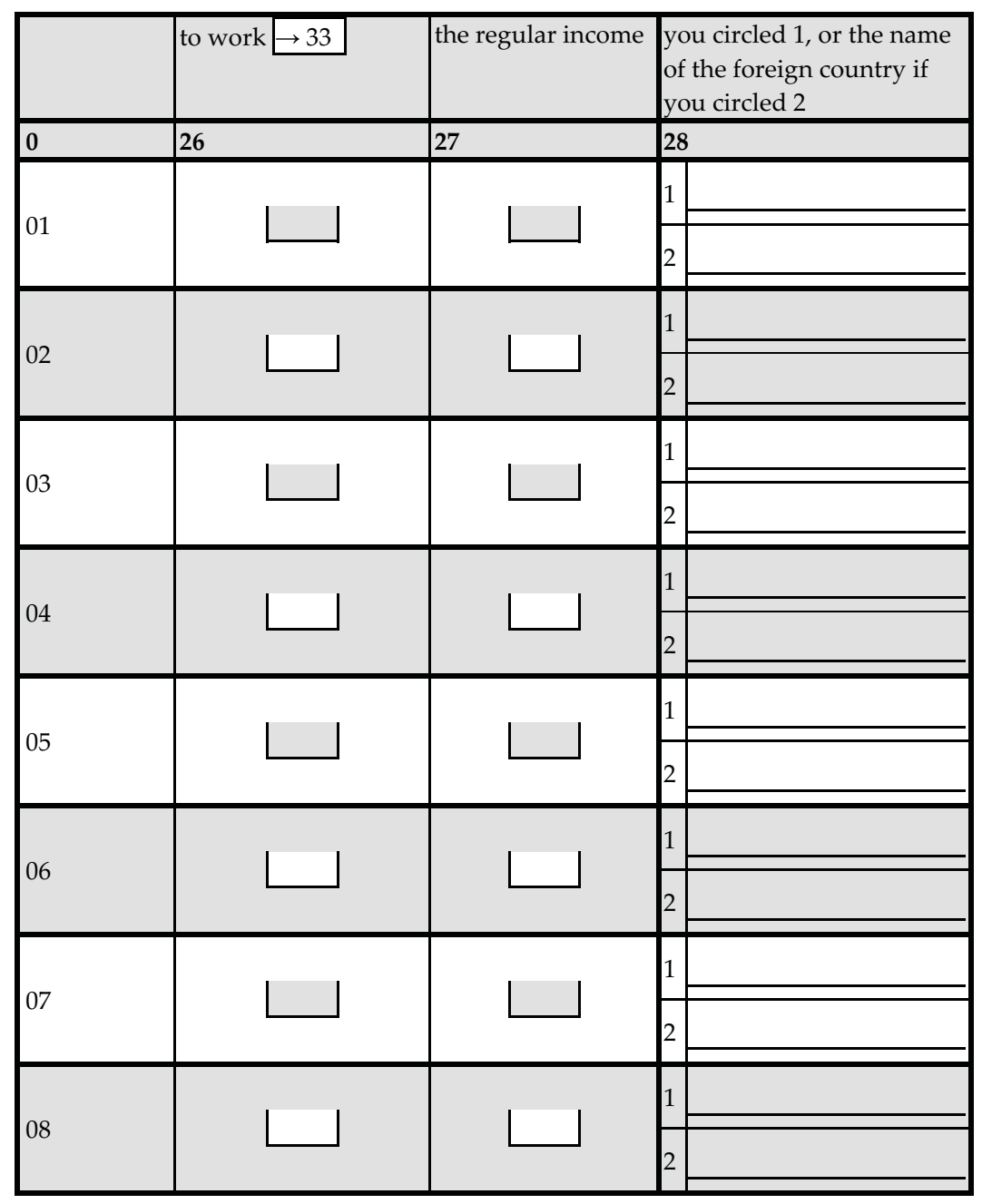

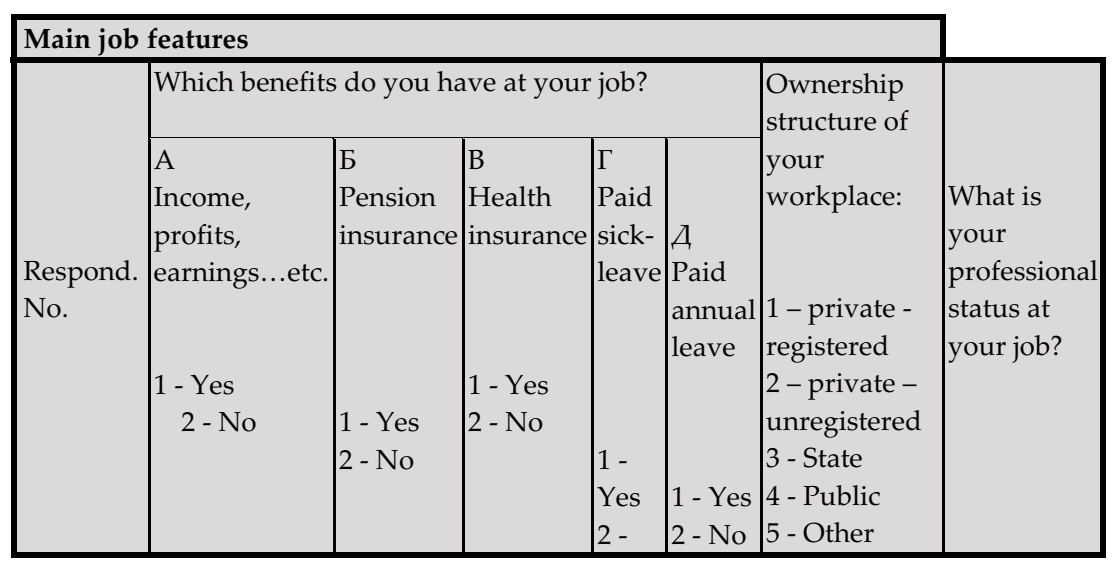




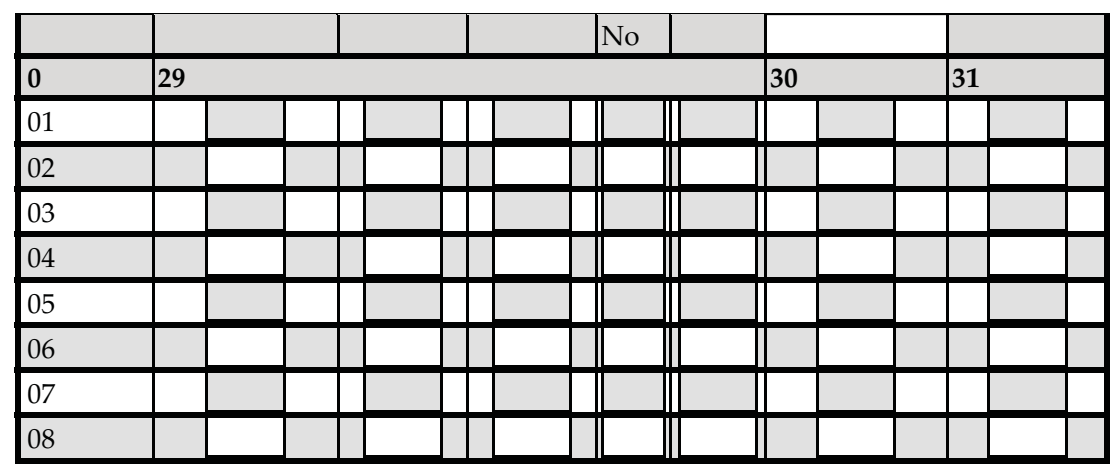

What's your professional status at your job?

1 - Company (institution) owner

2 - Entrepreneur or a partner in an enterprise (sole trade/service business, independent craft consignment shop, law firm, medical private practice and other legal business operations)

3 - Person receiving a contracted compensation as a sole source of income - "part-timer" (temporary service contract, commercial brokerage and agency contract, copyright contract...etc)

4 - Independent artist, athlete or a person performing cultural, art or religious activities, activities based upon authorisation of a relevant association or regulatory institution

5 - Other forms of independent business operations not mentioned

6 - Independent farmer

7 - Employed worker

8 - Unpaid assistant in a family business

\begin{tabular}{|c|c|c|c|c|c|}
\hline \multicolumn{2}{|c|}{ Main Job Features } & \multicolumn{4}{|c|}{ Previous Work Experience } \\
\hline $\begin{array}{l}\text { Respondent } \\
\text { No. }\end{array}$ & $\begin{array}{l}\text { Do you work in: } \\
\text { A company/institution: } \\
1 \text { - on the basis of a } \\
\text { written employment } \\
\text { contract } \\
2 \text { - without a written } \\
\text { employment contract } \\
\text { In a shop (sole } \\
\text { trade/service business, } \\
\text { independent craft } \\
\text { consignment shop, law } \\
\text { firm...etc) }\end{array}$ & $\begin{array}{l}\text { Have } \\
\text { you ever } \\
\text { worked } \\
\text { before? } \\
1 \text { - } \\
\text { Yes } \\
\text { No } \rightarrow 37\end{array}$ & $\begin{array}{l}\text { Have you } \\
\text { worked: } \\
1 \text { - on the basis } \\
\text { of a written } \\
\text { employment } \\
\text { contract } \\
2 \text { - without a } \\
\text { written } \\
\text { employment } \\
\text { contract }\end{array}$ & $\begin{array}{l}\text { How } \\
\text { long did } \\
\text { you } \\
\text { work } \\
\text { for? } \\
\text { (Please } \\
\text { write in } 0 \\
\text { if less } \\
\text { than } 1 \\
\text { year) }\end{array}$ & $\begin{array}{l}\text { Main reason } \\
\text { for } \\
\text { terminating } \\
\text { your work }\end{array}$ \\
\hline
\end{tabular}




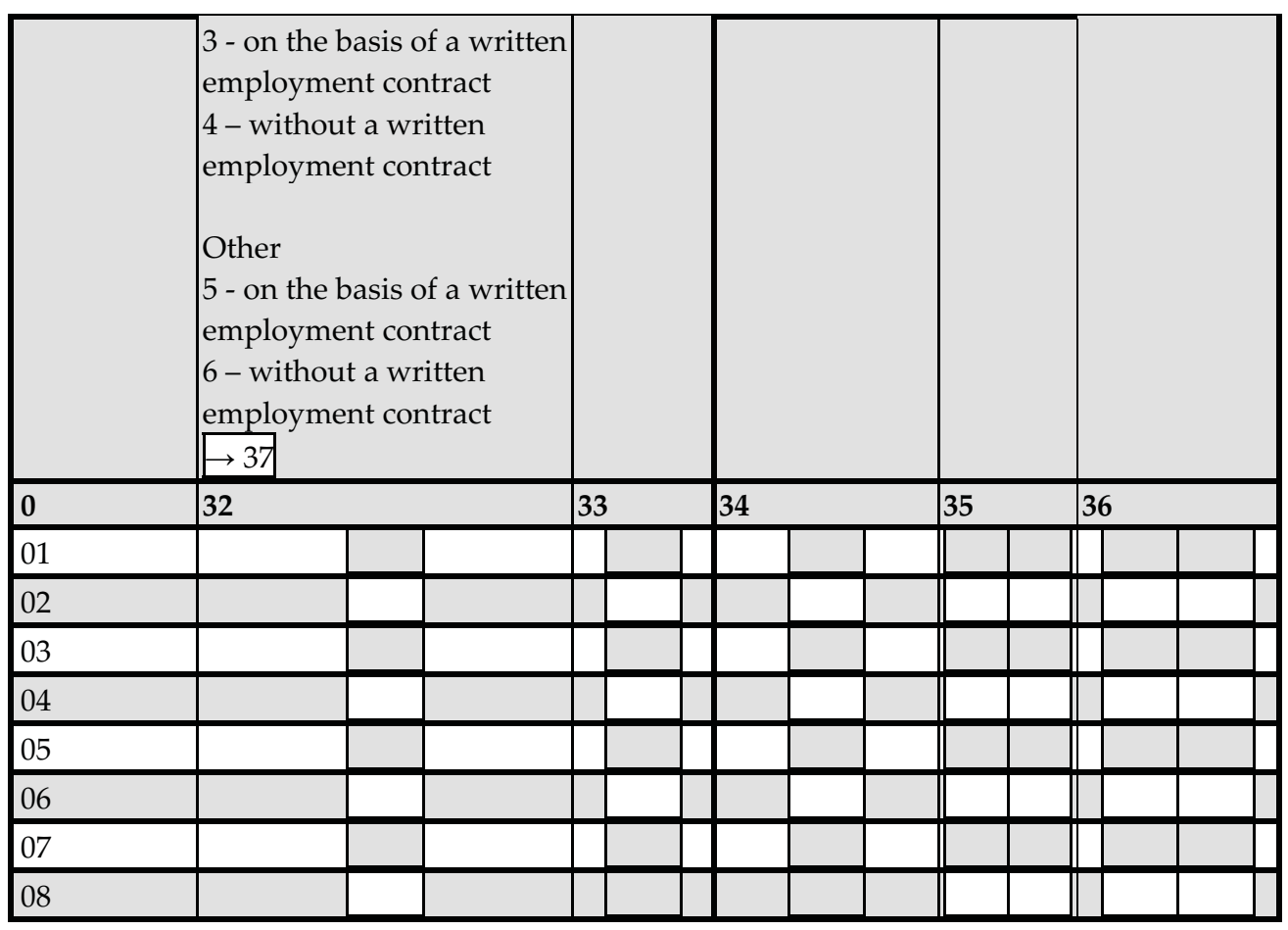

Main reason for terminating your work

01 - A layoff (including company bankruptcy)

02 - Temporary or seasonal job

03 - To take care of children or disabled elderly persons

04 - Other personal or family reasons

05 - Your illness or disability

06 - Education or training

07 - Early retirement

08 - Regular retirement

09 - Military service

10 - Other reasons 


\begin{tabular}{|c|c|c|c|c|c|}
\hline \multicolumn{6}{|c|}{ Participation in public works } \\
\hline \multicolumn{2}{|c|}{\begin{tabular}{|l|l} 
engaged in any \\
public works \\
during the \\
Respondent \\
No. & $\begin{array}{l}\text { period while you } \\
\text { were receiving } \\
\text { the MOP and if } \\
\text { yes, how many } \\
\text { times? } \\
\text { Once } \\
\text { Multiple times } \\
\text { Never } \rightarrow 39\end{array}$ \\
\end{tabular}} & $\begin{array}{l}\text { Were the } \\
\text { earnings } \\
\text { incurred from } \\
\text { public works } \\
\text { a significant } \\
\text { motivation to } \\
\text { work?? } \\
\\
\begin{array}{l}1 \text { - Yes } \\
2 \text { - No }\end{array}\end{array}$ & $\begin{array}{l}\text { Were you } \\
\text { engaged in } \\
\text { some works by } \\
\text { the } \\
\text { municipality? } \\
\mathbf{1} \text { - Yes } \\
\mathbf{2} \text { - No } \rightarrow \mathbf{4 1}\end{array}$ & $\begin{array}{l}\text { Means of } \\
\text { payment by } \\
\text { the } \\
\text { municipality? } \\
\mathbf{1} \text { - Single } \\
\text { payment } \\
\text { 2- Temporary } \\
\text { service } \\
\text { contract } \\
3 \text { - Other } \\
\text { (please write } \\
\text { in) }\end{array}$ & $\begin{array}{l}\text { Have you } \\
\text { been engaged } \\
\text { in some work } \\
\text { activities by } \\
\text { NGOs, the } \\
\text { Red } \\
\text { Cross...etc? } \\
1 \text { - Yes } \\
\mathbf{2} \text { - No } \rightarrow \mathbf{4 4}\end{array}$ \\
\hline 0 & 37 & 38 & 39 & 40 & 41 \\
\hline \multicolumn{6}{|l|}{01} \\
\hline \multicolumn{6}{|l|}{02} \\
\hline \multicolumn{6}{|l|}{03} \\
\hline \multicolumn{6}{|l|}{04} \\
\hline \multicolumn{6}{|l|}{05} \\
\hline \multicolumn{6}{|l|}{06} \\
\hline \multicolumn{6}{|l|}{07} \\
\hline 08 & & & & & \\
\hline
\end{tabular}




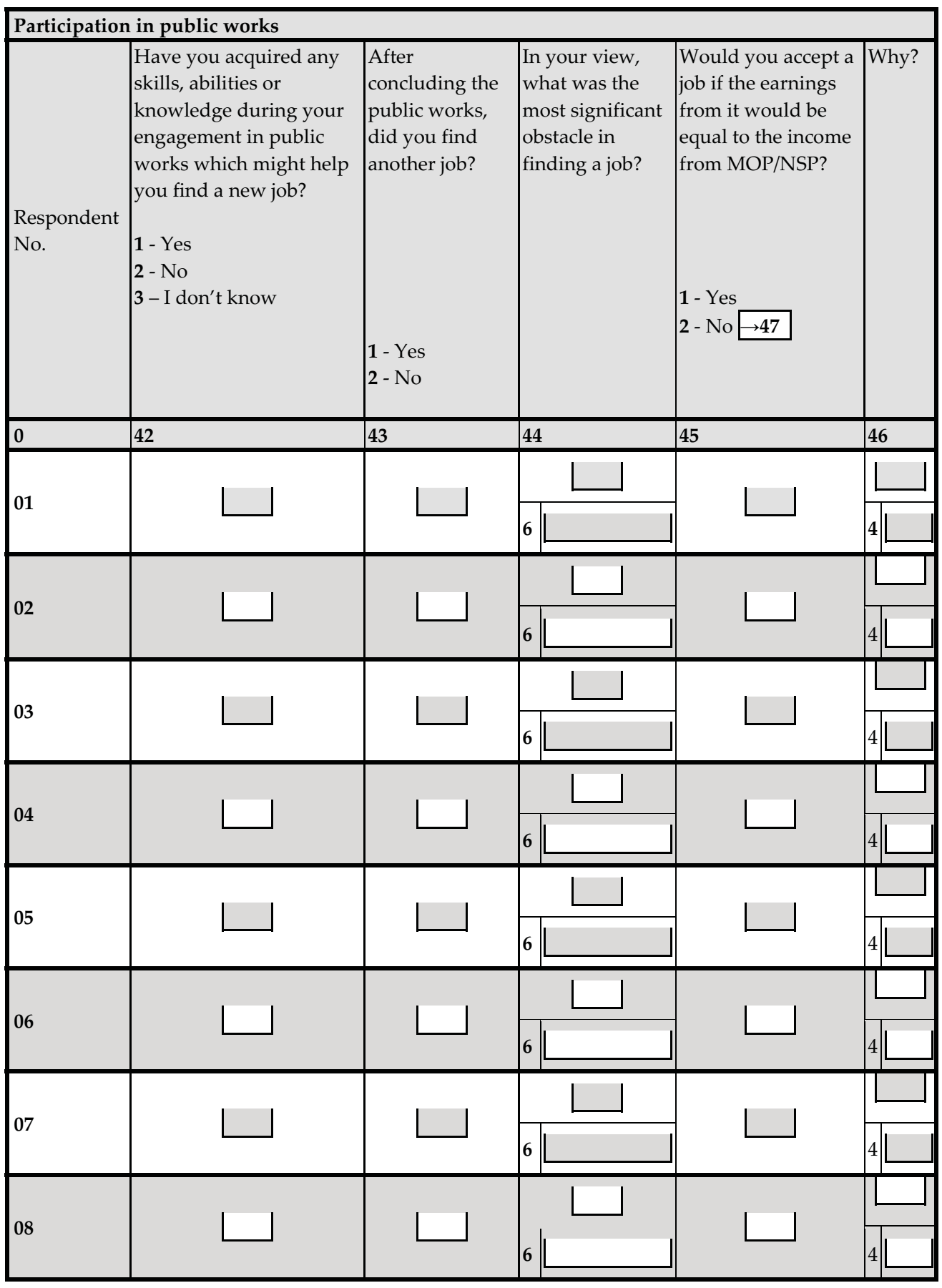


In your view, what was the most significant obstacle in finding a job?

1 - Insufficient qualifications

2 - Lack of work

3 - Age

4 - Poor health condition

5 - Taking care of a child, an elderly person or a household member

6 - Other (please write in)
Why?

1 - Feeling of accomplishment, satisfaction, respect...etc

2 - I do not like to receive charity

3 - Getting work experience and a possibility to climb up the career ladder or to find a better job

4 - I would like to secure a minimum pension for old age

5 - Other (please write in)

\section{Participation in public works}

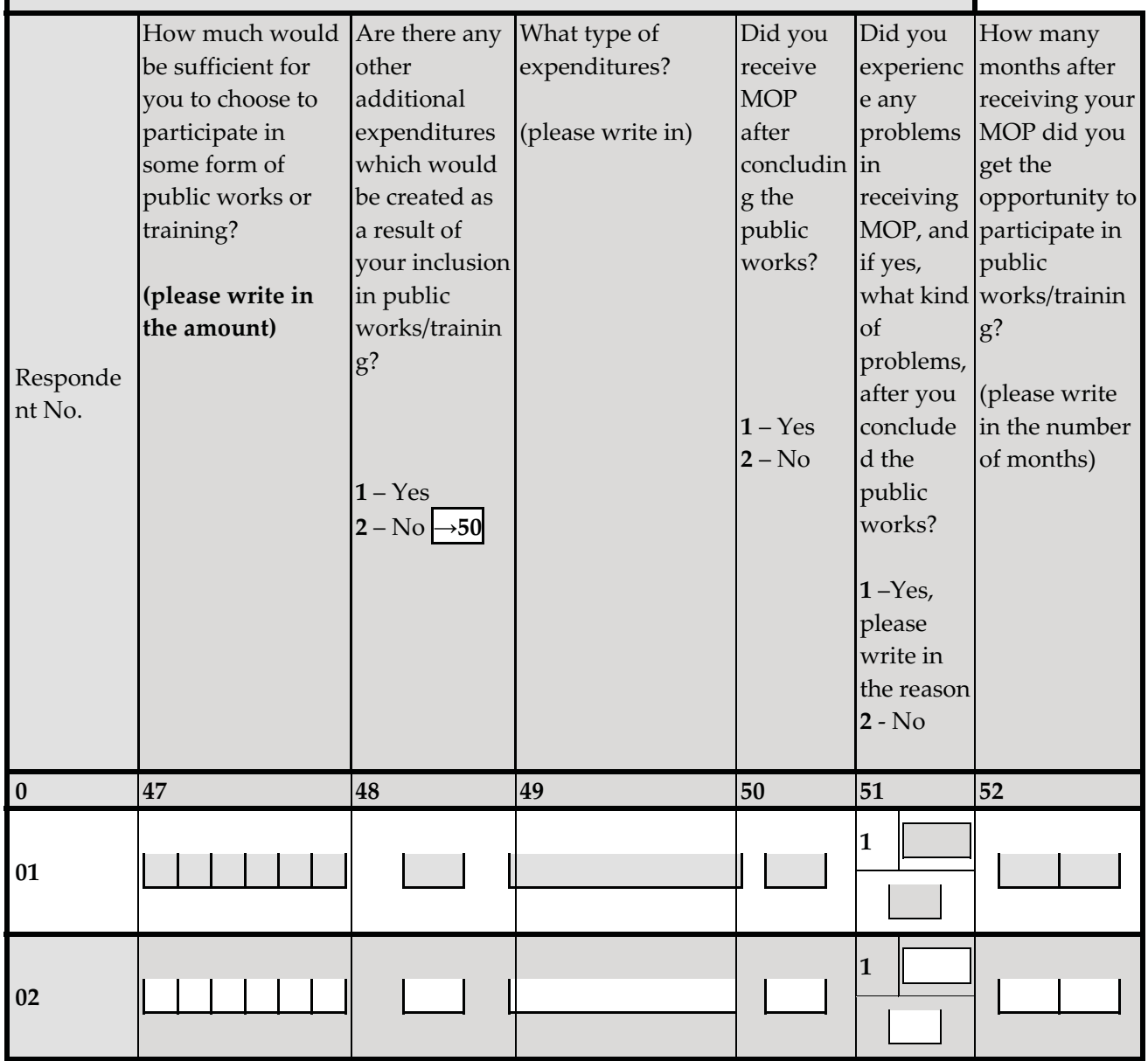




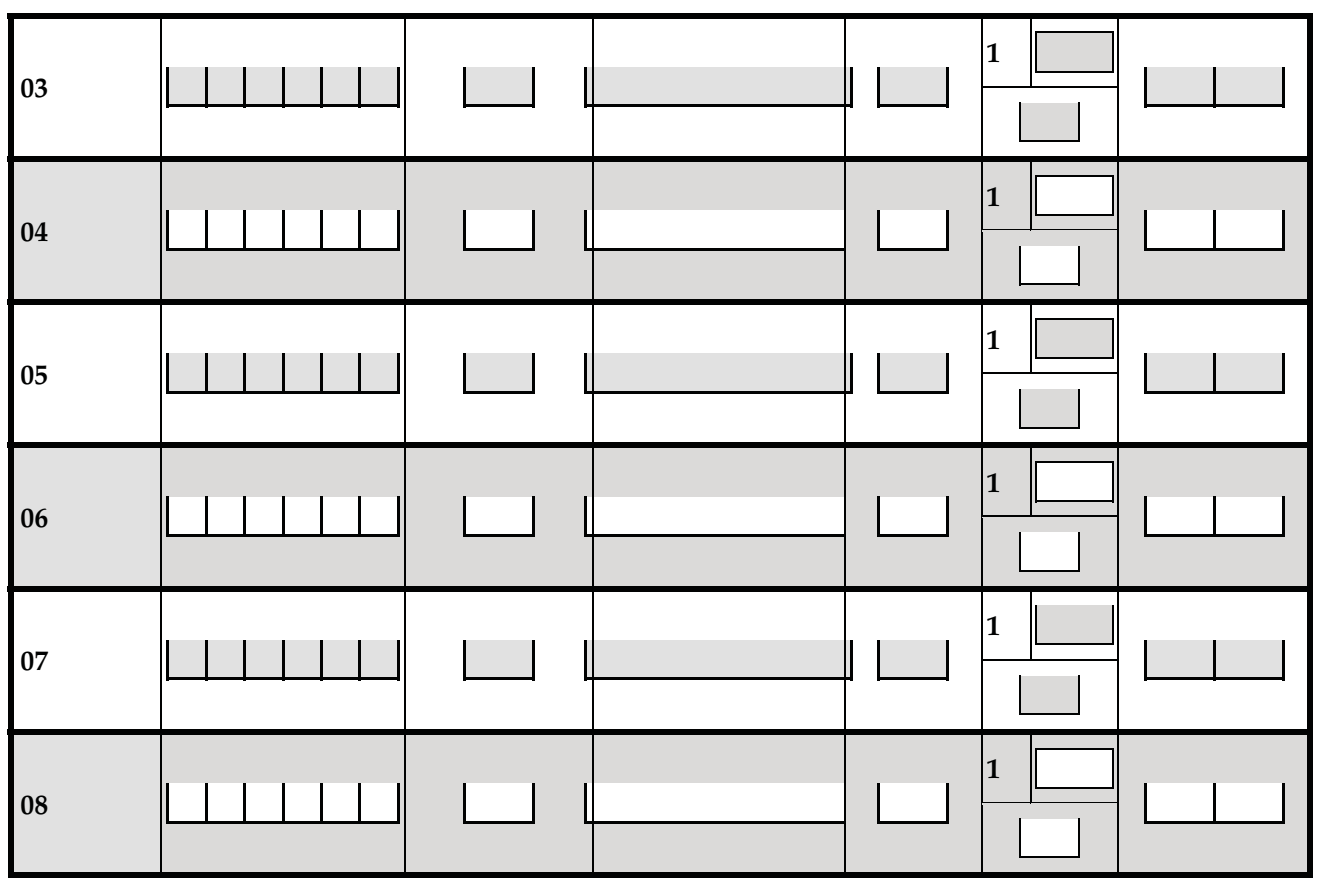

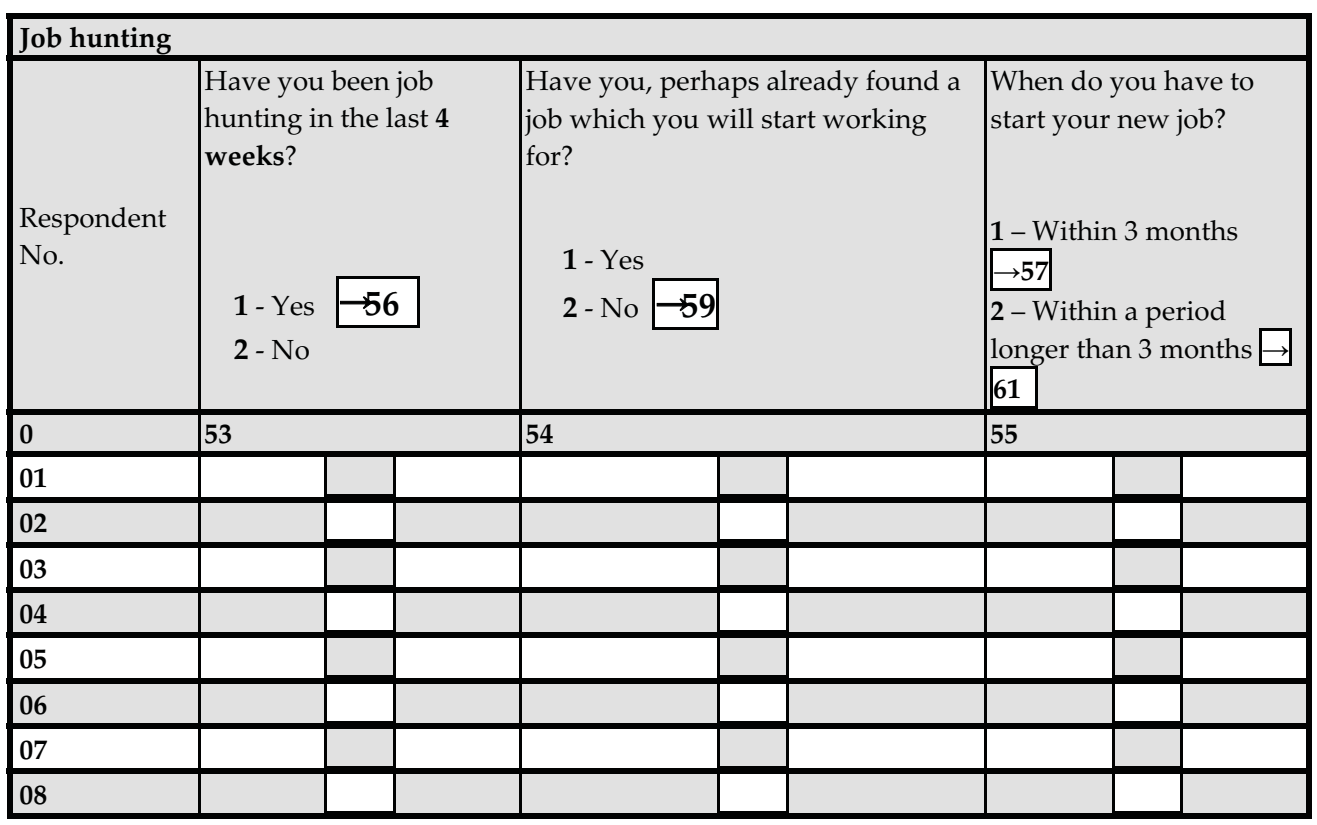




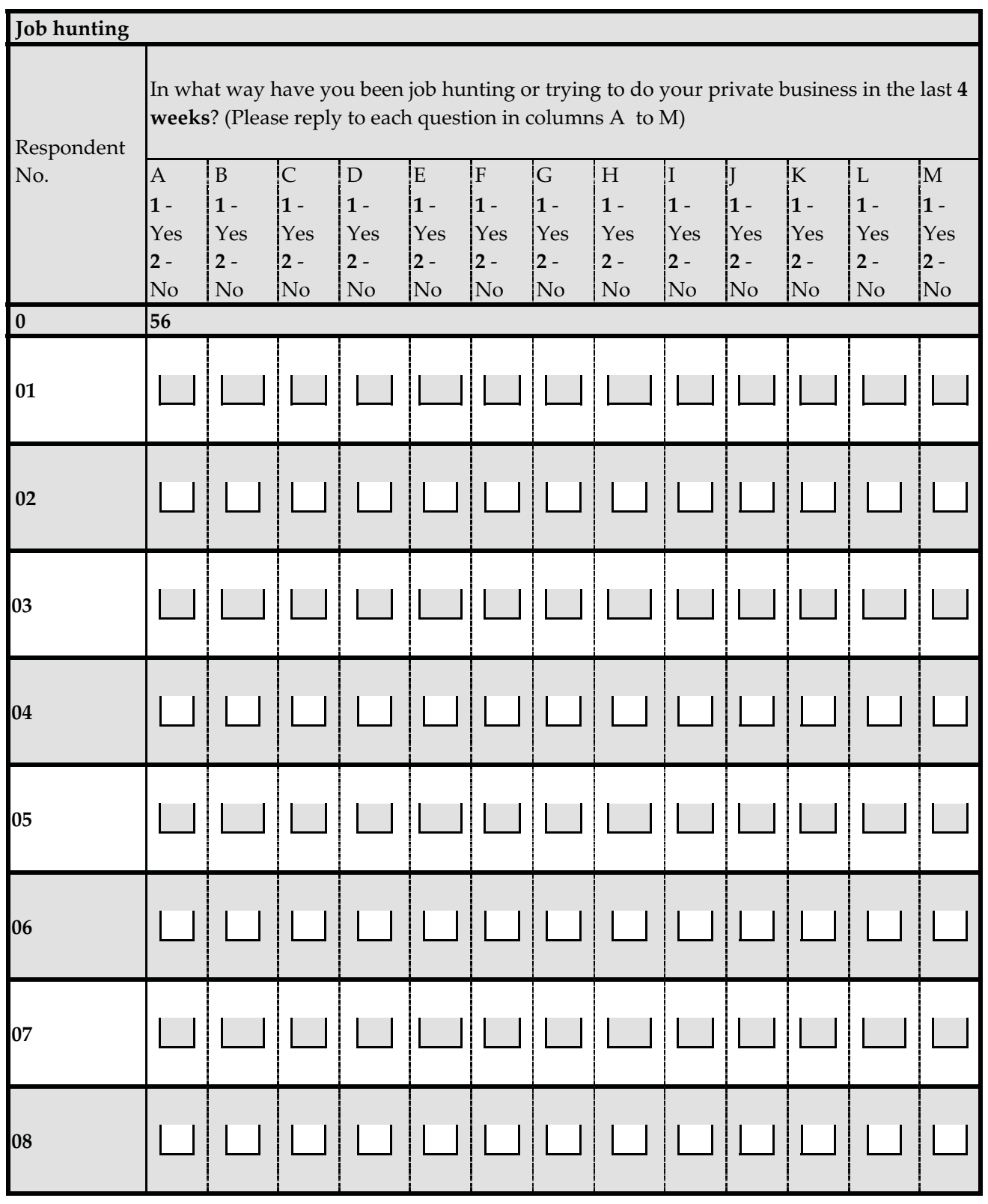

\footnotetext{
A - Through the National Employment Service

B - Through a private employment agency

C - Through direct contacts with the employer

D - Through a friend, relative or a Union

E - Through a job advertisement (publishing or replying to a job advertisement in the newspapers, magazines or the Internet)

F - By checking job adverts in newspapers, magazines and the Internet

G - By taking a test, going to an interview or an examination
} 
$\mathrm{H}$ - By looking for land, office space or work equipment

I - By requesting a work permit, licence or financial assets

$\mathrm{J}$ - By waiting for results of a job application which you have recently sent

$\mathrm{K}$ - By waiting for a call from the National Employment Service

$\mathrm{L}$ - By waiting for the job competition results in a public institution

$\mathrm{M}$ - Some other way

\section{Job hunting}

\begin{tabular}{|c|c|c|c|}
\hline $\begin{array}{l}\text { Respondent } \\
\text { No. }\end{array}$ & $\begin{array}{l}\text { Job hunting period } \\
\text { Please check the codes in the } \\
\text { box under the column }\end{array}$ & $\begin{array}{l}\text { Have you rejected a job offer in } \\
\text { the last } 12 \text { months? }\end{array}$ & $\begin{array}{l}\text { Reasons for failing to } \\
\text { look for a job }\end{array}$ \\
\hline 0 & 57 & 58 & 59 \\
\hline \multicolumn{4}{|l|}{01} \\
\hline \multicolumn{4}{|l|}{02} \\
\hline \multicolumn{4}{|l|}{03} \\
\hline \multicolumn{4}{|l|}{04} \\
\hline \multicolumn{4}{|l|}{05} \\
\hline \multicolumn{4}{|l|}{06} \\
\hline \multicolumn{4}{|l|}{07} \\
\hline 08 & & & \\
\hline
\end{tabular}




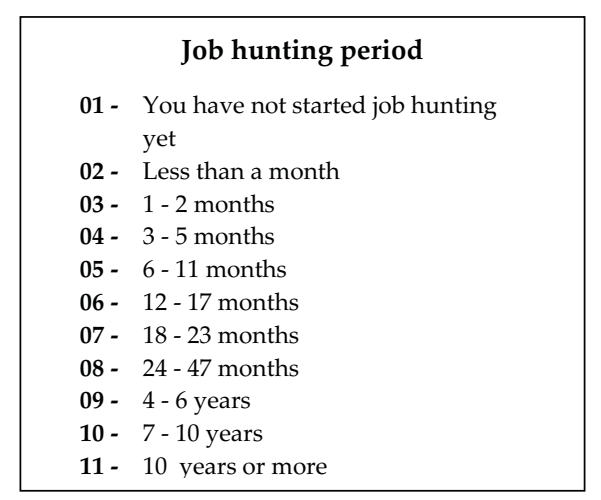

Have you rejected a job offer in the last 12 months?

\section{Yes, reason:}

1 - Does not match your qualifications

2 - Inadequate earnings

3 - Distance from the place of residence

4 - Absence or illness at the time of the job

- offer

5 - Unsuitable type of job

6 - Inconvenient working hours

7 - Other reasons

8 - No

\begin{tabular}{|ll|}
\hline \multicolumn{1}{|c|}{ Reasons for failing to look for a job } \\
\hline 1 - & $\begin{array}{l}\text { You are expecting to return to your previous job } \\
\text { (temporary layoff) }\end{array}$ \\
2 - & Your illness or disability \\
3 - & Taking care of children, elderly or disabled persons \\
4 - & Other private or family reasons \\
5 - & Education or training \\
6 - & Pension \\
7 - & You have lost hope in finding a job \\
8 - & Doing military service \\
\hline
\end{tabular}

\section{Job hunting}

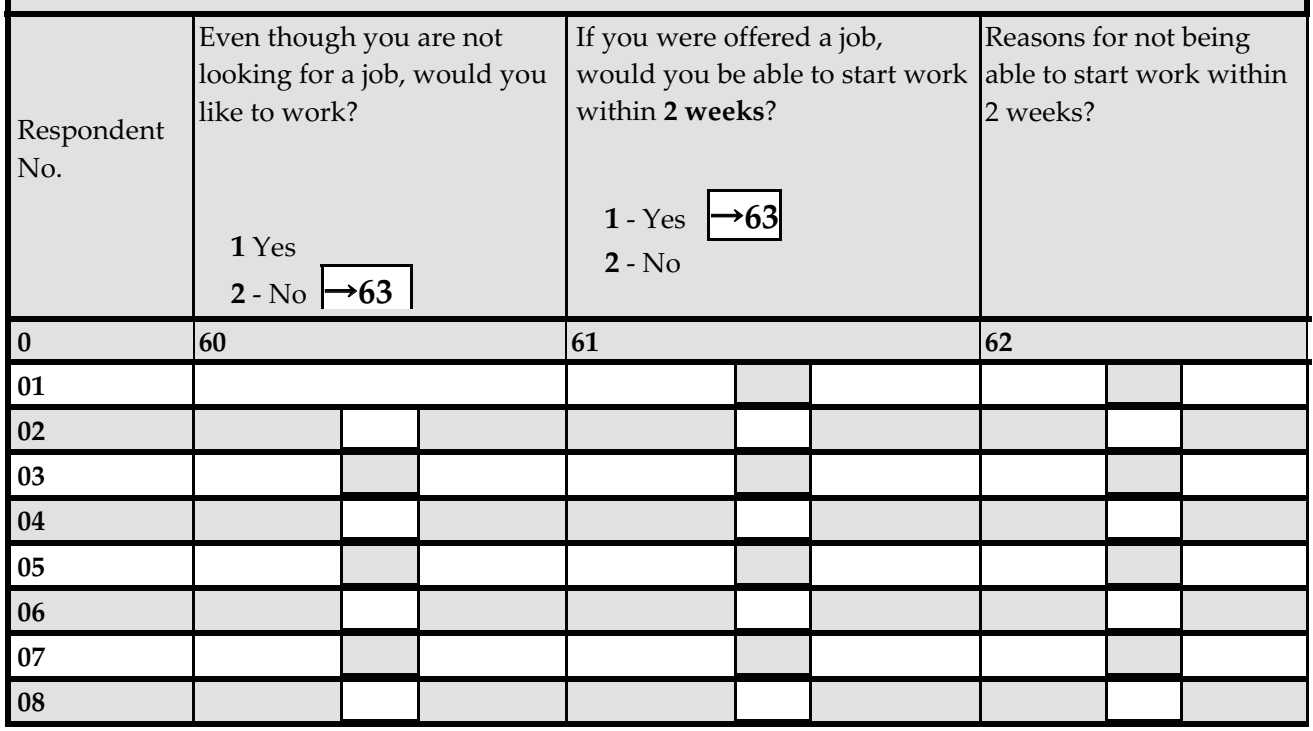




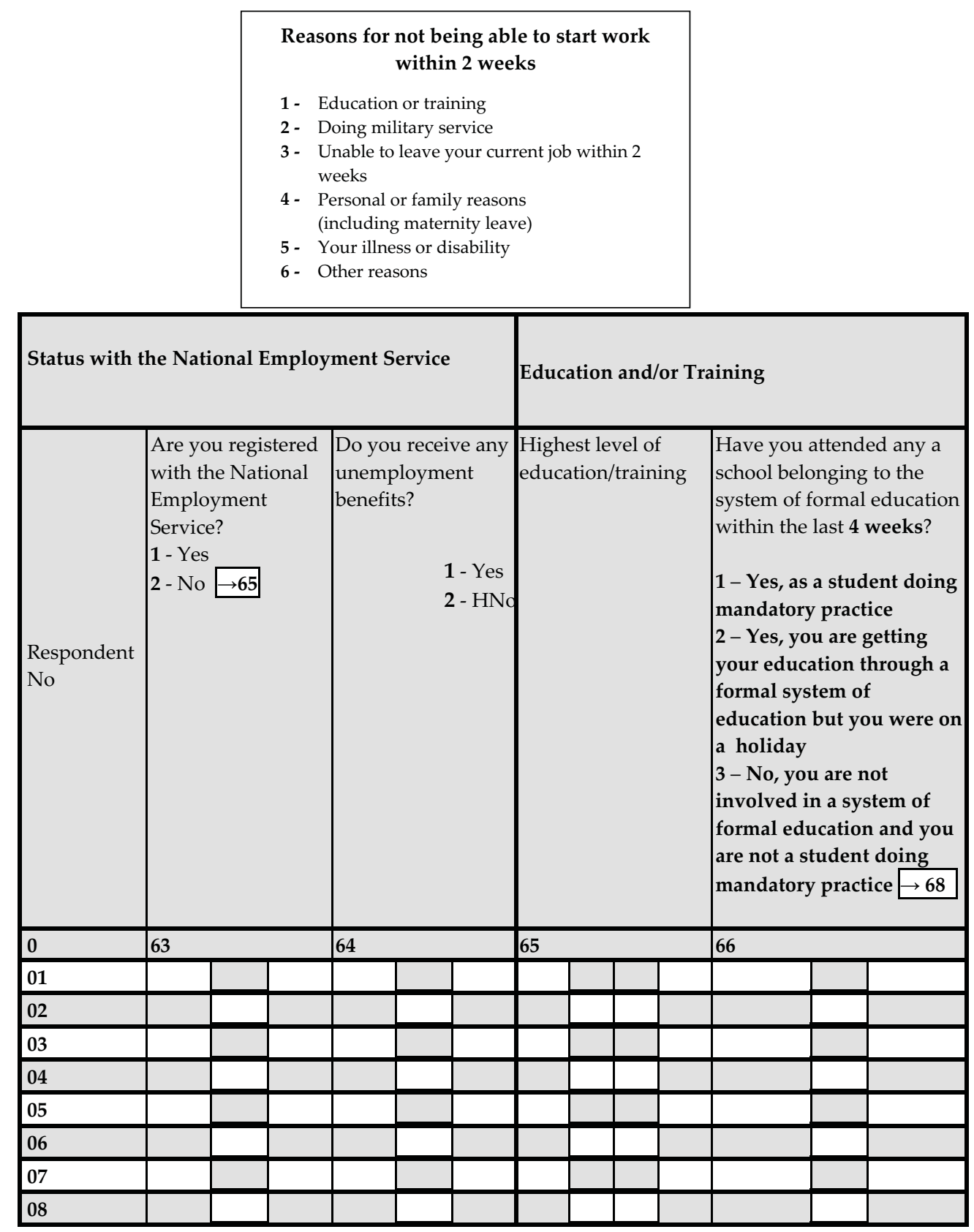




\section{Highest level of education/training}

01 - No school

02 - 1-4 grades of primary school

03 - 5-7 grades of primary school

04 - Primary school (eight years)

05 - Secondary school (between 1 and 3 years)

06 - Secondary school (between 4-5 years) or grammar school

07 - College

08 - Faculty, academic or university degree

09 - Masters degree

10 - Doctorate degree

\section{Education and/or training}

\begin{tabular}{|c|c|c|c|}
\hline $\begin{array}{l}\text { Respondent } \\
\text { No }\end{array}$ & $\begin{array}{l}\text { Which type of school } \\
\text { did you attend? } \\
\text { 1 - Primary school } \\
2 \text { - Secondary, } \\
\text { vocational school for } \\
1-3 \text { years } \\
3 \text { - Secondary } \\
\text { vocational school for } \\
4-5 \text { years or grammar } \\
\text { school } \\
4 \text { - University, } \\
\text { academy or college } \\
5 \text { - Post-graduate or } \\
\text { doctorate studies }\end{array}$ & $\begin{array}{l}\text { Have you ever attended any training } \\
\text { program outside the formal system of } \\
\text { education (a course, seminar, conference, } \\
\text { private lessons...etc)? } \\
\qquad \begin{array}{l}1-\text { Yes } \\
2 \text { - No }\end{array}\end{array}$ & $\begin{array}{l}\text { Do you plan to return } \\
\text { to the process of formal } \\
\text { education/ to a school? } \\
\begin{array}{l}1 \text { - Yes } \rightarrow 1 \\
2 \text { - No }\end{array}\end{array}$ \\
\hline 0 & 67 & 68 & 69 \\
\hline 01 & & & \\
\hline 02 & & & \\
\hline 03 & & & \\
\hline
\end{tabular}




\begin{tabular}{|c|c|c|c|}
\hline 04 & 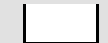 & L & L \\
\hline 05 & + & 1 & 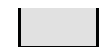 \\
\hline 06 & & L & L \\
\hline 07 & L & L & 1 \\
\hline 08 & & & D \\
\hline
\end{tabular}

Referral to educational, social welfare and employment institutions

\begin{tabular}{|c|c|c|c|c|}
\hline $\begin{array}{l}\text { Respondent } \\
\text { No }\end{array}$ & $\begin{array}{l}\text { The main } \\
\text { reason for non- } \\
\text { inclusion in the } \\
\text { education } \\
\text { process? }\end{array}$ & $\begin{array}{l}\text { Would you agree to } \\
\text { participate in training outside } \\
\text { the formal system of } \\
\text { education (course, } \\
\text { seminar...etc) which would } \\
\text { include adequate support? } \\
\qquad \begin{array}{l}1 \text { - Yes } \rightarrow 73 \\
2 \text { - No }\end{array}\end{array}$ & $\begin{array}{l}\text { The main } \\
\text { reason for } \\
\text { non- } \\
\text { inclusion in } \\
\text { training? }\end{array}$ & $\begin{array}{l}\text { Under the threat of a } \\
\text { reduction or withdrawal of } \\
\text { the MOP/NSP support } \\
\text { would you consent to } \\
\text { return to the process of } \\
\text { formal education /school? } \\
1 \text { - Yes } \\
2 \text { - No }\end{array}$ \\
\hline 0 & 70 & 71 & 72 & 73 \\
\hline 01 & & & & \\
\hline 02 & & & & \\
\hline 03 & & & & \\
\hline
\end{tabular}




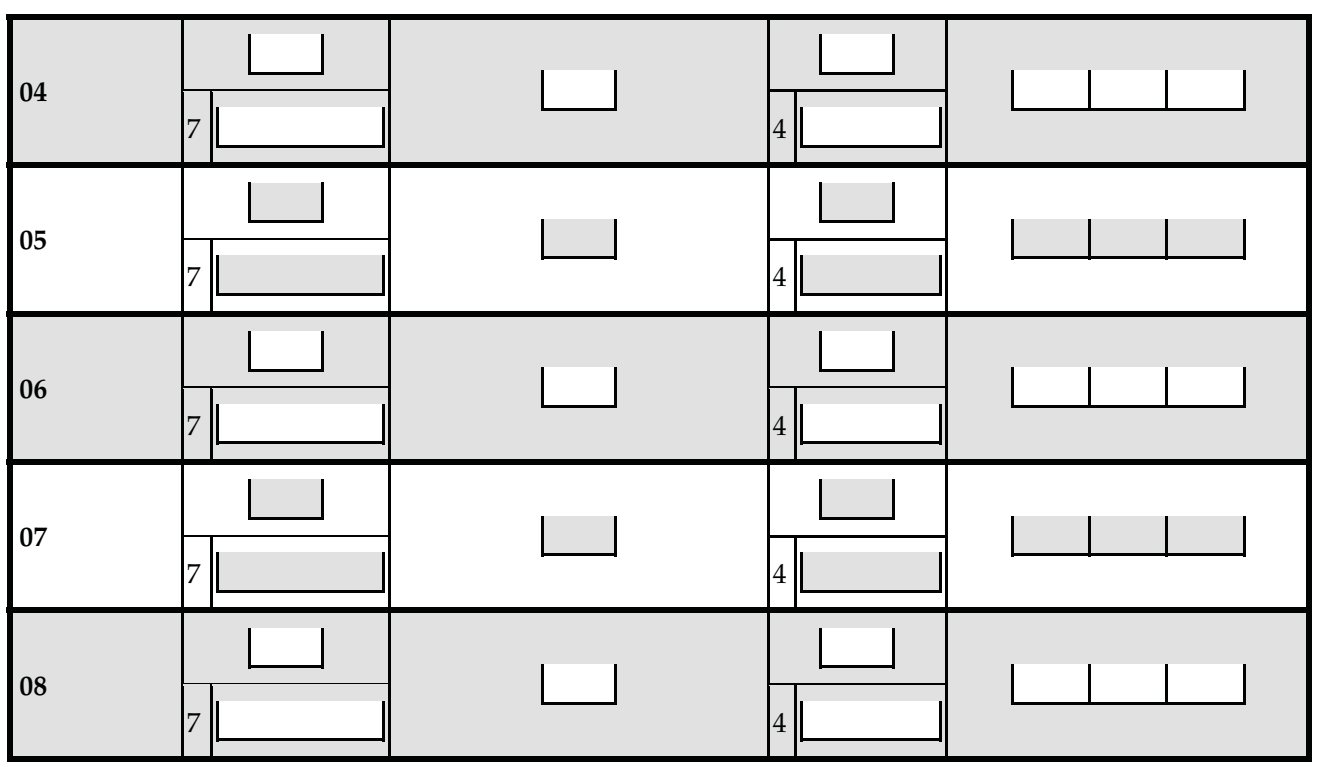

Main reasons for non-inclusion in the education process

1 - You have to earn a living

2 - You are too old

3 - The education process is inadequate and does not help you find a job

4 - The school is too far

5 - Education is too expensive

6 - Care for children, elderly or disabled persons

7 - Other (please write in)

\section{Main reasons for non-inclusion in the training process}

1 - You are too old

2 - You are not sure it would help you get a job

3 - You were unaware of such possibilities

4 - Other (please write in) )

\section{Referral to educational, social welfare and employment institutions}

\begin{tabular}{|c|c|c|c|c|}
\hline $\begin{array}{l}\text { Respondent } \\
\text { No }\end{array}$ & \begin{tabular}{|l|} 
Under the threat of a \\
reduction or \\
withdrawal of the \\
MOP/NSP support \\
would you consent \\
to take part in a form \\
of training outside
\end{tabular} & $\begin{array}{l}\text { Has anyone ever } \\
\text { referred you to } \\
\text { return to formal } \\
\text { education (Social } \\
\text { welfare centre, } \\
\text { National } \\
\text { Employment } \\
\end{array}$ & $\begin{array}{l}\text { Has anyone ever } \\
\text { referred you to } \\
\text { training outside the } \\
\text { system of formal } \\
\text { education (Social } \\
\text { welfare centre, } \\
\text { National }\end{array}$ & $\begin{array}{l}\text { Are you informed of the } \\
\text { rights and services } \\
\text { provided by the Social } \\
\text { welfare centre } \\
\text { (counselling services, } \\
\text { referral to other } \\
\text { institutions...etc)? }\end{array}$ \\
\hline
\end{tabular}




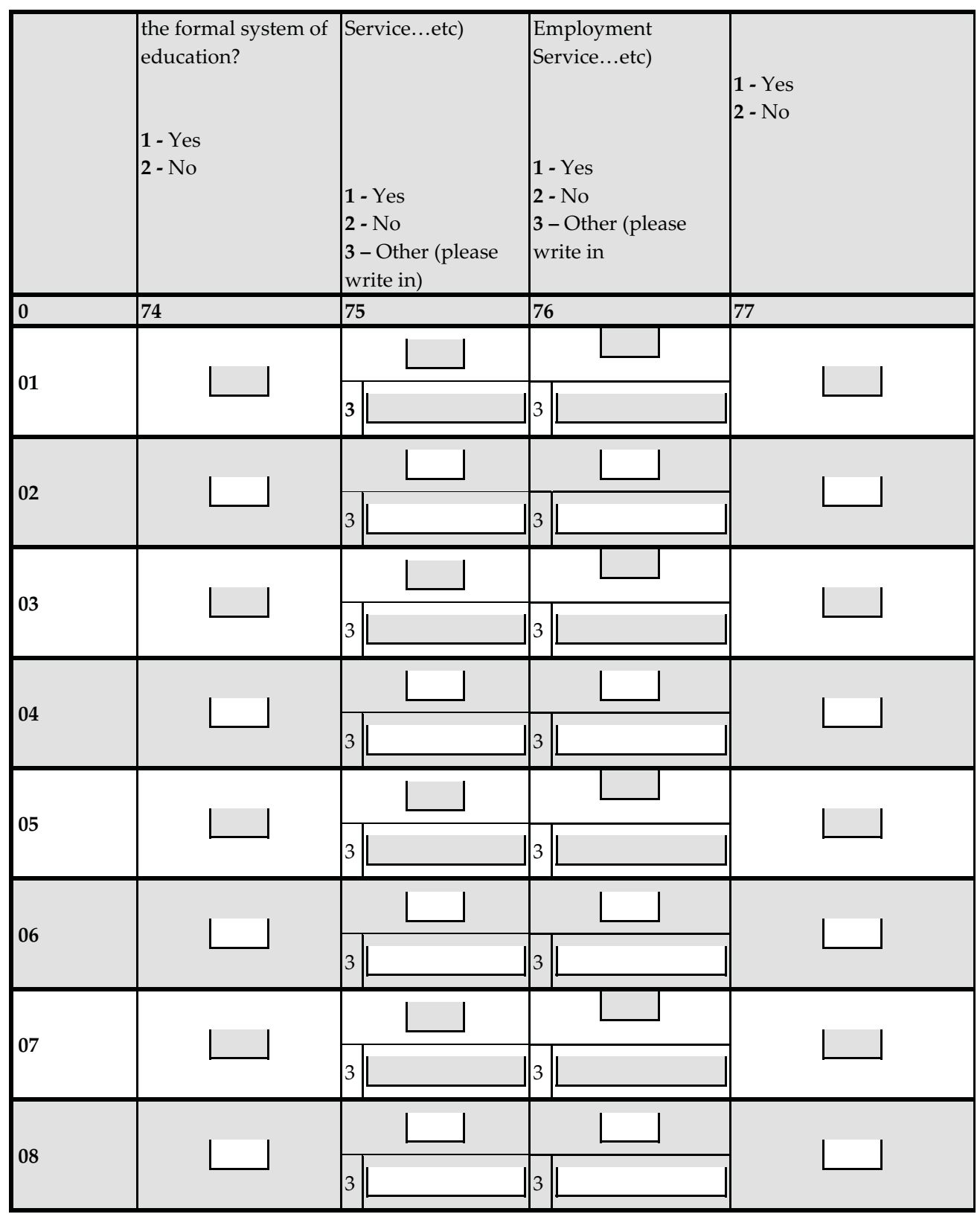




\begin{tabular}{|c|c|c|c|c|}
\hline \multicolumn{5}{|c|}{ Referral to educational, social welfare and employment institutions } \\
\hline $\begin{array}{l}\text { Respondent } \\
\text { No }\end{array}$ & $\begin{array}{l}\text { How would you } \\
\text { rate the support } \\
\text { offered by the } \\
\text { Social Welfare } \\
\text { Centre (SWC)? } \\
1 \text { - Excellent } \\
2 \text { - Good } \\
3 \text { - Average } \\
4 \text { - Poor } \\
5 \text { - There is no } \\
\text { support }\end{array}$ & $\begin{array}{l}\text { Are you informed of } \\
\text { the rights and services } \\
\text { provided by the } \\
\text { National Employment } \\
\text { Service? (NES) } \\
\\
1 \text { - Yes } \\
2 \text { - No }\end{array}$ & $\begin{array}{l}\text { How would you } \\
\text { rate the support } \\
\text { offered by the } \\
\text { National } \\
\text { Employment } \\
\text { Service? } \\
1 \text { - Excellent } \\
2 \text { - Good } \\
3 \text { - Average } \\
4 \text { - Poor } \\
5 \text { - There is no } \\
\text { support }\end{array}$ & $\begin{array}{l}\text { Are you involved in the } \\
\text { so-called "case } \\
\text { management" within the } \\
\text { Social Welfare Centre and } \\
\text { do you have a case } \\
\text { manager } \\
1 \text { - Yes, I have a case } \\
\text { manager } \\
2 \text {-I have a social worker, } \\
\text { a legal expert...etc tasked } \\
\text { for my case } \\
3 \text { - No } \\
4 \text { - I do not know }\end{array}$ \\
\hline 0 & 78 & 79 & 80 & 81 \\
\hline 01 & & & & \\
\hline 02 & & & & \\
\hline 03 & & & & \\
\hline 04 & & & & \\
\hline 05 & & & & \\
\hline 06 & & & & \\
\hline 07 & & & & \\
\hline 08 & & & & \\
\hline
\end{tabular}




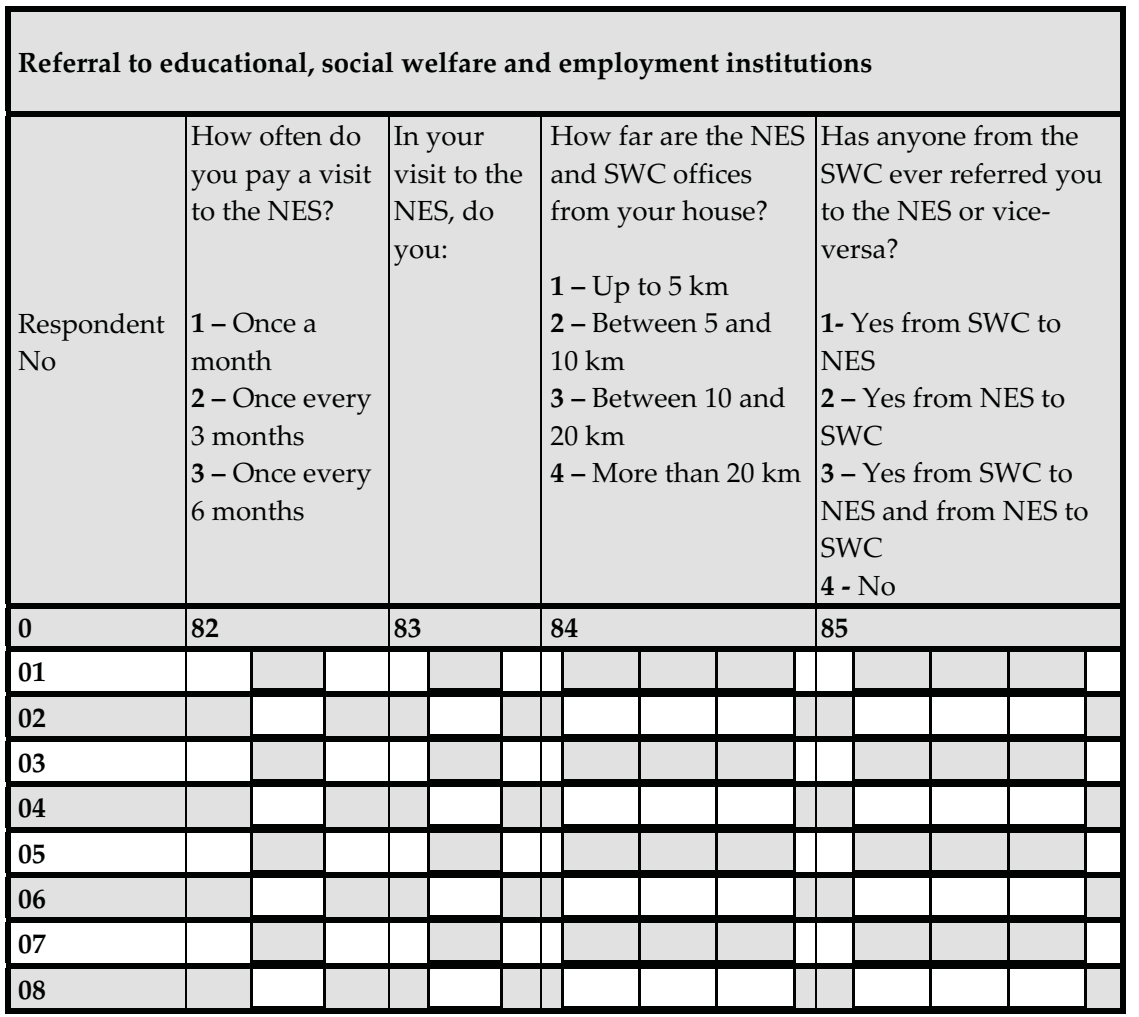

\section{In your visit to the NES do you:}

1 - Solely fulfil your obligation of reporting to an advisor

2 - Have additional consultations regarding your individual plan for employment

3 - Have additional consultations to boost your inclusion into some of the measures on offer

4 - Wish to get informed (ex. through an advert, personally...)

5 - Request additional support and advice

6 - Other 


\begin{tabular}{|c|c|c|c|c|}
\hline \multicolumn{5}{|l|}{ MOP/NSP } \\
\hline $\begin{array}{l}\text { Respondent } \\
\text { No }\end{array}$ & \begin{tabular}{|l|} 
How long have \\
you been \\
receiving \\
MOP/NSP? \\
(please write in \\
the total number \\
of years) \\
Please write in \\
00 if the total \\
period is less \\
than a year
\end{tabular} & $\begin{array}{l}\text { In the last month, what } \\
\text { amount of MOP/NSP } \\
\text { did you receive? } \\
\text { (please write in the } \\
\text { total amount) }\end{array}$ & \begin{tabular}{|l} 
Have your \\
parents \\
received the \\
MOP as well? \\
1 - Yes \\
2 - No
\end{tabular} & $\begin{array}{l}\text { How much of your } \\
\text { household needs } \\
\text { does the MOP/NSP } \\
\text { which you receive } \\
\text { cover? } \\
\text { 1-Less than a third } \\
\text { 2-Between a third } \\
\text { and a half } \\
\text { 3-More than half } \\
\text { 4-Totally } \\
\text { 5- I do not know }\end{array}$ \\
\hline 0 & 86 & 87 & 88 & 89 \\
\hline 01 & & & & \\
\hline 02 & & & & \\
\hline 03 & & & & \\
\hline 04 & & & & \\
\hline 05 & & & & \\
\hline 06 & & & & \\
\hline 07 & & & & \\
\hline
\end{tabular}




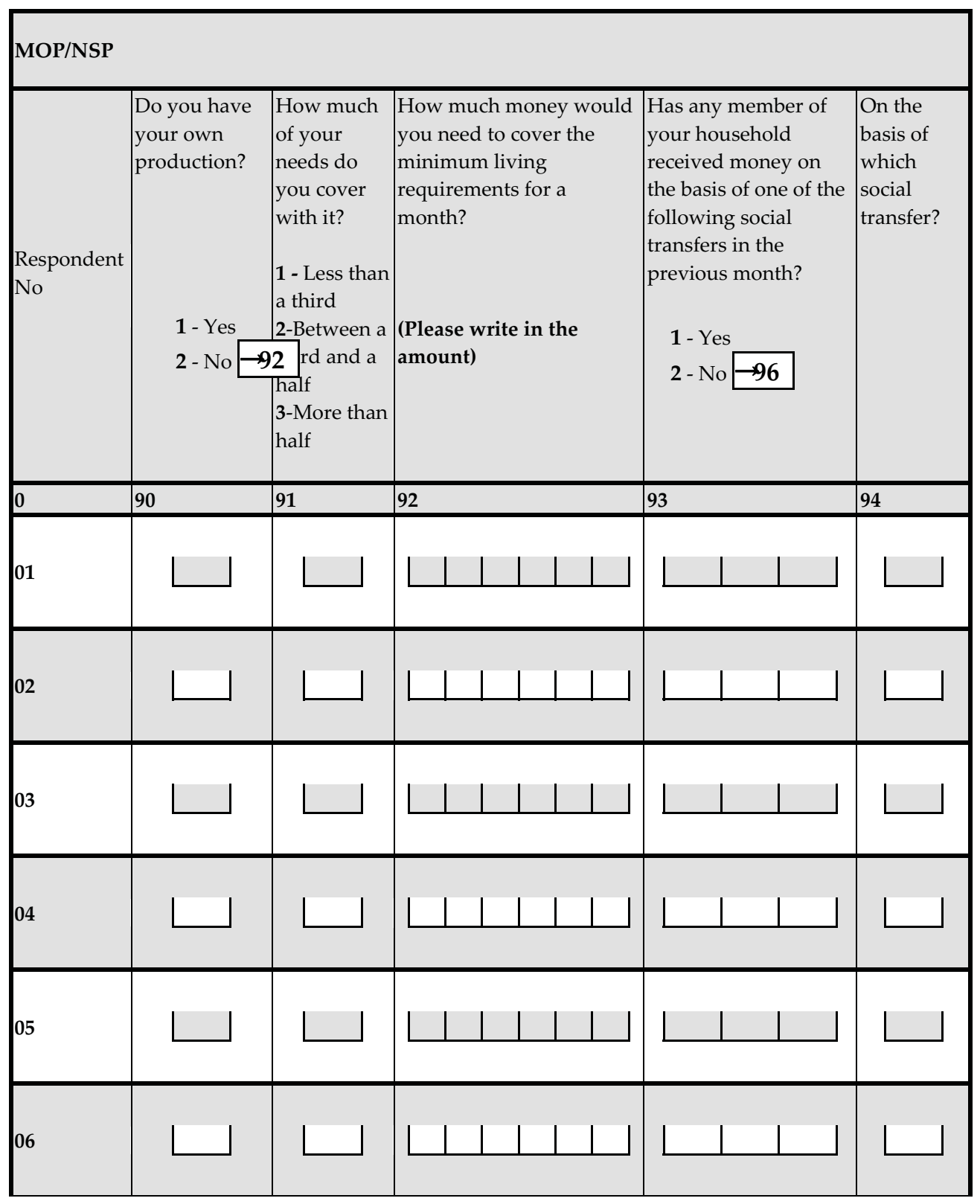




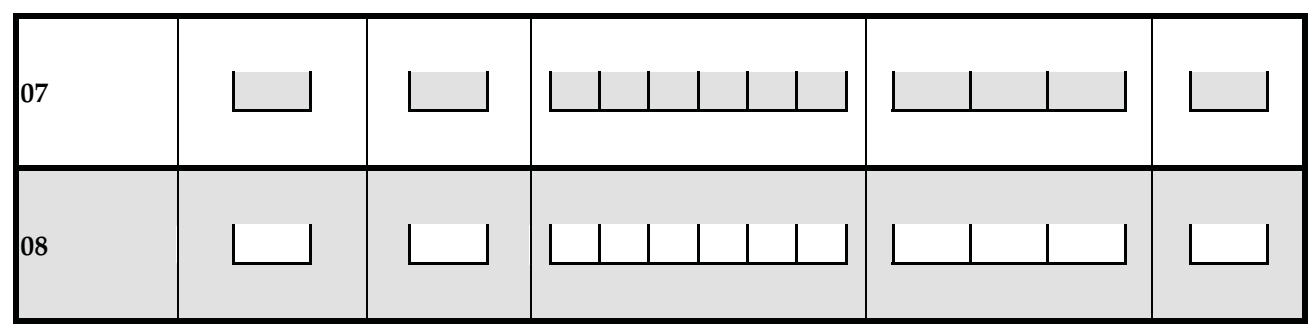

\section{On the basis of which social transfer}

1 - Nursing and assistance aid

2 - Humanitarian aid

3 - Single financial assistance

4 - Child care allowance

5 - Parental allowance

6 - Student allowance

\begin{tabular}{|c|c|c|c|c|c|c|}
\hline \multicolumn{5}{|l|}{ MOP/NSP } & \multicolumn{2}{|c|}{ Electricity bill subsidy } \\
\hline $\begin{array}{l}\text { Respondent } \\
\text { No }\end{array}$ & $\begin{array}{l}\text { Total amount? } \\
\text { (please write in) }\end{array}$ & $\begin{array}{l}\text { Number } \\
\text { of } \\
\text { household } \\
\text { members } \\
\text { receiving } \\
\text { social } \\
\text { transfers } \\
\text { (including } \\
\text { children) } \\
\text { (please } \\
\text { write in) }\end{array}$ & $\begin{array}{l}\text { Do you receive any } \\
\text { other form of aid? } \\
\text { (food or hygiene } \\
\text { packages, soup } \\
\text { kitchen meals, } \\
\text { firewood, } \\
\text { electricity, utility } \\
\text { bill } \\
\text { subventions...etc.)? } \\
1 \text { - Yes } \\
2 \text { - No }\end{array}$ & $\begin{array}{l}\text { How } \\
\text { much of } \\
\text { your } \\
\text { needs to } \\
\text { you cover } \\
\text { with such } \\
\text { assistance? } \\
\text { 1- Less } \\
\text { than a } \\
\text { third } \\
\text { 2-Between } \\
\text { a third } \\
\text { and a half } \\
\text { 3-More } \\
\text { than half }\end{array}$ & $\begin{array}{l}\text { Does your } \\
\text { household } \\
\text { have a } \\
\text { subvention } \\
\text { on the } \\
\text { electricity } \\
\text { bill? } \\
\begin{array}{l}\mathbf{1} \text { - Yes } \rightarrow \mathbf{1 0 1} \\
\mathbf{2} \text { - No } \\
\mathbf{3} \text { - I don't } \\
\text { know } \rightarrow \mathbf{1 0 1}\end{array}\end{array}$ & $\begin{array}{l}\text { Main } \\
\text { reason for } \\
\text { not having } \\
\text { a } \\
\text { subvention? }\end{array}$ \\
\hline 0 & 95 & 96 & 97 & 98 & 99 & 100 \\
\hline 01 & & & & & & \\
\hline 02 & & & & & & \\
\hline 03 & & & & & & \\
\hline 04 & & & & & & \\
\hline 05 & & & & & & \\
\hline
\end{tabular}




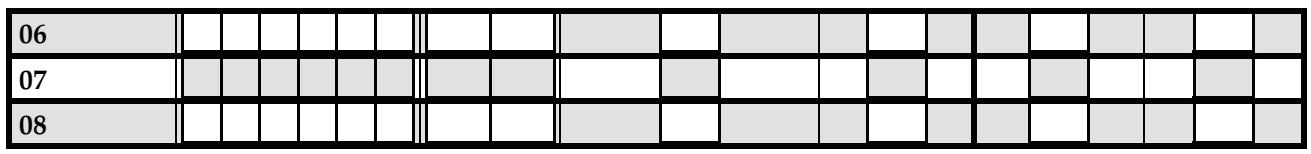

Main reason for not having a subvention

1 - Household income is too high

2 - Absence of a differentiated tariff system

3 - Too complicated procedure for being granted a subvention

4 - Other (please write in)

101. Surveyor code

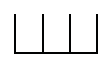

102. Survey date ....

(day) (month) (year) 


\section{Samenvatting in het Nederlands}

Doelstelling van dit proefschrift is om te onderzoeken in hoeverre binnen de sociale bijstandsprogramma's van de overheid, activeringsbeleid zoals het geven van trainingen en het bieden van werk, sociale integratie van bijstandsgerechtigden bevordert. Dit wordt onderzocht door de resultaten van diverse kwalitatieve en kwantitatieve evaluaties van objectieve arbeidsmarkt gegevens als ook van subjectief welzijn te analyseren. Er wordt gekeken vanuit een macroniveau waarbij de focus ligt op sociale en economische factoren die het betreffende sociale beleid en de resultaten daarvan in landen beïnvloeden, maar ook vanuit een microniveau waarbij de benadering geheel land-specifiek is. Deze gecombineerde aanpak biedt een krachtig en gedetailleerd beeld van met elkaar samenhangende processen die sociale uitsluiting en sociale integratie van bijstandsgerechtigden beïnvloedt. In dit proces gaan we uit van drie hypothesen. Ten eerste: activering en sociaal-professionele integratie van bijstandsgerechtigden die kunnen werken is een noodzakelijke conditie voor het verminderen van hun armoede. Ten tweede: sociale uitsluiting van bijstandsgerechtigden is multidimensionaal en significant hoger in bepaalde domeinen en ten opzichte van andere bevolkingsgroepen. Ten derde: het activeren van bijstandsgerechtigden door werk heeft een belangrijke positieve invloed op hun sociale integratie in termen van objectieve (arbeidsmarkt) en subjectieve (welzijn) resultaten. De bevindingen van iedere stap van de analyse worden hieronder samengevat.

Sociale uitsluiting is een complex sociaal fenomeen. Met behulp van een analyse van set relaties werden complexe causale verklaringen van zogenaamde noodzakelijke en voldoende voorwaarden voor sociale uitsluiting vastgelegd. Mogelijke combinaties van relevante voorwaarden werden verkend, die leiden tot de gekozen maatstaf voor sociale uitsluiting, 'de lage-risico-armoede-graad' (low at-risk-poverty-rate'). De analyse is uitgevoerd in twaalf EU-landen. Hierbij is vooral gekeken naar de rol van activering en de sociaal-professionele integratie van bijstandsgerechtigden binnen bepaalde combinaties van factoren. In lijn met onze verwachtingen, toonde de analyse aan dat sterke activering en sociaalprofessioneel integratiebeleid bijdragen aan verbeterde armoede uitkomsten onder uitkeringsontvangers. Niettemin, de bevindingen suggereren dat alleen activering, niet leidt tot de noodzakelijke of voldoende voorwaarde die nodig is voor lagere niveaus van armoede. Met ander woorden, activering is een onvoldoende maar noodzakelijk onderdeel van een voorwaarde die bestaat uit bepaalde macroeconomische factoren in combinatie met de respectievelijke sociale zekerheidsstelsels om op die manier bij te dragen aan verbeterde resultaten voor 
bijstandsgerechtigden.

Van deze één-dimensionale definitie van sociale uitsluiting gericht op relatieve armoede uitkomsten, gaan we naar de meer omvattende verklaring van multidimensionale aard. Sociale uitsluiting is in dit proces gedefinieerd om zowel het onvermogen van burgers om hun fundamentele rechten uit te oefenen op het hebben van een minimale levensstandaard, als ook om een aantal andere vormen van niet-deelname aan de samenleving te verklaren. Op die basis wordt een context-specifieke index voor sociale uitsluiting ontwikkeld voor Servië. Dit vereist een zorgvuldige afweging van de verschillende dimensies van sociale uitsluiting en de daarbij behorende relevante indicatoren, alsmede een analyse van elke specifieke bijdrage van de dimensies aan de index van sociale uitsluiting. Met betrekking tot de indicatoren, onderzoeken we het verband tussen monetaire en niet-monetaire achterstanden als ook het belang van monetaire armoede voor het verklaren van andere ontberingen. Bijzondere aandacht wordt besteedt aan die groep van uitkeringsgerechtigden die traditioneel een groter risico hebben op armoede en uitsluiting.

De resultaten van het onderzoek naar sociale uitsluiting in Servië laten zien dat bijna iedere tiende persoon uitgesloten is. Er wordt onderscheidt gemaakt tussen vier groepen: stad en platteland, sociale uitkeringsgerechtigde en niet sociaal uitkeringsgerechtigden. De analyse bevestigt dat personen in uitkeringsgerechtigde plattelands huishoudens relatief hogere niveaus van sociale uitsluiting ervaren. De resultaten suggereren verder dat terwijl uitsluiting van diensten zoals gezondheidszorg, onderwijs en dergelijke het meest bijdraagt aan sociale uitsluiting, alle drie de dimensies een belangrijke rol spelen in het verklaren van de uitsluiting. Uit de analyse van het verband tussen monetaire en nietmonetaire achterstanden blijkt dat er slechts beperkt sprake is van overlap, wat aangeeft dat veel vormen van sociale uitsluiting niet kunnen worden verklaard door geld gebrek alleen. Bovendien toont de analyse van het relatieve belang van bepaalde voorspellende variabelen aan dat monetaire armoede weliswaar een belangrijke rol speelt, maar dat de status van werkloosheid de kans op achterstanden in andere gebieden aanzienlijk verhoogt. Dit resultaat heeft belangrijke implicaties voor beleid dat sociale uitsluiting tegen gaat.

De volgende stap in het onderzoek is een analyse van een bepaald overheidsbeleid vanuit het perspectief van subjectief welzijn. Onderzocht is of en hoe activering van uitkeringsgerechtigden via publieke werkgelegenheidsprogramma's (public works) hun subjectieve welzijn beïnvloed en wat het verband is met de doelstellingen van sociale integratie. Het onderzochte beleidsprogramma betrof het 'Public Works Programme' in Servië. De analyse van de gegevens die verkregen zijn uit semigestructureerde diepte interviews was gericht op de 
veranderingen in de verschillende dimensies van subjectief welzijn. Er werd gekeken naar de perioden voor en na de programma activiteiten. Ondanks de lage arbeidsparticipatie van de deelnemers na voltooiing van het programma, die over het algemeen wordt gezien als een belangrijke arbeidsmarkt doelstelling, bleek uit de kwalitatieve analyse dat deelname aan werk een significant positief effect had op het subjectieve welzijn van de bijstandsgerechtigden. Directe positieve gevolgen van deelname aan het werk programma waren: de frequentie en het niveau van sociale contacten waren verbeterd; uitkeringsgerechtigden voelen zich meer en beter gehoord; hun werk wordt gewaardeerd; hun motivatie om te werken en zelfvertrouwen namen toe; het aantal contacten als ook hun positie in de samenleving verbetert met hun participatie in de arbeidsmarkt; ze voelen zich meer geaccepteerd en geïntegreerd. Alle genoemde veranderingen moeten in acht genomen worden bij het meten van sociale integratie resultaten. In dit specifieke geval lijkt activering van uitkeringsgerechtigden een belangrijke rol te spelen bij het aanpakken van sociale uitsluiting en bij het versterken van de resultaten in sociale integratie.

In het voorliggende onderzoek zijn een aantal effecten van de indicatoren voor de objectieve arbeidsmarkt als ook die voor subjectief welzijn onderzocht. Hieruit komen minimaal twee trajecten naar voren die de interactie tussen activering en sociale integratie verklaren. Aan de ene kant, zal sociale integratie naar verwachting plaatsvinden via directe formele werkgelegenheid. Echter, de beschikbare literatuur suggereert dat tijdelijke werk (zoals publieke werkgelegenheids programma's)over het algemeen niet erg effectief is in termen van formele werkgelegenheidsuitkomsten. In het onderzoek wordt erkend dat heel weinig bijstandsgerechtigden werk vinden na voltooiing van de publieke werkgelegenheid-activiteit. Aan de andere kant, en zoals ook blijkt uit deze studie, is er een significante invloed van deelname aan deze publieke werkgelegenheid programma's op bepaalde aspecten van het leven, zoals het verwerven van kwalificaties en vaardigheden, het verbreden van sociale contacten en het opbouwen van zelfvertrouwen voor een meer sociale uitwisseling. Deze ontdekking verhoogt niet alleen ons begrip van subjectief welzijn van de armen en hun vooruitzichten, maar voorziet ook in de noodzakelijke koppeling tussen activering, subjectief welzijn en sociale integratie.

Hoewel de algemene bevinding suggereert dat activering door middel van publieke werkgelegenheidsprogramma's belangrijke positieve effecten heeft op het subjectief welzijn en de sociale integratie van bijstandsgerechtigden, wordt er rekening gehouden met de bestaande meningsverschillen ten aanzien van de algemene effectiviteit van publieke werkgelegenheidsprogramma's. Op welke wijze het programma wordt bezien, is afhankelijk van een aantal factoren, variërend van het programma-ontwerp, institutionele regelingen, processen en 
verwachte resultaten. Het doel van dit onderzoek was vooral om het belang van het meten van de perceptie van de deelnemers aan het programma te benadrukken en om de gevolgen voor hun welzijn in relatie tot de resultaten van sociale integratie te bespreken. De analyse bevestigt dat het bieden van gelijke kansen op de arbeidsmarkt aan hen die gemarginaliseerd en vaak verwaarloosd worden, hun sociale integratie in de samenleving verhoogt. Dit maakt de weg vrij voor meer beleidsacties die leiden tot een verhoogde activering en sociale integratie van uitkeringsgerechtigden. 


\section{Biography}

Marina Petrovic was born in 1973 in Belgrade, Serbia. She obtained her bachelor degree in Social Policy and Social Work from the University of Belgrade in 1996 and master's degree in Public Policy and Administration from the University of Massachusetts in 2001. Prior to joining the PhD program at the University of Maastricht in 2006, she worked as a human development operations officer in the World Bank's country office for Serbia and Montenegro. Since 2009, she has focused her research and policy work on integrated labor market and social service delivery models and the overarching activation agenda. She has divided her time among working for the Serbia based think-tank (Center for Liberal-Democratic Studies), consulting for various international organizations (World Bank, ILO, UNDP) and governments (Serbia, Macedonia), and completing her PhD. She is currently employed by the World Bank in Washington, D.C. as a social protection specialist in the Europe and Central Asia region. 


\section{MGSoG Dissertation Series}

\section{Laura Torvinen}

Assessing Governance Assessments; The Case of Mozambique

Governance Assessments in the Context of Aid Effectiveness Discourse

MGSoG Dissertation Series, nr 36 (2013)

Biniam Egu Bedasso

Institutional Change in the Long Shadow of Elites

Essays on Institutions, Human Capital and Ethnicity in Developing Countries

MGSoG Dissertation Series, nr 35 (2013)

Sepideh Yousefzadeh Faal Deghati

Childhoods Embargoed

Constructing and Reconstructing Multidimensional Child Poverty in Iran 1984-2009

MGSoG Dissertation Series, nr 34 (2013)

Robert Bauchmüller

Investing in Early Childhood Care and Education:

The Impact of Quality on Inequality

MGSoG Dissertation Series, nr 33 (2013)

Martin Rehm

Unified Yet Separated

Empirical Study on the Impact of Hierarchical Positions within Communities of Learning

MGSoG Dissertation Series, nr 32 (2013)

Dorcas Mbuvi

Utility Reforms and Performance of the Urban Water Sector in Africa

MGSoG Dissertation Series, nr 31 (2012)

Lina Salanauskaite

Distributional Impacts of Public Policies:

Essays in Ex-Ante and Ex-Post Evaluation

MGSoG Dissertation Series, nr 30 (2012)

Esther Schüring

To Condition or not - is that the Question?

An Analysis of the Effectiveness of Ex-Ante and Ex-Post Conditionality in Social Cash Transfer Programs

MGSoG Dissertation Series, nr 29 (2012) 
Joe Abah

Strong Organisations in Weak States

Atypical Public Sector Performance in Dysfunctional Environments

MGSoG Dissertation Series, nr 28 (2012)

Zina Samih Nimeh

Social Citizenship Rights: Inequality and Exclusion

MGSoG Dissertation Series, nr 27 (2012)

Lenka Eisenhamerová

Legitimacy of 'Humanitarian Military Intervention'

MGSoG Dissertation Series, nr 26 (2011)

Sonila Tomini

Informal Payments for Health Care Services in Albania

MGSoG Dissertation Series, nr 25 (2011)

Jinjing Li

Dynamic Microsimulation in Public Policy Evaluation

MGSoG Dissertation Series, nr 24 (2011)

Aziz Atamanov

Rural Nonfarm Employment and International Migration as Alternatives to Agricultural Employment:

The Case of Kyrgyztan

MGSoG Dissertation Series, nr 23 (2011)

Frieda Vandeninden

Poverty Alleviation: Aid and Social Pensions

MGSoG Dissertation Series, nr 22 (2011)

Juliana Nyasha Tirivayi

The Welfare Effects of Integrating AIDS Treatment with Food Transfers:

Evidence from Zambia

MGSoG Dissertation Series, nr 21 (2011)

Agnieska Ewa Sowa

Who's Left Behind? Social Dimensions of Health Transition and Utilization of Medical Care in Poland

MGSoG Dissertation Series, nr 20 (2011) 
Emmanaouil Sfakianakis

The Role of Private Actors in the Provision of Public Goods with Applications to Infrastructure and Financial Stability

MGSoG Dissertation Series, nr 19 (2011)

Siu Hing Lo

White Collars Green Sleeves

An Interonganizational Compariso of Deteminants of Energie-Related Behaviors among Office Workers

MGSoG Dissertation Series, nr 18 (2011)

Treena $\mathrm{Wu}$

Constraints to Human Capital Investment in Developing Countries:

Using the Asian Financial Crisis in Indonesia as a Natural Experiment

MGSoG Dissertation Series, nr 17 (2011)

Henry Espinoza Peña

Impact Evaluation of a Job-Training Programme for Disadvantaged Youths:

The Case of Projoven

MGSoG Dissertation Series, nr 16 (2011)

Florian Tomini

Between Family and Friends

Understanding the Interdependency of Private Transfers

MGSoG Dissertation Series, nr 15 (2010)

Michał Polalowski

The Institutional Transformation of Social Policy in East Central Europe:

Poland and Hungary in comparative and historical perspective

MGSoG Dissertation Series, nr 14 (2010)

Maha Ahmed

Defining, Measuring and Adressing Vulnerability:

The Case of Post Conflict Environments

MGSoG Dissertation Series, nr 13 (2010)

Pascal Beckers

Local Space and Economic Success

The role of spatial segregation of migrants in the Netherlands

MGSoG Dissertation Series, nr 12 (2010) 
Victor Cebotari

Complicting Demands in Ethnically Diverse Societies

Ethnopolitical Contention and Identity Values in Europe

MGSoG Dissertation Series, nr 11 (2010)

Dennis Gyllensporre

Competing and Complementary Perspectives on the EU as a Crisis Management Actor:

An Examination of the Common Security and Defence Policy through the Lenses of Idealism and Realism

MGSoG Dissertation Series, nr 10 (2010)

Judit Vall Castello

Business Cycle and Policy Effects on Labour Market Transitions of Older and Disabled Workers in Spain

MGSoG Dissertation Series, nr. 9 (2010)

Keetie Roelen

False Positives or Hidden Dimentions: the definition and measurement of child poverty MGSoG Dissertation Series, nr. 8 (2010)

Denisa Maria Sologon

Earning Dynamics in Europe

MGSoG Dissertation Series, nr. 7 (2010)

Melissa Siegel

Money and Mobility: Migration and Remittances

MGSoG Dissertation Series, nr. 6 (2010)

Jessica S. Hagen-Zanker

Modest Expectations: Causes and effects of migration on migrant households in source countries

MGSoG Dissertation Series, nr. 5 (2010)

Mirtha R. Muniz Castillo

Human Development and Autonomy in Project Aid: Experiences from four

bilateral projects in Nigaragua and El Salvador

MGSoG Dissertation Series, nr. 4 (2009)

Christiane Arndt

Governance Indicators

MGSoG Dissertation Series, nr. 3 (2009) 
Britta Augsburg

Microfinance - Greater Good or Lesser Evil?

MGSoG Dissertation Series, nr. 2 (2009)

\section{Geranda Notten}

Measuring and Managing Poverty Risks

MGSoG Dissertation Series, nr. 1 (2008) 